\title{
FACTORS AFFECTING THE IMPLEMENTATION OF INFORMATION LITERACY EDUCATION IN MALAYSIAN PRIMARY SCHOOLS
}

\author{
BY \\ SAIDATUL AKMAR ISMAIL
}

A thesis

submitted to the Victoria University of Wellington in fulfilment of the requirements for the degree of Doctor of Philosophy

Victoria University of Wellington 2014 


\begin{abstract}
Information literacy (IL) is one of the $21^{\text {st }}$ century survival skills. The concept of IL has spread widely, and IL programmes have appeared in many countries in formal settings such as schools and higher education institutions, workplaces, and community and continuing education programmes. Information literacy education (ILE) in Malaysia is officially integrated into the school curriculum. Though the Malaysian government claims that IL has been implemented in the country's education system, anecdotal evidence suggests that the extent of ILE is uneven across schools. Thus, the goal of this qualitative study has been to identify the factors affecting the implementation of ILE in Malaysian primary schools and to explore how these factors are facilitating or hindering the process.
\end{abstract}

The first stage in the research was to develop a preliminary model based on three theories: Hall and Hord's Concerns Based Adoption Model (CBAM), Chen's Action Model and Fullan's Theory of Educational Change. CBAM provided a guide to identify the stages of implementation and factors that could affect ILE implementation within schools. The other two theories were used to identify and understand potential factors internal and external to the school ecology. Also incorporated into the model were other factors identified from the literature, such as teachers' lack of time and resources. The interpretive paradigm was chosen in order to produce deep insights into the research problem. To explore how ILE was being implemented and to identify factors that were facilitating or hindering its implementation, case studies were conducted involving four primary schools of different types in Malaysia. Documentary evidence was gathered and semi-structured interviews were conducted with staff in these schools and with key stakeholders in education administration.

Analysis of the transcripts of the interviews showed that the development and progress of ILE implementation is slower than might be expected. Hence, a range of factors hindering and facilitating ILE implementation have been 
identified. Most interviewees had positive attitudes towards ILE. They believed that ILE was important and had the potential to make teaching and learning activities more engaging and fun. The interviewees however also reported that there were problems in implementing ILE. These problems were associated with individual, organisational, social and cultural factors. It was also noted that there were different priorities accorded to ILE implementation in the case study schools. This was related to the different linguistic settings.

Findings from this study are significant to reorient the education and training system in the country so that students are able to develop the knowledge, skills and expertise essential to fully participate in today's digital environment. Findings also provide insight into ILE implementation in different social and cultural contexts, so contribute new perspectives to existing, Western dominated theory.

Keywords: information literacy education, implementation, national schools, teachers, library and media teacher, primary schools, key informants, education administration 


\title{
Acknowledgements
}

\author{
All praises be to Almighty Allah, Lord of the Universe \\ and peace and blessings be upon Muhammad, the Prophet.
}

In the completion of this thesis, it would be most appropriate to acknowledge my gratitude to my two supervisors, Dr. Dan Dorner and Dr. Gillian Oliver for their advice, continuous support, guidance and most importantly their patience throughout the completion of this thesis. Thank you for keeping me focused and on track throughout these years. Deep appreciation is also expressed to Dr. Val Hooper and Dr. Brian Harmer for their advice, encouragement and hope.

I want to extend my appreciation to the Ministry of Higher Education of Malaysia for the scholarship award to finance my study, support from my employer, MARA University of Technology and Prof Dr. Adnan Jamaluddin for the chance of a lifetime. My gratitude is also extended to the academic, administrative and library staff of VUW, particularly those at the School of Information Management for valuable discussions during the thesis defence, ethics approval process and other assistance throughout this journey. I would like to express my appreciation to the Economic Planning Unit of the Prime Minister's Department, Educational Planning and Research Division as well as School Division of the Ministry of Education for their approval of the study to be conducted in the selected schools and government agencies.

I also take this opportunity to graciously thank the principals of all schools involved in the study and, most importantly, their teachers and LMTs for generously parting with their precious time to respond to the interviews. I also want to thank the Educational Technology Division of the Ministry of Education, the Perak State Educational Technology Division and Teachers' Activity Centre for participating in this study. Without their support, this study would not have materialized. 
I would like to acknowledge my utmost gratitude to my husband, Shukran, my son, Uwais, my mum, Azizah and my dad, Ismail who were on many occasions deprived of my fullest attention due to my persistence to see this thesis done. I also want to thank my sisters and brothers for their prayers... Thank you for always being there for me... my sources of inspiration and strength... This thesis is our "book of life" filled with our blood, sweat and tears...

Finally, my warm thank you to my colleagues who supported me during my tough times, Nishanie, Kak Anah, Bell, Su, Kak Shidah, Siti, Sya, Namali, Van, Kak Zah and Linda... and to the rest who had made my life more meaningful in Wellington...

\section{Ehara taku toa, he taki tahi, he toa taki tini}

My success should not be bestowed onto me alone, as it was not an individual success but success of a collective...

Saidatul Akmar Ismail 


\section{Table of Content}

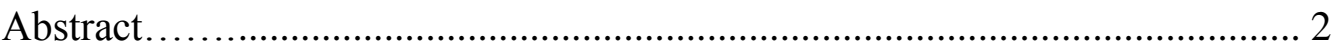

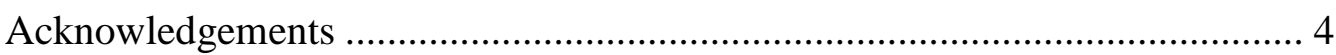

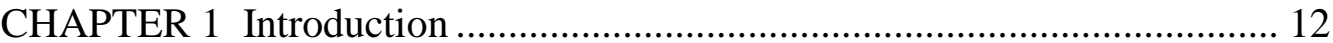

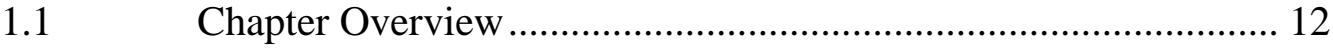

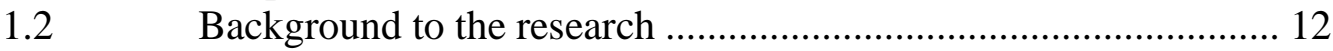

1.3 Research Problem, Questions and Objectives ............................. 16

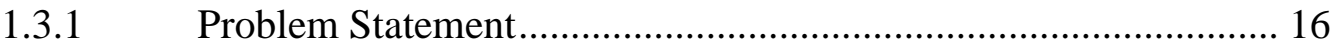

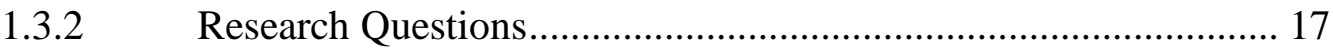

1.3.3 Objectives of Research ........................................................... 17

1.4 Definition and Description of Terms ......................................... 18

1.4.1 Information Literacy (IL) .......................................................... 18

1.4.2 Information Literacy Education (ILE) .................................... 18

1.4.3 Implementation ................................................................ 19

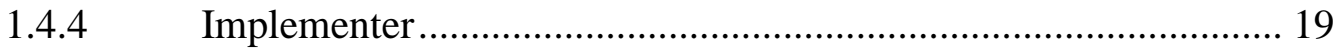

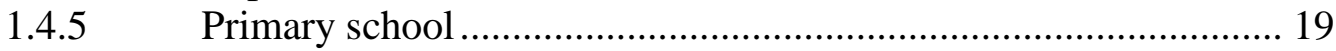

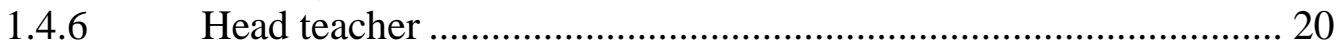

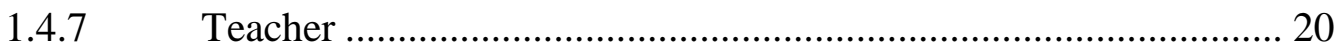

1.4.8 Library and Media Teacher (LMT) ........................................ 20

1.4.9 School resource centre (SRC) .................................................. 21

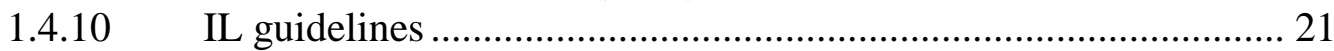

$1.5 \quad$ Theoretical Framework.............................................................. 21

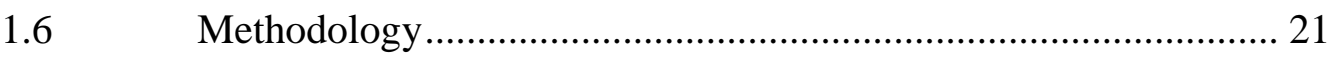

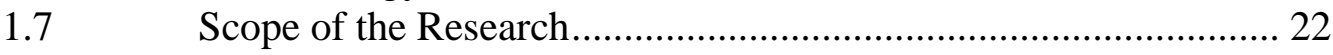

1.8 Delimitations and Limitations of the Research .......................... 22

$1.9 \quad$ Outline of the Thesis.................................................................... 23

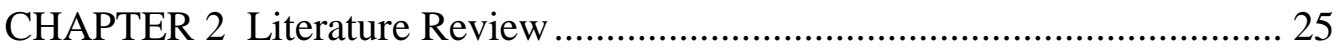

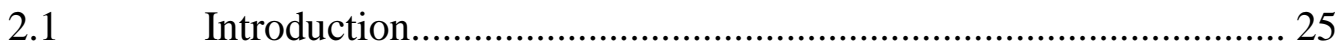

2.2 Definitions, Descriptions and Development of Literacy .............. 26

$2.3 \quad$ Information Literacy (IL) ........................................................... 27

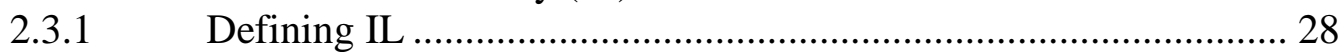

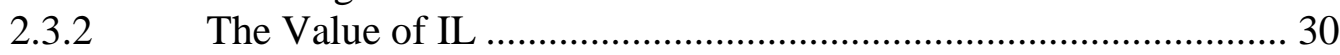

2.3.3 IL Initiatives and Implementation ........................................... 31

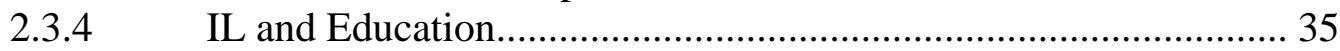

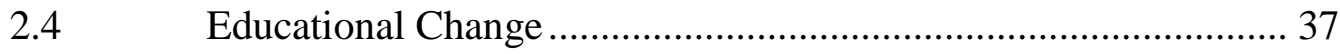

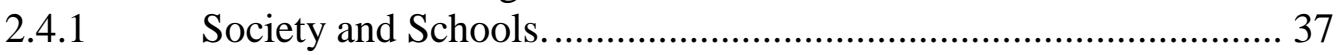

2.4.2 Characteristics and Properties of Schools.................................... 39

$2.5 \quad$ Research Perspectives on ILE ................................................. 40

2.5.1 Execution of IL: Teaching approaches, Transferability and Assessments ......................................................................... 40

2.5.2 Factors Affecting ILE in Schools .............................................. 43

2.6 Information Literacy (IL) in Malaysia: An Overview ................... 52

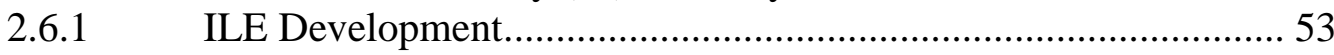

2.6.2 The appointment of Library and Media Teachers (LMT) ............ 56

2.6.3 Research on IL and ILE implementation in Malaysian schools .... 57 


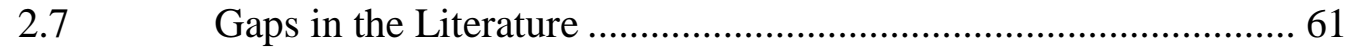

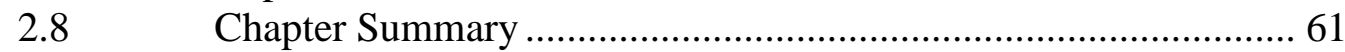

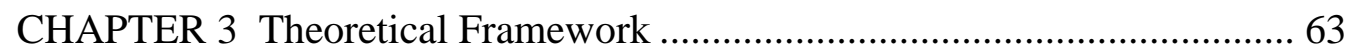

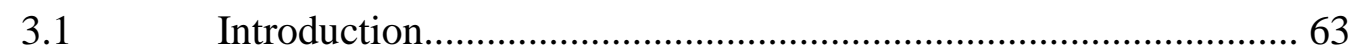

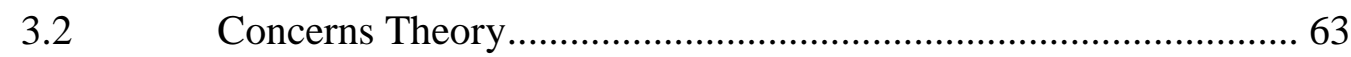

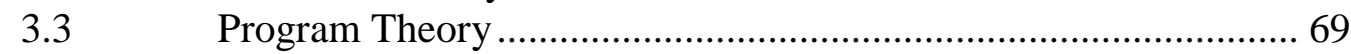

3.4 Theory of Educational Change …............................................. 73

3.5 The preliminary model for investigating ILE implementation in Malaysian primary schools .................................................. 80

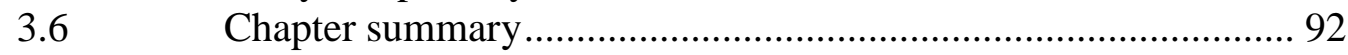

CHAPTER 4 Research Approach.............................................................. 93

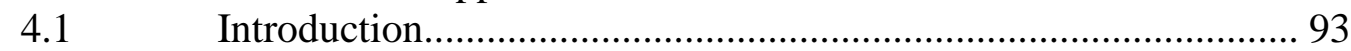

4.2 Paradigm: Interpretivism .................................................... 93

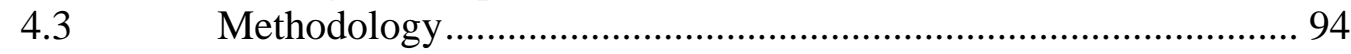

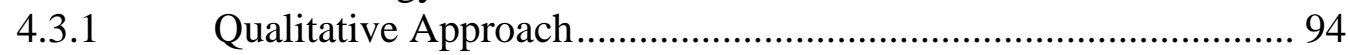

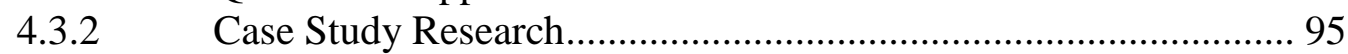

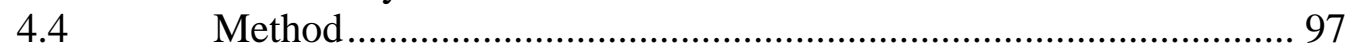

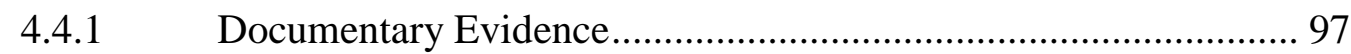

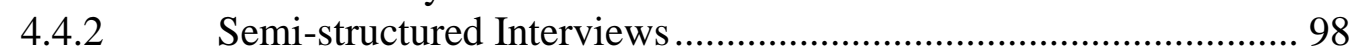

4.5 Selection of Research Sites and Participants .............................. 98

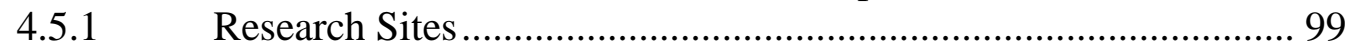

4.5.2 Selection of Participants ....................................................... 102

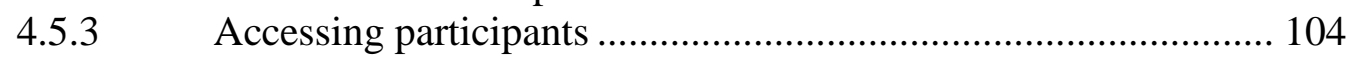

4.5.4 Participant recruitment.......................................................... 104

4.6 Procedures for data gathering and analysis ............................. 105

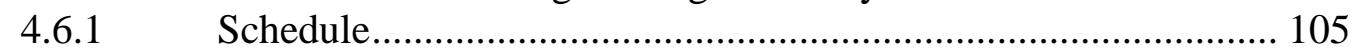

4.6.2 Data triangulation: analysis of documents and observation ........ 106

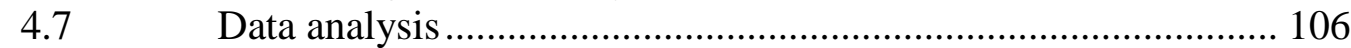

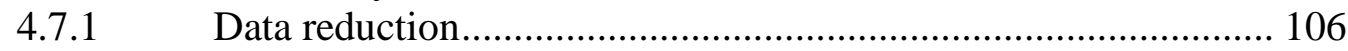

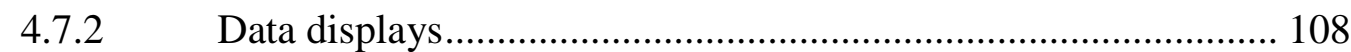

4.7.3 Conclusion drawing or verifying ............................................ 108

Issues related to the research .................................................... 110

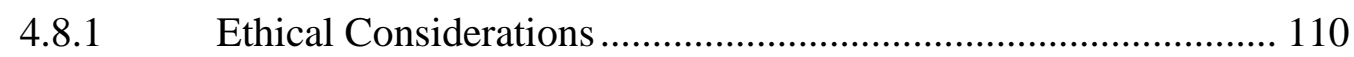

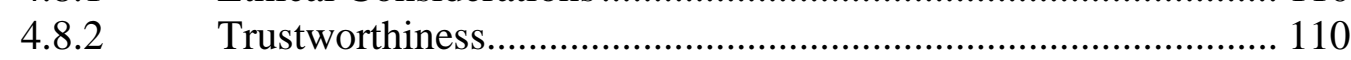

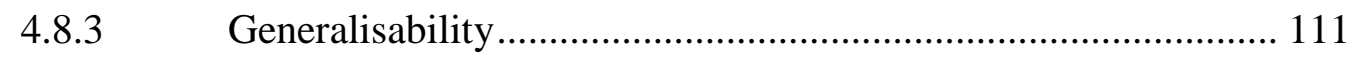

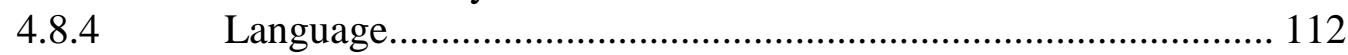

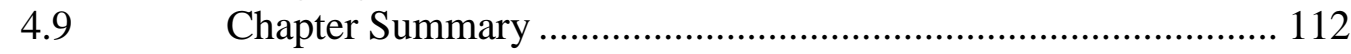

CHAPTER 5 Setting of Case Study Schools and Interviewee Profiles ........ 113

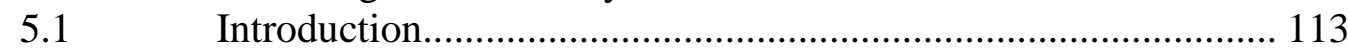

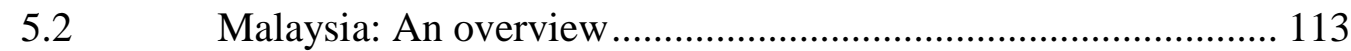

5.2.1 Malaysia - the country profile ................................................ 113

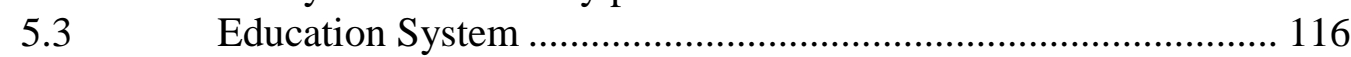

5.3.1 Administration and Management ........................................... 116

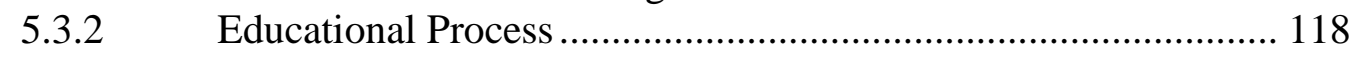

- ILE in Malaysian schools .......................................................... 125

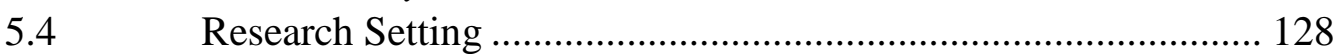

5.4.1 The state context: Perak ......................................................... 128 
5.4.2 The district context: Kinta North............................................ 129

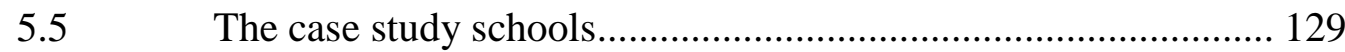

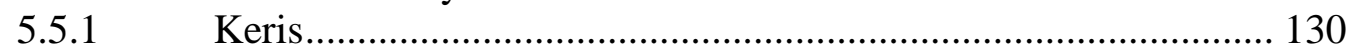

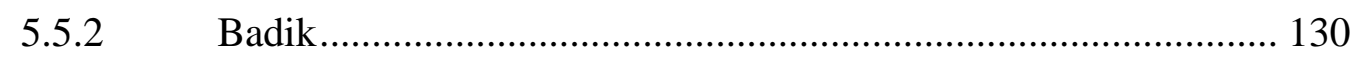

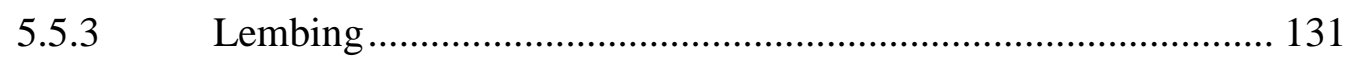

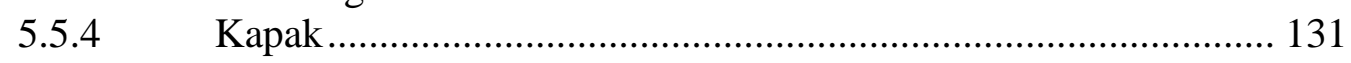

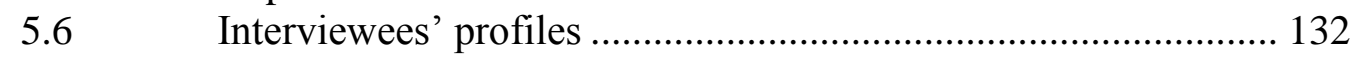

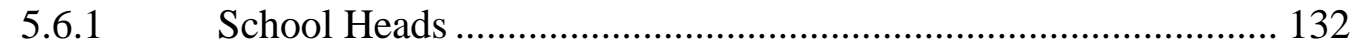

5.6.2 Library and Media Teachers (LMT) ...................................... 133

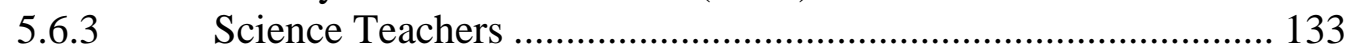

5.6.4 Local Studies Teachers ........................................................ 134

5.6.5 Islamic Religious Studies or Language Teachers ....................... 134

Key informants' profiles.......................................................... 134

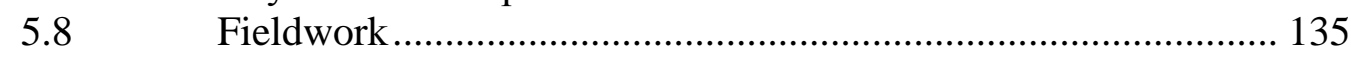

5.8.1 Reaching the interviewees and key informants ........................ 135

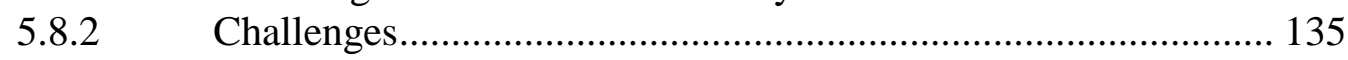

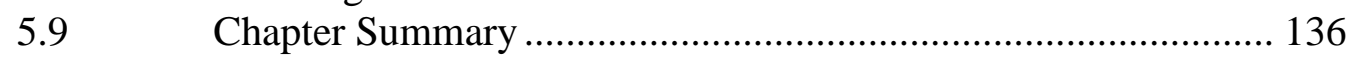

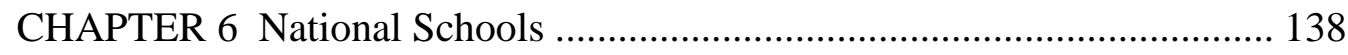

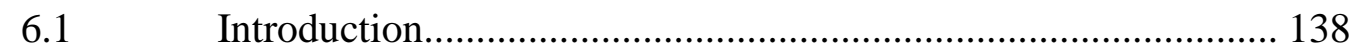

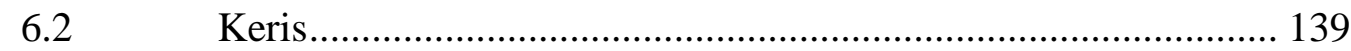

6.2.1 Stage of ILE implementation................................................... 139

6.2.2 Factors affecting ILE implementation ..................................... 141

6.2.3 How do these factors facilitate or hinder ILE implementation in

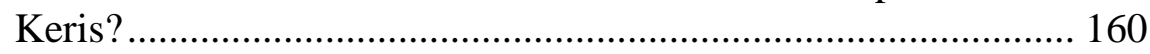

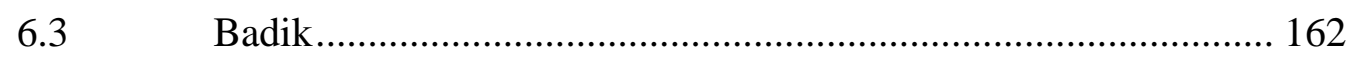

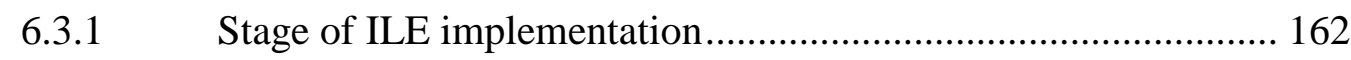

6.3.2 Factors affecting the ILE implementation ................................ 164

6.3.3 How do these factors facilitate or hinder ILE implementation in

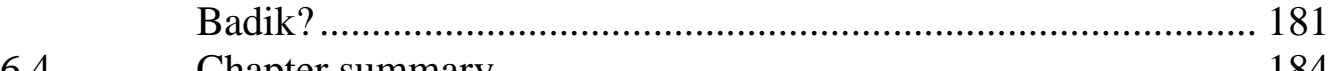

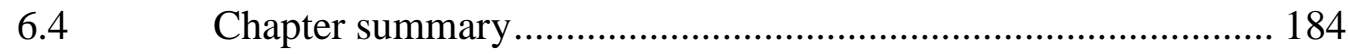

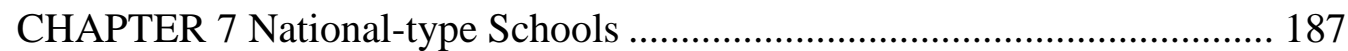

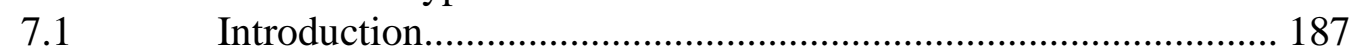

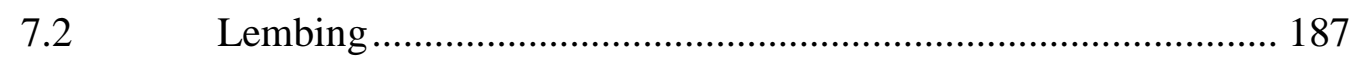

7.2.1 Stage of ILE implementation............................................. 187

7.2.2 Factors affecting the ILE implementation ................................ 188

7.2.3 How do these factors facilitate or hinder ILE implementation in

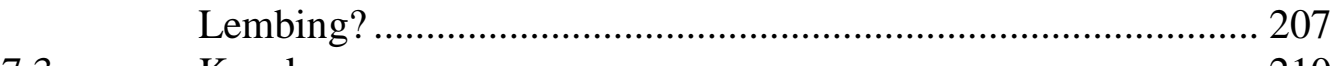

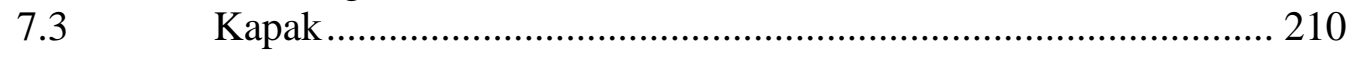

7.3.1 Stage of ILE implementation................................................... 210

7.3.2 Factors affecting the ILE implementation ............................... 212

7.3.3 How do these factors facilitate or hinder ILE implementation in Kapak?231

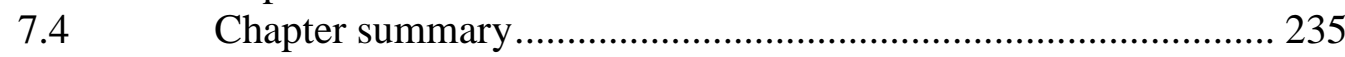

CHAPTER 8 Key Informants at the District, State and Federal Levels....... 238

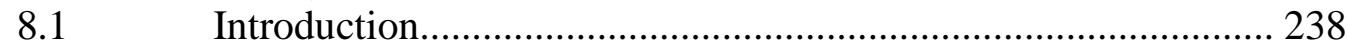

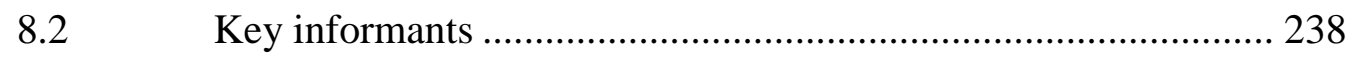

8.2.1 Stage of ILE implementation................................................ 238 
8.2.2 Factors affecting the ILE implementation

8.2.3 How do these factors facilitate or hinder ILE implementation in Malaysian primary schools? .................................................... 268

8.3 Chapter Summary ........................................................... 272

CHAPTER 9 Information Literacy Education in Malaysia: Synthesis and Interpretation of the Findings ............................................... 274

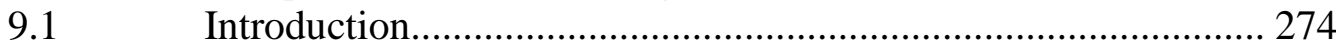

9.2 Comparison of the perspectives of federal, state and district key informants with the perspectives of the case study schools'

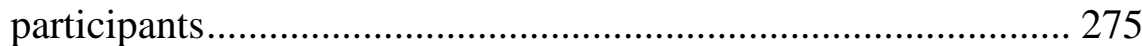

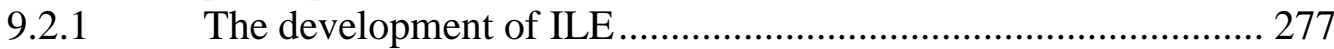

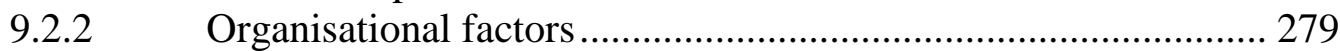

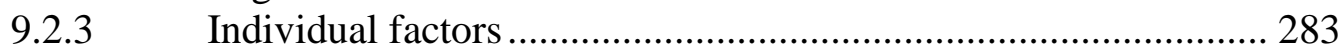

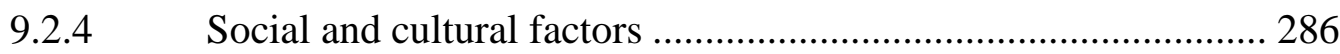

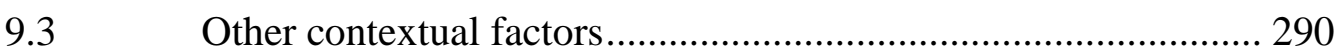

9.4 Revisiting factors in the preliminary model of ILE implementation297

9.5 Chapter Conclusion .......................................................... 300

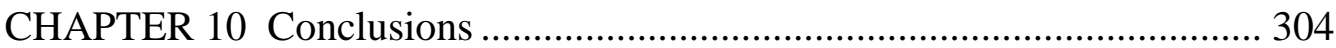

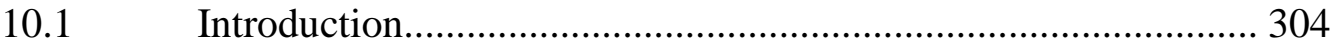

10.2 Major findings and conclusions .............................................. 304

10.2.1 What are the factors affecting the implementation of ILE in Malaysian primary schools? ...................................................... 305

10.2.2 How do these factors facilitate or hinder ILE implementation in Malaysian primary schools? ..................................................... 310

$10.3 \quad$ Implications for Theory ................................................... 313

10.4 Implications for Policy and Practice......................................... 322

$10.5 \quad$ Recommendations for Future Research ................................... 327

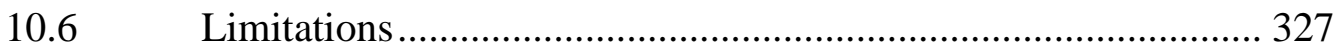

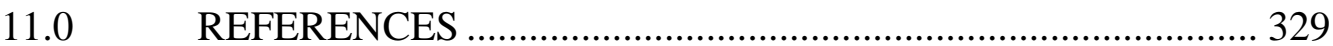

Appendix 1 - Letter of Approval from the Human Ethics Committee, School of Information Management ...................................................... 355

Appendix 2 - Information sheet for school ............................................. 356

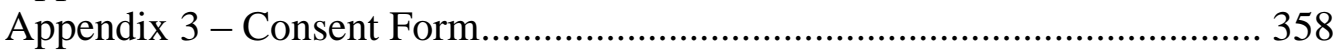

Appendix 4 - Interview Protocol ............................................................. 359

Appendix 5 - Government channels negotiated for accessing participants and

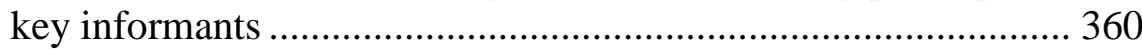

Appendix 6 - Interview transcript and highlighted important terms............. 361

Appendix 7 - Initial coding of case study schools ..................................... 362

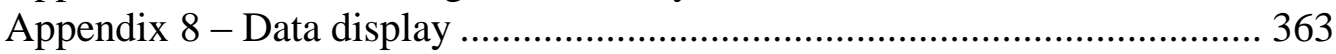

Appendix 9 - Mind mapping: Factors affecting ILE implementation from participants at case study schools ............................................. 364

Appendix 10 - Logical flow of the thesis ................................................... 365

Appendix 11 - A summary of factors that facilitated and hindered ILE implementation in Malaysian primary schools............................ 366 
List of Tables

Table 3.1. Definitions: Stages of Concern about the Innovation (adapted from Hall, Wallace \& Dossette, 1973).

Table 3.2. Levels of implementation of the ILE: Typical behaviours (adapted from Hall, 1992)

Table 3.3. Factors that Affect the ILE Implementation: the Action Model by Fullan's Theory

Table 4.1. Participating primary schools.

Table 4.2. Participants' characteristics at school, and key informants at district, state and federal levels of education administration.

Table 4.3. Criteria of truthfulness (adapted from Denzin \& Lincoln, 2000, p.13)

Table 5.1. Educational Components of Malaysian Education for ICPS and ISSC (sources from Hashim, 2004)

Table 9.1. Comparison of the perspectives of key informants and case study schools

Table 9.2.General similarities and differences between ILE and MES 290

Table 10.1. Summary of suggested factors in the preliminary model and factors found in the data.

List of Figures

Figure 3.1. A Conceptual Framework of Program Theory (A comprehensive form) (Chen, 2005)

Figure 3.2. Four Phases of the Change Process (Fullan, 2001) ...................... 74

Figure 3.3. Interactive Factors Affecting Implementation (Fullan, 2001) ....... 75

Figure 3.4. The adaptation of dimensions to the preliminary model for the study.....

Figure 3.5 (a). Factors affecting the implementation of change by Fullan's Theory of Educational Change (adapted from Fullan, 2001) .83

Figure 3.5 (b). Factors affecting the implementation of change by Chen's Action Model (adapted from Chen, 2005) .84

Figure 3.6. The adaptation of variables and factors to the preliminary model for the study 85

Figure 3.7. The Preliminary Model of ILE Implementation in Malaysian Primary Schools.

Figure 5.1. Malaysia - East and West Malaysia (EPU, 2009) ....................... 113

Figure 5.2. Management structure of the Malaysian education system (MOE, 2004, p.5)

Figure 5.3. Structure and organisation of the Malaysian education (UNESCOIBE, 2010/2011, p.7)

Figure 5.4. The state of Perak and the geographical location of the case study schools (Department of Statistics, c2011; Google Map).

Figure 10.1. The modified model of ILE implementation in Malaysian primary schools. 


\section{List of Abbreviations}

$\begin{array}{ll}\text { CBAM } & \text { Concerns Based Adoption Model } \\ \text { CDC } & \text { Malaysia. Ministry of Education. Curriculum Development } \\ & \text { Centre } \\ \text { EPU } & \text { Economic Planning Unit } \\ \text { ETD } & \text { Educational Technology Division } \\ \text { IL } & \text { Information Literacy } \\ \text { ILE } & \text { Information Literacy Education } \\ \text { ISSC } & \text { Integrated Secondary School Curriculum } \\ \text { KSSR } & \text { Primary School Standard Curriculum (Kurikulum Standard } \\ & \text { Sekolah Rendah) } \\ \text { LMT } & \text { Library and Media Teacher } \\ \text { MOE } & \text { Ministry of Education } \\ \text { MSSP } & \text { Malaysian Smart School Project } \\ \text { NILAM } & \text { Pulse of Education is the Reading Habit (Nadi Ilmu Amalan } \\ & \text { Membaca) } \\ \text { ICPS } & \text { Integrated Curriculum for Primary School } \\ \text { SETD } & \text { State Educational Technology Division } \\ \text { SRC } & \text { School Resource Centre } \\ \text { TAC } & \text { Teachers' Activity Centre } \\ \text { TED } & \text { Teacher Education Division }\end{array}$




\section{CHAPTER 1 Introduction}

\subsection{Chapter Overview}

This chapter provides the background to the research problem and an overview of the remainder of the thesis. Next, the research problem, research questions, and research objectives are identified. A list of definitions is included. An overview of the theoretical framework, methodology and scope is provided along with the delimitations, limitations, and justification of the research. Finally, an overview of the thesis is given.

\subsection{Background to the research}

Since the early 1990s, the school curricula of most developing countries have undergone many significant changes. The multiple changes of education can be attributed to the "twin metonymic conditions of greater internationalization of market economies and globalization of the cultural economy' (Rivera, 2003, p.553). Most developing countries participate in significant ways and at varying degrees in the international market. To participate in this global market, developing countries have to transform themselves and prepare their resource capital (human resource in particular) for the post-industrial era.

In 1991, the then Prime Minister, Tun Dr Mahathir Mohamad (1991, p.1) envisioned Malaysia to become 'a fully-developed, matured and knowledgerich society by the year 2020'.This vision was named as Vision 2020 which calls for the nation to achieve fully developed nation status by the year 2020, encompasses all aspects of life such as economic prosperity, political stability, world class education, social, cultural and spiritual well-being. The government has made the move towards a knowledge-based society starting with economy as its main target. In developing the knowledge economy, 
knowledge has to be the key factor of production replacing labour and capital. The move towards a knowledge economy has seen ICT (information and communication technology) and associated high technology activities such as e-commerce playing a leading role.

The Vision 2020 towards Malaysia's Knowledge Society has a good basis because the Malaysian society uses a wide range of ICT related technologies in everyday life. As of 2009, Malaysian internet users were about 15,355 million (Central Intelligence Agency (CIA), 2013). Users of mobile phones were also more than the number of landline telephones.

Another brighter side of ICT related technologies is that Malaysian society has begun to recognise information or knowledge as important or of value. The rapid advancement of ICT technologies has made it possible for members of society to transmit and process information at faster speed, in a greater volume, and with better accuracy (Zaman, 1998). These changes represent the very symbol of the information society. Thus, the importance of information and knowledge in an information society is comparable to the importance of raw materials in agrarian society and capital in an industrial society (May, 1998).

However, according to Zaman (1998), the term information society cannot be explained solely on its importance and significance to a section of society or the amount of use of information or the changes in the way of working style by a certain group of society. A true information society or information-rich society requires 'a conscious effort by the whole nation to inculcate information values to permeate the whole society and thus provide the necessary infrastructure and education in all aspects of...society' (para. 3). In order to assure the whole nation's conscious effort, the Government as the driving force has to ensure that its people are literate. The ultimate goal is to achieve $100 \%$ literacy rate by 2020 , which would thus increase the population's ability to become information literate. To accomplish the target of $100 \%$ literacy and other national developments, the Malaysian government has initiated multiple educational reforms. 
The educational reforms started with the introduction of a value-based education system in the 1980s. The infusion of moral and spiritual values was seen to balance the cognitive and affective development of the curriculum. In the 1990s, we witnessed other moves by the government with the democratization of secondary education, improvement of access to higher education, reform of the educational structure and school curriculum, and the introduction of ICT in education (Lee, 1998).

With such significant changes evolving around the education system, the school administrators and the teachers encountered a "dilemma" that continues to exist (Ahmad, 1998). The dilemma arises because values education is meant to ensure that their teachings are not influenced by their personal beliefs (Ahmad, 1998). At the same time, the development of Smart Schools which centres on the concept of teaching using ICT, self-directed and independent learning has emerged. The teachers, who are still confused as to how to teach values education (Ahmad, 1998; Balakrishnan, 2009), have to face further dilemmas with the internet in the classrooms.

The Malaysia Smart School Project (MSSP) stresses the integration of information and communication technology (ICT) into education as an enabler of creative teaching and learning processes, and as a means to enhance the efficiency, effectiveness and productivity of management in education (Multimedia Development Corporation, 2005). According to the Ministry of Education (MOE), ICT literacy skills are a requirement in the Smart School Project (MOE, 1997). The Conceptual Blueprint of the MSSP describes ICT literacy as "the ability to use IT tools and IT sources to collect, analyse, process and present information support meaningful learning in a variety of contexts [to] prepare for working life" (p.37).

ICT literacy skills are needed to prepare students for the Information Age challenges. According to Chan (2002) the Blueprint discusses "information literacy" as the knowledge and skills which contribute to a student's personal 
empowerment and freedom to learn. Thus, both ICT and 'IL' skills are emphasised in the MSSP in order to equip students to be 'self-paced, selfdirected and self-accessed' learners (MOE, 1997, p.133), 'critical and creative' thinkers and lifelong learners (p.27).

Several official statements and reports indicate that information literacy education (ILE) has been integrated into the education system (see Mohamad, 2002; Jusoh, 2002; Chan, 2002; Yusoff, 2006). ILE is seen as a vehicle to support the on-going development of Smart Schools by encouraging teachers and students to be involved in planned learning activities incorporating the electronic resources and the collections from the school resource centre (SRC). The statements made by the MOE officials seem to require a student to possess IL skills once he or she graduates from the school system.

Therefore, it is important to investigate how ILE is being implemented in order to understand the process and implications of its implementation.

According to several sources (for example: Tan \& Singh, 2008; Malaysia. Ministry of Education. Educational Technology Division (ETD), 2006; Malaysia. ETD, 2005), a range of factors could be responsible for impeding developments. These include lack of curriculum resources and framework, lack of leadership, and lack of necessary skills and understanding to implement IL among the principals and teacher librarians, in particular, and the school communities in general.

Motivation for this study came from my own experience formerly as a reference librarian in a leading academic library in Malaysia and currently as an educator in a university also in Malaysia. From these experiences, I identified gaps in the use of information among students and faculty members as well as in the teaching and learning approaches used from the primary to the higher education level. I could see that what was expected of the students to be able to survive in the $21^{\text {st }}$ century did not match up to grassroots practice. In other words, even with values education, Smart Schools and ICT in schools, the environment in schools was still leading students to be passive and 
dependent. The learning environment has also meant that the development and progress of ILE into the education system has been quite slow.

\subsection{Research Problem, Questions and Objectives}

Based on this background information, this section identifies the research problem, research questions, and research objectives for this study.

\subsubsection{Problem Statement}

In Malaysia, ILE appears to be something that policy makers, educators and librarians all believe to be important. Several statements and reports indicate that ILE has been integrated in the education system (see Mohamad, 2002; Jusoh, 2002; Chan, 2002; Yusoff, 2006, cited in Edzan, 2008). It is also highlighted in the ETD (2006) report that $60 \%$ of school heads said that ILE was implemented in the schools. However, there is little evidence to support this claim.

According to the findings of Tan and Singh's study (2008), 61.9\% of Library and Media Teachers (LMT) did not teach IL in the school resource centres (SRC) due to the lack of curriculum resources and framework, and $81 \%$ of the respondents (i.e. LMTs) indicated that no one in their schools, either 'a language teacher, a local studies teacher, a technology teacher, or someone else' was teaching ILE in their respective schools (p.6). The respondents indicated that there was no time allocation for ILE in their school timetable, and uncertainty as to whether to teach ILE as a subject or to integrate it into teaching subjects. Thus, Tan and Singh's findings suggest that the vast majority of schools have not implemented ILE.

The ETD's (2006) report also showed that only $30 \%$ of the school heads, SRC coordinators and subject teachers were exposed to seminars, courses or other staff development programs relating to ILE. That means $70 \%$ of the participants of the study were not exposed to ILE.

While the MOE's officials have claimed that ILE is integrated into the education system, ILE does not appear to be implemented in most Malaysian 
primary schools. There are a number of possible explanations, including (a) characteristics of the implementation system, such as lack of curriculum resources and framework, and lack of time (Tan \& Singh, 2008); (b) characteristics of the implementers, such as lack of necessary skills and understanding (Tan \& Singh, 2008), lack of training (ETD, 2006; ETD 2005, cited in Tan \& Singh, 2008); and (c) characteristics of the setting, such as lack of space and financial allocations (ETD, 2006). Another possible explanation is the lack of recognition and support for ILE within the MOE's official documents (Edzan, 2008).

So, there is a discrepancy between the MOE's official claims and the research evidence. It is unclear what the possible factors are that affect ILE implementation. Therefore, the problem to be investigated in this research is to identify the factors that facilitate or hinder the implementation of ILE in Malaysian primary education.

By coming to understand this problem, it should be possible to plan a better programme for ILE that will help the implementers to progress in incorporating ILE into their teaching practices.

\subsubsection{Research Questions}

The following questions guide this study:

- What are the factors affecting the implementation of ILE in Malaysian primary schools?

- How do these factors facilitate or hinder ILE implementation in Malaysian primary schools?

\subsubsection{Objectives of Research}

The objectives of this study are:

- To identify the factors affecting ILE in Malaysian primary schools;

- To determine how these factors affect the implementation of ILE in the Malaysian primary schools; 
- To develop, test and if necessary, revise a contextual model to explain the factors that are facilitating and hindering ILE implementation in Malaysia.

\subsection{Definition and Description of Terms}

\subsubsection{Information Literacy (IL)}

IL refers to the ability of individuals or groups

- to be aware of why, how, and by whom information is created, communicated and controlled, and how it contributes to the construction of knowledge

- to understand when information can be used to improve their daily living or to contribute to the solution of needs related to specific situations, such as work or school

- to know how to locate information and to critique its relevance and appropriateness to their context

- to understand how to integrate relevant and appropriate information with what they already know to new construct knowledge that increases their capacity to improve their daily living or to resolve needs related to specific situations that have arisen (Dorner \& Gorman, 2006, p.284)

For the purpose of this study, this definition of IL is chosen as an operational definition in order to understand factors affecting the implementation process of IL in the developing countries context, like Malaysia, and to construct new knowledge from this new definition of IL. This is discussed further in section 2.3 .

\subsubsection{Information Literacy Education (ILE)}

ILE refers to a process of teaching and learning of IL based on learner centred approach and reflective practices (Andretta, 2005). That means, students are taught and learn IL through constructing relevant knowledge and experiences, and reflecting on the knowledge and experiences built into the curriculum. For the purpose of this study, ILE is used throughout the thesis as referring to the process rather than the skills itself. 


\subsubsection{Implementation}

Implementation literally means execution or carrying out a task or an operation. A basic definition proposed by Yeaton and Sechrest (1981, cited in Domitrovich \& Greenberg, 2000) is 'the degree to which treatment is delivered as intended'. Similarly, Durlak (1995, cited in Domitrovich \& Greenberg, 2000) described implementation as 'what a program consists of in practice' and how much it is delivered according to how it was designed (Durlak, 1998, cited in Domitrovich \& Greenberg, 2000). For the purpose of this study, implementation refers to the process of how ILE is delivered as envisaged by the MOE in the primary school system.

\subsubsection{Implementer}

According to the Merriam Webster dictionary (2010), implementer is an individual person who carries out a task or gives a 'practical effect' to an operation. Another definition by McLaughlin (1987) refers to implementers as 'those responsible for implementation at various levels of the policy system.' (p.172). For the purpose of this study, I use the term 'implementer' to refer to those persons who are responsible for the implementation of ILE at various levels of the Malaysian education system.

\subsubsection{Primary school}

A primary school is a school that provides education to achieve basic skills such as reading writing and arithmetic, the so-called 3Rs. In Malaysia, a public primary school is known as a national school. According to the Malaysian Education Act 1996, a national school is

a government or government-aided primary school:

(a) providing primary education appropriate for pupils from the age of six years;

(b) using the national language as the main medium of instruction;

(c) in which the English language is a compulsory subject of instruction; and

(d) in which facilities for the teaching of:

(i) the Chinese or Tamil language shall be made available if the parents of at least fifteen pupils in the school so request; and 
(ii) Indigenous languages shall be made available if it is reasonable and practicable so to do and if the parents of at least fifteen pupils in the school so request.

For the purpose of this study, a primary school is as defined by the Malaysian Education Act 1996.

\subsubsection{Head teacher}

In theory, a head teacher or principal is the most powerful person in the school organization (Campbell, Bridges \& Nystrand, 1977). His or her power plays an important role to strengthen and sustain the school structure, organization, culture and environment. For the purpose of this study, the term 'head teacher' refers to a qualified teacher who has been appointed by the MOE of Malaysia to lead a school organization which consists of teachers, administrative staff, and students. The specific term is also used throughout the Malaysian Education Act 1996.

\subsubsection{Teacher}

According to the Malaysian Education Act 1996, a teacher is

a person who -

(a) teaches pupils in an educational institution; or

(b) prepares or issues lessons or corrects returned answers in, for or through a distance education centre, and includes a head teacher or principal.

For the purpose of this study, the definition of teacher follows the country's Education Act.

\subsubsection{Library and Media Teacher (LMT)}

In this study, the MOE's terminology for the role of teacher librarian is used. According to Professional Circular Number 3/ 2005, LMT refers to a professional teacher with a minimum of three years of classroom teaching experience and additional qualifications in the selection, management, and utilization of learning resources, who manages the SRC and works with other teachers to design and implement resource-based instructional programmes (MOE, 2005). 


\subsubsection{School resource centre (SRC)}

The school resource centre (SRC) is basically made up of four units; a) the school library; b) the audio visual (AV) room, where all the audio visual materials are kept; c) the teaching aid or Alat Bantu Mengajar (ABM) room where all the teaching assisting materials such as wall charts and maps are kept; and d) computer laboratory. For the purpose of the study, I restrict SRC to the four basic units mentioned above which every school in Malaysia has.

\subsubsection{IL guidelines}

IL guidelines refer to any online and print instruction that can assist in teaching the skills needed to identify, locate, evaluate and use all types of information resources. For the purpose of this study, they refer to the MOE official IL framework or standard or scheme of work for the LMT and the IL framework for students that can facilitate instruction.

\subsection{Theoretical Framework}

The study seeks to identify and understand factors affecting the implementation of ILE in Malaysian primary schools. Three relevant theories along with factors emanating from the literature have been used to develop a preliminary model.

The Concerns Based Adoption Model (CBAM) by Hall and Hord (2005) has provided a guide to identify the stages of ILE implementation and the factors affecting ILE within the schools. The Action Model by Chen (2005) and the Theory of Educational Change by Fullan (2001) have been used to identify and understand factors internal and external to the school ecology. Factors such as teachers' lack of time and resources have been identified from the literature.

As a result, a preliminary model based on the three theories and the relevant literature was used to guide the study.

\subsection{Methodology}

I employed a qualitative research approach for the project, focusing on cases, and using a qualitative method, within an interpretive philosophy. Semi- 
structured interviews were carried out with the participants, and then followed by documentary analysis. Analysis and review of documents related to IL was used to complement data collected through interviews.

\subsection{Scope of the Research}

The population for this research was limited to school heads, classroom teachers and LMTs at school level and officials from the state and federal levels. The study was conducted at the Kinta North district in Ipoh, Perak, Malaysia because Perak is a large state, and the Kinta North district comprises both urban and rural areas, and is thus fairly reflective of the variation in the country. This research used a purposive sample of four of 112 primary schools. The primary schools included two national schools, a national-type of Chinese school and a national-type of Tamil school. Selection of the four schools was guided by the category of schools, geographical location, medium of instructions and IL involvement.

\subsection{Delimitations and Limitations of the Research}

The delimitation of this study is that it was only concerned with explicating the factors affecting the implementation of ILE in Malaysian primary schools. This study was based on the perspectives of the school heads, LMTs, and classroom teachers from four primary schools who are involved in incorporating IL as a strategy in the teaching and learning of the primary pupils, and the perspectives of officials from the state and federal levels. It did not aim to develop an instrument for measuring the effectiveness of ILE implementation or to verify the extent to which ILE is embedded into the students' learning.

The limitation of the study is in possible shortcomings in translating the results of data analysis into English since the data were collected in Malay language and English. To limit these shortcomings, several actions were considered and are discussed in section 4.8.3. 


\subsection{Outline of the Thesis}

This first chapter of this thesis has discussed the background to the research and sets the context of the study.

The second chapter reviews the relevant and related literature on IL. The literature is examined from different perspectives of IL, its importance and value, its initiatives and implementation, including the IL position in Malaysia. Both theoretical and research perspectives of IL are identified.

The third chapter discusses theories that are used to guide the study. Based on the theories, a preliminary conceptual model for this study is presented and described.

The fourth chapter discusses the paradigm that guides the study, followed by an elaboration of the research methodology and methods used, that is, qualitative methodology and methods within an interpretive philosophy. Next, the selection of research sites, participants and key informants are described. Then, I present the data analysing strategies and conclude this chapter addressing the ethical issues and language, validity and reliability concerns.

The fifth chapter begins with the background information of the research setting, specific details of the case study schools, and profiles of the interviewees and key informants. This chapter concludes with my reflection on, prior to and during the fieldwork.

In the sixth through eighth chapters, I present the case study findings of ILE implementation in national schools, national-type schools and from the key informants. The structure of these chapters is identical. Each chapter concludes with a summary of the factors affecting ILE implementation in each case study school and from the key informants.

The ninth chapter presents the interpretation and synthesis of the findings related to the four case study schools and the key informants at the three levels 
of education administration (district, state and federal). The purpose of this chapter is to provide the interpretive insight of these findings so that a holistic understanding of the factors affecting ILE implementation can be achieved. A synthesis of the ILE and Malaysian Education System (MES) and the implication of the findings are explored. The chapter concludes with the reexamination of my preliminary model of ILE implementation from the third chapter.

In the tenth and final chapter, I present the conclusions drawn from the findings relating to the four case study schools and key informants at the three levels of education administration (i.e., district, state and federal). The chapter provides a discussion of the major findings, the conclusions drawn, the implications for theory, policy and practice, recommendations for further research as well as the study's limitations. 


\section{CHAPTER 2 Literature Review}

\section{$2.1 \quad$ Introduction}

In this $21^{\text {st }}$ century, IL is seen to be one of the survival skills (Fitzgerald, 2004). In this literature review, IL is a concept to be integrated into the school curriculum. It is a concept that emphasizes resource-based learning, critical thinking skills, problem solving skills and research skills. Teaching and learning in IL can be applied to any program to teach skills that prepare individual students to be information literate persons. IL skills are required skills just like other skills that students must acquire (reading skills, writing skills, thinking skills, ICT skills and others) (Breivik, 2005). Therefore, there is a need for ILE to explore the theoretical and research perspectives in order to provide some insights on the intrinsic and extrinsic factors affecting the process of ILE implementation and the problem of this study.

This review is divided into eight sections. The first discusses briefly the background of literacy and its development. The second outlines the root of IL, its value in education, and its initiatives worldwide. The third provides a discussion about educational change, and its relation to change in society. The fourth discusses an integrated analysis of the research, review and discussion of articles, theses, reports and conference papers that have built upon two areas: (1) execution of IL; (2) factors affecting ILE based on three levels of factors: individual level, organizational level and social and cultural level. The fifth is about IL in Malaysian schools and factors affecting IL implementation. The sixth highlights gaps in the literature. The seventh section of this review sketches the theoretical considerations to guide the study. 


\subsection{Definitions, Descriptions and Development of Literacy}

The needs of society at any point of time determine the way a concept is defined and applied. Prior to and during the $21^{\text {st }}$ century, literacy is seen as a functional skill which refers to the ability to read and write. UNESCO, as a strong advocator of the international literacy movement, has defined literacy as the

ability to identify, understand, interpret, create, communicate, compute and use printed and written materials associated with varying contexts. Literacy involves a continuum of learning in enabling individuals to achieve their goals, to develop their knowledge and potential, and to participate fully in their community and wider society. (UNESCO, 2004)

In the modern context, to be literate means to successfully function at certain levels in society. Therefore, every segment of society has to be taught how to be literate and schooling has become the catalyst.

The history of literacy goes back several thousand years. Prior to the industrial revolution, reading materials were very expensive. Only wealthy individuals and institutions could afford them. However, by the mid-nineteenth century, after the industrial revolution and with the invention of the movable type printing machine, finally cheap paper and cheap books were made available to all classes of societies of industrialised Western societies. But still a small percentage of the world's population was literate.

What constitutes literacy has changed throughout history (Venezky, 1996). At one time, a literate person was one who could sign their name (Kaestle, 1985). At other points, literacy was measured by the ability to read the sacred texts (Clifford, 1984) such as the Talmud, Bible, Qur`an and Veda. For example, in Islam, the Muslims as believers have to learn and read the Qur'an in the original Arabic alphabet (Goody, 1968, cited in Foster \& Purves, 1996, p.2645) for the purpose of five times a day prayers and other rituals. Similarly, Judaism places great importance on the study of holy texts, the Tanakh and the Talmud. Most Jewish males learn to read and write Hebrew, at least (Parush, 
1995). Thus, the highly literate cultures and societies in the past and present world learned reading and writing as religious obligations.

UNESCO (2004) has propagated the idea of literacy as '...a fundamental right... [literacy] has been considered something to which every person is entitled'. Until the mid-1960s, literacy was a right primarily understood as 'a set of technical skills: reading, writing and calculating'. Followed by a few other international announcements in the 1960s and 1970s, further actions and strategies were undertaken to build literacy (UNESCO, 2004). In the 1990s, UNESCO conducted a series of campaigns and promotional activities which led to a significant announcement made in 2002, that is, United Nations Literacy Decade 2003-2012. Literacy is recognized as a very crucial skill to all members of society in order to perform better in certain levels of society (UNESCO, 2006).

Following the initial development of literacy as the ability to read and write, its significant impact has extended to the development of other literacies, namely 'critical literacy', 'computer literacy', 'media literacy', 'visual literacy', 'technology literacy', 'digital literacy', and 'information literacy' (Breivik, 2005; Owusu-Ansah, 2003). The rapid advancement in information and communication technology and proliferation of knowledge production can be one of the contributing factors for this development of other literacies.

\subsection{Information Literacy (IL)}

The emergence of IL as a "phenomenon" can be traced back to 1946 when UNESCO propagated the idea of literacy as a fundamental human right. However, the concept of traditional literacy alone was seen to be ill-equipped in the post-industrial societies. As the needs of society became more complex, the capacity to survive grew more complex.

Parallel to the emerging need of the information society, the phrase 'information literacy' made its appearance in 1974 in a report prepared by Paul G. Zurkowski on behalf of the U.S. National Commission on Libraries and 
Information Science. The report laid out the need to enhance the ability of individuals in society from knowing how to do, to knowing how to learn. Then, in 1989, the final report of the American Library Association (ALA) Presidential Committee on IL officially laid the foundation for an IL teaching approach within educational settings with emphasis on libraries (ALA, 1989).

The need to promote IL continues. UNESCO considers IL as a basic human right and the beacon of information society in the $21^{\text {st }}$ century (UNESCO, 2010). At present, IL has captured the attention of many education systems such as in the U.S.A., Australia and New Zealand. It is now beginning to be accepted and demanded in sectors such as health and finance and is seen to be having a significant impact (Ivanitskaya, O’Boyle \& Casey, 2006; OwusuAnsah, 2003).

\subsubsection{Defining IL}

Numerous definitions of IL have been produced and discussed. In this literature review, I begin with the most accepted and widely used definition. IL is defined as the ability of an individual to access, evaluate, and use information from a variety of sources (Doyle, 1994; ALA, 2006; Webber and Johnston, 2003). This is the generic definition that focuses on specific skills and outcomes.

Since the ALA's seminal work on IL in 1989, its definition has been discussed and debated in many conferences and workshops. It seems that different contexts need different kinds of definitions. The following is a list of definitions by information professionals:

1. Acquiring mental models of information systems (Moore, 2000)

2. A set of skills (ACRL, ALA, 1989)

3. A combination of information and IT skills (SCONUL, 1999)

4. A process (Spitzer, Eisenberg \& Lowe, 1998)

5. A way of learning (Kulhthau, 1987)

6. Information behaviour (Johnston \& Webber, 2003) 
While there were more IL definitions based on generic skills, a few definitions described IL as the way of experiencing information use (Bruce, 2000) and as the ability of individuals or groups within a particular context such as in developing countries (Dorner \& Gorman, 2006). Bruce (1997), in her Seven Faces of Information Literacy, describes IL as a phenomenon which includes a range of experiences using information. Her research (1997) revealed seven qualitatively different ways of experiencing IL.

Dorner and Gorman (2006) defined IL based on the social and cultural dimension, as follows:

The ability of individuals or groups

- To be aware of why, how, and by whom information is created, communicated and controlled, and how it contributes to the construction of knowledge;

- To understand when information can be used to improve their daily living or to contribute to the solution of needs related to specific situations, such as work or school;

- To locate information and to critique its relevance and appropriateness to their context;

- To understand how to integrate relevant and appropriate information with what they already know to construct new knowledge that increases their capacity to improve their daily living or to resolve needs related to specific situations that have arisen.

(Dorner \& Gorman, 2006, p.284)

For this study, which is situated in the Asian country of Malaysia, Dorner and Gorman's operational definition of IL has been adopted because it focuses on ILE in developing or Asian countries.

The constant redefinition of the IL terms can be traced back to traditional literacy, i.e. reading and writing. It is not easy to define, execute and quantify the outcomes of traditional literacy. Similarly, for IL, there is no one definition that fits all societies. Campbell (2004) felt the need to produce more new 
definitions of IL with the hope of finding one definition that appeals to information professionals internationally. However, the discussions of alternative IL definitions and terminologies (see Snavely and Cooper, 1997) have not halted the genuine intention and vision of information professionals to promote the idea of critical thinking skills and lifelong learning in society as part of IL goals. In the Prague Declaration (UNESCO, 2003) IL and lifelong learning have been portrayed as the beacons of the information society (Horton, 2006). It is important to note a shift in emphasis from IL skills (e.g. ALA, 1989) to competencies that are more socially and educationally focussed (e.g. UNESCO, 2003; Bruce, 1997; Dorner \& Gorman, 2006).

Owusu-Ansah (2003) believes that the dilemma of IL is not the uncertainty of its definition but the difficulty of its execution. This statement relates to the problem of my study. The Malaysian government stresses the importance of ICT for economic development and global participation. The MOE promotes ICT and effective use of ICT to ensure current students can contribute fully in information society. Despite this policy, the development of ILE is given limited attention in schools and it is poorly implemented at the primary schools level.

\subsubsection{The Value of IL}

Recognition of the value of IL has increased gradually since the early 1970s. Over this period, the concept of IL has been interpreted in various ways by information professionals and educators. Varying approaches have been taken to bring the idea of IL closer to the individuals and groups in particular contexts so that their way of thinking and their value systems can give better interpretations of their needs for particular IL programs (Bruce \& Candy, 2000). In response to the value of IL, the following is the snapshot of a list of the possible outcomes for an individual:

- The information literate person is one who accesses, evaluates, and uses information critically and effectively (Doyle, 1992; Bruce, 1999). 
- The information literate person is one who engages in independent and self-directed learning (Bruce, 1999; Andretta, 2005).

- The information literate person possesses a sound knowledge of the world of information and makes full use of various sources of information technologies, systems, and resources (Bruce, 1999; SCONUL, 1999).

- The information literate person is one who actively participates in citizenship (ALA, 1989; Johnston \& Webber, 2003; UNESCO, 2003)

In short, these definitions provide a useful entry point to understanding the concept of IL. The emphasis of these descriptions allows IL instructors and educators, as well as information providers, to interpret and apply them into specific contexts and subjects or disciplines.

\subsubsection{IL Initiatives and Implementation}

At present, IL has captured the attention of education systems (e.g. U.S.A., Singapore and Malaysia) in terms of its position to support the emergence of the constructivist approach and critical thinking skills (Loertscher \& Woolls, 1997; Grassian \& Kaplowitz, 2001; Hepworth, 2000; Chan, 2002). Thus, there is a great deal of developmental work that has been done in translating theory into practical ideas. The following section discusses IL initiatives in schools worldwide.

\section{- IL Initiatives in Schools Worldwide}

The development of IL programs in schools can best be seen in the U.S.A. and Australia. There are also references to IL developments in Canada, China, New Zealand, Singapore, South Africa, and Europe. Significant initiatives can be seen in these countries, such as the formulation of guidelines, standards, and other strategic documents, teaching strategies, and the role of school library media.

\section{a) IL Guidelines and Standards}


IL became part of the U.S. schools' national agenda and was integrated into their educational technology plan as one of its goals in December 2000. There were a few strategic documents, including the two sets of IL standards (i.e. Information Power: Guidelines for School Library Media Programs and Information Literacy Standards for Student Learning), developed for the school sector and higher education. These documents highlighted the importance of students acquiring skills in accessing and evaluating information (Spitzer, Eisenberg \& Lowe, 1998; Riley, et al, 2000; Muir \& Oppenheim, 2001; Koch, 2001, cited in Virkus, 2003).

In Australia, the IL movement was initiated by the higher education sector. In 2001, a joint Australian and New Zealand Institute for IL (ANZIIL) was established. The IL standards produced by the Council of Australian University Librarians (CAUL) was adapted from the ACRL standards (CAUL, 2001) and was updated in 2004 (Bundy, 2004). The Central Queensland University (CQU) distance education IL programme was a focus for many grants and recognised as a flagship programme internationally (Bruce \& Candy, 2000).

In China, according to Rader (2003), for more than 20 years, Thsinghua University Library offered a very intensive program of library instruction, including seven required credit courses with more than 2,000 students a year. The library instruction was also addressed on an individual basis and through distance learning, to the extent that their librarians translated the ACRL IL Competency Standards into Chinese (Rader, 2003).

New Zealand has had a national curriculum framework that gives attention to information skills, communication and problem solving since 1993. The framework appears to provide a solid foundation for the development of IL throughout compulsory education (Moore, 2000). In 1997, a Department of Labour report stated that the "Government encourages more people to become "information literate", to gain basic ICT skills and to pursue tertiary ICT qualifications' (Muir et al., 2001). The emphasis was on ICT, but the need for IL was highlighted. As a result, in 2001 the Library and Information 
Association of New Zealand Aotearoa (LIANZA) published a document that stressed the urgent need for a national information strategy. The document contains recommendations and strategies which encourage the government to develop a national IL strategy as an integral element in an overall national information policy for New Zealand (LIANZA, 2001).

The Singapore government has also recognised the importance of IL for the progress of the Singapore economy. A number of IL initiatives have been put in place in primary and secondary schools (Hepworth, 2000). For example, in 1987, seven secondary schools participated in an information skills' library instruction pilot program which led to the publication of the "black book". The black book was an information skills package published by the Languages and Libraries Development Branch, Curriculum Planning Division, MOE in 1989. Then, another publication known as the "orange book" was an information skills package for primary schools, published in 1991. The implementation and incorporation of these packages into the curriculum were not compulsory. It was left to the discretion of the schools and teachers (Hepworth, 2000).

Increased emphasis on IL and creative thinking by the Singapore government led to the publication of IL guidelines and implementation guidelines for secondary schools in 1997, which aimed to extend pupils' reading skills and experiences and information skills. Public libraries were also recognized as playing a key role in society by the government. However, less emphasis was placed on tertiary curriculum changes (Hepworth, 2000).

South Africa has been more active in the IL area than any other African country. The Centre for Educational Technology and Distance Education, part of the Department of Education of South Africa, published a policy document for school libraries. The policy emphasised the relationship between outcomebased education, learning resources and the school library. This was in support of the integration of IL and library use in the school curriculum (Muir et al, 2001). In the higher education sector, The Cape Library Cooperative is behind the INFOLIT project. The aim of INFOLIT was to promote IL in the five South African higher education institutions (Karelse, 2000). 
In Europe, the development of IL has been led by academic libraries. IL initiatives in higher education have taken a variety of forms: stand-alone classes, web-based tutorials, course-related and course integrated instruction. There is a considerable experimentation with using ICTs in delivering IL courses in European higher education institutions. In general, it is an effort to improve the on-campus learning experience and to improve delivery of distance learning. For example in the U.K., the University of Leeds briefly experimented with computer assisted library instruction at the end of 1970s (Fjallbrant \& Malley, 1984, cited in Virkus, 2003). In Denmark, the Aalborg University Library has a successful IL initiative, known as the SWIM (Streaming Web-based Information Modules) project which use streamingserver technology where the tutorial enables the students to make a number of choices about search strategy and problem solving (SWIM, 2003).

\section{b) The Role of School Library Media and IL Instruction}

The emergence of constructivism with its emphasis on critical thinking has led to transformative practices across education including school libraries (Loertscher \& Woolls, 1997). According to Loertscher and Woolls (1997), the role of the library media specialist in instructional design first popularized in Canada by Loertscher and Turner was known as "resource-based teaching". They further claimed that the movement evolved into increased interest in IL, which is the library media version of constructivism and critical thinking.

Other authors (for example: Rader, 1991; Snavely \& Cooper, 1997; Bruce, 2000) believe that the IL movement has evolved from precursors such as library instruction, bibliographic instruction, and user education in universities, which is library driven in nature and aims to orient the library users to its collection and services.

On the other hand, in schools, the term resource-based learning was popularized in some countries in the late 1980s 'signifying the adoption of IL principles in learning projects using a wide variety of information sources and 
technologies' (Loertscher \& Woolls, 1997). The term has been used in school library media centres for problem-based and inquiry-based learning in education referring to the constructivist approach to learning. With the interweaving of critical thinking, resource-based learning and IL, school library media specialists play a vital role to bring the best information resources and technologies to the learning process.

Many IL models emerged to assist in the development of IL. Only a few have gained substantial acceptance and use in teaching IL as a process, for example Stripling and Pitts Research Process Model, 1988; Kuhlthau's Information Search Process (ISP), 1989; Eisenberg and Berkowitz's Big Six, 1990; California School Library Association IL Model, 1994; Pappas and Tepe Pathways to Knowledge Information Skills, 1995; AASL and AECT IL Standards for Student Learning, 1996 (Loertscher \& Woolls, 1997). The most developed guidelines, with holistic learning approaches, are the AASL and AECT IL Standards focussing on schools.

The following discussion presents the need for ILE in schools, and its relationship with other educational reform.

\subsubsection{IL and Education}

Much literature has extensively discussed the need to promote IL as an integral part of the education system (Lennox \& Walker, 1993; Behrens, 1994; Shapiro \& Hughes, 1996). The aim of ILE is to facilitate individuals to become lifelong learners. It is envisaged that an information literate individual has knowledge and skills to sift and sort the huge amount of information, use proper information sources to make decisions and solve problems in life.

In order to prepare individuals at the earliest stages of their schooling, IL has to be integrated into the school curriculum. Dr Sigrun Hannesdottir, (1999, cited in Bruce, 2002), Director of the Nordic Council for Scientific Information, noted that information handling training should begin in primary schools. 
Thus, we can assume that IL has to be introduced as early as primary school. Primary education has two main purposes: to produce a literate and numerate population that can deal with problems encountered at home and in society, and to serve as a foundation on which further education is built (UNESCOUIS, 2008).

With the advancement of information and communication technology and proliferation of knowledge production in this $21^{\text {st }}$ century, IL is seen as a necessary skill. The underlying notion of IL is the challenge of teaching higher order cognitive and problem-solving skills (Bereiter \& Scardamalia, 1987).

In education, the focus of teachers as "sages on the stage" and students as passive learners has long been accepted as a way of teaching and learning tradition (Grassian \& Kaplowitz, 2001). Behaviourism first developed by B.F. Skinner in the 1950s, uses the concepts of 'positive' and 'negative' reinforcement to control behaviour. This theory explains learning behaviour simply: reward students who perform well, and punish students who do not (Skinner, 1953, cited in Grassian \& Kaplowitz, 2001). Many of the ideas of instructional development in educational technology stemmed from the behaviourist perspective (Loertscher \& Woolls, 1997).

In the U.S.A., John Dewey (1938, cited in Elkind, 1997) brought public education fully into the modern era by focussing on "progressive" pedagogy in which the student was an active participant rather than a passive recipient. The work of Dewey had become the foundation principles for constructivism. The constructivist theories stress the need to provide experience and contexts that enable students to learn effectively and willingly. In the constructivist view, change occurs solely as result of the interactions with the environment and can happen at any age or level of development. Knowledge is not viewed as simply passing from teacher to student. Knowledge is actually constructed in the learner's mind (Grassian \& Kaplowitz, 2001, p.43). Teachers have to become 'guides on the side', rather than 'sages on the stage'. 
Armed with the work of John Dewey in the 1930s, Benjamin Bloom in 1956 gave arise to inquiry learning and critical thinking (Loertscher \& Woolls, 1997). The idea of critical thinking has taken its roots in modern education, which can be traced from "the ideas of Plato and Aristotle and onward through Aquinas, Descartes, Bacon, Machiavelli, Hobbes, Locke, Newton, Boyle and many others" (Loertscher \& Woolls, 1997). With the rise of inquiry learning and critical thinking in modern learning, resource-based learning, which is synonymous with IL, should be a part of every student's learning experience. Rotherham and Willingham (2009) urge $21^{\text {st }}$ century skills such as IL to be taught in schools and counter the challenge of teaching such skills by improving the curriculum, teacher quality and introducing common assessment.

The following section discusses educational change and how changes in society have affected the education system.

\section{$2.4 \quad$ Educational Change}

Change is ubiquitous. The word "change" has often been used interchangeably with the word 'progress', 'improvement', 'evolution', 'reform' and 'development'. These are among the key concepts of modernity (Whitaker, 1993). Change has become central in the education sphere as a result of paradigm shifts in society.

\subsubsection{Society and Schools.}

According to Reigeluth and Garfinkle (1994), the changes from the agrarian period to the information age brought massive changes to all systems, including the family, schools, and business. Family, as the smallest unit in a society, has changed dramatically from being an extended family during the agrarian era, nuclear family in the industrial era, and single-parent and/or dualincome family in the information age. This phenomenon was a Western phenomenon, experienced typically in the U.K., the U.S.A., and Northern 
Europe. During the industrial era, the schools in Western countries underwent 'systemic change' from 'one-room schoolhouses to the industrial, assemblyline model' that exists today (p.4). Businesses during the agrarian period were generally a family affair, such as a family farm and a family trade. However, in the industrial era, family businesses gave way to a 'bureaucratic form of organization' (p.4). Today, in the information age, these businesses have tended to transform into 'team-based' approaches.

Similarly, Elkind (1991) discussed the history of the family and schools in the Western society, particularly the U.S.A., as evolving into three stages: the premodern era, modern era, and postmodern era. During the pre-modern era, the family generally lived in rural areas, and engaged in farming. The family played a major role and was responsible for the child's 'religious, moral and social upbringing' and 'craft skills' as a preparation to earn a living when adults (p.3). Then, during the modern era, the change in society was influenced by the changes in technology. Elkind also mentioned that the machine-made goods such as computers have transformed from the idea of 'bigger is better' to 'smaller is better' (p.7). Similarly, the size of the family generally decreased as a large number of women entered into workforce due to equality in education and job opportunity. Gradually, in this postmodern era, most families are increasingly dependent on outside social institutions to assist them in child rearing. It is a trend now that schools are taking over more childrearing functions from the parents. Schools have now modelled a factory-like system.

In the context of Malaysia, the education system cannot be isolated from external and internal social influences. According to Hashim (2004), during the $14^{\text {th }}$ century, Malaysia had a traditional Islamic education system. The system was informal and was held in the houses of religious teachers to teach adults and children Islamic teachings (Khoo, 2011). Khoo claimed that there was no formal education in the Malay Archipelago at that time. Only after the British Rule $\left(19^{\text {th }}\right.$ century), modern and formal schools were introduced. Education was given emphasis. The recruitment of government staff was also done 
through education qualifications. Due to the urbanisation and demand and supply of human resources, modern schools became highly populated. Today, teachers have to work hard to handle changes in education along with large class sizes and changes in society. This could affect the implementation of ILE in schools.

\subsubsection{Characteristics and Properties of Schools}

Numerous publications categorise schools as service organizations which are designed to produce changes in children (see Blau \& Scott, 1962; Gallaher, 1965; Sieber, 1968, cited in Giacquinta, 1973). The "clients" of the school, that is, parents and children, are the main 'beneficiary' of the service organization. They are crucial in establishing the goals and authority of the organization. The teachers and school administrators are the professional people who run the service organization. However, the literature sees the task of teachers and school administrators as difficult, since they must 'serve the collective interests of the client group and at the same time retain their authority.' (Giacquinta, 1973, p.195).

Most literature on organizational change in schools (see: Fullan, 2001; Ely, 1999; Reigeluth \& Garfinkle, 1994; Zaltman, Florio, \& Sikorski, 1977; Giacquinta, 1973) discussed the vulnerability of schools to the internal and external environment. Sarason (1971, cited in Zaltman, Florio, \& Sikorski, 1977), for example, attributes the motivating factors that affect changes in education to either: '(1) the demand for the schools to respond to the socialization needs of the society; or (2) use of the schools to solve social problems' (p.4). These expectations have made schools not only prone to any changes in society but also symbolise the society itself. Therefore, any plans for and implementation of transformation in a school should be supported by its social environment.

In the context of Malaysia, the demand for schools particularly national schools was to respond to the need to live in harmony and helped Malays to keep abreast with other communities (Khoo, 2011). At the same time, schools 
were expected 'to preserve the originality and completeness of Malay society' in a multi-cultural country (p.38).

\subsection{Research Perspectives on ILE}

In this section, previous research concerning IL for the school environment, particularly primary education, is reviewed from two perspectives. The first concerns IL execution and implementation, the second considers the factors affecting ILE in schools.

\subsubsection{Execution of IL: Teaching approaches, Transferability and Assessments}

Various researchers and scholars have attempted to define IL (Moore, 2000; ACRL, ALA, 1989; SCONUL, 1999; Spitzer, et al., 1998; Doyle, 1992; Kulhthau, 1987; Bruce, 2000; Johnston \& Webber, 2003; Dorner \& Gorman, 2006; Andersen, 2008). These definitions can be synthesized according to IL as a skill, a process, a way of learning, and a way of seeing IL based on context.

While most information professionals and IL educators agree that ILE should be an important goal of the education system, researchers and practitioners have been unable to arrive at an agreed upon definition of ILE which makes the task of teaching IL even more difficult (see: Owusu-Ansah, 2003; Campbell, 2004; Snavely \& Cooper, 1997). These discrepancies in defining what IL is and how it should be taught led to dilemmas in making decisions concerning the teaching of ILE.

As mentioned earlier, teaching IL has taken a variety of forms: stand-alone courses, web-based tutorials, course-related instruction, or course integrated instruction.

The teaching of information and searching skills within the library setting has traditionally served as a classical way of bibliographic instruction. A stand- 
alone approach to teaching IL can be in the form of lectures or seminars or workshops. According to Breivik (1998), stand-alone courses are not always successful because the students may opt not to enrol in the IL courses unless they are compulsory. This approach can be valuable, if it is done interactively (Webb \& Powis, 2004).

Now, the trends are towards the integration of IL into subject areas. According to Eisenberg and Berkowitz (1988), educators must provide opportunities for students to learn information skills throughout the curriculum. This can be facilitated with the collaboration of teachers and librarians. Saunder (2007) noted that these collaborations could become a factor for furthering IL and help students to cope with the advancement of ICT.

Two crucial questions that need to be answered by both approaches is, whether (a) the competence acquired can be applied in a context different from that in which it was learned, and (b) to what extent the competence is taught in schools. Perkins and Salomon (1992) viewed the issue of transferability of skills as not being well-researched and paid little attention in education literature. In terms of IL skills, Herring (2008) confirms that there is little attention paid to transferable skills in IL literature.

Earlier research by Goodin (1991, cited in Spitzer, Eisenberg \& Lowe, 1998) examined the transferability of IL skills from high school to college in a study involving two groups of high school students. In this study, one group of high school students received instruction in library research skills in the context of IL, and another group did not. The students were given pre- and post-tests on college-level library and information skills. The participants wrote research papers that were subsequently evaluated by instructors. Goodin found that the students who received library skills instruction scored significantly higher in the post-test than students who did not receive instruction. She also found that the post-test performance of the first group of students was acceptable for college freshmen. This study provides evidence of the value of IL skills in preparing the high school students for higher learning. 
Later research by Herring (2009) assessed the IL skills of Year 8 students in preparing for an English assignment. Findings suggest that the teaching of IL should focus more on IL techniques and on the desired attributes of students and less on IL skills.

In a qualitative study, McGuinness (2006) found that students did not receive proper guidance when doing their research assignments. This was due to the belief of the faculty members that IL develops gradually through 'learning by doing' the coursework projects. Mokhtar, Majid and Foo (2008) supported McGuinness' findings that students need to be given "close coaching and mediated learning" in order to be able to prepare for a better research project (p.200).

In Southeast Asia, the development of ILE through school libraries was first examined in 2005 by a project team, comprising members from Malaysia, the Philippines and Thailand (Singh, David, Cheunwattana, Guaysuwan \& Choovong, 2005). According to this report, IL is a difficult term to translate into the national languages of the countries surveyed. At any rate, there is no proper implementation of IL taking place in school libraries in the countries involved. Among the obstacles to school library development highlighted in the study were:

Low literacy rate, classroom shortage, trained classroom teachers shortage, trained teacher-librarians shortage, limited school library collections, small or no budget for school libraries, lack of awareness among senior MOE officials about the role of school library programs, IL concept; shortage of space, limited facilities/ equipment; and few guidelines on how to integrate IL into regular teaching programs (p. 7).

In New Zealand, Moore (2000) reported that most teachers believed they had a practical understanding of information skills. But half of them responded that they were unfamiliar with ways in which the process of finding and using information could be broken down into steps for teaching. 
Another factor worth highlighting was the methods for the evaluation or assessment of IL. In an educational setting, assessments are part of the contract between trainer and trainee (Institute of Development Studies (IDS) et al., 2013, p. 22). Thus, according to IDS et al. (p. 20), IL training involves ongoing monitoring and evaluating activities to ensure the effectiveness and efficiency of a given training intervention. Even though monitoring and evaluating activities are important to IL, Mokhtar, Majid \& Foo (2008) found that IL was a non-examinable subject in Singapore schools and was conducted as an enrichment program. It was a factor that led to many students not completing projects. Similar to Malaysian schools, IL was not part of public examinations (ETD, 2006).

It can be concluded that $\mathrm{IL}$ is seen as important in the teaching and learning process. However, the move toward implementing ILE appears to be difficult due to the above mentioned reasons.

\subsubsection{Factors Affecting ILE in Schools}

Despite the fact that there are many definitions of IL and methods to execute teaching IL successfully based on the opinions of experts in the field, the school's role in developing students' IL skills has been questioned. There are many factors which affect ILE in schools highlighted in several studies. The factors that affect the implementation process of ILE can be considered from three levels: individual, organizational, social and cultural.

\section{- Individual Level}

Teaching IL is not only about the content, but also about the quality of the teaching involved and the extent to which the school environment helped the teachers and teacher librarian with the teaching. The key roles are the head of school, teachers and teacher librarian. They are recognized as the IL educator or instructor or implementer. Their perceptions, attitudes and behaviours toward the teaching of IL, and their method of instruction and activities may influence students' success in developing their IL skills. 


\section{a) Head of school}

Principal advocacy is the key to the development of a strong school library media program (Haycock, 1989; Henri, Hay, \& Oberg, 2002; McGregor, 2002; Lance, Rodney \& Russell, 2007; Sykes, 2010) and a crucial factor in the ability of the library media specialist to influence instruction (Henry \& Hay, 1995). However, in a study completed by Wilson and Blake (1993), 68\% of principals did not have a good understanding of the role of the library media centre in the schools, and were unaware of the instructional potential of the library media specialist. They tend to hold the more traditional view of the library media specialist (Dorrell \& Lawson, 1995; Kolencik, 2001).

Van Deusen and Tallman (1994, cited in Loertscher \& Woolls, 1997) examined the relationship between scheduling students into the school library media and how information skills instruction was performed. They found that in the elementary school when library media specialists used a mixture of flexible schedule and fixed schedule, information skills were integrated more often, particularly when the principal's expectation of integrated skills was high. The same issue echoed by McGregor (2002) that flexible scheduling is effective in supporting teaching and learning using relevant resources through the dynamic use of school library. Thus, the implementation of flexible scheduling is much related to the principal support of ILE in school.

Chalmers and Slyfield (1993, cited in Moore, 2000) further questioned principals on this possible role for school libraries in New Zealand, as in 1993, only $1 \%$ of primary school principals rated it as important. However, a study done in New Zealand primary schools by Ngan $(2011$, p.58) found that "many primary school principals perceive the importance of IL and the school library" even though the approach towards teaching information skills was not consistent across the schools.

Research has demonstrated the importance of the principal's advocacy in supporting library activities and ILE, even though the support may vary. The principal is prepared to support any activities in school if he or she found that 
the programme is effective and is proven useful (Van Deusen \& Tallman,1994) or if resources and practices were adequate and well-planned (Ngan, 2011).

An international study of the principal's role in supporting school library programmes showed the differences between principal's and teacher librarian's beliefs and perceptions based on age and gender, the role of principal and teacher-librarians in the on-going development of an information literate school community and principals spending more time informing new teachers the importance of collaboration with teacher-librarian (Henri, Hay \& Oberg, 2002, p.49).

\section{b) Teachers}

At present, IL appears to be more likely to be addressed in the training of teacher librarians or LMTs who represent a small minority of the teaching workforce. On the other hand, many classroom teachers who espouse the aims of the concept are uncertain when and how to include IL in their teaching.

Probert's research investigated teachers' understanding of IL and its practice in the classrooms. Her 2006 study found that the secondary teachers were not familiar with the concept of IL. In her 2009 report, she found that some teachers had a "reasonably good understanding of IL". She concluded that many teachers connected IL with reading or ICT skills; one school did specify the information process models in several social studies syllabus but none were practiced in the research assignment, and there were hardly any policies relating to IL (Probert, 2009).

Mokhtar and Majid (2005) discuss the use of school libraries among teachers in Singapore schools. They found in general teachers did not use school libraries effectively for reasons such as school libraries are not well-staffed and well-stocked. The teachers also hardly collaborate with teacher-librarians in planning their lessons or in other academic programs. Therefore, the ideas promoted by many IL practitioners that school libraries should lead in this IL movement could be hindered if such problems are unsolved. The findings of 
this research, though the sample was localized and relatively small, were sufficient to get a view on the status of school libraries.

A study by Moore (2000) also looked at perception as a barrier to IL implementation. The author studied four elementary schools in New Zealand. Despite the effort to implement IL in the school curriculum and acknowledgement by educators of the importance of such skills, Moore found that the students were still not equipped with the skills. She also found that teachers were uncertain as to the role and function of school librarians and that the teachers in all four schools 'were uncertain whether the library was central to learning'.

A study by Streatfield and Markless (1994, cited in Moore, 2000) consistently confirmed that students' use and view of the library is determined by that of the teachers. The way teachers approach and use information is likely to be followed by students. Thus teachers' information behaviours have implications for promoting IL.

Slyfield (2001) also found that in her analysis of school libraries in New Zealand, IL skills and ICT received the lowest ratings by school staff. Only $30 \%$ of primary schools said all or most teachers used the library to teach information skills to classes.

\section{c) Teacher Librarian or School Library Media Specialist}

McCracken (2001) developed a survey to find out how school library media specialists (SLMS) perceived themselves as being able to assume the leadership role in the use of instructional technology. The SLMS did see their role as important, but they felt incapable of fully implementing their role because of lack of time to plan with teachers, inadequate funding, lack of cooperation and support from teachers and clerical staff, and use of flexible scheduling. The author also acknowledged that the rapid change and advances in technology have had a profound impact on the role of the teacher-librarian. In some cases, technology has diminished their role as SLMS. 
In the same vein, Henri and Boyd (2002) looked at the level of teacher librarian influence as perceived by themselves and their principals in Australia. The study demonstrated that the principals regarded teacher librarians as influential persons in the school. This was because teacher librarians were not only liked by the students but also diligently helping out teachers with their teaching and learning activities. Teacher librarian tasks were clearly visible to the principal and to the school communities. And yet the teacher librarians felt that they had no influence over the principals and were less eager to take advantage of their potential for influence. To me, this study showed how teacher librarians perceived themselves and they tended to view themselves more in supporting roles rather than leading the way.

This kind of belief needs to be rectified because the emergence of constructivism and critical thinking as teaching strategies has led to increased interest in IL. Resource-based teaching and learning via school library media has become the forte of the teacher librarian. The role of school library media is greater and a teacher librarian has to act as the teacher of IL skills to the school communities and as the instructional partner (Church, 2008) to their fellow classroom teachers. With strong advocacy and support from the principal and the proper learning environment, teacher librarians can successfully implement ILE and lead the change in teaching and learning processes.

As stated by Oberg (2006), a teacher librarian has to build his or her 'professional credibility, to communicate effectively with principal and work to advance school goals' in order to gain the respect and support from his or her principal and the school communities as a whole.

\section{- Organizational Level}

Schools are complex organizations. Any advocates and planners of change in schools must deal with a 'multi-level of bureaucratic control structure' (Zaltman, Florio, \& Sikorski, 1977). This includes forces both internal and external to the school. For example, the smallest administrative unit like a 
classroom is influenced by a school administration, district office, state department of education, parents and teachers association, local community, parents and students, and teachers union. These forces may influence the planning and implementation of any educational policy and operation.

IL as a concept to be integrated into the school curriculum needs the involvement of all stakeholders. Many information professionals and educators see the concept of 'information literate school community' (ILSC) (Henry \& Hay, 1996), 'learning organization' (Fullan, 1993), or 'whole -school information skills' (Marland, 1987) as providing the basis of a promising theoretical framework for the development of better schools. However, in order to realize it, there is a need for concerted and conscious effort to make changes in pedagogy and teaching practices. The following provide insight into the organizational factors that affect ILE

A few studies highlighted the issue of scant support from the central authorities (in this case, the MOE and federal government) for teacher-librarian positions in schools (see Moore, 1999; Gavin, 1999). The National Curriculum, the National Education Monitoring Project and the activities of the Education Review Office in New Zealand have provided schools with extrinsic motivation towards the emphasis on IL (Moore, 1999) by placing information skills in the curriculum, and actively monitoring the progress towards achievement at a national level. The crucial part of the progress is at the grass roots which involves the teaching and application of information skills.

According to Henri and Hay (1996), the principal and teacher-librarian need to agree and share a vision for establishing an information literate school community. This is what Reigeluth (1994, p.9) meant by 'team-based organization' by which the decision making is shared. The decision-making system is 'client-driven' rather than 'bureaucracy-driven'. A survey of four primary schools in New Zealand by Moore (1999) shows that the principal needs the support of staff-wide agreement on the roles of staff leading the development of school library, information skills, and information technology. 
In most instances, organizational support is a key factor to educational policy and operation. In developing an information literate school community, principal support is the key. An international study by International Research Reference Group (Hay, Henri \& Oberg, 1999) investigated both the principals and teacher-librarians in seven countries. Findings showed that key factors were the principal's understanding, concern, shared vision, collaboration, partnership, and team work.

Another essential element to the success of cultural change is through professional development. The implementers (in this case, the principal, teachers, and teacher librarian) should have the resources and personal skills to plan and implement ILE. Some studies found that the principals had some reservations about support for professional development (Henri, 1995; Moore, 1999). For example, they found that although the principals supported individual staff to attend seminars, workshops, conferences or other staff development courses, knowledge gained from these activities were rarely shared, even if a platform for staff discussion was provided. As a result, active assimilation and integration of new knowledge across the curriculum is unlikely to happen.

Therefore, every individual in the school communities must have shared roles and responsibility to play in ILE. As Kuhlthau (1993, cited in Loertscher \& Woolls, 1997) commented:

successful implementation of the process approach to information skills calls for a shared philosophy of learning. It requires development of an instructional team and a break with the traditional concept of one teacher to one classroom. It requires a commitment to developing skills for living, working, and participating in changing technological society. It demands highly competent educators who instruct, guide, coach, and assess students and who design and redesign programs to enhance the learning process. 
Similar to Kuhlthau, Moore (2002) believes that the impetus for IL in schools tends to come from four directions: those responsible for library services to schools, educators, economists and information technologists, as well as their supporting professional associations. Such strong support and shared responsibility can foster changes in teaching and learning process.

The same points are also made by Skov and Skaerbak (2003) who claimed that teaching IL is an uphill battle for Danish educational libraries. The challenges are many: lack of national policy, lack of visibility at the policy-making level, lack of financial allocations, lack of teacher awareness, divided worlds of universities and libraries, and lack of appropriate continuing education .

\section{- Social and Cultural Level}

The school is a part of society (Dewey, 1933, cited in McKinzie, 1997). The values of the society in which this school community lives may affect and reflect teachers' and students' perceptions, attitudes and behaviours. Any changes that occur in a society may also affect changes in school.

Goodman (1995) views school reform from the historical perspective, noting that the school changes 'mirror' the change in larger society. He further describes three waves of reform. The first wave of reform was in the form of agrarian society. The second wave was the industrial age. The third was the post-industrial era which brought about change in school fostering the emerging 'information/technology age' (p.1). Educational reform efforts in the eighties and nineties focused on the third wave.

In this third wave, Batson and Bass (1996) pointed out that the teachers in schools find themselves juggling 'between the print culture and the digital culture' (p.46). A school community, especially the school head and teachers, finds it difficult to keep up with the rapidly changing technology and the social conditions that make up the learning environment (Peters \& Lankshear, 1996). The school head and teachers were concerned with, as highlighted by Wellington (2001, cited in Hannafin \& Hill, 2007), social conditions, such as 
teacher control, worries about plagiarism, and perceived threats to teacher authority.

Social conditions are further discussed by Walker and Hallinger (2007). In their analysis of the work of principals in East and South-East Asia, they described the tensions that resulted from principals meeting institutional and political demands for education reform in the cultural context of these societies. Tensions associated with teaching and learning reform consist of at least two features. First, the principals' traditional management role was expected to shift to that of educational, curriculum, or instructional leader. Second, the challenge arose from the suitability of multiple educational 'reform-implanted' pedagogies (p.264). This was particularly important in the case of student-centred learning approaches that underpin a constructivist philosophy of a classroom community. These were 'foreign' to the Asian educational context, as pointed out by Shaw (1999, cited in Walker \& Hallinger, 2007, p.264),

Blaming Asian schools for focusing on memorisation - as opposed to "thinking" - is too pat an excuse, as schools reflect the basic values of a society. It is ingrained in the Asian psyche that "correct" answers always exist and are to be found in books or from authorities.

Hallinger (2004, cited in Walker \& Hallinger, 2007) gave an example from a Thai primary school. One student complained that student-centred learning was linked to 'buffalo learning', meaning a form of learning from ignorance. This indicates that the Asian teachers and students are often uncomfortable with the constructivist approach and the uncertainty of the practices.

Thus, the idea that students, who are relatively uneducated, can learn independently or from each other conflicts with deeply held cultural assumptions about the place and role of the school and the teacher. Educational reform becomes more difficult and slows when it is coupled with insufficient resources to support quality training (Walker \& Hallinger, 2007). 
The influence of culture on ILE is further outlined by Dorner and Gorman (2006). They state that

the issue of cultural influence on ILE in particular has received insufficient attention, yet it has a major impact on the entire enterprise from how we define IL, to how we seek to structure programmes, and to how we deliver IL content (p.3).

They argue that for an effective, robust definition of ILE for developing countries, the term has to recognise 'the social construction and cultural authority of knowledge, and work within this paradigm'. They then present an operational definition of IL in developing countries.

To further investigate cultural, indigenous and traditional practices of information behaviour, a study was carried out by Dorner and Gorman (2008) in Laos. They conclude that in order to provide effective advocacy of ILE in Laos, they need to work closely with the local people, particularly the educators and librarians, and work within the local context.

The following discussion presents the development of IL in Malaysia, followed by research on IL in Malaysian schools.

\subsection{Information Literacy (IL) in Malaysia: An Overview}

Much literature on IL in Malaysia agrees that the rapid development of ICT in 1990s caused massive changes in Malaysian educational plans, programmes and policies (see NITA, 1996; Chan, 2003; Chan, 2002; Edzan, 2008). Since then, the Malaysian Government has introduced various initiatives and programmes such as the Malaysian Smart School Project (MSSP), MySchoolNet and the Electronic Book Project, to ensure ICT become a vehicle for knowledge dissemination and knowledge sharing in schools (Chan, 2002). 
The implementation of MSSP, launched in 1997, has set out the enabling technology in schools. The aim of the MSSP was to enhance teaching and learning in schools as well as to prepare the future workforce for the $21^{\text {st }}$ century challenges (Chan, 2002). Under MSSP, the teaching and learning process required a new learning culture in order to prepare students to be active learners, technology literate, creative and critical thinkers and move away from memory-based and rote learning. However, Chan (2003) noted that often the technological skills are given more attention than the information skills component. Consequently, the students enter higher education being technology literate but without having critical information skills.

The Educational Technology Division (ETD) of the MOE of Malaysia is the governing body responsible for the development and progress of ICT application and School Resource Centres (SRC). This is to ensure that the SRCs in Malaysia play their role in disseminating information, instilling the reading habit and effectively supporting teaching and learning activities. The ETD at the federal level and its network of State Educational Technology Division (SETD) at the state level and the Teachers' Activity Centres (TACs) at the district and local level conduct short courses in library management, reading, information literacy and use of programming and $\mathrm{CD} R O \mathrm{R}$ in teaching and learning process (Jusoh, 2002). In the case of ILE implementation, at the district level, the TAC was in charge of training activities and programmes. The officer in-charge was known as the educational technology officer. The officer was responsible for the support of ILE implementation in the school. ILE was one of the school resource centre (SRC) activities and appeared to be a joint activity with the reading programme. Usually courses at federal level focus on training the trainers, while at state level courses concentrate on training teachers in schools.

\subsubsection{ILE Development}

From the very beginning, it appears that the development of IL in Malaysia was championed by three entities, namely the National Library of Malaysia, the Ministry of Education (MOE) through the ETD and Institutions of Higher Education (IHE). These entities led to the introduction of IL and ILE in their 
own ways. The following discusses the development of ILE in Malaysia in relation to the three entities.

One of the challenges of Vision 2020 is to create knowledgeable and informed Malaysian society. Under the leadership of the National Library of Malaysia (NLM) the challenge was made functional to move Malaysia towards becoming knowledge society (Sheikh Kadir, 2003). The move began with the Reading Promotion activities in 1987 and the program has continued as a yearly event. Only in 2003, the NLM paid attention to IL after receiving development funds for conducting IL activities and an IL survey. Since the introduction of Reading Promotion in 1987, and the beginning of IL activities in 2003 at the NLM level, the reading program and IL become annual events that receive nation-wide attention and participation at all levels of society.

Next is the development of IL and ILE in the school system. According to Edzan (2008), IL was brought to the attention of the Malaysian MOE after the $31^{\text {st }}$ Annual Conference of the International Association of School Librarianship (IASL) in 2002. A speech delivered by the former Minister of Education, Tan Sri Dato Musa Mohamad stated several measures that have been implemented by the MOE to promote and enhance the reading culture in schools as part of ILE (Mohamad, 2002). In the same tone, Jusoh (2002) a former Deputy Director of ETD stated that one of these measures was 'reading and IL courses for state resources centre personnel to expose them to effective reading and information skills' so that they could carry out such courses in localised situations (para. 28). So, ILE was first introduced to schools with a purpose to instil reading habits among students, and thus, became the agenda of SRC to enhance teaching and learning (Selangor State Educational Technology Division, 2007).

The development of IL after the 2002 IASL Conference was that various IL and SRC management guideline and modules were distributed to schools and SRCs by the ETD through its network in 14 states to assist SRC coordinators to implement ILE and to manage SRC and its related activities such as the promotion of reading habits and the use of SRC in teaching and learning of 
ICT (ETD, 2002; Jusoh, 2002). The ETD sees IL as an umbrella to all other skills in teaching and learning (ETD, 2006)

The development of the national curriculum, however, was the function of Curriculum Development Division (CDD) within the MOE itself. The Division is responsible for the design, plan, execution and implementation of the school curriculum and the preparation and distribution of teaching and learning guidebooks, modules and strategies (UNESCO-IBE, 2010/2011).

One of the teaching and learning strategies in the Malaysian school curriculum is mastery learning (Malaysia. Ministry of Education. Curriculum Development Centre (CDC), 2001). Mastery learning is a learning method that helps students to achieve a high level of proficiency in their learning. This concept was introduced by Bloom (1968) based on the principle that all students can achieve a particular level of proficiency, given adequate time and a quality teaching and learning process. Drawing from the Malaysian school curriculum specifications for primary and secondary schools, thinking skills, learning skills, multiple intelligences, and values and citizenship are all built on in mastery learning (CDC, 2008).

According to the Curriculum Development Centre (2001), learning skills are:

- $\quad$ Skills in learning process

- $\quad$ Time management skills

- $\quad$ Library skills

- $\quad$ IL skills

- $\quad$ Reading skills

- $\quad$ Note taking skills

- Motivation skills

- $\quad$ Thinking skills

- $\quad$ Memorising skills

- $\quad$ Skills in answering exam questions

The rationale of IL skills particularly, and learning skills wholly, is to assist students to learn independently with the learning that they have mastered. 
Thus, according to the curriculum specification which was designed by the CDD, IL is only one of several teaching strategies (input) that would just become an option for teachers to use in their teaching plans, rather than as the outcome itself (being information literate).

Then, another development of ILE in the Institutions of Higher Education (IHE) was championed by academic libraries as early as the 1990s (Edzan, 2008; Chan, 2002b). Since then, the academic libraries continuously offer programmes such as IL or information skills which aim to prepare users to use information and prepare the students for $21^{\text {st }}$ century challenges. There is also another development where the element of IL is now become the mechanism for rating the Malaysian IHE. Two of the eight domains of learning outcomes in the Malaysian Qualification Framework are information literacy competencies, namely, problem solving, and information management and lifelong learning skills (Malaysian Qualification Agency, 2011). Thus, in IHE, IL is given much emphasis not only to prepare the future workforce but also to increase the international competitiveness of Malaysian IHE (Edzan, 2008).

To date, even though ILE is claimed to be integrated in general education as in primary and secondary schools, at higher education level and at National Library of Malaysia level, there is no clear direction of ILE implementation because there is no evidence of official information literacy policy statements in the national education policy (Tan \& Singh, 2010).

\subsubsection{The appointment of Library and Media Teachers (LMT)}

The SRC plays a significant role towards educational excellence through its resources and services. Prior to 2005, the SRCs were run either by coordinators who also full-time subject teachers, clerical staff or library assistants who were sponsored by the Parent Teachers Associations (Jusoh, 2002). In 2001, a proposal was made to position full-time SRC coordinators and library assistants in schools. In 2005, the appointment of full time teacher librarian was granted along with a circular and a list of roles and responsibilities (MOE, 2005). The position is known as Library and Media Teacher (LMT). 
At present, the SRC, managed by a library and media teacher (LMT), is responsible for three main duties: (1) administrative matters, (2) organization of information resources, and (3) reading guidance and IL (Selangor State Educational Technology Division, 2007). This third duty includes the role of LMTs to assist the classroom teachers to set up a Readers Peer Group (RP) aligned with the national reading programme (known by the local acronym as NILAM). In addition, the LMT has to educate and explain IL to the teachers and pupils. At the same time, the LMT is expected to help teachers to develop ILE according to teachers' subject specialisations. As such, teachers and students should be encouraged to use and incorporate the resources and services in SRC and be involved in planned learning activities so that ILE could be implemented.

To qualify as a LMT, a teacher has to have teaching experience of at least three years plus a library qualification, training or resource centre working experience(refer MOE, 2005). The training of LMTs is carried out by the Teachers Training Division, the Educational Technology Division and its network of 14 State Educational Technology Division (SETD) and the 367 TACs (Jusoh, 2002).

With these qualifications, the LMT is expected to be able to manage the SRC and to implement ILE and assist teachers to translate ILE into the classroom.

\subsubsection{Research on IL and ILE implementation in Malaysian schools}

There are five issues identified from the literature relating to IL implementation in the Malaysian school system: the (a) different interpretations and understanding of IL; (b) exam oriented school system; (c) lack of official documents, plans and policies, curriculum resources and frameworks; (d) lack of necessary skills and understanding, lack of training; and, (e) lack of space and funds. The following discussion explores these issues. 


\section{- Different interpretations of $I L$}

The Curriculum Development Centre (CDC) of Malaysia as an operating agency is responsible for bringing the Malaysian curricula up-to-date, and ensuring that the curricula are parallel to the National Philosophy of Education and meets the changing needs of the Malaysian society. CDC identifies IL as one of the skills in mastery learning (CDC, 2001). On the other hands, the ETD (2006) claims that IL skills are embedded in the curriculum and act as umbrella to other skills such as thinking skills, learning how to learn skills, ICT skills, values and citizenship, multiple intelligences, and knowledge acquisition. The way IL is implemented is just like other skills, that is, infused in teaching and learning activities. While CDC seems to place IL as one of the skills in a bundle of teaching and learning strategies, ETD puts IL as a major component of other skills mentioned. Thus, these two federal agencies see the value of IL differently in the curriculum.

- The education system is exam-oriented and dependent on the academic performance of the students.

Since education is exam-oriented, the students' future undertaking is dependent on high achievement in public examinations. Unfortunately, IL competencies are not part of the examination questions (ETD, 2006). The students are not required to acquire IL skills in order to achieve top results in exams. Moreover, due to the exam-oriented education system, the teachers have to ensure all teaching and learning activities are geared towards achieving high grades in exams. Not surprisingly teachers tend to revert to the traditional way of teaching and learning, that is, teacher-centered and rote learning in order to ensure the students receive enough factual data and information for the exams.

- Lack of official documents, plans and policies, curriculum resources and frameworks

IL has been on the SRC's agendas. The SRC is seen as an important supporting agent that could provide significant contribution towards educational excellence through its resources and services. However, in the 
Smart School Roadmap 2005-2020: An Educational Odyssey (2005) by MOE, one crucial area has been left out in the discussion, that is, the important role of the SRC in realizing the smart school vision. The roadmap has given such a comprehensive overview of the nation's most hopeful educational achievement. While the paper elaborately discussed the various ways of ICT utilization in smart schools, the roles and functions of SRC as one of the support agents was not mentioned at all. The lack of recognition of the role of SRC in education system can be one of the obstacles in IL implementation.

Throughout my review of papers prepared by MOE, particularly ETD officials, I found that, when the documents were discussing IL, terms such as, information gathering, access, critical and creative thinking skills, independent learning skills, goal-oriented, resource-based subject, were frequently used in the documents, instead of IL (see Ismail, 2002; Hassan, 2009; Abdul Kader, 2008).

At present, the implementation of IL initiatives in Malaysia is seen as championed by a specific interest group, particularly librarians. Every education and information institutions works relatively independently of each other. The proposal of a national framework for IL in Malaysia by Edzan and Mohd Saad (2005) is a first step, if realized, to effectively implement IL in the country. They suggested that a dialogue among parties concerned should be organized in order to lay out and build the standards. There was also a proposed module, presented at the International Workshop on IL, which was held in Kuala Lumpur, Malaysia in 2006 (Abu Seman \& Mohd Saad, 2006). It has laid out the learning outcomes expected for primary school IL programs. However, there is no evidence or studies made to measure the outcomes.

\section{- Lack of necessary skills, understanding, and training}

The ETD of the MOE of Malaysia (2006) has also reported that only $30 \%$ of teachers in schools were exposed to seminars or courses or other staff development programs in IL. The other $70 \%$ of teachers were untrained in IL (ETD, 2006). 
In an earlier study of the ETD (2005, cited in Tan \& Singh, 2008), 76\% of the LMTs were aware of the concept of IL. $60 \%$ of the LMTs claimed that they were not exposed or trained in IL. Furthermore, the time allocated for implementing IL in most schools was limited to less than $10 \%$ of the teachers' teaching time. These results present a challenge as the LMTs are expected to play a key role to assist, provide and teach IL skills in schools.

A study by Tan and Singh (2008) found other problems in ILE implementation. They found that $61.9 \%$ of LMTs did not teach IL in the SRCs due to a lack of curriculum resources and framework, lack of time allocation in their time table and uncertainty whether to teach ILE as a subject or to integrate into their teaching subjects.

Tan, Gorman and Singh (2012) discovered that the LMTs' lack of commitment for IL training is due to their commitment inside and outside class, even though many LMTs are in need of IL training. Thus, this factor leads to the lack of the necessary skills and understanding to implement ILE.

The lack of skills among school heads, teachers and LMTs can also be associated with the limited number of IL courses held by ETD at federal level and ETD at state level. Due to a lack of resources, ETD can only cater for a small number of teachers. Besides, statistical data from ETD (2009) training needs analysis show that the school library programme is the most unpopular choice of training by the teachers. Another issue is the frequent changes in the SRC coordinators or LMTs either due to staff transfer or staff promotion or staff on study leave or others can result in misplacement or untrained new LMTs taking over the role.

\section{- Lack of space and funds}

ETD (2006) found that three constraints inhibited the SRCs' achievements and developments, namely, staff, space and funding. The three constraints were also the main factors that affect the implementation process of ILE, due to the fact that IL instruction has been placed under the responsibility of the LMT and SRC (ETD, 2006). 


\subsection{Gaps in the Literature}

It is noted that the development of IL initiatives, guidelines and standards is apparent and much work has been done on the part of librarians and professional associations, and/ or with the support of the governments. Numerous teaching activities and techniques of IL have been used, including 'just-in-time' instruction that focuses at the time of students' need, and direct teaching models.

While most countries in the world recognise the importance of ILE to their future generations, the IL implementation and delivery has been put in place mostly in the higher education sector and much less in primary schools.

Few references to ILE development in education sectors worldwide discuss the school culture as a motivating or inhibiting factor in ILE. However, attempting to identify individual factors such as principal factor or teacher factor or learner factor seemed to be the focus in most IL studies.

Similarly, in Malaysia, there was little research exploring issues pertaining to school culture and leadership in ILE, and not much focus on the needs of primary education.

These shortcomings have given rise to the research problems that have inspired this study, which has two key aims: (1) to develop a model that will be used to understand the factors affecting the implementation of ILE in primary schools, and (2) to identify the factors that affect the implementation of IL in primary schools.

\subsection{Chapter Summary}

This literature review has discussed what IL is, what is being investigated, how it is being investigated, and why it is important as a phenomenon. There are actually varying ways of scholars and researchers seeing IL. In general, the IL definition provided by the ALA (1989) is widely accepted by the IL 
implementers and practitioners all around the globe. However, there are other definitions that were considered in this review in order to have a better picture of how IL is supposed to be implemented according to context.

The research perspective section has been divided into two main issues: (i) IL execution and implementation; and (ii) factors affecting ILE in schools. The first issue discusses research findings related to approaches in IL teaching, effective transfer of ILE, and rate of implementation. The second issue highlights three levels of factors, namely: individual, organisational and social and cultural. The individual level of factor focuses on principal factor, teacher factor, teacher librarian factor, and learner factor, followed by the organisational level (such as, school, district, state, and federal organisations), and social and cultural factor.

Finally, IL in Malaysia is still at its infancy. The implementation of ILE remains difficult and not well researched. There are many areas of IL that have not been empirically and systematically examined by IL scholarly community in Malaysia. Most research studies focus on IL in higher education, rather than school settings. Thus, in order to understand the current status of IL in Malaysia, there is a need for an exploratory type of study of IL implementation so that the factors affecting it can be identified. 


\section{CHAPTER 3 Theoretical Framework}

\subsection{Introduction}

This chapter discusses the theories that underpin my research. They are the Concerns Theory (Hall \& Hord, 2005), Program Theory (Chen, 2005), and Change Theory (Fullan, 1985, 1991). These three theories provide useful models to investigate the problem of the study and the context in which it was conducted because they support the investigation and/or implementation of change in educational organisations such as schools. I did consider Roger's diffusion of innovations (DOI) theory and Hofstede's dimensions of culture, but I chose not to use either of them because:

1. From the very beginning, I did not want to limit my data and thinking in this study only to cultural factors (if I chose Hofstede's theory).

2. I did not opt for DOI because of its focus on the adopter of an innovation and the adoption process, whereas my study focused on the process of ILE implementation which took into account the individual, organisational and social resources and support to modify teaching and learning strategies.

In this research, I focus on change in the form of ILE implementation in primary schools. In the final section of this chapter, I introduce the research's theoretical framework that demonstrates how in combination of these three theories mentioned above supported in-depth exploration of the research questions.

\subsection{Concerns Theory}

Concerns Theory has been developed by Hall and colleagues since the beginning of 1970s. It was in 1973 that Hall, Wallace, and Dossett first proposed the Concerns Based Adoption Model (CBAM). CBAM is also known as an 'adoption-diffusion' theory (Straub, 2009, p.627; Alias \& 
Zainuddin, 2005) and the theory of change (Garrett, 2009). Anderson (2002) claimed that this theory was widely used as a model for studying the process of implementing educational change. CBAM has been designed to describe change as it affects individuals and to prompt more successful change efforts. This model emphasizes the teacher and the innovation as the main focus in school improvement, yet also acknowledges social and organizational forces.

This theory indicates several propositions. First, it asserts that people change only after their concerns or needs have been met. Second, it suggests that the nature of these concerns within any single group of people will differ based upon a range of factors including personality, past experience and education, skills and knowledge related to the change. Third, the concerns of people will differ at various points in the change process. Fourth, passage through these stages is sequential in nature. Fifth, Hall and Hord (2005) contend that the failure to meet the concerns of an earlier stage will result in an inability to progress effectively through subsequent stages.

CBAM was used to study teachers' responses to change processes in schools such as new teaching practices and new innovation materials or technology in school, particularly to plan for staff development in education innovation. Fuller's (1969) work on the affective domain of adult development was the pioneer in using Concerns Theory. Fuller explored the relationship between novice teachers' concerns and their teaching behaviours (Conway \& Clark, 2003). Hall and colleagues credited the work of Fuller as informing CBAM, which resulted from their study on programme adoption by educators (Hall \& Hord, 2005).

Further, researchers also used CBAM to study teachers' attitudes towards integrating ICT into their teaching and learning practices (Overbaugh \& Lu, 2008; Askar \& Usluel, 2001; Al Shammari, 2000), and attitudes toward a new subject introduced in the curriculum such as in the science curriculum (BitanFriedlander, Dreyfus \& Milgrom, 2004) and geography curriculum (Rout, Priyadarshani, Hussin, Pritinanda, Wan Mamat, \& Goh, 2010). Others have used CBAM to evaluate programme implementation such as in the study of 
Beauchat, Blamey and Wadpole (2009) on preschool teachers' instruction of oral language and literacy. However, there was one study of ILE that documented the extent of implementation using CBAM (e.g. Serotkin, 2006).

CBAM describes, explains, and predicts possible behaviours of teachers in the change process. It holds that people tend to ask questions when using an innovation and experiencing various kinds of changes. The model is made up of three dimensions: Stages of Concern, Levels of Use and Innovation Configurations (Hall \& Hord, 2005).

The Stages of Concern dimension focuses on the affective side of the adopters. The Levels of Use dimension looks at the behavioural progress of innovation in practice. It involves an instrument to evaluate the change progress at the individual level. These individuals must actually make the innovation work. The Innovations Configurations (IC) dimension is made up of a component checklist that should be developed prior to the implementation of innovation. In Malaysian primary schools however, ILE is claimed to be implemented by the MOE. Thus, this checklist is irrelevant to the study.

As applied to my study, the first two dimensions seem appropriate to focus on the people who are carrying out the ILE implementation and the school as an implementing organization. It is essential to know and understand such aspects of the process of ILE implementation such as the following: What are the stages of concerns that implementers go through as ILE is implemented? What are the implementer's concerns at the current stage of ILE implementation? What are the factors affecting the implementation of ILE in Malaysian primary schools? How do these factors facilitate or hinder ILE implementation in Malaysian primary schools?

According to Hall (1992), an individual's concerns directly affect performance, and because concern levels correspond with the levels of use, the lower-level concerns must be resolved so that the higher-level concerns can emerge. Thus, these stages of concerns and levels of use span transitions from initial awareness and non-use of ILE to exploring how to refocus, improve and use 
ILE in the curriculum. These stages and levels relating to ILE implementation are shown in Tables 3.1 and 3.2.

With regard to Table 3.1, while Hall et al. (1973) refer to Stages of Concern about an innovation, I have adapted their model in referring to Stages of Concern about ILE implementation. The stages and names in columns 1 and 2 are the same as those in Hall et al. (1973); however, I present definitions relevant to this study in column 3 . 
Table 3.1. Definitions: Stages of Concern about the Implementation of ILE (adapted from Hall et al., 1973)

\begin{tabular}{|c|c|c|c|}
\hline \multicolumn{2}{|l|}{ Stage } & Name & Definitions \\
\hline \multirow{3}{*}{$\begin{array}{c}\text { Self- } \\
\text { concerns }\end{array}$} & 0 & Awareness & Little concern about or involvement with ILE \\
\hline & 1 & Informational & $\begin{array}{l}\text { A general awareness of ILE and interest in learning } \\
\text { more detail about ILE is indicated. The person seems } \\
\text { to be unworried about himself/ herself in relation to } \\
\text { ILE. She/he is interested in substantive aspects of the } \\
\text { ILE in a selfless manner such as general } \\
\text { characteristics, effects, and requirements for use. }\end{array}$ \\
\hline & 2 & Personal & $\begin{array}{l}\text { Individual is uncertain about the demands of the ILE, } \\
\text { his/ her inadequacy to meet those demands, and his/ } \\
\text { her role with the ILE. This includes analysis of his/ } \\
\text { her role in relation to the reward structure of the } \\
\text { organisation, decision-making and consideration of } \\
\text { potential conflicts with existing structures or } \\
\text { personal commitment. Financial or status } \\
\text { implications of the ILE program for self and } \\
\text { colleagues may also be reflected. }\end{array}$ \\
\hline $\begin{array}{c}\text { Task } \\
\text { concerns }\end{array}$ & 3 & Management & $\begin{array}{l}\text { Attention is focused on the processes and tasks of } \\
\text { implementing ILE and the best use of information } \\
\text { and resources. Issues related to efficiency, } \\
\text { organizing, managing, scheduling, time demands are } \\
\text { upmost. }\end{array}$ \\
\hline \multirow{3}{*}{$\begin{array}{l}\text { Impact } \\
\text { concerns }\end{array}$} & 4 & Consequence & $\begin{array}{l}\text { Attention focuses on impact of ILE on students in } \\
\text { his/ her immediate sphere of influence. The focus is } \\
\text { on relevance of ILE for students, evaluation of } \\
\text { student outcomes, including performance and } \\
\text { competencies, and changes needed to increase } \\
\text { student outcomes. }\end{array}$ \\
\hline & 5 & Collaboration & $\begin{array}{l}\text { The focus is on coordination and cooperation with } \\
\text { others regarding use of ILE. }\end{array}$ \\
\hline & 6 & Refocusing & $\begin{array}{l}\text { The focus is on exploration of more universal } \\
\text { benefits from ILE, including the possibility of major } \\
\text { changes or replacement with a more powerful } \\
\text { alternative. Individual has definite ideas about } \\
\text { alternatives to the proposed or existing form of ILE. }\end{array}$ \\
\hline
\end{tabular}

Table 3.1 describes the nature of people's concerns at different stages of the change process. Different people will experience the same change differently at various points in the process. This dimension highlights the assumption that change is a complex process. It involves the gradual development of new 
knowledge, skills and attitude. The Awareness and Informational Stages are the stages that the implementers are often not aware of either the need or the basis of ILE. Thus, the implementers who are supposed to implement ILE are basically unconcerned and not yet engaged in ILE.

At the Personal Stage, the Individual Implementers are uncertain about the need of ILE particularly in relation to their role and ability to perform their role. This is the stage where training has to be given, followed up with regular feedback, and monitoring the implementers' needs and concerns. Thus, leadership support becomes more crucial at this stage in order to encourage the idea of ILE into the implementers' teaching practices.

Later, when the implementers begin to put ILE into their teaching practices, their concerns are more towards improving their efficacy, effectiveness, and efficiency in their work. It is at the Management Stage when the implementers enquire about the issue of time allocation and proper scheduling for ILE. Thus, the implementers begin to become users of ILE in their teaching and learning activities.

With regard to Table 3.2, while Hall et al. (1973) refer to Levels of Use of an innovation, I have adapted their model by referring to Levels of Implementation. The levels and names in column 1 and 2 are the same as in Hall et al. (1973); however, in column 3 I present new behavioural indices of level of use relevant to the study. 
Table 3.2. Levels of implementation of the ILE: Typical behaviours (adapted from Hall, 1992)

\begin{tabular}{|c|c|c|c|}
\hline \multicolumn{2}{|c|}{$\begin{array}{c}\text { Level of } \\
\text { Implementation }\end{array}$} & Name & $\begin{array}{c}\text { Behavioural Indices of Level } \\
\text { of Implementation }\end{array}$ \\
\hline \multirow{3}{*}{$\begin{array}{l}\text { Non- } \\
\text { user }\end{array}$} & 0 & Non-Use & No action is being taken with respect to ILE. \\
\hline & I & Orientation & The person is seeking out information about ILE. \\
\hline & II & Preparation & The person is preparing to use ILE. \\
\hline \multirow{5}{*}{ User } & III & $\begin{array}{l}\text { Mechanical } \\
\text { Use }\end{array}$ & $\begin{array}{l}\text { The user is using ILE in a poorly coordinated } \\
\text { manner and is making user-oriented changes. }\end{array}$ \\
\hline & IVa & Routine & $\begin{array}{l}\text { The user is making few or no changes and has an } \\
\text { established pattern of use. }\end{array}$ \\
\hline & $\mathrm{IVb}$ & Refinement & $\begin{array}{l}\text { The user is making changes to increase } \\
\text { outcomes. }\end{array}$ \\
\hline & V & Integration & $\begin{array}{l}\text { The user is making deliberate efforts to } \\
\text { coordinate with others in using ILE. }\end{array}$ \\
\hline & VI & Renewal & $\begin{array}{l}\text { The user is seeking more effective alternatives to } \\
\text { the established use of ILE. }\end{array}$ \\
\hline
\end{tabular}

Table 3.2 predicts the behavioural progress of the Individual Implementers and can also be used to categorise the implementing schools in terms of implementation and non-implementation of ILE. The level of nonimplementation is from Level 0 to II, and level of implementation is from Level III to VI. This dimension highlights people's actions and behaviours at different stages of change process. For example, at the non-user level, the dimension explains that the Individual Implementers basically have no knowledge and skills of ILE. Thus, they do not implement ILE in teaching and learning process. However, during the Preparation Stage, the implementers are prepared for the knowledge and skills needed for successful implementation of ILE. This is a stage where the implementers involve themselves in intensive training and get support from within and outside school.

\subsection{Program Theory}

The initial conceptual framework of Program Theory was developed by HueyTsyh Chen in 1990. Program Theory is defined as 'a set of explicit and/or implicit assumptions held by stakeholders about what actions are required to solve a social problem and why the problem will respond to these questions' (Chen, 2005, cited in Chen, 2006, p.76). Program Theory is also known as the stakeholders' theory. However, Chen (2006) stated that stakeholders usually 
do not clearly and systematically document their assumptions. Therefore, Program Theory is useful in guiding evaluators in clarifying the stakeholders' assumptions.

A programme is understood to be an 'organised effort to enhance human wellbeing' whether for health and financial purposes as well as teaching skills (Chen, 2005, p.3). Program Theory was used to study education policy such as school-based implementation effort and social policy such as those that are implemented in workplace. For example, in a school-based anti-smoking programme, a comic book containing the messages of anti-smoking was used as an intervention (Chen, Quane, Garland \& Mracin, 1988).

In this theory, Chen (2004) proposes the following characteristics for an effective programme evaluation. First, an Implementing Organisation has the tendency to oversee the effort. The programme evaluation helps to continually improve the programme. The programme stakeholders should know what to do next. Second, in programme evaluation, there is a need to strike a balance between the scientific credibility of evaluation and the stakeholder credibility. The stakeholders' views, concerns, and needs should be taken seriously, along with the design of instruments that follow the necessary scientific principles. Third, programme evaluation has to be done in a holistic approach. Both the intrinsic value and the context in which the programme is implemented must be considered together to adequately evaluate it.

Chen (2005) stated that a comprehensive Program Theory has two major components: Causal Theory and Prescriptive Theory. First, the Causal Theory is also known as the Change Model. It specifies how the programme produces its intended outcomes. Second, the Prescriptive Theory is the programme's Action Model. It provides guidelines for delivering the programme and describes the context necessary for successful implementation. The following conceptual framework illustrates both components of program theory (see Figure 3.1) 


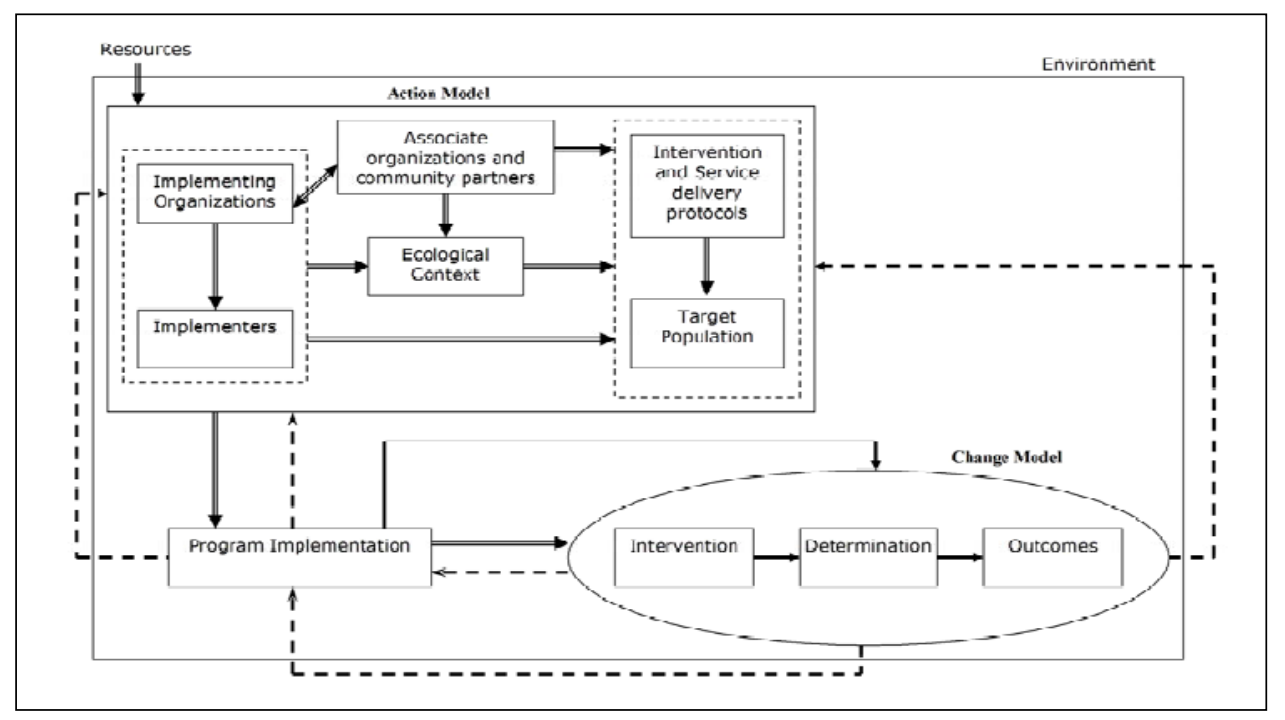

Figure 3.1. A Conceptual Framework of Program Theory (A comprehensive form) (Chen, 2005)

In this study, I used one component: Prescriptive Theory or the Action Model because the Action Model drives the day-to-day implementation of a programme and thus it helped to identify the factors affecting the ILE implementation in the school setting.

In Figure 3.1, the Action Model is placed on the top of the framework. It represents a systematic plan for arranging staff, resources, the setting, and support organizations in order to reach the target population and programme implementation. The Action Model consists of six components: (a) implementing organization; (b) programme implementers; (c) associate organizations and community partners; (d) ecological context, (e) intervention and service delivery protocols; and (f) target population (Chen, 2004, 2006). In this study, Programme relates to ILE implementation. The Action Model is interpreted as follows:

(a) Implementing organization

A programme depends on an organization in terms of its resources, staff to be recruited and trained, and coordinating its activities. The capability of the organization affects the quality implementation of a 
programme. Thus, it is important to ensure that the organization has the capacity to run ILE well.

(b) Programme implementers

Implementers are those people who are responsible for delivering or carrying out the programme as intended. In the case of ILE, the classroom teachers and LMTs are the active implementers. Thus, it is crucial to know the implementers' qualifications, competencies, and commitment towards the delivery of the programme, especially ILE.

(c) Associate organizations and community partners

A programme can benefit from the cooperation or collaboration of the organization with other organizations or local community. Thus, it is useful to know whether the implementing organization has established the needed collaboration for the programme being implemented.

(d) Ecological Context

The involvement of a supportive environment can enhance the quality of programme implementation. Chen (2004) has divided the contextual factors in two: 'micro level contextual support' and 'macro level contextual support'. The micro level context refers to the 'social, psychological and material support' the implementers need to continuously implement the programme. In addition to the micro level support, the programme developer or designer should also consider the macro level context of a programme such as community support, strategies and procedures. In the case of ILE, these factors can hinder or facilitate the process of implementation.

(e) Intervention and service delivery protocols

An intervention protocol is a curriculum that states the exact nature, content, and operating procedures of the programme. The service delivery protocol refers to the particular steps to be followed to operate the programme in the field. With regards to ILE, the protocol is important as a guide to implement it particularly in schools. 
(f) Target population

The target population is a group of people that the programme is intended to serve, for example the student. The success of a programme relies on the commitment and cooperation from the target group. Thus, it is important to identify, to screen, and to serve the target group.

Program Theory is therefore valuable for gathering data from the stakeholders' perspective, particularly data about the required actions to solve a social problem such as ILE implementation.

\subsection{Theory of Educational Change}

Michael G. Fullan is well known for his theories and studies of educational change. In 1982, Fullan published an extraordinary work entitled 'The Meaning of Educational Change' later expanded to 'The New Meaning of Educational Change' $(1991,2001)$ that provides insight into the change process and the type of strategies recommended for making improvement possible.

The Theory of Educational Change has been used to study education innovation including ILE implementation and to identify the characteristics of successful change efforts in schools and school systems. Plomp and Carleer (1986) used it as their theoretical framework to analyse the factors that influence the introduction of information and computer literacy courses in Dutch secondary schools. Another study by Wan Ali, Mohd Nor, Hamzah and Alwi (2009) describes the conditions that can facilitate and hinder the implementation of Information Communication Technology (ICT) integration in the Malaysian Smart Schools. They found that time, course content and technical support to be the main problems during the process of implementation. 
Fullan (2001) proposes that there are four broad phases in the change process, that is, initiation, implementation, continuation, and outcome (see Figure 3.2). First, initiation is a process that leads up to and includes a decision to adopt a change. Second, implementation is a process that involves initial use. It is the first experiences of attempting to put the new idea into practice. Third, continuation is a process where the new idea has become routine and a part of the on-going process of the system. Fourth, the concept of outcome is added on into the phases to complete the cycle of change process. Fullan also proposed that the core idea for Figure 3.2 is, 'change is a process, not an event'. This proposition is also similar to CBAM.

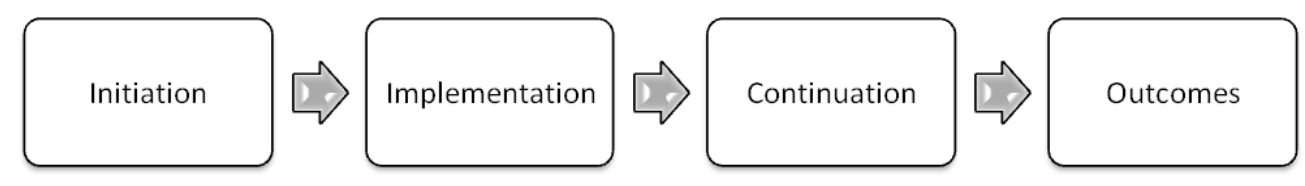

Figure 3.2. Four Phases of the Change Process (Fullan, 2001)

In this study my focus is on the implementation phase of change. In Fullan's theory, he identifies the following three areas of the major factors affecting implementation (see Figure 3.3):

(a) characteristics of change (need, clarity, complexity, quality),

(b) local characteristics (district, community, principal, and teacher)

(c) external factors (government and other agencies). 


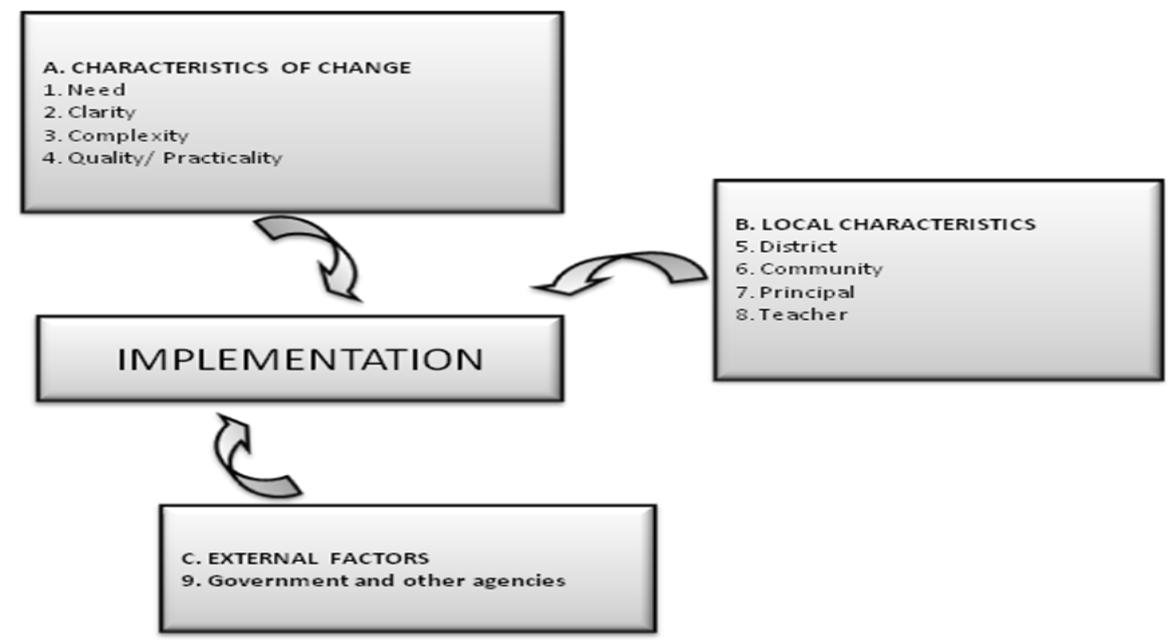

Figure 3.3. Interactive Factors Affecting Implementation (Fullan, 2001)

(a) Characteristics of Change

The implementation of ILE is affected by the characteristics of change. These characteristics are associated with the four factors of change highlighted by Fullan (1991). First is [perceived] need. The Individual Implementers such as teachers and LMTs should have well-defined needs for and solutions related to ILE in their teaching practices to ensure better chances for ILE implementation. This expression or feeling of needs becomes greater as the Individual Implementers get used to practicing IL in their teaching. However, need interacts with other factors (see below).

The second important factor is the clarity of the goals and means of ILE. Whenever a new idea or rule or even apparatus is introduced to the school, there is a tendency for the intended users (in this case, the ILE Individual Implementers) to be unclear about what they are expected to do. Thus, the implementers may not be certain about their needs or what they want.

The third factor, complexity of change, reflects the amount of new skills, the modification of beliefs and behaviours, use of different 
materials and so on. Simple change may be easier to implement because it involves less effort and less risk of failure. In the context of ILE implementation in a developing Southeast Asian country such as Malaysia, one of the challenges is to modify the beliefs and behaviours especially in terms of role and relationship between teacher and student, superior and subordinate.

This is where the complexity of change interacts with the final factor, that is, quality and practicality of change. Quality means that the new idea is carried out well with the available funds and resources such as, the existing teachers' abilities and student characteristics, parents' expectations, social and cultural values. Thus, in order for ILE to work well in Malaysian primary schools, the quality aspect of ILE implementation, its practicality must be recognised by the Individual Implementers.

\section{(b) Local Characteristics}

Fullan (2001) claims that educational reform efforts fail because the change planner has the wrong assumptions. First, change fails because 'it is hyperrational'. Second, it fails to consider the "local context and culture". Third, it is 'dangerously seductive and incomplete' (p.96). Fullan then explores the local scene and describes the roles of the district administrator, the community, the principal, and the teacher. The focus is on the local administration, development and involvement.

First, district administrators play a very specific and crucial role. Fullan (2001) explains this in the following manner:

It is possible for an individual school to become highly collaborative despite the district it is in, but it is not likely that it will stay collaborative. If the district does not foster professional learning communities by design, it undermines them by default. 
We now know that schools will not develop if left to their own devices (p.165).

The involvement of district administrators is important in terms of active and moral support of any ILE related activities such as staff development and training, allocation of funds and resources, monitoring the instruction, teaching and learning, and changes in the culture of the school (Fullan, 2001). Fullan advises the administrators to develop their management capabilities so that they can lead change. This can provide conducive conditions for the implementation of ILE in schools.

Second, school boards, parents and the local community may not be directly involved in the ILE implementation. But, their influence on the management of the school whether politically, economically or socially can help to accommodate to specific circumstances such as fund raising for a new training centre or new reading materials.

Third, the role of school management, that is, the principal and the management team is important to ILE implementation. School leadership is complex due to the fact that educational reform is more than redirecting the school operational procedures and arrangements. There are a number of dilemmas that the principal faces in the implementation of new reform ideas in the context of Southeast Asian countries. According to Walker and Hallinger (2007), the principals' cultural beliefs and values are different (for example to the Western leadership practices) and often contrasting leadership practices and characteristics that need to be employed in the change process. Fullan (2001) advises that principals can only be provided with guidelines for action rather than checklists or steps to be followed.

Fourth, the teacher is crucial to educational change. 'Educational change depends on what teachers do and think - it's as simple and as complex as that' (Fullan, 2001, p.117). Their commitment, attitudes, 
competencies, and interaction patterns make up crucial factors for the ILE implementation. Since the implementation of ILE requires teachers to modify their teaching practices particularly their roles and relationships with students, they have to be motivated to engage in the change process. Otherwise, nothing can happen. Fullan believes that the actions of the individual count. Change involves learning new things. Therefore, the Individual Implementers have to participate in decision making, exchange ideas, and open communication with others in order to create a better learning environment. This can provide 'powerful models of work environments that stimulate continuous improvement' (Fullan, 1991, p.77).

\section{(c) External Factors}

The last set of external factors covers the role of governments and other agencies such as the professional preparation and development of teachers as the future of educational change. In Malaysia, this means the role and responsibility of the Curriculum Development Centre (CDC), the ETD, and the Teacher Education Division (TED) of the MOE. The implementation of educational policies and plans made at the federal level is carried out at the state level through the fifteen State Education Departments (SEDS). It is a centralized education system and practices a top-down approach.

Fullan (2001) offers some guidelines to improve the situation. First, 'governments can push accountability, provide incentives (pressure and supports), and/or foster capacity building' (p.220). The key here is for the government to do all three at the same time. Second, the preparation, recruitment and induction of teachers should be about changing the culture of the profession and having deep and lasting changes, not merely structural reform. Third, the professional development of teachers is not about one-shot 'workshops and courses; rather, it is at its heart the development of habits of learning that are far 
more likely to be powerful if they present themselves day after day' (p.253).

Table 3.3 below integrates the Action Model of Programme Theory (Chen, 2005) and Fullan's Change Theory (2001). Together these two theories provide a useful conceptual lens for viewing the factors that hinder or facilitate the implementation of ILE in Malaysian primary schools.

Table 3.3. Factors that Affect the ILE Implementation: Incorporating Chen's Action Model and Fullan's Change Theory

\begin{tabular}{|c|c|c|c|c|c|c|}
\hline $\begin{array}{l}\text { Fullan's Action Model } \\
\text { Theory }\end{array}$ & $\begin{array}{l}\text { Implementing } \\
\text { Organization }\end{array}$ & $\begin{array}{c}\text { Programme } \\
\text { Implementers }\end{array}$ & $\begin{array}{l}\text { Associate } \\
\text { Orgs and } \\
\text { Community }\end{array}$ & $\begin{array}{c}\text { Ecological } \\
\text { Context }\end{array}$ & $\begin{array}{c}\text { Target } \\
\text { Population }\end{array}$ & $\begin{array}{c}\text { Interventi } \\
\text { on and } \\
\text { Service } \\
\text { Delivery } \\
\text { Protocol }\end{array}$ \\
\hline \multicolumn{7}{|l|}{$\begin{array}{l}\text { Characteristics of } \\
\text { Change }\end{array}$} \\
\hline 1. $\quad$ Need & & & & $x$ & & $x$ \\
\hline Clarity & & & & & & $x$ \\
\hline Complexity & & & & $x$ & & $x$ \\
\hline $\begin{array}{l}4 . \quad \text { Quality } \\
\text { Local } \\
\text { Characteristics }\end{array}$ & & & & & & $x$ \\
\hline District & & & $x$ & $x$ & & \\
\hline Community & & & $x$ & $x$ & & \\
\hline Principal & $x$ & & & & & \\
\hline 4. Teacher & & $\times$ & & & & \\
\hline External Factors & & & & & & \\
\hline $\begin{array}{l}\text { a) Government } \\
\text { and other agencies }\end{array}$ & & & & $x$ & & \\
\hline
\end{tabular}

In Table 3.3 above, the elements of Chen's Action Model are shown across the top, and the elements of Fullan's Change Theory are shown in the left column. The crosses within the table indicate common elements between the two theories. As the table shows, both theories hold that the factors that affect the implementation of ILE can derive from the characteristics of the programme (change), the characteristics of the individuals (such as the implementers and target population), the characteristics of the implementation protocol, the characteristics of the implementing organizations (such as schools), and the Ecological Context (such as social support and social norms). In this study, I presented ILE implementation as "change". The only factor that is highlighted 
explicitly in the Action Model that is not mentioned in Fullan's Theory is "target population". However, Fullan does identify students as one of the factors to be taken into account. In this study, the students were not included as a factor because the focus is on the implementer. Thus, this table shows the factors that can facilitate or hinder a school to implement or not implement ILE in teaching and learning activities. The following preliminary model (Figure 3.7) illustrates a framework to support my investigation of ILE implementation.

\subsection{The preliminary model for investigating ILE implementation in Malaysian primary schools}

The preliminary model (Figure 3.7) is presented as a framework for conducting this study. It guided the data collection and data analysis process to identify and understand the factors that affect ILE implementation in Malaysian primary schools. This section shows how it incorporates elements of three theories: CBAM, the Action Model and Change Theory. Before proceeding to the discussion of the preliminary model, I justify the use of the three theories described above.

\section{Use of CBAM, Action Model and Change Theory}

I employed CBAM because this study is concerned with identifying factors affecting the implementation of ILE in Malaysian primary schools. CBAM focuses on factors related to change in education that affects individuals. This theory provides possible factors to be identified at the individual level. While CBAM is a useful framework, it is not sufficient to be a sole theory for this study.

The Action Model and Educational Change Theory allowed for the identification of possible factors that affect the community and education administrators in ILE implementation, and also for the identification of the individual interactions with the ecological context in relation to ILE 
implementation. For example, teachers at school do not exist in isolation, and interact with the community and education administrators. These interactions affect ILE implementation in primary schools.

Using the CBAM alone would result in an isolated view of potential factors affecting ILE implementation at the individual level. Weaving CBAM with the Action Model and Change Theory provided a basis for rich information and elaborated the professional development needs of ILE implementers. Thus, the use of these three theories contributed to a solid theoretical framework to conduct research on ILE implementation.

\subsubsection{Adaptation of variables and factors in ILE implementation from related theories}

As shown in Figure 3.4 below, based on the Concerns-based Adoption Model (Hall \& Hord, 2005), the two dimensions, Stages of Concern and Level of Use were adapted to determine the stages of ILE implementation and were incorporated in the preliminary model. The 8 levels of use were reformed into three levels of Non-Use, Early Use and Use. These three levels of use align with particular stages of concern. 
Two dimensions in the Concerns-based Adoption Model:

Stages of Concern and Levels of Use.

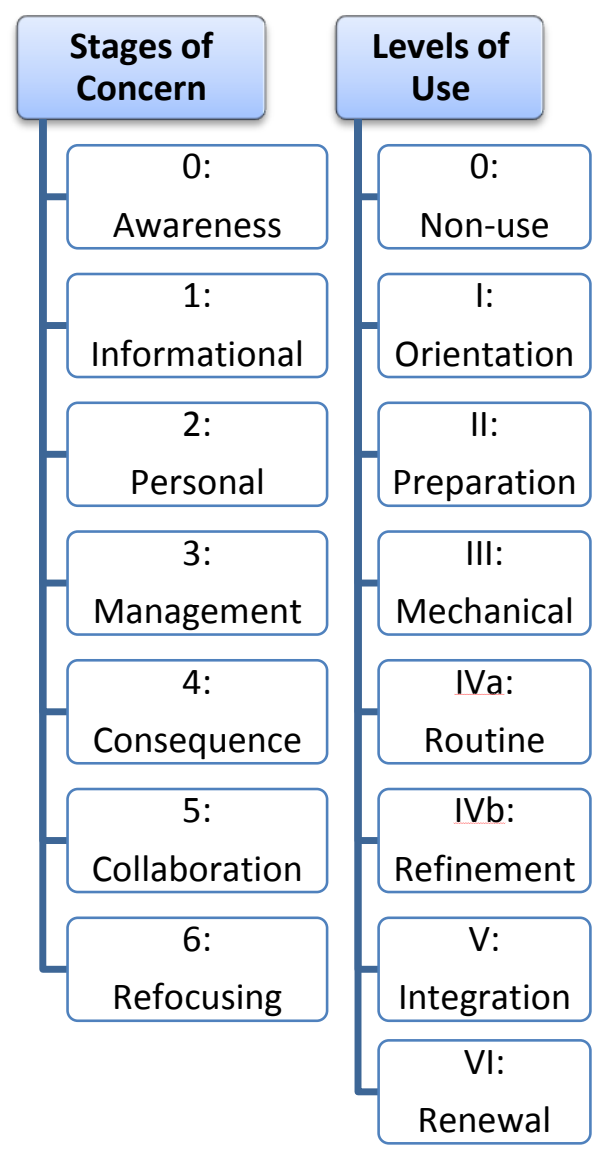

Dimensions adapted for this study's preliminary model
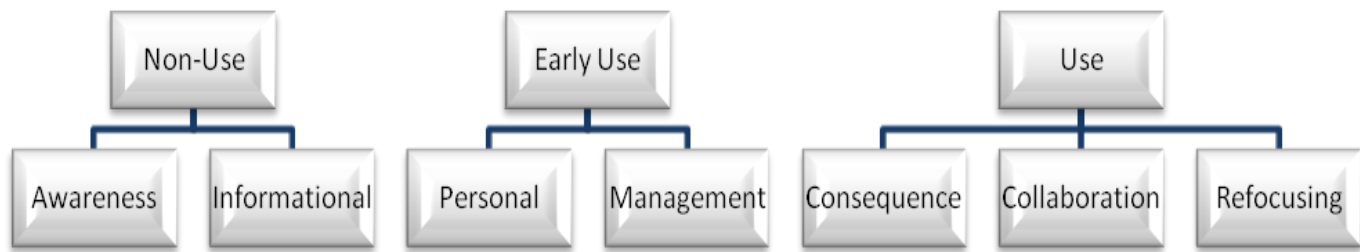

Figure 3.4. The adaptation of dimensions to the preliminary model for the study 
In addition, as shown in Figure 3.5 below, based on (a) the Theory of Educational Change (Fullan, 2001) and (b) the Action Model (Chen, 2005), there is an interaction among the factors (such as characteristics of change, characteristics of the Individual Implementers, characteristics of implementing organization, characteristics of the implementation process, and Ecological Context). These factors affect the implementation of ILE.
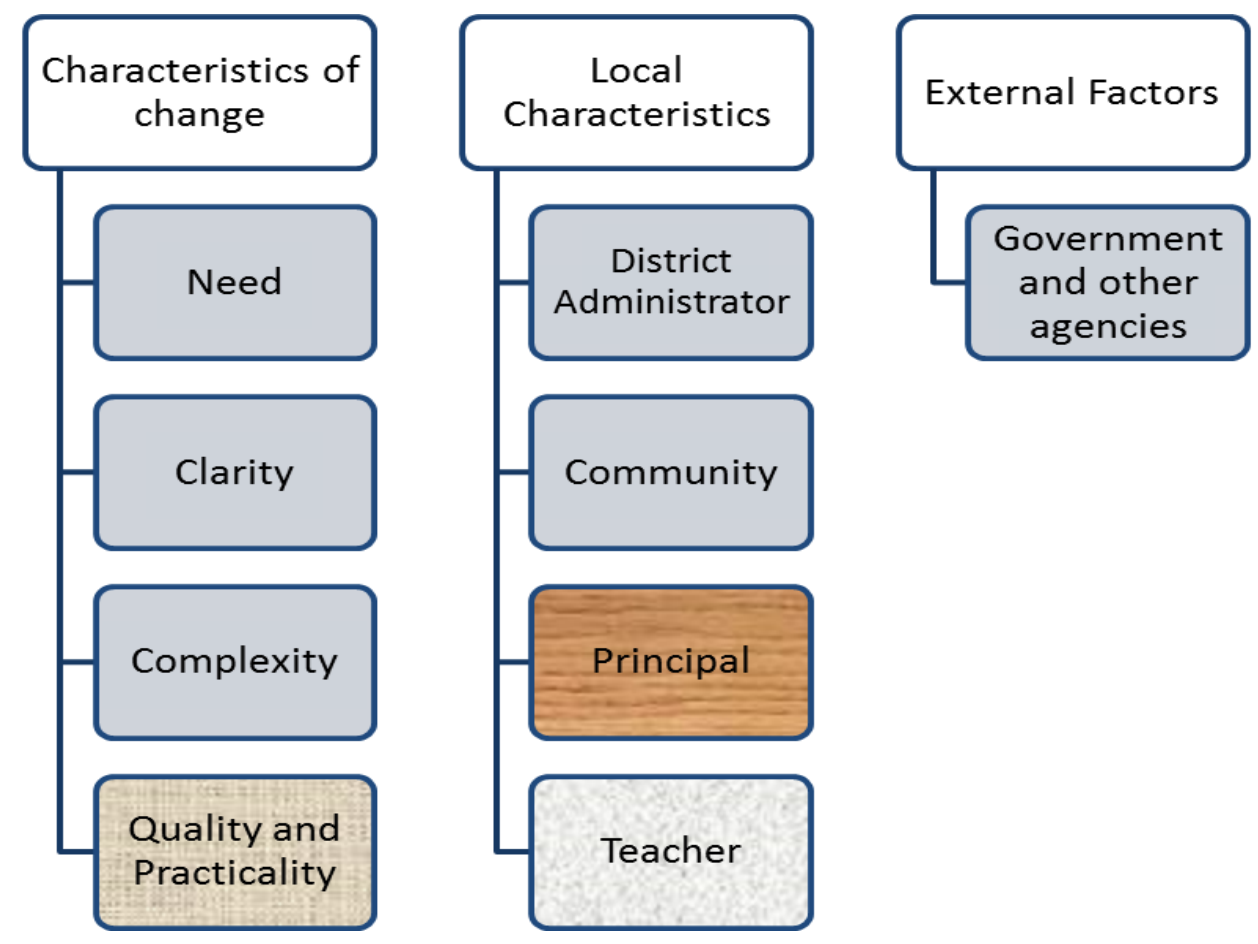

Figure 3.5 (a). Factors affecting the implementation of change by Fullan's Theory of Educational Change (adapted from Fullan, 2001) 

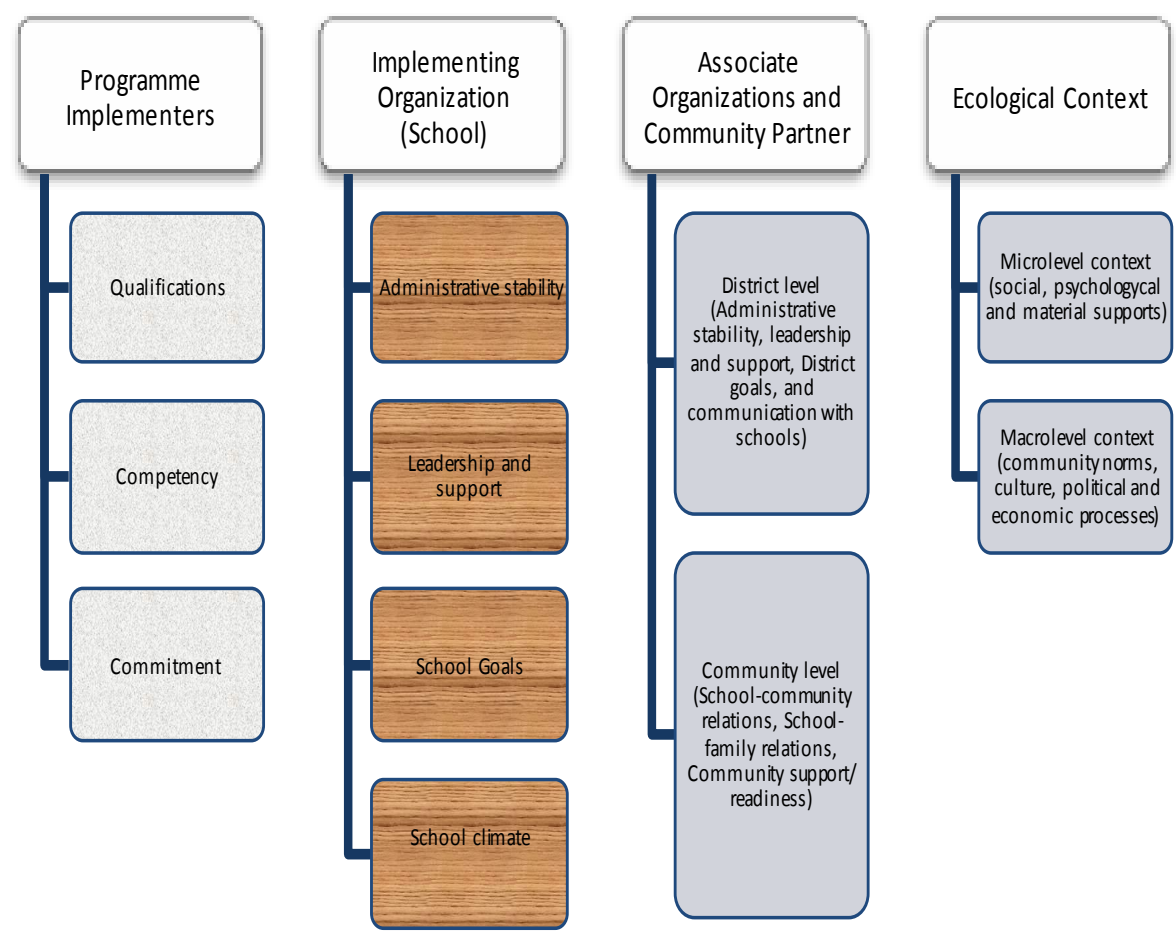

Intervention and Service Delivery Protocols

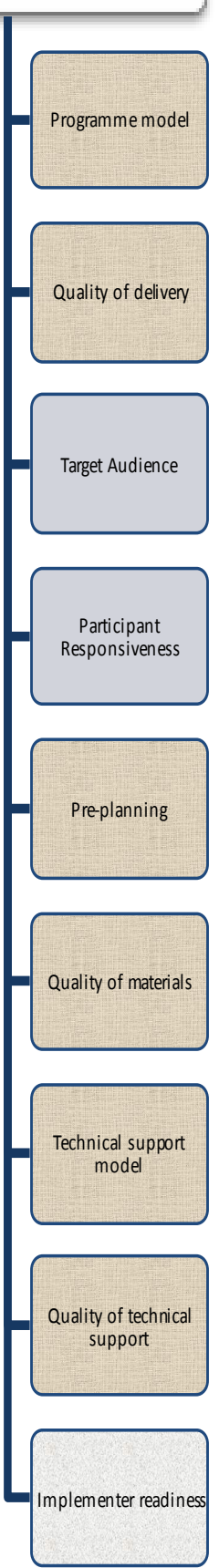

Figure 3.5 (b). Factors affecting the implementation of change by Chen's Action Model (adapted from Chen, 2005) 
Adapted factors from Fullan and Chen for the preliminary model of this study
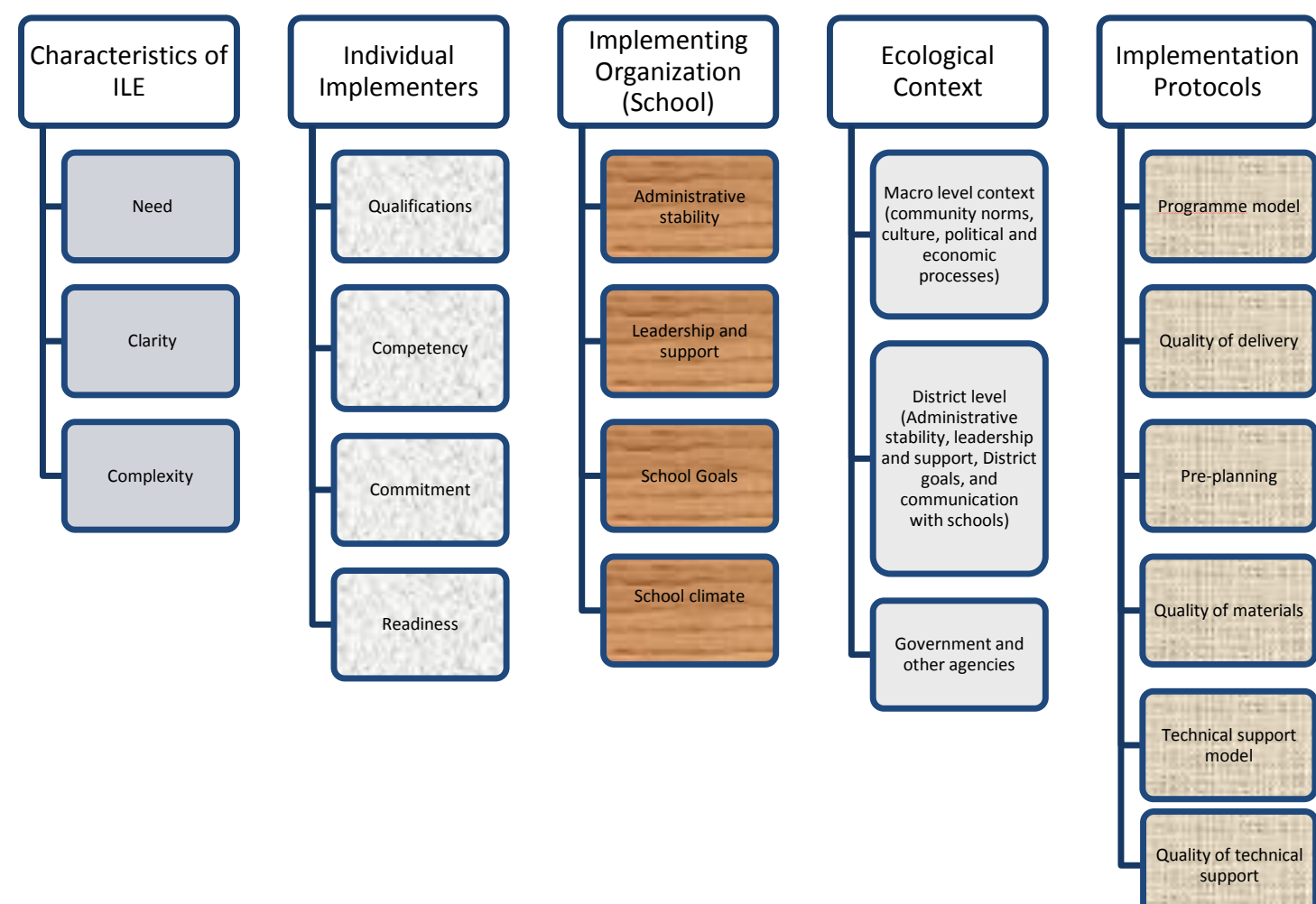

Figure 3.6. The adaptation of variables and factors to the preliminary model for the study. 
Figure 3.5 (a) and (b) outlines key factors and variables affecting the implementation in Fullan's Change Theory and Chen's Action Model. Figure 3.6 shows how I combined and adapted elements of Chen's model and Fullan's theory for this preliminary study.

The following Figure 3.7 presents the preliminary model for this study's investigation of ILE implementation in Malaysian primary schools.

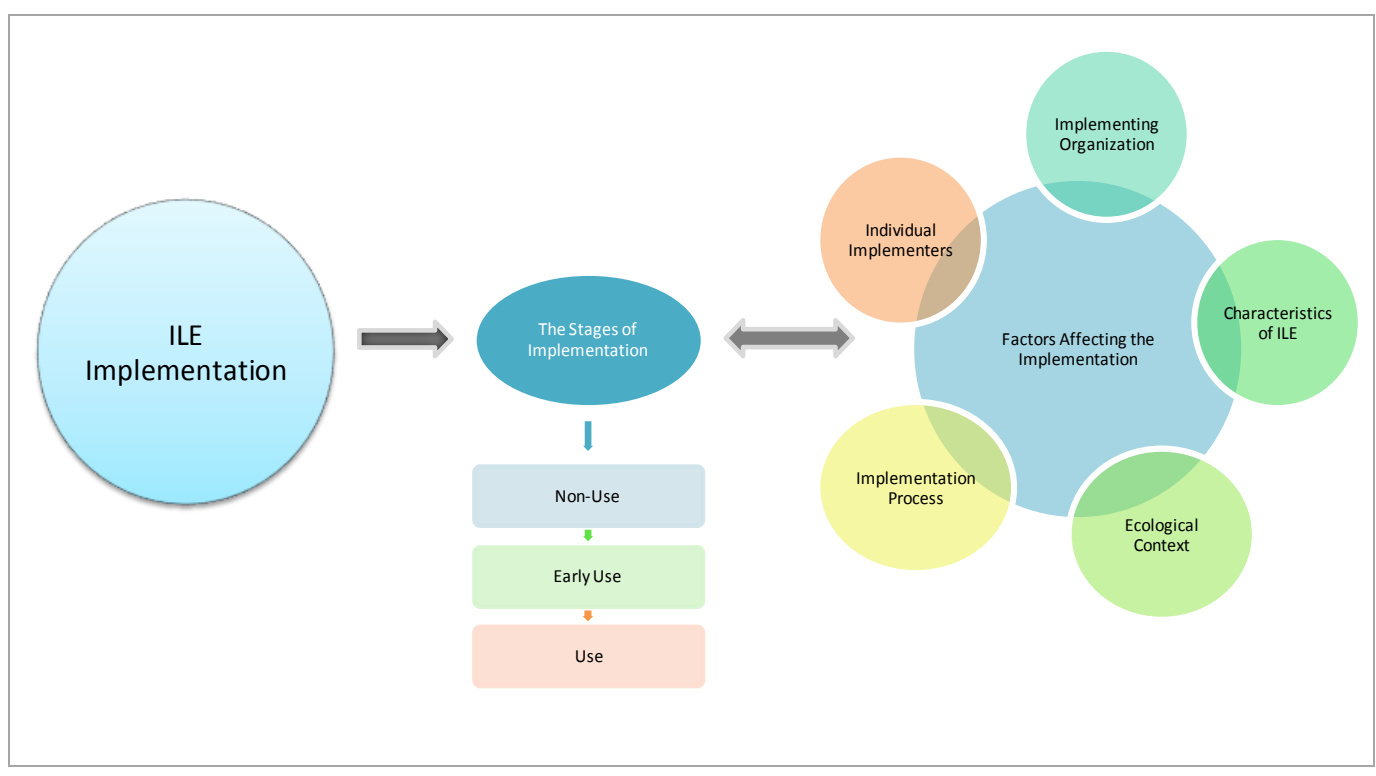

Figure 3.7. The Preliminary Model of ILE Implementation in Malaysian Primary Schools.

The dimensions, variables and factors adapted in developing the preliminary model for this study consist of two parts. The middle part of the model was used to identify the stages of each school's ILE implementation using an adapted version of CBAM's two dimensions: Stages of Concern and Levels of Use (see Figure 3.4). The following levels were established:

(1) Use - School which teaches IL to the students; 
(2) Early Use - School which is at the preparation phase, that is, at least one teacher or LMT is preparing him or herself for the ILE (for example: by attending an in-service course);

(3) Non-Use - School which does not teach IL to the students.

The second part of the model on the right hand side of Figure 3.7 used both Chen's Action Model and Fullan's Theory of Educational Change (see Figure 3.6). The factors adapted from both theories are as follows:

(1) Characteristics of ILE - need, clarity and complexity.

(2) Individual Implementers (teachers and LMTs) - qualifications, competency, commitment, readiness.

(3) Implementing organization (school) - administrative support, leadership and support, school goals and school climate.

(4) Ecological Context - Macro level (Community norms and culture, government and other agencies, district level (administrative support, leadership and support, district goals, and communication with schools).

(5) Implementation Protocols - programme model, quality delivery and materials, pre-planning, technical support model, quality of technical support.

Figure 3.7 illustrates the possible interaction of various factors in the implementation of ILE. The factors could be seen as facilitating or hindering the ILE implementation in Malaysian primary schools. The model shows the possible interactive process of ILE implementation. The double-banded arrows between two parts of the model represent the likely sequential order between the two parts. The completion of one stage of ILE implementation should provide the basis for the interaction of one factor to the other. Some factors may have stronger influence than another. Some factors may be weaker than others to influence the implementation.

For example, in a school which is in the early use stage of ILE implementation, the school administration might play an important role as an enabler in the 
implementation process whereas in a school which is not implementing ILE and is at the non-use stage, the school administration might be a barrier to implementation. In a school which teaches IL to their students, the teachers and LMT may be seen as the most important decision makers and may be involved in the school administration. The factors may be found in a school which teaches ILE to the students (use) or in a school which is at the preparation stage (early use) or in a school which does not teach ILE to the students (non-use). In this study, the factors were identified and examined in relation to the stages of implementation to determine how the factors are affecting the implementation process. The following discusses the suggested factors and variables to be used in the study.

\subsubsection{Justification for factors and variables in the study}

\section{- Characteristics of ILE - need, clarity and complexity.}

The higher the need of the implementers to find solutions to their teaching practices, the better the chance in improving the implementation process (Fullan, 2001). This means ILE can be actively implemented and used in the school, if the implementers felt a higher need of ILE for student learning. However, the clarity of the goals and means to deliver ILE is also important in order to reduce the complexity of implementing ILE such as the need to apply new skills, alter behaviours, use new materials, and so on. Fullan's advice is 'to break the complex changes into components and implement them in a divisible or in incremental manner' (Fullan, 1994, p. 2841). These variables have a strong influence particularly at the early phase of ILE implementation. Accordingly, they are included in the preliminary model.

In the context of Malaysia, the process of educational reform is a top-down approach. In most instances, whenever new concepts or ideas are introduced by the MOE and announced by the Minister, the teachers concerned will be trained and prepared to use the new materials and teaching strategies. However, the amount of new ideas introduced in the education sector is 
multiple. Most of the time, the teachers do not have a sense of control to their work

For this study, the Characteristics of ILE such as need, clarity of goals and means, and complexity of ILE implementation were identified as potential factors affecting the implementation of ILE in teaching and learning activities in Malaysian primary schools because it could help to understand the implementation process of ILE.

\section{- Individual Implementers (teachers and LMTs): qualifications,} competency, commitment, readiness.

Individual Implementers are the people responsible for carrying out ILE to the students such as teachers and LMTs. The implementers' qualifications and competency, commitment, enthusiasm, and other attributes could directly affect the implementation of ILE.

In the Malaysian context, as mentioned in the problem statement of the study, a number of school heads, teachers and LMTs have not undertaken any ILE related courses or training or staff development (Tan \& Singh, 2008; ETD, 2006). These Individual Implementers require knowledge and skills of ILE in order to motivate them to implement ILE in their teaching and learning activities. Therefore, qualifications and competency (knowledge and skills), commitment and readiness are investigated as potential factors affecting the implementation of ILE in Malaysian primary schools.

- Implementing organization (school): administrative support, leadership and support, school goals and school climate.

An ILE programme generally relies on an organization to allocate funds and resources, to coordinate activities, to recruit, train, and supervise the implementers and other staff. In school, we are referring to the principal or school. 
In Malaysia, the principal or school head is the most powerful person in school administration to shape the organizational conditions necessary for success. Therefore, the principal or school head's support and participation in ILE implementation is likely to be a crucial factor. However, the school head does not play an active role in the implementation because of factors such as the beliefs, culture and values that he or she embraces. In the case of ILE, there might be a need for the school community to change not only to the use of new materials but to their roles and relationships. The school heads may find it difficult to transform their traditional, more passive role into a new and more active role as "change agent' or facilitator of change" (Fullan, 1991; Hall and Hord, 2005).

Therefore, in this study, administrative support, leadership and support, school goals and school climate were identified as potential factors affecting Malaysian primary schools in implementing ILE.

- Ecological Context: Community norms and culture, government and other agencies, district level (administrative and leadership support, and communication with schools)

Most programmes need a supportive environment or ecological context to work effectively. Chen (2006) divides the Ecological Context into two levels: the micro and the macro levels. In this study, only the macro level was considered because the micro level was absorbed into other factors such as school and implementers. At the ecological macro level are three supports: community or society, government and other agencies, and district administrator. With regard to the community support, I considered the community's or society's culture and norms. For the government and district support, I focussed on the administrative and leadership support, district goals and communication with schools, particularly associated with the aspect of ILE. 
In Malaysian society it is characteristic to show respect for authority. This social norm gives a greater power to the leaders at all level. Hofstede (2001) identifies Malaysia's power distance as greater than in Western societies such as New Zealand. Unlike in Western societies, the school stakeholders for example, school head, teachers, students, and parents in Malaysia have the inclination to be polite and unquestioning of any reforms introduced by the leaders at the federal or state level. For example, ILE is claimed to be integrated into the curriculum by the MOE and so the teachers could be expected to know and apply ILE in their teaching practices. But, due to the culturally-influenced nature of Malaysian teachers if they do not understand, they may not inquire. They may not want to be rude or question the instruction from the leaders or those who have the authority in the area of ILE. That situation may lead to insufficient understanding and hinder the whole process of implementation of ILE. The lack of communication between the school stakeholders and the key persons at the federal and state level could also be a factor.

Therefore, in this study, I investigate social and cultural factors that affect the implementation of ILE, and the administrative and leadership support at the federal and state level and their communication with the schools.

- Implementation Protocols: programme model, quality delivery and materials, technical support model, quality of technical support.

A programme generally needs proper planning in order to be able to run smoothly. Perhaps the most essential components of a programme are the content of the programme, the structure, the time allocation, and the dosage (Chen, 2005). All these components are generally stated in the curriculum of the education system. At the same time, the programme needs a guideline or steps to be taken in delivering the content of the programme. The guideline may also be known as service or programme delivery protocol.

In the Malaysian education system, school heads and teachers are equipped with the school curriculum, the subject syllabi supported by the syllabi 
specifications. In these documents, the curriculum is explained in greater detail. There is one set of specifications for each level of schooling. This study was at the primary level of schooling. However, there are multiple activities and strategies specified by these documents and used in the teaching and learning process. The challenge is on the time allocation and the dosage of each strategy to be exposed to the students. Research found that the Malaysian teachers have limited time to spend on ILE (see Tan \& Singh, 2008). As a result, only a small amount of ILE appears to reach the students.

Therefore, in this study, programme model, quality delivery and materials, technical support model, and quality of technical support were investigated as potential factors that affect the implementation of ILE in Malaysian primary schools.

\subsection{Chapter summary}

The theoretical framework has been developed and discussed. A preliminary model was developed based on three theories, namely CBAM, the Action Model of the Program Theory, and the Theory of Educational Change. This preliminary model was aimed at addressing the influence of internal, external and individual factors on ILE implementation. The preliminary model supports the identification of factors affecting ILE, and is valuable for helping to determine and understand the stages of ILE implementation in the context of Malaysian primary schools. This understanding is crucial for preparing an achievable and effective ILE programme in terms of content, structure and approach. Chapter 4 discusses data collection and the analysis that was carried out. 


\section{CHAPTER 4 Research Approach}

\subsection{Introduction}

This chapter begins with discussion of the paradigm that guides the study, followed by an elaboration of the research methodology and methods used, that is, qualitative methodology and methods within an interpretive philosophy. Next is a discussion of the selection of research sites, participants and key informants. Then, I present the data analysing strategies. Finally, I conclude this chapter by addressing the ethical issues and language, validity and reliability concerns.

\subsection{Paradigm: Interpretivism}

A paradigm is 'the basic belief system or world view that guides the investigation' (Guba \& Lincoln, 1994, cited in Krauss, 2005).

For this study, I chose the interpretivist paradigm because it lends itself to the particular investigation that I undertook. Following the ontological belief of interpretivism, the social world is not "given" (Orlikowski \& Baroudi, 1991, p.14). The social world is shaped and supported by humans through their "subjective and inter subjective" perceptions and interactions (p.5). In this study, I explored the actions and interactions among the Individual Implementers (participants of this study) at school level and key informants at state and federal levels and how these shape and support (or do not support) the implementation of ILE. In other words, this study was an attempt to understand ILE implementation through accessing the meanings that participants at school level and key informants at state and federal levels assign to them. 
Epistemologically, the interpretive philosophy is premised on the belief that the phenomenon of interest is examined in its natural setting. This philosophy asserts that the language humans use in their setting describes their social practices (Orlikowski \& Baroudi, 1991, p.14). In order to understand the reality of the setting, the researcher has to go inside the world which is generating it. The meanings and practices of social reality are formed and informed by the language use, and cultural norms shared by the humans in the setting. In this study, I examined ILE implementation in primary schools in Malaysia by attempting to understand the participants' views of their social world and their role at school, state or federal levels. This study required me to understand how the practices and meanings shared by these participants work towards teaching and learning ILE in schools.

\subsection{Methodology}

\subsubsection{Qualitative Approach}

In this study I adopted a qualitative approach, to investigate the lack of knowledge about ILE implementation. Qualitative research can be defined as 'a family of approaches whose goal [is] understanding the lived experience of persons who share time, space and culture' (Frankel \& Devers, 2000, p.113). The use of this approach allows researchers to gather rich description of how people experience a phenomenon of interest or research issue, and access the human side of the issue. The use is effective to identify social reality in the cultural and contextual setting.

By adopting a qualitative approach in this research, I was able to be close to the participants and to understand how they view their social world, in this case, in school settings, and their role in ILE. It is important to know how different factors in their world interact and affect ILE implementation in schools. I used several data gathering methods to ensure the collection of "information rich" data in order to be able to describe and explain the phenomenon under study (Gorman \& Clayton, 2005). 
For this study, I used the case study as the strategy of inquiry. The following discussion provides the justification for using case study in the research.

\section{a) Reasons For Selecting Case Study}

Case study research is a strategy of inquiry that allows researchers to investigate the phenomenon of study deeply and closely, enabling a rich description, and revealing its deep structure (Cavaye, 1996). Following Yin (2009), case study was an appropriate strategy of inquiry in this research because the focus of the research question was a contemporary event, the types of questions posed were 'how' or 'why' questions, and I had little control over events.

The reason for choosing a case study strategy was, first, it would allow for an in-depth exploration of various contextual aspects of IL such as the educational and socio-cultural contexts within which I had little possibility to control any of the factors affecting the ILE implementation. Second, the forms of the research questions of this study were 'what' and 'how'. The first research question is the "what" question (i.e., what are the factors affecting the implementation of ILE in Malaysian primary schools?) which is exploratory in nature. It is exploratory because we know so little about ILE implementation in Malaysia and the factors that facilitate or impede its implementation. According to Yin (2009), an exploratory case study can be used with the 'what' question.

The second research question is the "how" question (i.e., how do these factors facilitate or hinder ILE implementation in Malaysian primary schools?) which is to explain the effect of the factors on the implementation and on each other. According to Yin (2009, p.9), this type of question leads to the use of 'case studies' as a preferred method of inquiry. Third, case study research is usually employed in a contemporary phenomenon such as innovation in education. The focus of this study is the implementation of ILE in schools, more 
specifically, identifying the factors affecting its implementation in Malaysian primary schools which is new to the country education system.

\section{b) Case Study Design: Multiple-Case Holistic}

Yin (2009, p.46) categorises case study design into four types: single-case (holistic) designs, single-case (embedded) designs, multiple-case (holistic) designs, and multiple-case (embedded) designs. Among these types, multiplecase designs are seen to be more appropriate than single-case designs, because of the possibility of 'replication', and thus, more robust (p.54). The holistic design is used rather than the embedded design because the aim is to study the global nature of the phenomenon. In this research, I applied a multiple-case holistic design.

Due to the replication logic, when using a multiple-case design, each case 'must be carefully selected' so that it could either reveal similar results or contrasting results for predictable reasons. In this study, a preliminary model was developed to guide the research design. As stated by Yin (2009, p.54), an

important step in the replication process is 'the development of a rich, theoretical framework'. That means the theoretical framework must identify clearly the conditions related to the phenomenon of study, act as a vehicle for generalising to new cases, and modifications must be made if cases do not work as predicted. The advantage of a multiple-case design is that the conclusions of each case can be considered to be information needing replication by other cases, and which contribute to the conclusions for the whole study.

\section{c) Unit Of Analysis}

Yin $(2009$, p.28) explains that the unit of analysis for case study research can be an individual, an event, or an entity or a process as the actual source of information. It relates to the basic problem of the study. The unit of analysis of my research was the process of ILE implementation in Malaysian primary schools. 


\subsection{Method}

In this study, I used multiple methods of data collection to triangulate evidence and to provide information rich data gathering. I visited the research sites (that is, the primary schools in Malaysia), and conducted interviews in which I asked the participants (that is, school heads, teachers and LMTs) and key informants (that is, education and government administrators) questions about ILE implementation in their teaching and administrative experiences. Then, I carried out documentary analysis to look for any evidence of IL implementation and factors that were affecting it.

\subsubsection{Documentary Evidence}

Documents for this study were chosen in order to provide a significant account of the ILE practices and IL policy under investigation. They were related to ILE implementation, and produced by the teachers and LMTs of the selected schools.

The analysis and review of documents related to ILE practices in primary schools provided a rich source of information with which to complement and supplement data collected through interviews. Course description, syllabus content, course related works, teachers' teaching plans, and assessments were collected and analysed for any evidence of ILE. I also requested access to any guidelines or manuals or modules developed for ILE. The documents helped to indicate any requirements as well as the purpose underlying the implementation of ILE and to contextualize the interview data.

In addition, I also requested access to any relevant documents from the key informants from the state and federal organisations. The collection of the documents from the key informants also further helped me to understand ILE and its implementation as well as the education system of the country. This was when I discovered information regarding my country's education development particularly the National Philosophy of Education (MOE, 2006; ETD, 2006). 


\subsection{2}

\section{Semi-structured Interviews}

In this study, the interview was the primary data collection method because it allowed me to capture the participants' viewpoints and experiences of implementing ILE. The interview was semi-structured so that I could generate new questions to further explore any interesting areas of inquiry which emerged. In addition, the participants' answers to each of the main questions affected the following questions. This allowed a certain degree of flexibility for me to probe and prompt. Compared to the structured interview, the semistructured interview provides "some latitude to ask further questions in response to what are seen as significant replies (Bryman, 2008, p.196).

In this study, the interviews were intended to last approximately half an hour to one hour per session. This was because the participants, particularly at school level, had to observe a tight and designated teaching schedule. I also followed the advice of Byrne (2001) to conduct an interview in three stages, that is, the introduction, the main part of the topics for investigation and the summary of the participant's responses.

Each interview was conducted with one participant at a time. Selection of the participants was made using two sample frameworks. First, the research sites were specified, and then the sample population was determined. The selection criteria for participants are discussed further in section 4.5.

All interviews were digitally recorded and when necessary notes were taken during the interviews. The recording was then transcribed verbatim by me as soon as possible after the interview.

\subsection{Selection of Research Sites and Participants}

The study is focussed on ILE implementation in primary schools, therefore four sample sites were chosen from the primary schools which are funded and administered by the Malaysian government. The criteria for selecting schools are discussed below. In addition, key informants were identified in the district 
and state levels' education administrations as well as in one of the divisions of the MOE. The reason for selecting key informants from these divisions is they are the ones who provide the administrative support such as staff development and training, allocation of funds and resources, and monitoring the instruction, teaching and learning process.

The following section explains how the research sites were specified, and how the sample population was determined.

\subsubsection{Research Sites}

The sample population of schools was situated in the Kinta North district in Ipoh, Perak, Malaysia. Perak is a large state. Kinta North, situated in Ipoh, Perak, was chosen because the district encompasses both urban and rural areas, and is thus fairly reflective of the variation in the country. There are 112 primary schools including 63 national schools, 35 Chinese national schools and 14 Tamil national schools in the Kinta North district (MOE, 2014). In addition, the SETD is also situated in this district.

All primary schools in Malaysia which possess a computer lab use ICT in the delivery of the curriculum (Perak State Department of Education, c2009). The use of ICT is seen as a means of expanding the students' horizons beyond the information and knowledge offered in schools, and to foster the development of skills in using online information services such as the internet for gathering information.

Although these primary schools are government funded and use ICT in learning and teaching, they differ in attributes such as category of school, geographical location of school, medium of instruction, and IL involvement. Thus, the selection of the sample sites in this study was made by taking into account the following attributes.

1. They are representative of one of the different types of national primary schools in Malaysia. 
This study focused on primary schools which include national school (known in local language as Sekolah Kebangsaan), and Chinese national-type of school (known as Sekolah Jenis Kebangsaan Cina and Tamil national-type of school Sekolah Jenis Kebangsaan Tamil) .

2. They represent different geographical locations, rural or urban.

There are two major locations of primary schools in Malaysia, namely primary rural and primary urban. The geographical location of the primary schools may influence the school ecology. The advantage of doing research in both geographical locations is that it provides insights to the similarities and differences of location affecting ILE implementation.

3. They represent the linguistic medium of instruction diversity, either Malay language, English, Chinese or Tamil.

4. They actively participate in IL-related activities at the district, state or national level.

The schools chosen have been selected based on certain levels of achievements related to IL activities, such as Champion in Interactive Website for Teaching \& Learning Resources at district level for 2007 or Champion in Interactive School Website at state level for 2004.

The attributes of sample sites were obtained from the Kinta North schools' portal (http://kintautara.net/), schools' blogs and homepages, and State department of education's portal (http://pelajaranperak.gov.my/v2/). Four schools were purposively selected according to the category of school, geographical location of school, the medium of instruction, and IL involvement. All these case study schools have qualified teachers and LMTs. Access to the schools was negotiated with the school head of each school accordingly. The attributes of the four schools selected are shown below: 


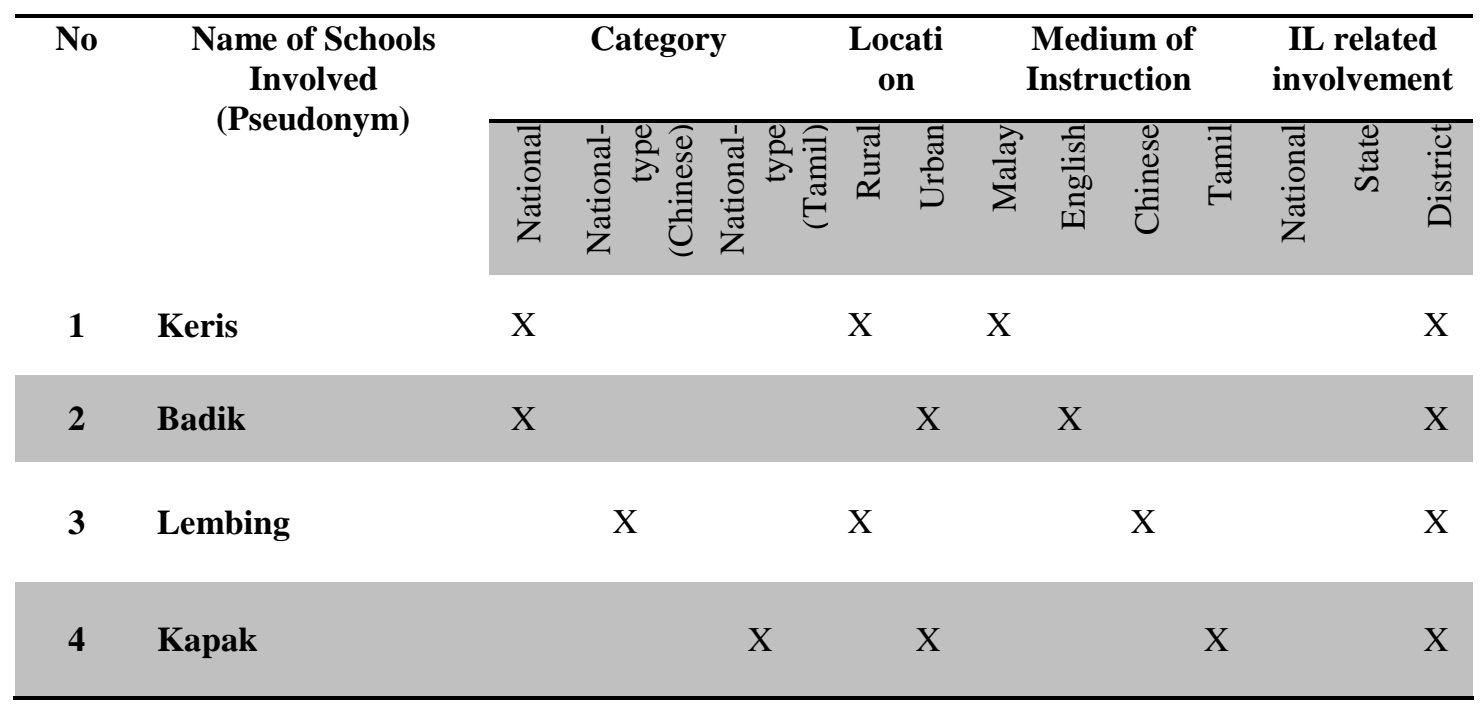

Table 4.1. Participating primary schools.

In addition to primary schools, district, state and federal level organisations are also included in the study. District and state level organisations were included because:

1. They play an important role in providing education and training for IL and librarianship inside or outside schools in Perak.

2. They are responsible for supporting IL implementation administratively in terms of educational programmes, learning resources, financial and technical support at state level.

3. They are the representatives of one of the educational administrations at state level and district level.

The federal organisation (one of the divisions of the MOE) was included because:

1. It is a governing body which is responsible for the development and progress of SRC and ICT application in Malaysian schools.

2. It plays an important role in providing education and training for IL, librarianship and ICT in education throughout Malaysia.

3. It is responsible to support IL implementation administratively in terms of educational programmes, learning resources, financial and technical support. 
Because of the large number of potential participants in these organisations, purposive sampling was used to identify respondents.

\subsubsection{Selection of Participants}

The sample in this study was selected from the individuals who were responsible for the implementation of ILE at various levels of the Malaysian education system. Thus, the participant group included school-based participants and key informants from government organisations, as outlined below.

a) School participants

Participants at school included the following individuals:

- School Heads who are administratively responsible for and/or participate in any IL related activities at district or state or federal levels.

- Teachers who teach one of the following subjects in the primary school syllabus:

- $\quad$ Science

- $\quad$ Language or Religious Studies

- $\quad$ Local Studies

The selection of teachers based on their subject specialisation was to ensure that the variation of subjects in the Malaysian primary education curriculum was represented.

- LMTs who are those responsible to educate and provide technical support for IL to students and teachers.

In accordance with the sample population framework, I chose the Individual Implementers from different categories of schools and different positions they played at four research sites (see Table 4.2 for illustration of participants from different categories of schools and positions). Each school therefore had five participants. The participants included: (1) the school head, (2) one teacher purposively selected from each of the following subject areas: science, social science and language, with input from the school head to identify the ones who 
seemed to be using the constructivist approach to teaching and learning and would, therefore, be more likely to be aware of or to incorporate IL in the classroom, and (3) the LMT. Also important was their willingness and time to talk.

\section{b) Key informants}

In this study, the key informants were the officials at the district, state and federal government organisations who were involved directly or indirectly in terms of administration, education and training in the area of IL with the school communities. At the district and state level (i.e. SETD and TACs), two key informants were identified. At the federal level, two key informants were identified at the one of the divisions of the MOE (i.e. ETD).

Tremblay (1957) provided a set of criteria to help identify key informants for a particular research project, namely, the key informants' role in the community, their knowledge, willingness, communicability, and impartiality. Of these five criteria, I used the role of informant in the community as a preliminary criterion to identify the key informants in advance. After individuals who performed the key roles were detected, the other four criteria were considered in order to ensure the most productive informants were interviewed.

In the organisational structure of the district and state and that of the MOE, each administrative unit is led by an officer-in-charge, accompanied by three to six support staff. Based on Tremblay's principle of the role of informant in the community, I used his technique to identify the ones who led IL-related units, directly or indirectly involved in administration, education and training programmes of IL. My aim was to interview at least one key informant from each organisation to determine their support to the schools in terms of IL implementation. I ended up with four key informants from three government organisations. 
Table 4.2 shows the roles of the sample population.

\begin{tabular}{|c|c|c|c|c|c|c|}
\hline \multicolumn{2}{|l|}{ Position } & $\begin{array}{l}\text { Primary } \\
\text { Urban }\end{array}$ & $\begin{array}{l}\text { Primary } \\
\text { Rural }\end{array}$ & $\begin{array}{l}\text { Primary } \\
\text { (Chinese) }\end{array}$ & $\begin{array}{c}\text { Primary } \\
\text { (Tamil) }\end{array}$ & $\begin{array}{l}\text { Number of } \\
\text { Participants }\end{array}$ \\
\hline \multicolumn{2}{|c|}{ School Head } & 1 & 1 & 1 & 1 & 4 \\
\hline \multirow{3}{*}{$\begin{array}{l}\text { Classroom } \\
\text { teachers }\end{array}$} & Science & 1 & 1 & 1 & 1 & 4 \\
\hline & Language & 1 & 1 & 1 & 1 & 4 \\
\hline & $\begin{array}{l}\text { Social } \\
\text { Science }\end{array}$ & 1 & 1 & 1 & 1 & 4 \\
\hline \multicolumn{2}{|c|}{$\begin{array}{l}\text { Library \& Media } \\
\text { Teacher }\end{array}$} & 1 & 1 & 1 & 1 & 4 \\
\hline \multicolumn{2}{|c|}{ Key informant } & & & & & 1 \\
\hline \multicolumn{2}{|c|}{ Key informant } & & & & & 1 \\
\hline \multicolumn{2}{|c|}{ Key informants } & & & & & 2 \\
\hline \multicolumn{2}{|l|}{ Total } & & & & & 24 \\
\hline
\end{tabular}

Table 4.2. Participants' roles at school, and key informants at district, state and federal levels of education administration.

\subsubsection{Accessing participants}

Access to the participants and key informants at school, district, state and federal levels had to be negotiated by going through a series of Government channels (see Appendix 5).

This was complex as this research was from an overseas university and must first be vetted. This is a top-down bureaucratic process. When approval was granted, the school heads, teachers, LMTs and key informants at district, state and federal levels were contacted. Access to documents and classrooms was then negotiated with schools accordingly.

\subsubsection{Participant recruitment}

After the approval for the study was obtained, I approached the school heads to participate in the study. I requested them to provide the list of names and contact details for teachers who seemed to be using the constructivist approach 
and LMTs. Prior to recruiting the participants, I obtained permission from the school head to choose the classroom teachers based on their subject specialization, and willingness to participate in the interview. Once the potential participants agreed to participate in the study, a mutually agreed time and place to meet was decided.

The same process applied to the key informants at the district, state and federal levels of education administration. I first approached the head of department or sector to obtain permission to do the research on the premises. I requested staff names or contact details in the department or sector. I approached one or two staff for an informal conversation in order to identify key informants. Once the key informants were identified, I approached the informants personally along with the letter of invitation, information sheet (Appendix 2) and consent form (Appendix 3) for the study.

\subsection{Procedures for data gathering and analysis}

This part outlines the procedures and techniques I used for data collection and analysis, and concludes by addressing the ethical issues and language, validity and reliability issues.

\subsubsection{Schedule}

The gathering of data for this study required approximately 12 weeks, averaging two weeks per school.

I spent two weeks in each case study school conducting interviews, and two days in each participating organisation. Each interview lasted from 30 minutes to three hours. I asked the school head and teachers for the required documents. I also spent one to two days in each research site (case study schools and key informants' organisations) to select, read and review IL related documents or other relevant documents. 


\subsubsection{Data triangulation: analysis of documents and observation}

In this study, I used two types of data triangulation:

1. Collecting data from multiple participants and key informants such as school heads, teachers, LMTs, district, state and federal officials;

2. Using multiple data sources such as interview and document analysis.

During the interview sessions with teachers and LMTs, I asked the participants to provide their course-related work, teachers' teaching plan, and assessments such as quizzes and tests for any evidence of ILE implementation.

\subsection{Data analysis}

In a qualitative study, data analysis involves several stages. To guide my data analysis in this study I adapted Miles and Hubermans' interactive model (1994) which has been widely used in qualitative research. I also used the inductive technique of analysis to make sense of multiple participants' views and sources. I analysed my data in three iterative processes: data reduction, data display, and conclusions.

\subsubsection{Data reduction}

In the beginning, I reviewed the research questions and the preliminary model (Figure 3.7) to create a list of relevant and possible codes. The initial list included the three stages of ILE implementation in the primary schools, that is, use, early use, and non-use, as well as the suggested factors affecting the implementation of ILE. The three stages of ILE implementation and suggested factors are the dimensions and variables in the preliminary model of the study (refer to Figure 3.7). This was when I decided the questions to ask and the documents to acquire during the interview sessions.

The next stage was pursued after the completion of the data collection and interview transcription. Since most interviews were conducted in the Malay language, the transcripts were mostly prepared in that language with only a few transcripts in English. After transcribing the interviews, I read and reread the transcripts and highlighted the important terms or phrases that were relevant to 
answering the research questions (see Appendix 6). A similar process was continued until all the relevant terms or phrases in the transcripts were highlighted. After I had transcribed and highlighted the contents in the transcripts, I started to translate the transcripts into English. Translating the transcripts into English was not an easy task. The implications of translating between languages for data analysis were further discussed in section 4.8.3.

Then, I began to attach descriptive codes to the highlighted terms and phrases in the texts that represent the concepts. After the coding, the data were ready to be categorised. The codes developed were analysed in order to assign them into higher level categories. The data were then compared against the preliminary model of prior theories I used, also known as within-unit analysis (Eisenhardt, 1989).

Microsoft Excel was used to manage and analyse the data. The preparation for data analysis began with inputting into the Excel sheet the initial codes which were derived from the dimensions and factors of my preliminary model of ILE implementation in Malaysian primary schools. There were two parts of the model, namely (a) the stages of ILE implementation: non-implementation, early implementation and implementation; and, (b) the factors affecting the implementation of ILE.

Based on the first part of the model, I prepared a sheet consisting of the profiles of each of the participants and key informants, namely, their position, research site, level of implementation, gender, years of experience as a teacher and as a school administrator. Then, the next sheet of the initial coding was based on the second part of the model, namely the characteristics of change, programme implementers, Implementing Organisation (School), Ecological Context, and Implementation Protocols.

After the process of familiarisation and identification of important terms or phrases, I separated the terms or phrases into two columns. One column was dedicated to terms or phrases in the Malay language identified in the transcripts, and another column was the English translation of the terms or 
phrases.

Next, after separating the terms and phrases into columns, I created two sheets named "initial coding - school participants" and "initial coding - key informants" (Appendix 7). These two sheets consisted of all important terms and phrases identified in the transcripts which were derived from the school participants and key informants at the district, state and ministry levels. The purpose of these two sheets was to visualise the overall terms and phrases identified.

The next stage was to divide the data further according to the stages of implementation as expressed by the participants. I prepared three worksheets: School - Non Implementation; School - Early Implementation; and, School Implementation. For each term and phrase, I assigned possible subcategories. The subcategories were the related terms or phrases that I felt relevant to the participants' viewpoints.

In the final stage, all the concepts and categories were put together. I looked for the differences and similarities between the data. If two pieces of data were found to be contradicting, the data would be further investigated.

\subsubsection{Data displays}

I extracted the information to show the most essential concepts and relationships (see Appendix 8). I got an overall sense of the data, and identified the main points. I distinguished primary or main factors and secondary or subfactors, or essential from non-essential data. Data displays helped me to get immediate access to the data in compact form and to see the flow of the data, and from there I moved to the next step and drew conclusions.

\subsubsection{Conclusion drawing or verifying}

Conclusion drawing or verification is the final analytical activity for the qualitative researcher. This was when I developed understanding of meanings. According to Miles \& Huberman (1994, p.11), at this phase, a researcher 
begins to take note on the "regularities, patterns (differences or similarities), explanations, possible configurations, causal flows, and propositions".

Interpretation took place after data were reduced to the most essential concepts and relationships. I prepared two mind maps to assist throughout this process (see Appendix 9). Through interpretation, I tried to identify the core meaning of the data, remaining faithful to the perspectives of the study of case study schools' participants and key informants, but with wider social and theoretical relevance to the research issue. I also tested the data in the mind maps against the tables and charts prepared for the findings of each case study school and key informant. This step aided me in my cross-case analysis of the data that is discussed in later chapters.

As an overall interpretation of the data, I identified factors that enable or hinder ILE implementation, identified how factors related to each other, explained how research questions were answered, and searched for any meaningful or symbolic content that was beyond the context of the study.

Hence, I repeated this process across the different participants until a state of saturation was achieved where further analysis produced no or minimal changes to the existing concepts or categories. The method of data analysis was very instrumental in the development of an ILE implementation model or framework to answer the research questions.

In this study, I analysed the data manually and also used Microsoft Excel. Excel was chosen because it allowed me to effectively and efficiently create the coding, linking and searching.

The findings arising from the data are presented as a number of factors that were linked together and that collectively analysed the research problem. Then, the current study was situated within prior research, and compared and contrasted with issues raised in the literature. Based on the analysis and synthesis process, I was able to come up with several conclusions, implications and various theoretical, practical and research-related recommendations. 
Appendix 10 illustrates the logical flow of this research from the research questions to the contributions.

\subsection{Issues related to the research}

\subsubsection{Ethical Considerations}

I received ethical approval from Victoria University of Wellington, School of Information Management, Human Ethics Committee, and conformed to the University's Human Ethics Policy (see Appendix 1). I also met the requirements of the Economic Planning Unit of the Prime Minister's Department of the Malaysian Federal Government and the MOE before undertaking fieldwork. The ethical requirements were presented in the information sheet and consent form to the participants prior to any engagement in the research (refer Appendix 2 and 3).

\subsubsection{Trustworthiness}

To ensure the trustworthiness of this research, I address the issues of validity and reliability. Creswell (2009, p.190) states that reliability is the degree of consistency that an instrument or data collection procedure demonstrates, while validity is the quality of data collection procedure that enables it to measure what it is intended to measure. The issues of validity and reliability in qualitative research correspond to the criteria of truthfulness - credibility to internal validity, transferability to external validity, dependability to reliability, and confirmability to objectivity (Denzin \& Lincoln, 2000, p.13) as highlighted in Table 4.3.

\begin{tabular}{cc}
\hline Quantitative & Qualitative \\
(Validity and Reliability) & (Trustworthiness) \\
\hline Internal validity & Credibility \\
External validity & Transferability \\
Reliability & Dependability \\
Objectivity & Confirmability \\
\hline
\end{tabular}

Table 4.3. Criteria of truthfulness (adapted from Denzin \& Lincoln, 2000, p.13) 


\subsubsection{Credibility}

To achieve credibility or internal validity, I carefully recorded and analysed all of the data and accurately explain what happened (refer section 4.7). Creswell (2009) highlights several strategies to tackle the issues of credibility in qualitative study including triangulation, follow-up interviews, member checking and clarification of bias. In this study, triangulation was used as mentioned in section 4.6.2.

\subsubsection{Dependability}

Dependability refers to the extent to which the data and interpretation are reliable and consistent (Cohen, Manion, \& Morrison, 2000). To ensure dependability, I provided a rich description of the participants in the study, the context of the study and also the steps that were taken to carry out the study. For example, I followed the research sample framework to ensure the representativeness of the sample. I also used an interview protocol to guide and enhance consistency in each interview session. This was also to ensure quality control in the research.

\subsubsection{Generalisability}

As the sample population was small in this study and the amount of control by me was minimal, statistical measures could not be used to achieve generalisability. Generalisation from the setting to a population was not sought. However, Yin (2009) argues that qualitative researchers can arrive at analytic generalisations. I have attempted to achieve this by relating the findings to theory in related previous studies. Hence, with the in-depth understanding of ILE implementation in Malaysian primary schools, the findings can be used to inform other settings.

Moreover, according to Creswell (2009), the value of qualitative research lies in the particular description and perspectives developed in the context of a specific site. Thus, 'particularity rather than generalisability is the hallmark of qualitative research' and also in-depth, authentic insights and lived experience (Creswell, 2009, p.193). 


\subsubsection{Language}

Because some of the data were collected in the Malay language but the study is presented in English, meaning equivalence in the translation process is an issue. I conducted the interviews in either Malay or English, according to the wishes of the participants. Due to the use of the Malay language in this research, the quality and validity of the translations of the interview were dependent on me, researcher-cum-translator.

Since Malay is my native language, I translated and interpreted the meaning and views of interviewees into English first from the original transcript. Then, I rechecked the grammar and sentence constructions with an English native speaker in order to reduce a risk of misinterpretation. This would ensure grammatical accuracy, but still a risk of loss of meaning in translation. This effort was intended to minimize the meaning equivalence issue of translation.

\subsection{Chapter Summary}

In conclusion, in this chapter I identified the use of the interpretive paradigm for my research which was conducted using qualitative methods within a case study research approach. The data were collected using semi-structured individual interviews and document analysis. Finally, considerations relating to data analysis have been identified along with the ethical issues related to qualitative research. 


\section{CHAPTER 5 Setting of Case Study Schools and Interviewee Profiles}

\subsection{Introduction}

This chapter sets the scene for the case studies. It begins with a discussion of the background information about Malaysia along with detail relating to the significant educational transformation in Malaysia. This is to provide a picture of the setting of the schools. Next, this chapter profiles the interviewees involved in the interviews. These interviewees also work and live within the neighbourhood of the case study schools, that is, the research site. The information presented derives from the various resources from the case study schools and individuals' interviews, printed and online resources. This information about the setting and profiles will assist the understanding of the development of ILE in Malaysian primary schools. The chapter concludes by considering processes and challenges that I experienced prior to and during the fieldwork.

\subsection{Malaysia: An overview}

The following section provides an overview of Malaysia which includes the history, socio-political and economic context.

\subsubsection{Malaysia - the country profile}

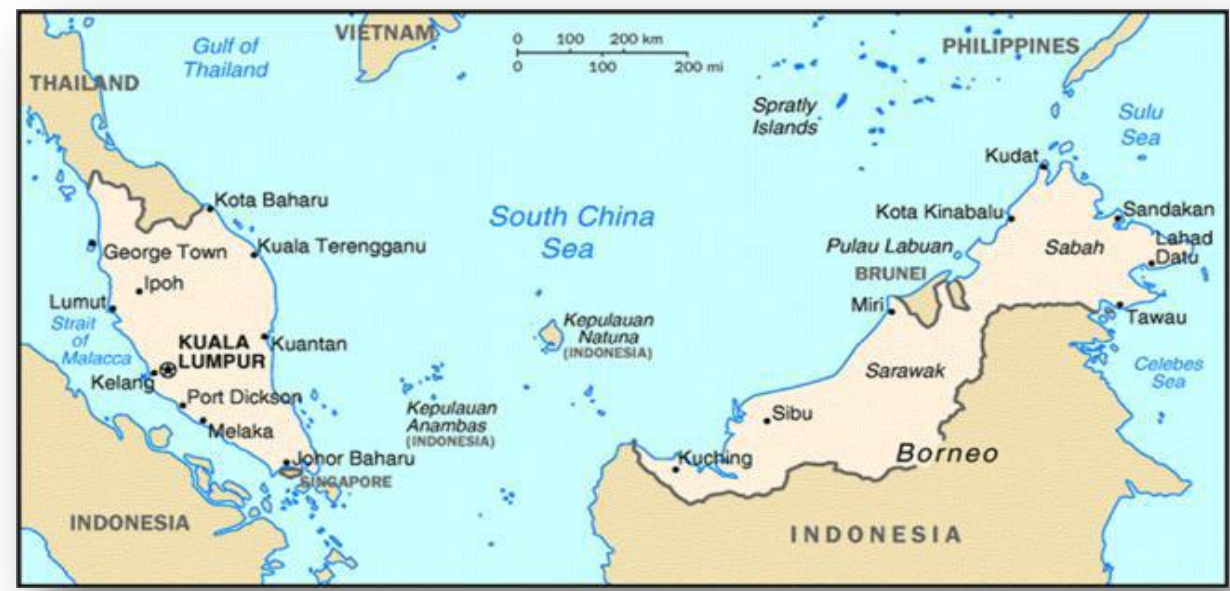

Figure 5.1. Malaysia - East and West Malaysia (EPU, 2009) 


\subsubsection{History}

Historically, Peninsular Malaysia has been populated mainly by the Malays (Khoo, 2011; Hashim, 2004). It consisted of nine states which were ruled by Malay Sultans (Rulers). In the $14^{\text {th }}$ century, the Malay Peninsula served as a trading place for the Chinese, Indian and Arabs traders (Hashim, 2004). This was when a rich diversity of cultures, languages, religions, and politics flourished in the society.

In the $19^{\text {th }}$ century, Malaya became a British colony (Khoo, 2011; Hashim, 2004). During the British colonial rule, the Chinese and Indian immigrants were brought into the country for economic purposes (Hashim, 2004). The British brought the Chinese indentured labourers to Malaya in 1850s to work in the tin mines, and brought the Indian indentured labourers in 1870 s to work in the rubber estates. These and subsequent economic migrations formed the bases of multi-ethnic and multi-cultural Malaysian society.

Malaya became an independent country in 1957, established as parliamentary democracy (Khoo, 2011; Hashim, 2004). Malaya as an independent country consisted of a federal government and 13 state governments. The Malay Sultans of the former Malay states continue their traditional role, the constitutional head of the federation is the King, rotated every 5 years among the Malay Sultans. Islam is the official religion of the country. However, the Constitution guarantees religious freedom of other faiths (Hashim, 2004). Thus, the unique feature about Malaysia is that while aspiring to be a developed and information rich society, its rich cultural heritage has been well preserved and conserved.

\subsubsection{Socio-Political and Economic Context}

Malaysia is a pluralist and collectivist society. In 2009, Malaysia's population was about 28 million people with a racial composition of $67 \%$ Malays and other Bumiputra (son of soil), 25\% Chinese, $7 \%$ Indians, and $1 \%$ others (EPU, 2009). The Malay language (known as Bahasa Melayu) is the official language. English is the second language and widely used in business transactions. The other major languages are Mandarin, Tamil, and other Chinese dialects. 
Politically, Malaysia is a democratic system, ruled by a coalition government under the banner of the National Front which is comprised of various political parties representing the three major races in the country (CIA, 2014). In this kind of collectivistic society, the interests of the individual are subordinate to the larger interests of the society (Raman \& Yap, 1996; Abdullah \& Pedersen, 2003). The government is strongly involved in the formulation and implementation of social, political, economic, industrial, and technological policies.

Economically, Malaysia is fast becoming industrialised ${ }^{1}$. Malaysia is also considered as an upper middle-income country with a record of strong economic performance and poverty reduction (Asian Development Bank, 2010). Like many other countries which gained independence from colonial power, Malaysia chose central planning and a plan-directed approach to economic policies and development. The planning approach was a five year one. The Ninth Malaysia Five-Year plan (known as Ninth Malaysia Plan 20062010) came to an end in 2010. In this plan, the country's target was to reduce the poverty rate to $2.8 \%$ by 2010 . However, this target may not have been achieved due to the gross domestic product contracting by $1.7 \%$ as a result of the downturn in world economic activity in 2009 and the country's dependence on world trade (Asian Development Bank, 2010).

The Tenth Malaysia Plan (10MP) was launched in 2010. According to the Prime Minister's Department, the 10MP was structured on a new economic model, based on innovation, creativity, and high value-added activities. The target is to achieve a high income and developed country in 10 years' time (Asian Development Bank, 2010).

\footnotetext{
${ }^{1}$ Malaysia is a newly industrialised country (NIC). According to Singal and Wokutch (2014), NICs are developing countries that have achieved higher standard of living and closed the gap in living standards between themselves and the developed countries such as US, Japan and Western Europe. Examples of NICs are Turkey, Thailand, Malaysia, Mexico, Brazil, Argentina, South Africa and India. Compared to poor developing countries such as Laos and Cambodia, NICs have better nutrition, health and education because industrialization led to increased trade and economy that could facilitate living condition.
} 


\subsection{Education System}

Malaysia inherited her national education system from the British (Bapoo Hashim, 2009; Hashim, 2004). The Malay language is the main medium of instruction, and English is taught as a second language. The Malaysian Government has long recognised the importance of education to national development. After 53 years of independence, the education system in this country has experienced many changes in its effort to ensure the students receive the best education. The transformation has involved the introduction of a curriculum that is geared to the development of the country (Bapoo Hashim, 2009). This is evident from the steady increase of funds allocated to the education sector (International Monetary Fund, 2005). For example, the Malaysian government spent 15,323 (in millions of ringgit) in 1999 on the education sector, and the amount increased to 29,418 (millions of ringgit) in 2002. In 2012, the education budget was 37 billion ringgit that is, $16 \%$ of total government spending (MOE, 2012). It was about 5 to 8 percent of gross domestic product (GDP). The result of this investment is a more educated human resource.

\subsubsection{Administration and Management}

The Ministry of Education (MOE) is organised into four levels of administration: (a) federal; (b) state; (c) district; and (d) school (see Figure 5.2) (MOE, 2004). At the federal level of administration, the MOE translates the policies of national education into plans, programmes and activities in line with national objectives. At this level also, the guidelines for the implementation of educational programmes are set. The Curriculum Development Division (CDD) is responsible for the design and development of the Malaysian school curriculum from pre-school to upper secondary school. The functions of the CDD are all matters regarding plans, formulation, development, execution and coordination of the national education curriculum including the preparation and production of teaching and learning materials. 


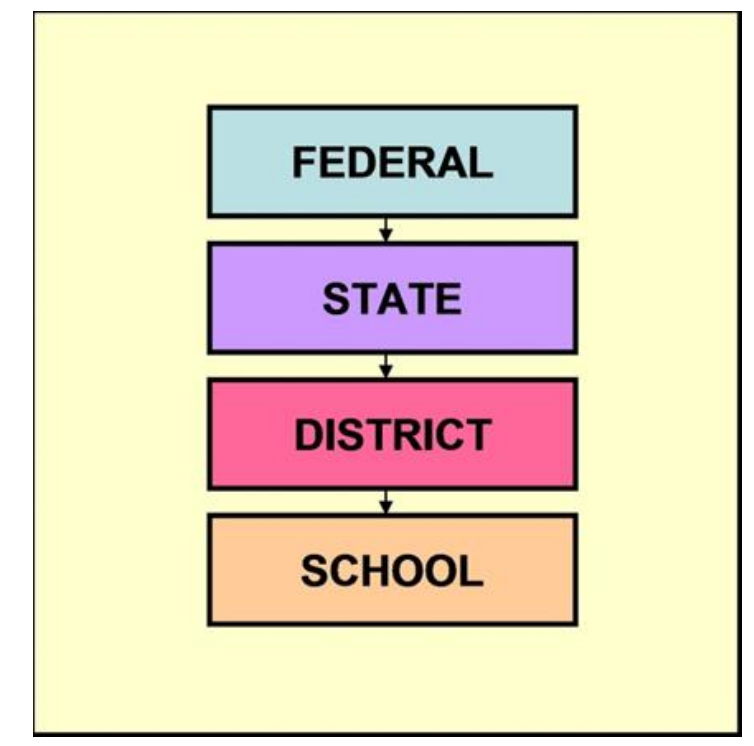

Figure 5.2. Management structure of the Malaysian education system (MOE, 2004, p.5)

The implementation of educational policies and plans made at the federal level is carried out at the state level through the fourteen State Education Departments (SEDs). The State Education Department is headed by a Director who is responsible for the implementation of education programmes and activities in the state. The main functions of the department are: (a) to organise and coordinate the administration of schools in the state in terms of staff and personnel configuration, finance and physical set-up; (b) to supervise educational programmes; (c) to formulate and implement educational plans; (d) to provide regular feedback and communication to the Ministry, where necessary, on the implementation of the National Education Policy.

At the district level, there are additional administrative units. The District Education Office (DEO) is an extension of the SED and forms the link between the school and the Department. It assists the SED in supervising the implementation of educational programmes, projects and activities in the schools of the district.

At school level, the primary school is headed by a school head and the secondary school is headed by a principal. The school heads and the principals are responsible for providing professional and administrative leadership in schools. Moreover, every government aided primary and secondary school as 
well as some government owned primary and secondary schools have a Board of Managers (BoM). In addition, there is a Parent-Teacher Association (PTA) in every school. Thus, the BoMs and PTAs provide assistance in the management of schools and become the link between the school and the community.

\subsubsection{Educational Process}

Malaysian education is structured into four distinct levels: (a) pre-school education (kindergarten); (b) primary education; (c) secondary education; (d) higher education (UNESCO-IBE, 2006/2007) (see Figure 5.3).

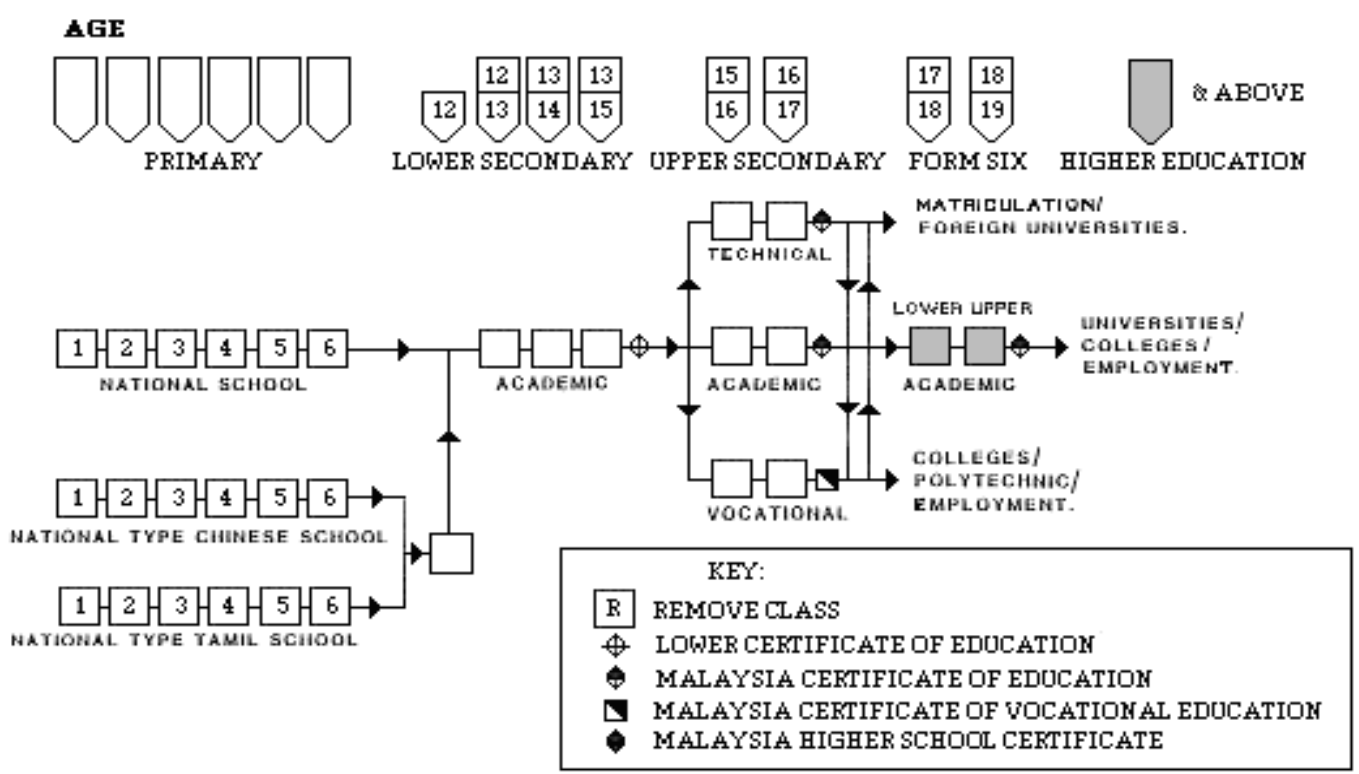

Figure 5.3. Structure and organisation of the Malaysian education (UNESCO-IBE, 2010/2011, p.7)

The schooling process starts at the pre-school level (better known as Early Childhood Care (ECE)) which targets children from 0-6 years of age. This ECE programme is provided by the government agencies, private and voluntary bodies, but it has to be registered to the MOE.

The primary school level covers a period of six years, but it can be completed within five to seven years. The enrolment age is 6 . This level is divided into two phases: (a) Phase 1 (Year 1 - 3); and (b) Phase 2 (Year $4-6$ ). The primary 
school has two types: national and national-type schools. National schools use the Malay language as a medium of instruction, while national-type schools use Mandarin and Tamil as their medium of instructions. The pupils of all these schools sit for a common public examination, that is, the Primary School Assessment Test (UPSR). These schools are free and attendance is compulsory.

So, at the primary school level, the students spend six years, followed by the secondary and upper six high schools for six more years. At the tertiary level, the school leavers spend about one to six years depending on the choice of discipline. The Malaysian education system is an exam-oriented system. At every level of primary, lower secondary, upper secondary and pre-university, the students need to sit for national examination.

\subsubsection{Education Developments}

According to Hashim (2004, p.156), the Malaysian education philosophy has evolved in three stages, as follows:

(a) Colonial (or pre-Independence) period,

(b) From Independence to the Cabinet Committee Report of 1979,

(c) Post-1979 developments.

Each stage has had its own aims, contents and methods. Darus (2009), in her account of English language in Malaysia, reports that during the colonial period, the mediums of instruction for the primary schools were Malay, English, Mandarin and Tamil. Malay was used in the national school, whereas English, Mandarin and Tamil were used in the national-type schools. The secondary schools were either English or Malay. But tertiary education used mainly English as a medium of instruction. The schools were geographically separated, and so were the ethnic groups. The Malays lived in villages (rural and remote areas). The Chinese lived in the urban areas. The Indians stayed in the rubber estates.

Darus (2009) further said that the English medium schools were located in urban areas and thus, the ethnic Chinese benefitted from the English medium 
schools as well as other ethnic groups such as Indian and Eurasians. The Malays seldom attended the English schools because of their location (Darus, 2009) and the parents feared that their children were 'alienated from their own society' (Hashim, 2004, p.46). Hashim also added that the British model of education during the colonial period left a deep imprint into the later educational policy development in the country, i.e. secularisation and modernisation.

After Independence, English was still the medium of instruction in urban schools, even though in 1967, the Malay language was declared the national language (Darus, 2009). However, a severe racial riot of $13^{\text {th }}$ May, 1969 was the catalyst for the conversion process of English to Malay language medium at national schools, followed by the secondary schools and completed in 1981 (Hashim, 2004, p.76). The Malaysian education system was then customized towards the development needs of the country to conform to the multi-ethnic, multi-cultural and multi-religious society. Most importantly it promulgated the idea of unity and integration among Malaysian citizens (Hashim, 2004).

However, after Independence, the structure of the curriculum was weighted towards science, mathematics and technology-oriented courses to meet the demand for scientific and technical manpower. The school curriculum was thought to emphasise "too much rote-learning, to be too examination-oriented and excessively dependent on textbooks (Lee, 1993),).

It was at the third stage (i.e. Post-1979 development) that Malaysian education transformed to balance attention between affective and cognitive development, and moral or ethical considerations. Moral and spiritual values were recognised as important aspects of a holistic human development. The Cabinet Committee Report of 1979 set new directions and dimensions for national education. As a result, the New Primary School Curriculum (ICPS or often referred to as KBSR in local acronyms) was implemented in 1983. It was followed by the Integrated Secondary School Curriculum (ISSC) in 1989 (Hashim, 2004). 
The ICPS was used until 2010 and it was replaced by the Standard Curriculum for Primary Schools (KSSR) in 2011 (refer section 4.3.2.2(b) on KSSR). The ICPS goal was "to help each pupil attain an overall and balanced development in the physical, spiritual, intellectual, social, emotional and moral domains" (MOE, 1990, p.18). Its specific objectives can be grouped into three basic considerations, namely, communicative, man and his environment, and individual self-development (shown in Table 5.1). The underlying philosophy of ICPS is a "child-centred curriculum" which recognises the importance of individual differences, individual achievement, and emphasises the overall development of the child (Azizah, 1987, cited in Lee, 1999, p.90). An offshoot of this was the introduction of Moral Education for the non-Muslim students (Hashim, 2004).

ICPS emphasised the acquisition of basic skills and knowledge through the use of a variety of instructional materials, and a variety of student group work. It also provided remedial and enrichment programs to cater for the different ability of the students, and practices continual assessment of the student's progress. The ICPS was implemented progressively from 1983 to 1988. 
Table 5.1. Educational Components of Malaysian Education for ICPS and ISSC (sources from Hashim, 2004)

\begin{tabular}{|c|c|c|}
\hline ICPS & $\begin{array}{c}\text { Lower Secondary } \\
\text { (ISSC) }\end{array}$ & $\begin{array}{c}\text { Upper Secondary } \\
\text { (ISSC) }\end{array}$ \\
\hline \multirow{6}{*}{$\begin{array}{l}\text { Basic Communicative } \\
\text { Skills } \\
\text { (languages and } \\
\text { mathematics) }\end{array}$} & Core & Core \\
\hline & Malay Language & Malay Language \\
\hline & English Language & English Language \\
\hline & Islamic/ Moral & Islamic/ Moral \\
\hline & Education & Education \\
\hline & Mathematics & Mathematics \\
\hline \multirow{5}{*}{$\begin{array}{l}\text { Man and the } \\
\text { Environment } \\
\text { (Science and social } \\
\text { studies) }\end{array}$} & Science & Science \\
\hline & History & History \\
\hline & Geography & Geography \\
\hline & Physical \& Health & Physical \& Health \\
\hline & Education & Education \\
\hline \multirow{4}{*}{$\begin{array}{l}\text { Self-development } \\
\text { (Arts, music and } \\
\text { physical education) }\end{array}$} & Art Education & \\
\hline & Living Skills & Additional \\
\hline & & Chinese Language \\
\hline & & Tamil Language \\
\hline Islamic/ Moral & & Communicative Arabic \\
\hline \multicolumn{3}{|l|}{ Education } \\
\hline & Additional & Elective \\
\hline & Chinese Language & Humanities \\
\hline & Tamil Language & Vocational/ Technical \\
\hline & & Science \\
\hline & & Islamic Studies \\
\hline
\end{tabular}

In 1989, the Integrated Secondary School Curriculum (ISSC, referred to as KBSM in the local acronym) was introduced as a continuation from the graduation of the first batch of the new primary school curriculum (Hashim, 2004). 
Another significant move post-1979 development was the formulation of the National Education Philosophy in 1987. This move was considered timely, and was the first time the country's education philosophy was made explicit by the MOE (see Malaysia. Ministry of Education. Educational Planning and Research Division, 1990):

Education in Malaysia is an on-going effort towards further developing the potential of individuals in a holistic and integrated manner, so as to produce individuals who are intellectually, spiritually, emotionally and physically balanced and harmonious, based on a firm belief in and devotion to God. Such an effort is designed to produce Malaysian citizens who are knowledgeable and competent, who possess high moral standards, and who are responsible and capable of achieving a high level of personal well-being as well as being able to contribute to the harmony and betterment of the society and the nation at large.

The philosophy grew out of the government's commitment to the 'nation's economic plans and political moods' during that time (Hashim, 2004, p.159). It is very clear that the nation's education system aims at producing a good Malaysian citizen who believes in God, is knowledgeable and competent, possesses high morality, is responsible to the self, society, and nation, and makes a contribution to the society and nation. The philosophy can be universally applied as it aims to produce good citizenry.

However, the phrase 'based on a firm belief in and devotion to God' should be made clear (Hashim, 2004). It refers not only to the monotheistic God of the Muslim, but is also applicable to other religions as well. The only difference is the concept of God held by individual religions. Thus, as Malaysia is a multireligious society, it is appropriate for its education philosophy to have moral instruction based on religious values. There are sixteen core values that have been agreed upon by the different religious communities, integrated into the curriculum (see MOE. Educational Planning and Research Division, 1990). 
The following is an overview of related curriculum reforms that contribute to IL in Malaysian primary schools.

\subsubsection{Curriculum Reforms}

\section{a) Malaysian Smart Schools}

In February 1997, the MOE launched the Smart School project in order to prepare students for the information age. There were 85 smart schools set up in January 1999. All schools were to be converted to smart schools by the year 2010 (MOE, 1997). The idea of smart schools is to have teaching and learning processes enhanced by the use of extensive multimedia technology.

The educational approach promoted in the Malaysian Smart School Conceptual Blueprint (1997) shows a strong influence from Perkins's (1995) conception of a 'smart school'. Perkins's idea of a smart school employs educational approaches informed by cognitive science, and responds to the need for deep learning. Perkins's discussion of pedagogy of understanding has been placed explicitly in the Malaysian Smart School Blueprint (1997) which aims to infuse the elements of knowledge such as 'content knowledge, problem solving knowledge, epistemic knowledge, and inquiry knowledge' in the curriculum in an integrated manner (p.31).

Thus, to guide the teachers to integrate the new reform ideas into the classrooms, several official guides have been published and distributed to all schools (see CDC, 2001a, 2001b, 2002). For example, official guidance advocated for the constructivist practice, mastery learning, science process skill, thinking skill and meta-cognition (Eng \& Ruthven, 2010).

The new reform ideas come with officially new recommended practice (constructivist approach). The teachers have to modify their teaching practices. The smart schools continue to use the same curriculum as the mainstream schools or 'smart schools to be', and to prepare the students for the same public examination. This creates another dilemma for the teachers because they are confused as how to implement the new practice in the classroom. 
- ILE in Malaysian schools

The Malaysia Smart School Project (MSSP) stresses the integration of information and communication technology (ICT) into education as an enabler of creative teaching and learning processes, and a means to enhance the efficiency, effectiveness and productivity of management in education (Multimedia Development Corporation, 2005).

ICT is depicted as having the capability of 'bringing the world into the classrooms, providing access to quality teaching and learning materials to the areas not reachable by conventional means, and ultimately improve IL' (Hassan, 2009). According to the MOE (1997), ICT literacy skills are a prerequisite. Thus, the MSSP aspires to equip students with the necessary learning and thinking skills through the use of ICT and information resources in the classrooms, in the library or media centre, and in any other school facilities.

As pointed out by Chan (2002) (a senior officer of MOE), 'it is critical that school librarians, teacher librarians, or media coordinators, as important stakeholders in the Malaysian Smart School [Project], help promote the Smart Schools as a vehicle for the realisation of the goals of IL in schools'. However, since IL has yet to become an integral part of the school curricula, the development and implementation of ILE seems to be very slow in Malaysian schools.

\section{b) Standard Curriculum for Primary Schools (locally known as Kurikulum Standard Sekolah Rendah (KSSR))}

As part of the Tenth Malaysian Plan (2011-2015) and the Government Transformation Programme, the national primary school curriculum was subject to evaluation and improvement. In October 2010, MOE issued a circular on the implementation of KSSR which replaces ICPS in stages starting with Year 1 students in all primary schools in 2011 (MOE, 2010). 
Concurrently, a new assessment system known as the National Education Assessment System (NEAS) is being introduced. The NEAS is set up in order to minimise the focus on public examinations, to improve students' learning, to create holistic and continuous assessment, to develop better human capital and to strengthen school based assessment (Malaysian Examination Board, 2011). In KSSR, changes can be seen in the aspect of key areas, curriculum documentation, design, organisation, content, elements and focus. Table 5.2 lays out the changes of key areas KSSR from ICPS.

\begin{tabular}{|c|c|}
\hline KSSR & ICPS (KBSR) \\
\hline $\begin{array}{l}\text { Curriculum design is based on } 6 \text { areas: } \\
\text { - Communication } \\
\text { - Spiritual, Attitude and Values } \\
\text { - Humanitarian } \\
\text { - Physical and Aesthetical Development } \\
\text { - Science and Technology }\end{array}$ & $\begin{array}{l}\text { Curriculum design is based on } 3 \text { areas: } \\
\text { - Communication } \\
\text { - Man and his environment } \\
\text { - Self-development of the individual }\end{array}$ \\
\hline $\begin{array}{l}\text { Curriculum Materials } \\
\text { - Curriculum Standard documents }\end{array}$ & $\begin{array}{l}\text { Curriculum Materials } \\
\text { • Study syllabus }\end{array}$ \\
\hline $\begin{array}{l}\text { Design of the Curriculum: } \\
\text { - Modular }\end{array}$ & $\begin{array}{l}\text { Design of the Curriculum: } \\
\text { - Linear }\end{array}$ \\
\hline $\begin{array}{l}\text { Organisation of the Curriculum: } \\
\text { Level I (Year 1, } 2 \& 3 \text { ) } \\
\text { - Basic Core Modules, Thematic Core } \\
\text { Modules and Elective Modules }\end{array}$ & $\begin{array}{l}\text { Organisation of the Curriculum: } \\
\text { Level I (Year } 1,2 \& 3 \text { ) } \\
\text { - Core, compulsory and additional subjects }\end{array}$ \\
\hline $\begin{array}{l}\text { Level II (Year 4, } 5 \text { \& 6) } \\
\text { - Core and Elective Subjects }\end{array}$ & $\begin{array}{l}\text { Level II (Year } 4,5 \& 6 \text { ) } \\
\text { - Core, Compulsory and Additional subjects }\end{array}$ \\
\hline $\begin{array}{l}\text { The elements of creativity and Innovation, } \\
\text { entrepreneurial, information technology and } \\
\text { communication }\end{array}$ & $\begin{array}{l}\text { Elements of Analytical and creative thinking } \\
\text { skills }\end{array}$ \\
\hline $\begin{array}{l}\text { Focus: } \\
\text { 4M (Reading, Writing, Counting and } \\
\text { Reasoning) }\end{array}$ & $\begin{array}{l}\text { Focus: } \\
\text { 3M (Reading, Writing and Counting) }\end{array}$ \\
\hline
\end{tabular}

Table 5.2. Key areas of KSSR (MOE, 2012)

In Table 5.2, it can see that a new word "standard" is introduced. Thus, KSSR consists of a set of standards of learning. KSSR is designed to go beyond communication skills and self-development. It is enhanced with understanding 
of humanitarian issues and aesthetical development. KSSR has 4Ms with "reasoning" added to the original 3Ms. There is a need for the students to learn to think and reason, making connections between prior and new knowledge in their problem solving and decision making, which is the description of information literate students.

The MOE has undertaken training to expose primary school teachers with the relevant pedagogical knowledge to successfully and meaningfully impart the newly improved curricula content, apply the required skills and instil the expected values inherent in the KSSR. KSSR is seen as a progressive and constructive initiative by MOE to address the weaknesses of ICPS and thus, prepare the future generations to the needs and challenges of the $21^{\text {st }}$ century (MOE, 2012).

\section{c) Other plans and policies}

The following are other related policies to reform society through education (see Malaysia, MOE, Interim Strategic Plan 2011-2020, 2012). The policies have been introduced to improve the existing social conditions and to strengthen education in the $21^{\text {st }}$ century. Among the policies are:

- In terms of the type of school, the MOE has introduced the High Performance Schools type to enhance schools' performance through autonomy and accountability levels by allowing schools to implement innovation in their administration with central curriculum and personnel.

- In terms of assessment, the MOE has introduced school-based assessment which focuses on all aspects of students' academic and nonacademic performance compared to the former assessment which was more focused on academic achievement through examination. This assessment assesses the processes and products in the formative and summative assessment for learning over the academic achievement of students at the end of their study. 
- In terms of professionalism, the MOE has introduced in-service training, in-school training and continuing education.

All these policies are vital components to support ILE implementation in schools.

\subsection{Research Setting}

\subsubsection{The state context: Perak}

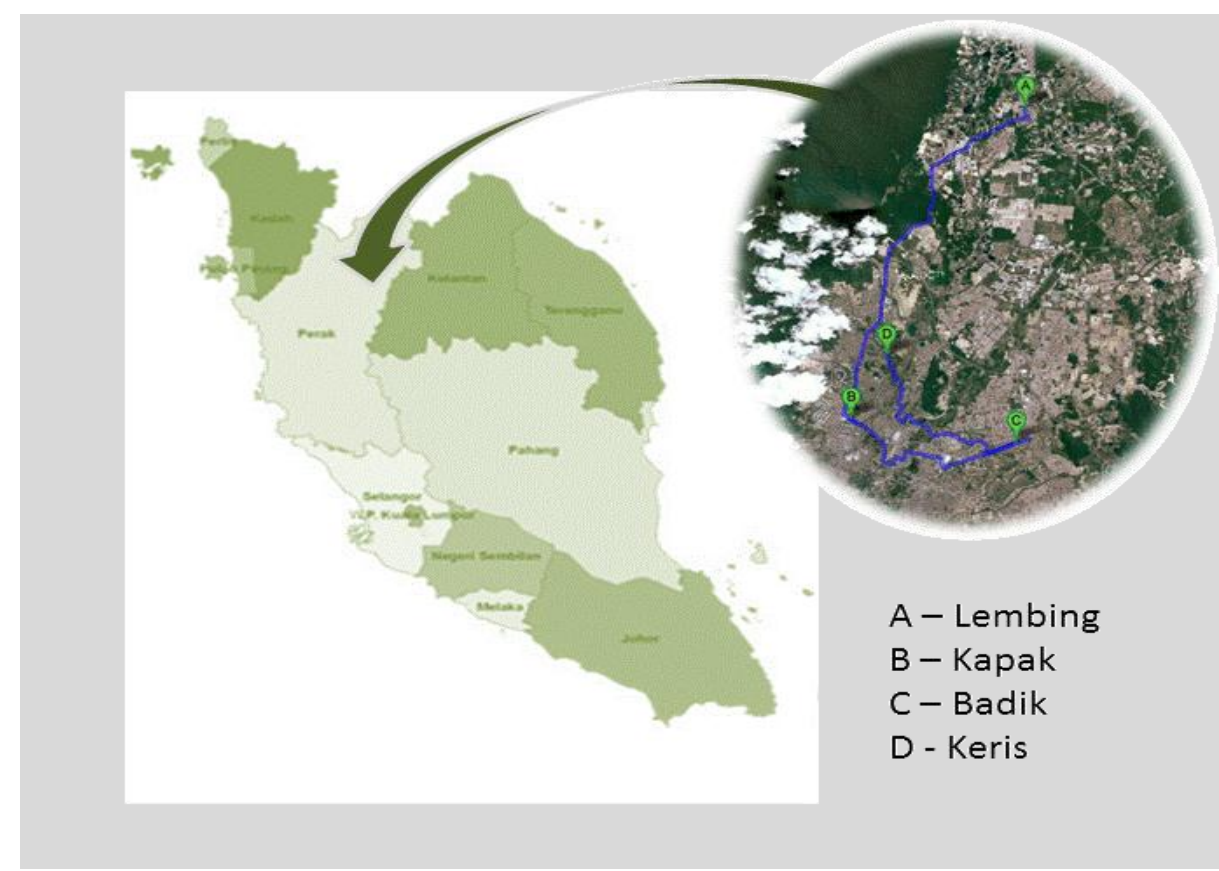

Figure 5.4. The state of Perak and the geographical location of the case study schools (Department of Statistics, c2011; Google Map).

Perak is the second largest state in Peninsular Malaysia with an area of 21,005 sq. km (see Figure 5.4). It covers an area of $6.4 \%$ of the total area of Malaysia and has hot and humid weather throughout the year. It is divided into 10 districts, which include rural areas and significant urban centres (Economic Planning Unit of Perak, 2007). The Sultan of Perak is the Head of the State Constitution. The Chief Minister is appointed by the Sultan and holds executive power (Perak online, 2011). 
In terms of education, as of 30th June 2013, Perak has 852 primary schools and 242 secondary schools. The total enrolment is 216,231 for primary schools and 212,619 for secondary schools (MOE, January 2013). The teacher population is 21,698 for primary schools and 17,915 for secondary schools. The ratio of student enrolment and teacher population for primary schools is about 1:10 and for secondary is about 1:12. Perak also has 45 institutes of higher education including public universities, private universities, technical and vocational institutes, community colleges and polytechnics.

\subsubsection{The district context: Kinta North}

Kinta is one of the districts in Perak and is the most congested area. As of 2007, the population was about 819,600 (Economic Planning Unit of Perak, 2007). The majority of the population lives in the upper part of Kinta, known as Kinta North, in the capital of Perak, Ipoh.

Historically, this area became well-known to many when tin was discovered in this area at the beginning of the $19^{\text {th }}$ century. This attracted many Chinese to immigrate to Malaya, especially the district of Larut, and then the Kinta valley. The tin mining industry was the major economic activity and attracted many to work and live in Perak (Teachers' Activity Centre of Sungai Pari, 2010).

As of $30^{\text {th }}$ April 2014, Kinta district has 177 primary schools and 66 secondary schools (MOE, 2014). In the Kinta North district, there are 112 primary schools, namely 63 national schools, 35 Chinese national-type schools and 14 Indian national-type schools.

\subsection{The case study schools}

The following section provides the background information, geographical location, students and teacher population at the time of the data gathering, and infrastructure details of each of the case study schools. Each school is named after a traditional weapon that can be found in many Malaysian households. 


\subsubsection{Keris}

The first case study school that I went to is a national school which I refer to as Keris. A keris is a traditional type of dagger. The medium of instruction at Keris is the Malay language. Keris is situated in a rural area and is a coeducational school. It operates in two sessions, morning and afternoon. At the time of the data gathering in this research (i.e., 2011), the enrolment is 830 students, that is, 447 male students and 383 female students. It has 48 teachers and seven administrative staff.

Since Keris is a national school, it receives full aid from the Malaysian government. The Government ensures that all national schools receive the same infrastructure, namely computer lab, science lab, library, audio-visual room, school hall, cafeteria with attached kitchen, security post and staffing.

\subsubsection{Badik}

The second case study school, which I refer to as Badik, is also a national school, but situated in an urban area. A badik is a traditional type of dagger. The medium of instruction at Badik was English, but since 1970, there has been a gradual conversion from an English medium primary school to a Malay language medium national school due to the national language policy (see Postiglione \& Tan, 2007; Hashim, 2004). Badik is a missionary girls' school. It operates in two sessions, morning and afternoon. The student enrolment is 880 with 50 teachers (as of 2011). There are five administrative staff.

Since Badik is a missionary school, the funding comes from both the missionary organisation and the Government. This school is considered a government aided school. Therefore, the school receives partial aid from the Government. In terms of its infrastructure, Badik has all the needed facilities and equipment. However, the school finds it difficult to fund essential maintenance and replacement or upgrading of equipment and facilities because of the lack of funds. 


\subsubsection{Lembing}

The third case study school, which I refer to as Lembing, is a national-type school. A Lembing is a Chinese traditional spear. The medium of instruction is Mandarin. Although the school is classified as an urban school, the location of the school is in a small town. The small town is actually the business area which is surrounded by rural communities. It has just one session and is coeducational. The student enrolment is 550, that is, 280 male students and 270 female students (as of 2011). It has 32 teachers who are supported by five administrative staff.

The school was established and funded by the local community and was originally a private school. Later, when it became a public school, it began to receive Government support. The school's hall has become the centre of the neighbourhood's activities. The activities include social activities like wedding ceremonies or book exhibitions, and formal activities such as the launching of new services by the local parliament representative. This is one of the ways the school generates its income to fund school related activities and facilities thus not relying solely on government funding. The school infrastructure is at par with national schools and is well maintained.

\subsubsection{Kapak}

The fourth case study school is another national-type school, which I refer to as Kapak, a traditional Indian axe used to chop through armour. Kapak is a Tamil missionary school so its medium of instruction is Tamil. It is situated in a suburban area, and is a girls-only one session school. The enrolment is about 400 students (as of 2011). There are 21 teachers who are supported by four administrative staff.

Kapak is a government aided school. It provides a similar infrastructure as other schools because of donations from individuals and corporations. The school has a computer lab, science lab, cafeteria with kitchen, security post and a meeting room. 


\subsection{Interviewees' profiles}

There were 20 interviewees involved in the individual interviews. They were the school heads and teachers who teach one of the following subjects in the primary schools: Science, Social Science and Humanities. The selection criteria of the interviewees were discussed in Section 4.5.2. It is necessary to provide the information about the interviewees in order to set the stage for their views towards ILE implementation and their challenges to implement ILE in their teaching and learning activities.

\subsubsection{School Heads}

Three school heads participated as interviewees. One school head chose not to be interviewed because she was very new to the school. The day I went to this school to deliver the invitation and set the appointments with the interviewees was the school head's first day in the school. She was transferred to the case study school because the previous school head had retired. The principal requested the school's Senior Administrative Assistant to replace her for the interview session. The Senior Administrative Assistant had been with the school more than 4 years. She was well-versed regarding the school involvements and achievements.

Each of the four schools had a female school head. All school heads (including the Senior Administrative Assistant) had 17 or more years' experience as a teacher. Three school heads had more than 15 years' experience as a school administrator and only the Senior Administrative Assistant of Keris had less experience (8 years). As school administrators, they also had the responsibility to teach one or two subjects in a week.

In terms of the level of ILE implementation in the case study schools, all school heads, including the Senior Administrative Assistant believed that all their teachers were working towards that. However, individually one school head and the Senior Administrative Assistant indicated that they did not use ILE in their teaching approach. One school head indicated that she is in her early use of the approach. Only one school head indicated that she uses the approach in her teaching and learning. 


\subsubsection{Library and Media Teachers (LMT)}

Four LMTs were interviewed and were all female teachers. In each school, the LMT's office is in the school library, not in the teacher's common room so the LMT is somewhat isolated from the rest of the teachers.

In order to be appointed as a LMT, one has to have experience as a teacher of at least three years and librarianship qualifications. In this study, each of the LMTs had from 3 to 21 years of experience as a teacher. Three LMTs received official appointment as LMT from the State Department of Education and had been in that role for more than six years. They had undergone librarianship training. There was one LMT who held the same position in the same school for about 14 years. She has requested to step down from the position a few times, but the school head persuaded her to stay in her job. Only one LMT did not receive the official appointment letter from the State Department of Education. But she did not participate in librarianship and has been doing the job for three years.

When asked Buluh, a key informant about the LMT appointment, said that the State Department of Education may have either overlooked the official appointment of the new LMT or the school head may have not notified the State Department of his or her newly appointed LMT. The new LMT could not enjoy the incentives such as reduced teaching loads and more time for IL related activities due to the lack of an official written appointment.

\subsubsection{Science Teachers}

Four Science Teachers in the schools were willing to participate in the research: two male and two female teachers.

Three of the science teacher interviewees indicated that they had teaching experience of more than 25 years. The remaining science teacher had seven years of teaching experience, but had working experience as a chemist before deciding to become a teacher. 


\subsubsection{Local Studies Teachers}

The four Local Studies Teachers interviewed were three females and one male. Three had teaching experience of 10 to 17 years, while the other had seven years.

Local Studies is not one of the core subjects in the primary school curriculum. The learning is not subject to evaluation in the national exam. However, this subject puts emphasis on group work, project work or course work. The students are trained in self-directed learning and teamwork.

\subsubsection{Islamic Religious Studies or Language Teachers}

Islamic Religious Studies and Language teachers were also invited to share their views on ILE implementation. Two Religious Studies teachers (two female) and two Language Teachers (one male and one female) were willing to participate. Their teaching experience ranged from 8 to 15 years.

\subsection{Key informants' profiles}

Key informants were the ones who were directly or indirectly involved in the administration, education and training programmes of ILE. The selection of key informants was explained in section 4.5.2.2.

In this study, four key informants participated, one each from the district and state levels, and two from the federal level. The individual interviews with the key informants were conducted after the interview sessions at the school level. The aim was to determine the key informants' support for the schools in terms of ILE.

Three of the key informants were female officers and one was one male officer. Each had from 10 to 22 years of experience as a teacher. Two of them have been in administration for 11 years and 19 years respectively. The other two key informants had five and six years of administrative experience. 


\section{$5.8 \quad$ Fieldwork}

This section describes the processes and challenges of obtaining ministerial permission for the study, and identifying, locating and meeting interviewees and key informants.

\subsubsection{Reaching the interviewees and key informants}

At each school level I met the school heads and informed them in person about the research. The school heads had already provided the teacher interviewees with general information about this research. Teacher interviewees who came to meet me had differing attitudes and understandings, but all of them admitted that they were not familiar with the term IL.

I began each session with the interviewees and key informants explaining the requirements of the research. I explained the interviewees' rights regarding confidentiality and being able to withdraw from the study at any time, and I gained their signed consent. I had to convince them that the research was not to highlight any good or bad points in the individual teaching practices and not for auditing the school or staff performance.

I briefed the interviewees and key informants at the beginning of the meeting. I explained their role as interviewees and key informants and my role as a researcher. I also described my interest in undertaking the research on ILE in primary schools. Since the interviewees at school level were not familiar with the term IL, I used terms such as student centred learning, self-access learning, constructivist learning and inquiry learning to refer to ILE related activities throughout the data gathering process. On the other hand, I used the term IL throughout the individual interviews with the key informants at the district, state and federal levels, after providing the introductory explanation of the research.

\subsubsection{Challenges}

Particular challenges encountered centred on obtaining written approval and locating the interviewees and key informants. 


\subsubsection{Obtaining written approval}

Prior to accessing the research sites, I had to obtain written approval from the Prime Minister's Department and the MOE. It took about three months to obtain the approval from both agencies and several follow-ups were necessary. The next step was to obtain approval from the State Department of Education. It took about 5 working days just to obtain the official letter.

When the official approvals were ready, I proceeded with contacting the school heads to invite them to participate in the study and seeking permission to interview the teachers. The same process applied to the key informants at the district, state and federal levels.

\subsubsection{Locating the interviewees and key informants}

An early challenge was when one school head did not want to participate in the research because she was new to the school. She did not know anything about the school activities and achievements. Fortunately, she requested her Senior Administrative Assistant (deputy of the school head) to participate on her behalf and allowed me to interview her teachers.

Another challenge was to identify key informants. Not all key informants could be identified via online resources. One interviewee was particularly challenging to gain access to because of unexpected health problems. In the end, it took about 6 weeks to arrange the interview.

\subsection{Chapter Summary}

This chapter has described the background of Malaysia, the research setting and the case study schools. This information was followed by the profiles of the interviewees and the key informants. The research was conducted in four case study schools at one of the states in Peninsula Malaysia, namely Perak. The interviewees were the school heads, teachers and library and media teachers. The key informants were identified from the district level up to the federal level. 
In order to reach the interviewees and key informants, there were technical matters and challenges involved such as getting official approval and identifying, locating and meeting interviewees and key informants. In the next chapters, I provide the findings that is, the factors affecting the implementation of ILE in Malaysian primary schools. 


\section{CHAPTER 6 National Schools}

\subsection{Introduction}

In the previous chapter, I discussed the background information of the research setting, specific details of the case study schools, and profiles of the interviewees and key informants. In this chapter, I present the case study findings of ILE implementation in national schools. I will discuss the findings of ILE implementation in national-type schools in Chapter 7, followed by the findings of ILE implementation from the key informants' perspectives in Chapter 8.

In this chapter and in Chapter 7, I begin with a discussion of the stages of ILE implementation of each case study school, namely national schools (Keris and Badik) and national-type schools (Lembing and Kapak), and three levels of education administration (district, state and federal). It is crucial to identify the stage of ILE implementation in each case study school prior to the discussion of factors affecting the ILE implementation, in order to show the variation between the cases. The following categorisation as presented in Figure 3.7 is used to denote the extent to which ILE has been implemented at a particular school:

Level 1: Use Stage of Implementation - School which teaches ILE to the students;

Level 2: Early Use Stage of Implementation - School which is at the preparation phase, that is, at least one teacher or LMT is preparing him or herself for ILE (for example, by attending an in-service course);

Level 3: Non-Use Stage of Implementation - School which does not teach ILE to the students.

Next, I identify the factors that facilitate or impede the implementation of ILE in the case study schools. The factors were identified from the interviewees' responses to the interview questions, which in turn sought to address the two research questions: 
- What are the factors affecting the implementation of ILE in Malaysian primary schools?

- How do these factors facilitate or hinder ILE implementation in Malaysian primary schools?

Quotes from the interviewees' and key informants' interviews are placed throughout this and the following chapters. Extracts from the interviewees' and key informants' documents are also inserted when they assist in providing context. Each chapter concludes with a summary of the factors affecting ILE implementation in each of the case study schools and the three levels of education administration.

\subsection{Keris}

Keris is the first case study of the research.

\subsubsection{Stage of ILE implementation}

The stage of ILE implementation was assessed from the interviews with the Senior Administrative Assistant (SAA) who substituted for the new School Head ${ }^{2}$ (see section 6.4.1), the Science Teacher, Local Studies Teacher, Islamic Religious Studies Teacher (Ustazah) and Library and Media Teacher (LMT).

The interviewees viewed ILE implementation differently. The Science Teacher, Local Studies Teacher and Islamic Religious Studies Teacher ${ }^{3}$ indicated that the implementation of ILE was ' $10 \%$ to $30 \%$ ' of the teaching and learning activities in their classroom. The LMT indicated that the ILE implementation in the school was 'average'. The SAA viewed ILE

\footnotetext{
${ }^{2}$ In Chapters 6, 7 and 8, I have used upper case characters for the initial letters in "School Head", "Science Teacher", etc., because I am referring to a formal position within the schools. In other chapters, I tend to use lower case characters for the initial letters in the term because in general, I refer to a type of position such as a school head or a teacher.

${ }^{3}$ The Islamic Religious Studies Teacher is locally known as Ustazah for a female teacher and Ustaz for a male teacher who teaches Islamic education in all spheres.
} 
implementation in the school was 'not successful'. It seemed that ILE was partially implemented.

The interviewees had attempted to teach ILE to the students when it was first introduced (see section 2.6.2). From the responses discussed below, the complexity of factors affecting ILE implementation indicated Keris to be only at the Early Use Stage of ILE implementation.

When I asked about the stage of ILE implementation, I received a range of responses based on each interviewee's background and subject specialisation. For the Science Teacher, the nature of the syllabus was more hands-on. The students had to prepare the experiments on their own or in groups. The teacher was only guiding them to do the preparation. Therefore, ILE appeared to be implemented in the science lab.

The Local Studies Teacher seemed to have implemented ILE in his teaching because he saw that the approach allowed him to engage with and involve the students in the classroom activities. He saw his role as being 'more towards getting ideas from the students...get to know the students' backgrounds and experiences' (Local Studies Teacher).

The Local Studies Teacher seemed to be approachable and open to students. This was evident from the way students greeted him. He treated his students more as friends rather than as in a formal teacher-student relationship. In fact, according to the SAA, this Local Studies Teacher knew most of his students' houses. He used to 'chase' after his students, if the students took a long absence from his class.

The Ustazah felt that ILE would be much easier to implement in a 'small group of students' and would 'depend on the class'. She viewed ILE as 'not easy to practice' due to her lack of IL knowledge and skills. 
The scenario was different with the LMT. Her implementation of ILE depended on circumstances such as the availability of time and internet access. She commented:

I don't think it [ILE implementation] is $100 \%$, may be about $50 \%$, if I have the time. It depends on the broadband connection. (LMT) Based on her practices in her classrooms, the LMT equated IL with internet.

The SAA had not implemented ILE because of her lack of competency in information and communication technology (ICT) skills. She believed that all her teachers were working towards implementing ILE in their teaching strategies. However, in terms of her own implementation, she said, 'Not at all. Previously, I had tried using the CD-ROM. But I did not know how to operate it. I had to seek help from other teachers' (SAA). Again, another teacher (SAA) equated IL with technology.

Both the LMT and SAA frequently associated the implementation of ILE to the application of the computer and internet in the classroom. This was one of their main reasons for not implementing ILE.

Most Keris interviewees therefore indicated that they were either at the early phase or implemented ILE in their teaching and learning approach, except for one who had not implemented ILE at all. Views on the stage of ILE implementation were wide-ranging from unsuccessful to having carried out ILE in classrooms. In Keris, the responses led to various factors that then were found to have affected the implementation of ILE at school level.

\subsubsection{Factors affecting ILE implementation}

This section discusses the factors impeding or facilitating ILE in relation to the stage of its implementation in Keris. These are discussed according to (a) characteristics of IL; (b) Individual Implementers; (c) Implementing 
Organisation (School); (d) Ecological Context; and (e) Implementation Protocols.

\subsubsection{Characteristics of IL}

As presented in the Figure 3.7 model, the 'characteristics of IL' refers to the interviewees' understanding about needs for ILE, clarity of the IL concept and its goal, and complexity of ILE implementation.

\section{(a) Need for ILE}

Most interviewees thought that IL was an important skill for teachers and students. The interviewees had different views on the importance of IL.

The Science Teacher and Local Studies Teacher shared similar views. They felt that ILE gave students the opportunity to integrate out-of-school knowledge into classroom. The students were able to rebuild their knowledge by exploring and observation. The function of the teacher was to dig and get to know students' prior knowledge and experiences through constant communication and two-way interaction.

The LMT thought that the learning process became more meaningful particularly with the introduction of ICT and multiple resources. She stated:

As a teacher, I feel it [IL] is very important. Information is not only from the teacher as transmitter, the involvement of students is important too. If the teacher teaches the students, the students cannot understand. I don't think it is meaningful. For example today, the use of IT is so important. The teachers should not only use the existing, tangible sources. We should expose them to sources of information in the internet and resource centres. (LMT)

The Ustazah saw ILE as important but had difficulties implementing it in her classroom. She feared that she had 'no control' over her students and was unable to 'complete the syllabus'. On the other hand, the SAA of Keris did not implement ILE in her teaching strategies. She was actually 
'not interested' in the approach and felt 'very disturbed' when the policy was introduced.

Moreover, when asked about their own need for ILE and training, the Science Teacher, LMT and Ustazah, indicated that they were in need of them. However, both the Local Studies Teacher and SAA indicated they did not need training because they were too old and also they lacked interest because of no time.

\section{(b) Clarity}

The interviewees were also asked about their understanding of IL. Responses reflected varied levels of understanding, ranging from very specific to very broad:

- Student-centred or constructivist learning,

- Internet or computer or ICT,

- Use of information and resources,

- Locating or accessing information,

- Generating ideas,

- Inculcating values.

Only two responses referred to terms that are associated with the definition of IL: locating and accessing information, and use of information and resources. The rest of the above could be associated with IL in a broader sense.

Interviewees understood IL as student-centred learning or constructivist learning. They were more familiar with the constructivist or studentcentred approach rather than IL per se. This is due to the fact that the constructivist approach is one of the learning theories, and all interviewees received training in various learning theories during their pre-service courses. On the other hand, IL is a concept which is often associated with the school library or school resource centre management and reading activities in the Malaysian schools. Not surprisingly, only the LMT was familiar with the IL concept. 
All interviewees viewed ILE from the perspective of ICT usage. This was probably due to the Government's Smart School policy at the end of 1990s which led to the introduction of ICT in education. Accordingly, at this time, Keris set up a computer lab and teachers were expected to incorporate the use of ICT in teaching and learning. The teachers were expected to educate the students in order to be able to create, locate, use, evaluate, critique and integrate information. The teachers appeared to be familiar with aspects of IL, but not with the term IL or its underlying theory.

The LMT, Local Studies Teacher and Science Teacher considered that ILE was about the use of information and resources, locating or accessing information, and generating ideas. These terms were commonly associated with IL. The LMT was the one who was exposed more to the IL related activities and concepts due to her job specification. The Local Studies Teacher had attended school resource centre management courses, and so was familiar with school library activities. In addition, as a former chemist, the Science Teacher used to do research which required access to various sources of information. Consequently, he applied his knowledge and skills in the class and lab.

Only the LMT responded that IL was a strategy for inculcating values. Her view was in line with the expectation of the Educational Technology Division (ETD) of the MOE (2006) that the instilling of values and citizenship is to be embedded in the IL teaching and learning activities. However, it seemed that values and citizenship were not commonly known as components to be embedded in activities for teaching IL skills.

\section{(c) Complexity}

The complexity of change implementation was reflected in the amount of new skills, the modification of beliefs and behaviours, the use of different materials and equipment and so on as required by the change. 
The interviewees highlighted their concern about teachers' work attitudes which they associated with an unwillingness to promote IL. For example, one teacher commented:

The teachers themselves.... They have to be motivated. Actually the junior teachers are not committed. They work just for the sake of working. We senior teachers are committed because senior teachers give attention to the students' well-being. If we know well the students background, we know how to teach them...their acceptance.... The junior teachers tend to take the students lightly. (Local Studies Teacher)

The Local Studies Teacher also believed the junior teachers lacked work commitment due to a short period of teaching training, that is, "not even a year long' for a post-degree teacher's course, compared to the seniors who were trained for five years in teachers college. He pointed out the way junior teachers treated the students half-heartedly and gave less attention to students particularly in teaching ILE.

The SAA also expressed the same concern. However, she frankly admitted that as one of the school administrators she was not providing a good example in terms of ILE implementation. She believed she was not technology savvy and 'only a primary school teacher'. She was not approachable to students. In fact, she commented that students were 'ignorant. Teachers have to provide everything to the students'. She seemed to uphold the traditional role of teacher-student relationship.

The Science Teacher was not sure about the extent of his implementation of ILE in the class. He said that his implementation depended on 'the activities, students' level...time, and support materials'. For him, the implementation of ILE was highly contextual.

The complexity factors such as, teachers' attitudes and the extent of implementation, as described by the interviewees, seemed to derive from 
the internal and external environment of the case study school as well as individual factors.

\subsubsection{Individual Implementers}

This factor was investigated in order to identify interviewees' qualifications, competency, commitment and readiness to implement ILE in the school.

\section{(a) Qualification/ Competency}

Interviewees were asked about relevant training courses. None had attended any IL specific training, yet they said they knew about IL related approaches and activities through attending IL related courses during preservice training, and their "early years" as a teacher and LMT.

Not all interviewees had received recent IL training. Among the reasons for the lack of IL training were a lack of interest and age factors. The SAA and Local Studies Teacher responded that:

I do not want to attend any training. (SAA)

If I were in my 40s and still aggressive, I would never avoid attending any courses. But now, I am doing things based on my level best. On top of that, we are not going anywhere. If we are doing things excessively, other persons might be angry with us. (Local Studies Teacher)

Both were reluctant to attend courses and training. The LMT was not officially appointed to the job. When she attended LMT job-related courses, she had no knowledge at all about her job. She only learned from peers:

Actually I learn a lot from other teachers. I never attend any courses on school resource centre... I only attended regular courses, held by Manjoi Teachers' Activity Centre [known locally 
as PKG Manjoi] such as courses related to NILAM data analysis and standardisation of school resource centre. In fact, I attended these courses with zero knowledge. I only learn through other teachers' experiences. I am not officially appointed by the State Education Department or District Education Office. At the moment, I have not received any appointment letter. (LMT)

The Science Teacher, when asked about training opportunities in the school, responded he had attended training in his former school but did not mention anything about his present school where he had been for three years. In addition, the Local Studies Teacher bluntly told me that the teachers in his school were 'lazy to attend courses'. Usually the School Head had to force the teachers to attend courses.

The lack of IL specific training impacted on interviewees' knowledge and skills to implement ILE in the classroom. The following excerpts are related to the interviewees' IL competency:

I am only a primary school teacher. I am not competent using the computer ... handling of resources. (SAA)

...if I myself do not understand anything during the course, how am I going to make other teachers understand... (LMT)

In addition, the Ustazah expressed her change of heart after attending training. As she recalled,

Two to three years ago, I was called to attend an enrichment course on teaching and learning in class. After attending the course, I felt highly motivated... But after a while, I was back to normal way... (Ustazah)

The teachers tended to go back to the teaching practices they were familiar with when they were trained to use new approaches such as IL. 


\section{(b) Commitment}

As mentioned in section 5.2, interviewees described their school's implementation of ILE as $10 \%$ to $30 \%$, or 'average' or 'not successful'. As seen in the following paragraphs, this appears to be related to the teachers using a teacher-centred or didactic approach to teaching and learning.

This finding became apparent when exploring teachers' commitment towards ILE implementation. The following quote provides some insight into the rationale for the teachers' preference for the teacher-centred approach:

They [the students] don't even have any internet at home. My students receive any information that I provide to them. They are ignorant. So everything I have to provide them. To the extent that, their exercise books are not allowed to bring back home. (SAA)

The way interviewees showed their preferences for the teacher-centred approach varied. The Ustazah was concerned about the disciplinary aspect. The SAA maintained the concept of students as passive learners and teachers as 'sages on the stage' (Skinner, 1953, cited in Grassian \& Kaplowitz, 2001). Other interviewees talked about the constraints they experienced such as limited resources and time as well as the school's preference for examinations.

Four interviewees indicated they implemented ILE whenever the syllabus or the students allowed them to. Moreover, most interviewees believed they were able to implement ILE with good students rather than weak students.

Interviewees who chose the teacher-centred approach had more than 15 years of teaching experience and were therefore comfortable with that approach. In contrast, the interviewees who had less than 10 years of teaching experience preferred to use a student-centred approach. In Keris, 
these junior teachers were the university graduates. They were exposed to independent and resource-based learning at the tertiary level.

From further analysis of the interview data, I found another individual factor that hindered the implementation of ILE. The factor was very much related to the readiness of the interviewees.

\section{(c) Readiness}

Most interviewees, when asked about the extent of their implementation of ILE in their classrooms, shared similar views. Their readiness to implement ILE depended on the students' level of achievement and the suitability of syllabus topics. They claimed that ILE could be 'successfully implemented with good-to-excellent students' rather than mediocre students or in 'certain classes'. They also considered that ILE could only be implemented when the syllabus was appropriate.

Furthermore, there were other factors which hindered the readiness of interviewees to implement IL such as lack of funds, lack of time, lack of ILE guides and resources, teachers' attitudes, heavy workloads, lack of technical support, lack of IL knowledge and skills and requirements to meet school or academic targets. These factors were very much related to the lack of administrative and leadership support from the school, district, state and federal levels and will be discussed further in the subsequent section.

\subsubsection{Implementing Organisation (School)}

The organisation's capability influences the quality implementation of a programme (Chen, 2005). A well run programme depends heavily on the proper administration of resources and staff, and coordination of activities. It is, thus, crucial to look into the administrative and leadership factors as well as the goals and climate of Keris. 


\section{(a) Administrative support}

All interviewees expressed their concerns over the lack of resources and equipment to support them in their teaching and learning, service and maintenance of tools and equipment or school facilities, and funds.

The most highlighted issues were damaged computers and broken equipment. Interviewees also raised the need for regular service and maintenance to the existing equipment and facilities in school. The SAA, for example, claimed that the Government 'takes time to replace the damaged equipment'. It seemed that action taken to replace damaged tools in school was slow. From the interviewees' point of view, the lack of maintenance and service was due to insufficient school funds. Most interviewees pointed to the MOE in particular, and Government as a whole for the lack of funding. Although in actual fact, the education sector receives among the highest national fund allocation, the funds seemed to be inadequate to ensure fast service and maintenance.

Keris is a national school which receives full support from the Government. National schools are not allowed to seek external funding from the individuals or corporate donations without the consent of the State Education Department and District Office (according to the SAA). Thus, the school had to solely rely on government funding and cannot raise additional income.

Teaching in the school seemed to be generally hindered by limited resourcing and maintenance. These limitations also had a negative impact on teachers' ability to implement IL. They need stronger administrative support to ensure adequate resources and technical support.

For the interviewees, the issues highlighted seemed to be a hindrance to implement ILE in the schools. However, none of the interviewees attributed the issues to the school-level leadership. 


\section{(b) Leadership and support}

Keris had a female School Head. At the time of this study, this individual was new to the school and was not ready to participate in the research. Thus, the SAA, who had been with the school for four years, replaced her as my interviewee. It is not surprising to see a headmistress at primary school. The interesting part is to understand her leadership style, including the process of decision making from the perspective of her staff.

According to the SAA, the former head of school was also a female. She said, during her term as school administrator, the school had achieved many awards and recognition at the district level. She ensured that all teachers gave their full commitment to all activities organised by the school, district and state level. This view was also shared by the LMT and Local Studies Teacher. When asked about the School Head's support of the ILE implementation in Keris, the SAA responded,

Absolutely yes. But in terms of implementation, it must come from the teachers themselves. Hard working or not, it is his/her attitude. Like myself as the senior administrative assistant, I am also lazy to switch on the computer. Other teachers may also face the same situation. The main hindrances are time spent and a large student population. In one class, we have about 40 students. The teacher has to control the students first so that they can sit still. Only then can the teacher can switch on whatever equipment or teaching aids that the teacher has. The time flies very fast. (SAA)

Though Keris had full support from the former School Head in all activities, factors such as time constraints and the large class sizes were seen as the main obstacles to implementing ILE.

When asked about the way to improve the implementation of ILE in the school, the SAA said that,

Actually, the number of students should be reduced so that it is easier to concentrate on the students. Like in America, I see that the teachers stay put in one class. They do not have to move from one 
class to another. Everything is placed in the class. They do not have to shift around. Here, the teachers are mobile. In America, the students are only 15 in a class. But here, we have 40-50 students in a class. There was hearsay that the number of students in a class will be reduced to 25 . But nothing happens. (SAA)

She further expressed her concern that the issue of class size and the need for a well-equipped classroom had been communicated to those in authority, particularly the MOE to improve the situation. However, no action had been taken.

The SAA explained that at primary school, the underlying philosophy of the curriculum is child-centred (see section 5.3). However, for the teachers it was difficult to implement the child-centred curriculum due to the large class size. The SAA claimed that the teachers were unable to give full attention to the students individually to the extent that,

Even if we had to do a test, we have to fake the result such as a diagnostic evaluation that needs to observe the students. There is no time to ask students on a one-on-one basis. (SAA)

As a result of a large number of students in a class, the teachers had limited time to recognise the students' development and differences including IL.

On the other hand, relationships between the School Head and teachers seemed positive and unlikely to impede IL implementation. The Local Studies Teacher was positive about the openness of the former School Head towards her staff. He recalled,

that part is ok. At the moment, she did accept suggestions or new ideas. For example, in morning school assembly, the teachers may suggest different inputs, and she accepted. In terms of the relationship between the administrator and staff it was ok. (Local Studies Teacher) 
Furthermore, the Ustazah believed that the teachers need regular inspection and monitoring by the school administrator not only in teaching and learning but also in the classroom. She saw the monitoring exercise as a motivation for her to perform better: 'According to my experience, after the inspection, the teacher will be called individually. The School Head will tell you what you have or have not done. Then, we try to improve ourselves'.

In summary, all interviewees saw their school leadership as being supportive in all school activities including the implementation of ILE. However, none of them said anything negative about the school leadership. They also pinpointed obstacles in the school such as lack of availability of tools and equipment, and lack of funding.

\section{(c) School goals}

Most interviewees, when asked about their ILE implementation in teaching and learning activities, indicated that school goals emphasised academic success, and therefore they allowed limited time for ILE. They had to finish the syllabus so that the students were able to prepare for the exam. As a result, the interviewees were orientated toward students achieving excellent academic results, since academic results were seen to be the yardstick of school performance.

The Science Teacher responded differently when I asked about what he thought to be the obstacle in implementing ILE in the school.

I think first is the school culture because we are so exam oriented. We need to provide the opportunity for the students to think creatively. All this while we only want them to produce the similar answer as we wish. We are not ready to accept answers other than what we know. In fact, the state department and district office are so results oriented, that is exam results. Then, the parents push their children to get the most A's so that their children can be the best student of all.... The mentality of the society, administrator and people at the top there.... They try to limit things. The teachers are 
always being questioned about why the students get a $\mathrm{C}$ or $\mathrm{D}$ result. These weak students, even though they do not know how to read, know a lot of things. If we ask them something, they were able to answer the questions. Their only problem is to express their thoughts in writing. We evaluate them about $10 \%$ in writing. (Science Teacher)

The Science Teacher actually saw the current goals of the school as not supporting for the implementation of ILE. The school community was not prepared to go against the existing situation because the whole society was results-oriented and more accepting of students with As than students with creative minds.

I further asked the Science Teacher about the kind of improvement he thought was needed. As a Science Teacher, he was particularly concerned about the availability of tools and equipment. He then continued saying:

I think, the administrator, not the school administrator, but those top management from the Ministry do play their role.... However, when the issue stops at the state department, they have their own agenda.... For example, in Year 1, 2, 3, the Ministry says there is no exam. But when it comes to the state department, they are results oriented. They maintain the exam for Year 1, 2, 3. The Ministry is not so exam oriented. (Science Teacher)

The Science Teacher made the point that the state department and MOE were not coordinated. This could be another factor that was affecting ILE implementation in the school.

\section{(d) School climate}

Keris was considered a well-equipped rural primary school with a large number of students. The interviewees were concerned with the students' attitudes, class size, and working conditions. 
I found that among Keris's interviewees, only the Ustazah expressed her concern that implementing ILE would lead to the lack of 'teacher control over the students' discipline'. The rest did not express their concern in terms of students' discipline.

The SAA also complained about the class size which was generally about 40 to 50 students. This was the standard size in most Malaysian public school classrooms. The large class size could also hinder ILE implementation.

The LMT commented on the lack of reading habits among the students. Although the students were not picking up reading habits, she felt positive about the students' ability to think critically and creatively. It was the role of teachers to inculcate the reading habit and connect with the students 'emotionally'. As she saw it:

reading culture is low. If we train them, they can...to the extent that the students are capable, pick up the IL skills. The only thing is that the teachers have to work hard to expose them to the skills. Our students do have critical minds. What is needed is the opportunity to do so. Sometimes there were questions asked by them and they themselves provide the answers. There was information that could touch their heart. They were also capable of giving their ideas. Actually it is not easy to touch the primary school students emotionally. With a right approach, the teachers are capable of developing their minds critically. The most important thing is to inculcate a reading habit. That is why NILAM programme is introduced. (LMT)

Again, the problem seems to be lack of time and opportunity in the curriculum.

Another interesting view came from the Science Teacher. He told me that there was a perception that 'a quiet class is a learning class' when asked about the obstacles faced by teachers implementing ILE. He elaborated that 'if the class is noisy and the students are moving around, it seems that 
the teacher is not able to control the class...as if there is no learning process happening in the classes'. However, he thought that this was 'a wrong perception' because the students need to actively engage in the classroom in order to promote thinking.

\subsubsection{Ecological Context}

Most school programmes need a conducive and supportive environment to develop learning. In the case of ILE implementation, it is crucial to understand the extent of support received from the macro level: community or society, district and state administrators, and government and other agencies.

\section{(a) Community/ Society}

When asked about the support from the local community, the parents or guardians were the ones the interviewees constantly dealt with.

The SAA and Science Teacher commented on the lack of parental support to the school and parents' overly high expectations. According to the SAA, 'the parents did not come and help the school'. Many parents who lived nearby the school had a low socio-economic background: factory workers and petty traders paid on an hourly rate. Therefore, they could not afford to take leave just to participate in the school activities. Meanwhile, the Science Teacher saw the parents were pushing their children for many As in the exam results. The expectation of the parents was akin to the expectation of the society. The Science Teacher believed that society 'highlighted the achievement of the individual who gets many As'. But he said 'I do not think exam is everything'. He believed students should be well rounded including being information literate persons.

\section{(b) District/ State}

As discussed in section 4.3.1, the Malaysian MOE has a hierarchical and pyramid-like structure. When asked about the support from the district and state administrators, interviewees expressed concerns about staff 
development and training, communication with school, and administrative practice.

The LMT had attended courses organised by the TAC. But the courses were not specifically about ILE. Talking about her experience attending these courses, the LMT said the courses were 'more lecture based' and that she does not know how to apply what the courses taught in the classroom. I received a similar comment from the Ustazah who said she had "no place to refer to or ask questions' after the training course.

When asked about the ILE guidebooks or manuals to assist their implementation, all interviewees indicated that they did not have any. In courses that they attended, they were only provided with the lecture notes. Only the Science Teacher used the 'curriculum specification as a point of reference' to implement ILE through 'suggested activities' in the specification. Thus, the way courses were conducted was merely as oneoff-lectures with no after training support service. This was where the Science Teacher saw the need to improve the training modules for future staff training.

The Local Studies Teacher also highlighted an issue related to gender imbalance when he shared his experience attending the SRC related courses. He claimed that the majority of the attendees were women. There was a course where he was the only male attendee and had to be the leader-cum-moderator of the course. Consequently, he noted that he felt reluctant 'attending the courses because I was often chosen as a group leader or chair person. I did experience 4-5 courses. I just wanted to gain experience.' He seemed uncomfortable attending SRC courses because of this experience.

In terms of the education administrations' communication with school, the responses were varied. The SAA and LMT said that the state and district administrators 'support' and 'frequently interact' with the school. On the other hand, the Local Studies Teacher saw the relationship between the 
school and state or district level as difficult. He elaborated the unpleasant relationship between the School Head and the state officials in dealing with a problematic staff:

From my knowledge, those officers who visited the school were not the top rank officers. They were the middle management. So they were not able to make decisions and solve the problem. For example, the school has one office boy who is having a disciplinary problem, often not coming to work. Once he came to work, he stole the teachers' properties in the teachers' room. The School Head reported the problem to the state department. The School Head was blamed, not the office boy. The School Head was blamed on the basis of negligence and so on. The school administrator could not take any action. She could only report the incident with the hope that an investigation took place. The state officer came to the school not to investigate the matter or solve the problem, but to instruct the School Head to settle the problem and advise the office boy. The office boy was penalised by reducing his salary, but they could not sack him. (Local Studies Teacher)

From the Local Studies Teacher's expression, I could see that the school administrator was often faced with a dilemma. Any decision made by the school whether the decision involved funds or staffing or facilities had to be approved by the district and state administrators. This situation seemed to affect the acquisition of information resources and development of staff for ILE.

Furthermore, the Science Teacher expressed his concern over the state and district administrative practice of being 'so result-oriented'. They left no choice for the schools within the area but to achieve the target set by them.

\section{(c) Government and other agencies}

The Ministry of Education (MOE) is the highest authority in the educational administration at the federal level. All education policies are drafted, formulated and determined by the MOE. When asked about the 
role played by the Government and its agencies, the interviewees highlighted two issues: lack of proper planning and objectives, and poor communication at all levels.

The LMT, while discussing teachers' heavy workload and limited time to focus on teaching and learning pointed out the various activities and programmes initiated at all levels of education administration. She felt the teachers were unable to 'breathe well'. The school kept on receiving new instruction from all levels. The activities and programmes were done at the expense of teaching and learning time. She suggested that 'all initiatives introduced to the school must be well scrutinised and with well-defined objectives'.

In addition, the Science Teacher believed the 'Ministry's aspiration is not delivered' by the state and district level. He claimed that both district and state level had their own 'agenda'. It was probable that the school ground had been a "testing bed" and a platform for leaders of every level to introduce activities and programmes during their tenure to gain further recognition.

\subsubsection{Implementation Protocols}

When asked about the ILE guidebooks or manuals used to implement ILE, only the LMT and Science Teacher replied that they had not received any. The Science Teacher said that she relied on the 'curriculum specifications as a point of reference for suggested [class] activities'. She further thought that the 'school modules need to be transformed' in order to ensure ILE implementation.

The LMT and Science Teacher appeared to be unprepared and lacked proper ILE Implementation Protocols such as an IL guidebook and IL lesson plan. They were also unaware that these documents were available in the ETD portal. Only the Science Teacher claimed her full use of curriculum specifications as her guide to deliver the syllabus content. 
However, she believed that the syllabus needed to be trimmed to allow ILE implementation.

\subsubsection{How do these factors facilitate or hinder ILE implementation in Keris?}

In terms of ILE implementation, when the interviewees were asked individually about the factors that adversely affected them most, the answers were mainly about the lack of time, lack of leadership support for IL, lack of availability of information and resources, heavy workload, students' characteristics and teachers' attitudes.

I found that firstly, time was the teacher's enemy. At the individual level, the interviewees such as the SAA and the Ustazah said that they were not implementing ILE in the classroom because of fear of wasting time, being unable to complete the syllabus, and being unable to control the classroom. The time frame that the teachers had was divided into actual teaching and learning work, extra-curricular work and ad-hoc jobs from the school, district and state administrators.

Secondly, the frequent written tests and exams of the students led the teachers to be pressured to finish particular syllabus topics at a specific time. The teachers tended to focus on the syllabus rather than the students well-being. This obviously led to the teacher-centred rather than studentcentred approach.

On the other hand, the teachers' positive attitude appeared to be a factor that supported ILE implementation. The LMT, Local Studies Teacher and Science Teacher were willing to implement ILE in order to ensure the learning process was more meaningful with more two-way interaction in class. 
Thirdly, Keris had established in-house training. Teachers who attended any course would share their knowledge and skills with other teachers in the school. This practice was actually a new ruling by the MOE. The teachers are required to complete 42 hours of training annually. So every two to three months, the school would organise one session of in-house training. Moreover, there were collaborative efforts between the LMT and the academic panels to organise academic related programmes such as English Week, Information Hunt or a Debate Competition which were prepared throughout the academic year. The school had actually built a strong social bond among the school community.

In the case of ILE, the LMT's lack of training led to her inability to facilitate ILE implementation in the school. The LMT was supposed to be the expert and to be ready to facilitate the teachers to implement ILE in the classroom. However, although the LMT held the position for three years, she had not yet been officially appointed. Hence, at the time of the study, she had still not received specific training for her job specification from the district and state level. The only knowledge that she had to perform her job was from peer learning and pre-service courses attended. Thus, in the interview, she admitted her difficulty to assist teachers to implement ILE due to lack of ILE knowledge and skills.

Fourth, as I interviewed the SAA of Keris, I could sense there was a lack of understanding by the administrator with regard to ILE implementation. The SAA was adamantly reluctant to implement ILE due to time constraints, a heavy workload and lack of ICT skills. Due to her position in the school, her individual perception could influence other teachers. The SAA's view differed from teachers who perceived ILE as providing important skills to the students, but they blamed students' performance and limited resources for not implementing it.

Leadership support appeared to be crucial for ILE implementation in the school due to the nature of change required. In Keris, the SAA confessed 
that she was 'not giving a good example' to her teachers in terms of ILE implementation.

To implement ILE, the teachers were not only required to possess the relevant knowledge and skills, but also to modify their teaching practices to a more student-centred approach. The lack of support for them for the ILE implementation limited their ability to be involved. In addition, appropriate support from the district, state and federal level was not available. Thus, it was necessary but impossible for every level of the school system to share a common understanding of how to implement ILE so that changes would be better coordinated.

\subsection{Badik}

Badik is the second case study school.

\subsubsection{Stage of ILE implementation}

The stage of ILE implementation in Badik was assessed as being at the Early Use level from the individual interviews with the School Head, Science Teacher, Local Studies Teacher, Ustazah and Library and Media Teacher (LMT).

School interviewees from Badik, when asked about ILE implementation, provided varied and sometimes contradictory responses. The Local Studies Teacher and LMT responded negatively about the implementation of ILE in the school. The Local Studies Teacher indicated that the implementation of ILE was 'less successful' and the LMT indicated it was 'not successful'. On the other hand, the School Head was positive about the ILE implementation of the school saying that 'almost all teachers are working towards it [ILE]'. The Science Teacher only discussed briefly how she implemented IL related activities in her classes and the Ustazah did not comment on the ILE implementation of the school. 
It was apparent that there was a discrepancy between the head and the teachers' opinions. The School Head, when asked about ILE, seemed to be knowledgeable and understood the importance of ILE in teaching and learning. But the Science and Local Studies Teachers, who were also implementing ILE, did not respond convincingly about the way ILE was implemented in the school. The "half-hearted" responses led me to probe more about their concerns about ILE.

I received an unexpected answer from the LMT. She frankly claimed that she did not implement ILE in her teaching and learning activities because, as she said:

I do not understand. How am I going to deliver IL to my students.... There is no specific IL course for LMTs.... At the moment, I do not practice student-centred learning because I have not attended any related courses. (LMT)

This interviewee had been a LMT for more than 10 years. Her main reason for not implementing ILE was because of the lack of training and exposure.

The Science Teacher expressed her ILE implementation stage in the following way: 'I implement every time I am in the class. In science subjects, it is a more student-centred approach. The teacher does not always spoon feed the students. For her, the teaching and learning approach was often independent learning. The students had to prepare the experiments on their own or in a group, the teacher only facilitating them in the lab. Independent learning and teacher as facilitator are elements of ILE.

The Local Studies Teacher developed IL-related research skills in her teaching because she believed the local studies syllabus allowed her to educate the students to become independent learners:

Normally, I will give the students one research topic for them to prepare a folio. The students will prepare the folio themselves. 
Then, I will provide them with a checklist and facilitate them step by step... so that they can work on their own... especially like the folio. (Local Studies Teacher)

Although she tried to implement ILE in the class, the students themselves lacked interest in the local studies subject. There were times when she had to feed the students with class notes, particularly in the weak classes. The students were more interested in examination subjects such as mathematics, science, Malay language and English.

The Ustazah gave more attention to students individually because of the nature of the syllabus. One aspect of religious studies teaching was the reading of the Qur'an. The students were expected to 'read with teacher' one on one so that the students are able to recite and pronounce properly the Qur'an verses. The recitation of the holy verses involves a set of rules. According to the teacher, the only time that the students were asked to search for information was through identifying the related rules, after reciting 3 to 4 pages of the holy book. It was a recite-and-write exercise which encouraged rote learning among the religious studies students.

Thus, some interviewees viewed that they were either at the Early Use Stage of implementing ILE in their teaching and learning approach, except for the LMT and Ustazah who had not implemented it. At the school level, the teachers were doubtful about the success of ILE implementation, unlike the School Head. The School Head strongly believed that her 'teachers have received a lot of exposure' through courses and training and 'working towards implementing ILE'. There appeared to be a discrepancy between the School Head's and other interviewees' views on the stage of ILE implementation in Badik.

\subsubsection{Factors affecting the ILE implementation}

As with the first case study, the factors impeding or facilitating ILE are discussed in order to understand the implementation of ILE in Badik. This part is divided into five factors, including the related sub-factors. 


\subsubsection{Characteristics of IL}

The following is the report of the Badik's interviewees' needs for, and clarity of the IL concept and its goal. However, none of the interviewees highlighted the complexity of ILE implementation.

\section{(a) Need for ILE}

In Badik, when asked about ILE, most interviewees noted that IL was an important skill. The need for the skills was centred on students' and teachers' self-development.

The School Head of Badik saw that the acquisition of IL skills would guide the students to apply their creative minds and involve the full use of the five senses. She pointed out that

The school has many educational resources at present via ICT. The students are more interested in ICT.... The students understood more because they can use their five senses...contribute in the brainstorming.... Learn how to learn skills, creative thinking... [the teaching of IL] inculcates good values. (School Head)

The School Head shared a similar view with Keris's LMT about the inculcation of good values through ILE. According to the School Head and LMT, this belief can be associated with the foundation laid in the curriculum development and the education philosophy of the country. Further, she welcomed ILE as a contributing factor towards teachers' 'effective teaching and learning' and 'better learning approach'.

The LMT and Local Studies Teacher also thought that ILE was good and 'fun' for students, and teachers can also gain new knowledge due to students' involvement in the class. Yet, in terms of the ILE implementation, the LMT indicated that she did not use IL and the Local Studies Teacher was in the early stages. Both interviewees seemed to have faith in the implementation of ILE in the school. The LMT could actually see the need for ILE in terms of students' ability to 'come up with their own ideas in order to answer exam questions' and the Local Studies 
Teacher saw that the students were 'able to learn in more detail, more indepth and [were] not being spoon feed'.

However, when asked about the teachers' need of ILE and training, only the LMT indicated that she was in need of such training. The rest of the interviewees either indicated a lack of interest in training or did not comment.

\section{(b) Clarity}

When asked about the understanding of IL, Badik's interviewees referred to concepts such as 'speed reading' and 'reading habits', 'generating ideas', and 'group work', 'inculcating good values' and 'learn how to learn skills'. Their understanding of ILE appeared to be either too specific or too broad due to their lack of specific knowledge and skills about ILE. Similar to Keris, the interviewees of Badik were more familiar with the constructivist or student-centred approach rather than ILE due to their professional pre-service training.

For example, the Local Studies Teacher, when asked about her understanding of ILE, indicated the focus of the teaching was more on students, and the teachers only acted as facilitators. The Science Teacher also echoed a similar response and added that the strategy of teaching was 'more towards generating ideas from the students'.

On the other hand, the LMT who was supposed to be exposed to the IL concept and skills in the school was 'not clear' about ILE due to 'not much exposure'. She seemed to blame the lack of IL training as a reason for being ignorant about ILE. As she spoke about the school resource centre activities, she also discussed activities such as speed reading, and information hunt. She also tended to explain activities related to thinking skills such as using the enquiry method and group work in her classrooms. She appeared to have implemented some activities related to ILE without even realising them. 
The interviewees of Badik were well versed with the concept of constructivism and student-centred learning. But, the concept of ILE seemed unfamiliar to them.

\subsubsection{Individual Implementers}

The characteristics of interviewees in terms of qualifications and competency are described below, as an indication of their commitment and readiness to implement ILE.

\section{(a) Qualification/Competency}

When asked about the IL related courses attended, interviewees indicated they had not attended any. But, they had attended IL related courses during pre-service and in-service training. Their opportunities to attend courses and trainings varied.

In contrast to the other interviewees, the School Head received recent training due to the introduction of the new primary school policy (KSSR). The Science Teacher who had 26 years of teaching experience told me she attended the IL related courses during her early years as a teacher. The LMT and Local Studies Teacher said they participated in a few IL related courses about 5 to 10 years ago. Only the Ustazah attended the IL related courses in her pre-service training.

Interviewees provided various explanations:

- There is no specific IL course (LMT)

- The school has many Ustazahs. If I did not go, other teachers can go... (Ustazah)

- ...no need for training because I have been teaching for quite some time... (Science Teacher)

The interviewees seemed to have their own excuses for the lack of exposure to ILE. All these reasons for insufficient knowledge and skills in ILE appeared to be detrimental to its implementation in Badik. 


\section{(b) Commitment}

Variations in commitment of interviewees were reflected in their different levels of implementation (see 6.3.1).

When I interviewed the LMT, she admitted her non implementation of ILE was due to 'not attending any related courses'. She was unclear about the IL concept. She recalled the last training attended was on making videos. But in the course, the teachers were 'not taught how to apply the skills to students' learning'. The LMT felt that she lacked IL understanding and, therefore, was unable to teach other teachers in the school. On the other hand, she took an initiative to collaborate with the counselling teacher to organise a reading camp. In this camp, the LMT and counselling teacher gathered those students who had learning difficulties. The students were not only taught how to read but also how to 'locate information'. This initiative came from the LMT's 'own exploration through reading' rather than attending specific courses.

The Ustazah seemed to mistakenly understand ILE implementation as being the initiation of one to one learning. She said 'after every teaching session, I will always sit together with students... be with students'. She tended to make herself always available to her students during school hours. When asked about her commitment towards student learning, she said she felt accountable for it, particularly in regard to the students' ability to read the Qur'an and she felt 'guilty' if the students were unable to read the holy book well.

The Local Studies Teacher was willing to undertake ILE implementation 'twice a month'. She implemented ILE for the Level 2 students, that is, Years 4, 5 and 6 . She would begin by providing the students a list of research topics. The intention was to come up with a folio. She let the students choose a topic of interest and then provided them with a checklist of folio activities. She acted more as a facilitator than a teacher. The 
students had to be independent and direct their own learning. Hence, one of the strategies to implement ILE in the classroom for this teacher was to prepare for teaching and learning, for example, by creating a checklist of things to do prior to the class.

The School Head was positive that her teachers were all 'working towards it [implementing ILE]'. She believed that 'in primary school, the students do not know anything. It is the teacher who manages the learning environment according to a suitable learning strategy'. When asked about her opinion on the limited time to implement ILE, she said that 'time management depends on the teachers. The teachers have to sacrifice their time'.

\section{(c) Readiness}

When interviewees were asked about the extent of their implementation of ILE in classrooms, they expressed their concerns related to their subject specialisation and position. Among the factors discussed most by the interviewees were time constraints, heavy workload, teacher's perception and availability of resources and space.

The LMT, Local Studies Teacher and Science Teacher shared similar views on time constraints as an obstacle to the proper implementation of ILE in the classroom and science laboratory. The LMT pointed to her heavy workload as a reason for being unable to implement ILE. Moreover, due to the lack of IL knowledge and skills, she felt unprepared to implement ILE because 'it is not easy to use this method in every lesson because we have to use our creativity to form questions'.

The next factor related to the teachers' perceptions of students. The Local Studies Teacher believed that 'in primary school, the students are still in need of the teacher's guidance. The teachers cannot let the students to search [information] themselves'. She seemed to uphold the tradition of teacher control at primary school. The School Head felt the 'students did 
not want to take part' and were unprepared to change their learning approach.

In contrast, the Science Teacher, when asked about her first experience implementing ILE, commented positively on the experience. She said that 'in the beginning, I feared that the students might not be able to follow... . Then, I could see that the Year 6 students were capable of giving good feedback...' The outcome of her first attempt appeared to help her to change her teaching strategy.

Finally, the issue of lack of availability of resources and space was also highlighted by the Science Teacher who was concerned that it could hinder ILE implementation. Although, when asked about this issue, the School Head seemed positive about what the school had. As she said, 'tools and equipment are readily available'. She believed that the school had enough resources and space for the teachers to implement ILE.

The readiness of interviewees to implement ILE was very much related to how they dealt with their existing situations and their creativity, especially in the classroom. They generally appeared to emphasise the obstacles to ILE implementation rather than coping and finding ways for its implementation. But the Science Teacher seemed more positive.

\subsubsection{Implementing Organisation (School)}

In order to develop and be sustained, a school programme will need proper administration of resources and staff, and coordination of activities. Thus, through analysing the administrative and leadership support as well as the goals and climate of Badik, I was able to understand the way ILE was implemented from the interviewees' viewpoints. 
(a) Administrative support

As with Keris, most interviewees at Badik were concerned about the lack of availability of resources and equipment, funds, services and on-going maintenance activity. The topic discussed most was the lack of availability of resources.

The Local Studies Teacher, when asked about the school administration's support, said that one of the factors that hindered ILE implementation was 'limited resources'. She explained that 'the school library only possesses light reading materials and fiction'. To her, the reading resources were not enough for students to gain knowledge.

The School Head, when asked the same question, said there was "no problem with acquisition of resources and stationeries' in the school because the school fund was 'allocated to all academic panels'. The academic panels would come up with their budget plan yearly. Therefore, every academic panel received an amount of funding to support their academic activities. However, she admitted that as a government aided school, the school lacked space and facilities such as a proper computer lab due to limited funding. In addition, the LMT also highlighted the 'problem of the maintenance of equipment' such as computer software and hardware, and in particular the "pop-up companies" which supplied the software and hardware but existed only on a short-term basis. The school was unable to maintain some of its equipment due to lack of after sales service.

\section{(b) Leadership and support}

Like Keris, Badik had a female School Head. At the time of this study, she was close to retirement age, having led the school for 19 years. From her body language, she seemed a calm person. It was fascinating to find out from her perspective and then from the perspective of her staff, how she managed the school, including the decision making process. 
When asked about her support of ILE implementation in the school, she responded optimistically about the continuous efforts of the teachers. Further, when asked about the kind of support that she provided, she indicated that she 'believed in an instructional leadership'. She said that she used to "walk around the school compound in order to ensure the teaching and learning activities were running well'. When observing, she used to 'call up and discuss with the teachers' how to improve the teaching strategies. She advised the teachers to be 'attentive with the students' facial expression', indicating that the students would show their 'bored faces' if the teaching strategy was not interesting.

She believed, in her support for ILE implementation, that she needed to give more attention to the 'newly-come teachers' because of their lack of teaching experience. She commented that the 'experienced teachers were clever to accommodate their teaching styles with the students' situation'. For the new-comers, she thought that she needed to monitor them constantly and shared ideas with them. She even pointed out that one of the roles of academic panels was to share ideas with the newcomers on how to teach the students effectively through regular meetings.

Her opinion of the newcomers did not stop her from recognising their contribution towards the school. When asked her opinion about her teachers, she believed that ' $100 \%$ of the teachers play their part in the school'. She further elaborated about the important role played by the support staff as well such as the gardener, security officer and cleaner in the school. She believed that each staff member had his/her way and individual pace when asked to perform the job. As a leader, she had to be there for her staff, 'guide them' and offers a 'harmonious working environment'. This was what she meant by 'teamwork'. The School Head seemed to be quite open-minded in her leadership approach.

When asked about staff development and training, the School Head perceived the government's new ruling on training, that is, the 7-day inschool course, as beneficial and 'effective in curriculum related and extra- 
curricular related trainings' for Badik. During the in-school courses, all teachers of different subject specialisations would share their knowledge and experiences attending various courses. Similar to Keris, Badik had also prepared a platform for teachers to cultivate a knowledge-sharing culture through this 'compulsory' (as noted by the School Head) in-school training. In terms of ILE, if Badik's LMT ever received IL specific training from the district, state and federal level, the platform of knowledge sharing was ready for the transmission of IL knowledge and skills to the whole school community.

When the views of Badik's interviewees about the school leadership were sought, the LMT and Local Studies Teacher had different opinions. The LMT was concerned about the School Head's long service in the school. She kept on comparing her School Head with another school's head. She was of the opinion that the school needed an 'energetic School Head who is able to move teachers' potential'. She felt that the 'School Head did not treat the staff equally' particularly in terms of 'work delegation'. The School Head kept on burdening a few teachers with certain work because she trusted that these teachers would execute the work well. But other teachers could avoid any extra work. She claimed that the School Head 'encouraged' this phenomenon to persist in the school. Due to some teachers' heavy workload, the LMT suggested that the school should prepare a succession plan so that she would have a proper successor. She was also concerned about the need to rotate the job 'every five years'.

The LMT also expressed concern about the way the School Head evaluated staff performance. She said the School Head had the tendency to evaluate based on the seniority of the staff rather than on individual performance. This evaluation practice led to 'dissatisfaction' among the junior teachers who were burdened with heavy responsibilities, but received unfair evaluation. As a LMT, she felt the heavy workload and the unfair grading system led to her inability to develop her knowledge and skills of ILE and thus, implement ILE and assist its implementation in the school. 
When the Local Studies Teacher was asked about the School Head's support of ILE implementation, she highlighted the need to provide more resources such as varieties of reading and reference sources in the library for students. At the same time, she pointed out that the School Head had 'empowered $100 \%$ to the academic panels' to plan their activities and budget in order to acquire resources and coordinate activities. She seemed to believe that the academic panels should plan the resources rather than the head. But she further admitted that the school's funding was limited due to its position as a government-aided school.

The Local Studies Teacher saw that both teachers (particularly those academic panels) and School Head had their roles to play in the on-going support for ILE implementation. While the academic panels had to plan ahead and be proactive in ensuring teaching and learning resources were adequate, the School Head would administer the needs and wants of the academic panels within the limitation of funds.

Communication skills were also an important element to ensure the teachers were kept informed of all plans and policies. It seemed that Badik's School Head had done what was needed and was understood by the teachers. The School Head, however, did not realise that her method of evaluating teachers' performance led to dissatisfaction with her leadership (in the case of the seniority based evaluation). Therefore, there was a need for more communication between the School Head and the school-wide community so that the school ecology would be conducive to the changes needed for implementing ILE.

\section{(c) School goals}

All Badik's interviewees, throughout the individual interview session, stressed that their main aim was to prepare the students for examination. All the school's activities and effort were designed to produce more A grades in the exam. 
The Local Studies Teacher saw this academic orientation as a hindrance to ILE implementation. She indicated that

the students of convent school are so focussed on the four core subjects...[namely Mathematics, Science, Bahasa Malaysia, English and one aptitude test]. Sometimes when the teacher gave a folio assignment [for example, for Local Studies], their parents would come to school and raise complaint on the designated project. (Local Studies Teacher)

According to the teacher, the parents did not seem interested in the subjects that did not have examinations such as Local Studies, Morals and others.

In contrast, the School Head viewed the education system optimistically. She believed that 'each subject is important to the development of student's intellectual, emotional, physical and spiritual wellbeing'. She affirmed that the education system was able to 'produce a holistic student' due to the 'improvement made to the syllabus from time to time'. She pointed that the current reform of primary school syllabus (KSSR) was more student centred in approach and such improvement appeared to be beneficial to ILE implementation in primary schools.

\section{(d) School climate}

Badik is an all-girl missionary school, situated in an affluent area. When asked to describe the school climate, the interviewees focussed on the students' attitudes and behaviours, teachers' conditions, school facilities, and in-school training for staff.

The Science Teacher was of the opinion that, when considering on the students' attitudes and behaviours, the school had what was known as 'convent culture'. According to the Science Teacher, the students of this school were 'high competitive students... . The school is excellent because the students are interested in learning'. 
On the other hand, the LMT saw that the students lacked a reading habit and thinking skills due to the academic orientation. She suggested that in order to implement ILE the academic and non-academic activities 'had to be balanced and give some space to students' to be independent learners. She felt positive about the impact of ILE being that 'the students are able to produce more ideas in their writings'. This was what the LMT understood by ILE.

The School Head saw the students' discipline as crucial to teaching and learning. She said that the teaching and learning activities would 'run well in a disciplined environment.' She added that 'if the school had a disciplinary problem, the teacher's time is drained out in order to control the discipline' (School Head).

With regard to teacher's conditions, the Ustazah related the teachers' dedication to work to the 'convent culture', when commenting on the teachers' participation in the school. She believed that the 'teachers in the school are excellent and pay much of their attention to the students'. She pointed out that the teachers had 'many workloads. But the works were for the benefit of the students'. In most instances, the teachers were willing to work as a team to reduce the workload. The School Head highlighted the need to increase the number of teachers in the school in order to reduce the workload, and thus, teachers would have more time to spend on ILE implementation.

The issue of school facilities was highlighted by the LMT. She pointed out that Badik's two sessions of schooling, that is, the morning and afternoon sessions were problematic. According to the LMT, these two sessions were unavoidable because of the constraint of space and facilities. Badik had a high student roll, but had an undersized school compound. Moreover, the teachers had limited time and opportunity to communicate among themselves, and to organise any activities due to the shared space and facilities. The only time that the space and facilities could be used for other activities was in the evening and on weekends. However, it was difficult to 
ask the students and teachers to participate in activities that were organised in the evening or weekends. The LMT therefore saw these limitations as a hindrance to ILE implementation.

Furthermore, when asked about staff development and training, the LMT actually encouraged other teachers to participate in IL courses. She encouraged those teachers who had attended out-of-school courses to 'immediately disseminate the knowledge and skills received to the rest of the teachers'. There was a delay of the transmission of course related knowledge because in-school courses were held infrequently. In addition, due to the short time available, the related knowledge and skills could not be delivered well. Hence, according to the LMT, there was a need to improve the way in-school training was organised so that this platform could be properly used to transfer the knowledge and skills from the course attendees immediately and effectively, particularly on ILE.

\subsubsection{Ecological Context}

In the context of ILE, it is crucial to understand the kind of factors affecting its implementation which derives from the macro level such as community or society, district and state administrators, and government and other agencies.

\section{(a) Community/ Society}

When asked about the factors that may affect ILE implementation, most interviewees mentioned parents. The Local Studies Teacher said the parents were only concerned about high achievement in the examinations, rather than the non-academic activities. Thus, the students showed a lack of interest in preparing portfolio-type assignments which involved locating and organising various sources of information.

The LMT and Science Teacher also thought the parents only expected an excellent result from their children. According to the LMT, the parents' expectation was very high to the extent that their children had to attend 
extra classes (tuition) after school. The children appeared to have no time for themselves to do other recreational and reading activities. That led to a situation where, according to the LMT, the students were not in the habit of reading books. When the students went to the library and borrowed books, she found that they would 'vandalise' the books rather than look after them. The students were actually pressured with their homework routine which often involved many workbooks. Thus, they could 'not appreciate books anymore'. She further saw that the situation of lack of reading habits among students led to the lack of thinking skills.

The School Head claimed that, in terms of their role in the school, the parents would act as a "check-and-balance" to the teaching and learning activities. She said that the parents were very attentive to the child's school work to the extent that they would, for example, 'check whether the teacher marked his or her child's homework or not, and whether the information provided by the teacher was correct or not'. Any mistake or misinformation would be 'delivered directly and immediately to the School Head'. The School Head, then, would 'call and discuss the teacher involved'. The participation of parents in the children's school work had compelled the teachers to 'be more alert and sensitive with the school climate'. The School Head acknowledged that the parents and students were 'our customer. The school had to attend to their comments'. She also referred to the 'convent culture' where the parents were very involved in the school and the teachers were highly dedicated to their work.

From the responses received on the community involvement, the parents appeared to be quite powerful in Badik. The parents' expectation of the school was apparent in their frequent communication with the School Head and teachers. They focus on exams and teacher accuracy mitigated against IL. 


\section{(b) District/ State}

When asked about the support from the district and state administrators, only the LMT commented on them specifically, in terms of staff development and training, and school syllabus.

In the past 10 years, the LMT said that she attended five courses organised by the district, state and federal level. But the courses were not specifically about ILE. The first course was on school resource centre management. After that, there were a few follow-up sessions. She then elaborated her experience attending these courses. The courses were 'lecture based.... Like the one that I attended on moviemaker, the course instructor did not teach us how to apply in the classroom'. Normally, the courses were held in the Teacher's Activity Centre (TAC) in a large hall. The organiser of the district-level courses was frequently the State Educational Technology Division (SETD) via TAC. She added that she never had a proper guidebook for ILE and only received course notes as a guideline on IL.

The LMT further recommended the revision of the course syllabus to include IL and discussed a reasonable time length for each course. At the moment, she said, the time length was 'short and spread over a period of time'. When asked about any other activities organised by SETD via TAC, she recalled that 'the LMTs had gatherings two to three times for every six months. Usually we discussed how to coordinate LMT's work. The newly appointed LMTs found it useful'. The SETD needed to get more feedback and improve the way training was conducted so that knowledge and skills could be effectively delivered.

\section{(c) Government and other agencies}

When asked about the role played by the Government and its agencies, again only the LMT responded. She highlighted two issues: training, and educational resources.

According to the LMT, she only attended one course which was organised by the ETD. The course was known as EduWeb. She was told that 'the 
course was not originally from the MOE', but was out-sourced to a company, thus it was conducted by an expert outside the Ministry. She also believed that by attending courses, she could 'get to know other LMTs, exchange ideas and resources such as CDs'. She found it beneficial.

Speaking of her experience using the educational resources supplied by the MOE, she found that the resources were not used as intended in the classroom. She claimed that the 'CDs were mostly dysfunctional... could not be used'. She saw that the problem was due to

the way Government operates the supply of equipment and tools to the school. For example, when it comes to the supply of computers... one contractor supplied only the computers. Another contractor only supplied the network cable, and the next contractor only supplied the computer software... So because of too many sub-contractors, when it comes to service, maintenance or replacement of tools and equipment, the school finds it difficult to get hold of the exact contractor in-charge... (LMT)

In the above scenario, the school had no control over the supply of equipment or any educational resources in the school. The contract to perform specific tasks for school was solely derived from the MOE. The school was only able to write a report and send it to the State Education Department (SED) via SETD in the case of educational technology and resources if there were any problems. From the SED, the report would be delivered to the MOE, if needed, for further action. The school had to go through this red tape which hindered immediate action. It also appeared that the MOE was communicating very infrequently with the school directly. 


\subsubsection{Implementation Protocols}

When asked about the ILE guide books or manual used to implement ILE, only the LMT, Local Studies Teacher and Science Teacher responded. They indicated that they had not received any documentation.

The LMT commented that she had not attended any specific course for IL but most of the courses that she attended had included IL as an 'insertion' in the course syllabus. She added that with such a small amount of IL syllabus content, it was impossible for the LMT 'to relate IL to the student learning in school'.

The Local Studies Teacher suggested 'the MOE to provide teachers with guidebooks... so that teachers knew how to deliver the student centred approach' in classrooms.

In terms of the delivery of student-centred approach (an approach which is appropriate for ILE), the LMT and Science Teacher stated that they planned for it to occur spontaneously in the class.

The LMT, Local Studies Teacher and Science Teacher appeared to be unaware of the availability of any IL guidebook, IL lesson plan or other protocols in the ETD portal. They appeared to be waiting for the protocols to be delivered to them. In the same vein, both the LMT and Science Teacher had no proper plan to include ILE in their teaching strategy. They seemed to treat ILE as an add-on to the syllabus.

\subsubsection{How do these factors facilitate or hinder ILE implementation in Badik?}

These factors affected ILE implementation in Badik in a variety of ways.

First, change is not an easy process. The acceptance of change appears to depend on whether one was a risk taker or was risk averse. In terms of ILE 
implementation, when asked about the factors that affected ILE implementation, the interviewees' responses were about the lack of IL knowledge and skills, lack of training, lack of availability of information and resources, and students' attitudes. One interviewee was concerned about leadership.

I found that at the individual level, the LMT, Local Studies Teacher and Ustazah lacked confidence to implement ILE in the classroom. For the LMT and Local Studies Teacher, this was due to the lack of IL training that in turn led to the lack of IL knowledge and skills. This is evidenced from the claims made by both interviewees. The LMT, for the past 10 years as a LMT, attended only five job-related courses. The Local Studies Teacher attended her last training course about seven to eight years ago. On the other hand, the Ustazah and Science Teacher seemed to be avoiding attending courses. The reason for the Ustazah was that there was another Islamic Religious Studies Teacher who could take over her place in the course. Although the Science Teacher claimed to implement ILE, she used her long experience as a teacher as an escape from attending courses. Most of these interviewees appeared to lack the confidence needed to implement ILE and had excuses for their lack of training.

Only the School Head said that she recently attended a seminar on the new curriculum for primary school (KSSR) at the time of this research. The policy was focusing on the student-centred approach and $21^{\text {st }}$ Century skills. The focus of the new policy was actually in line with the concept of IL. Although she seemed to be knowledgeable about the need for ILE in the school, the School Head might have only communicated back to the teachers at school the limited amount of knowledge that she could absorb during the seminar. The seminar was about the new policy while the components of ILE were just a part of the seminar content. Hence, there was a need for the LMT and the teachers who were the ones to implement ILE in the classroom to be provided with more thorough knowledge of IL skills so that ILE could be implemented in the classroom. 
Next was the lack of availability of information and resources. Both the Local Studies Teacher and Science Teacher viewed lack of information and resources as another hindrance to the implementation of ILE. The Local Studies Teacher pointed out that the school library did not have enough non-fiction reference books for the students. The Science Teacher, when she was preparing for the lab session, claimed that the damaged and worn equipment was not replaced. The students had less chance to do any experiments themselves. Thus, the lack of information and resources were limiting students from being independent learners in the classroom or science lab, and were hindering the implementation of ILE.

Third, Badik had its own in-school training. Teachers who attended courses would share their course-related knowledge and skills with other teachers during the in-school training. According to the School Head, this training practice seemed to be effective in delivering the academic and non-academic based courses. All teachers, despite their subject specialisation, had to attend each in-school training session. Badik, thus, had a meeting point where the teachers could share their knowledge and skills including IL.

However, the LMT highlighted that the non-immediate transfer of courserelated knowledge and skills to other teachers in the school because of the infrequent scheduling of these sessions had inhibited the intended transfer of knowledge. Course attendees were unable to deliver the knowledge and skills as intended. Thus, the lack of immediate transfer of knowledge from the courses attended led the transfer of out-of-date and out-of-use information. Therefore, in the case of ILE implementation, in-school training was inadequate to support change in the school.

Fourth, in order for ILE to be implemented, the teachers needed to share similar needs for change and act upon them. The first person I interviewed in Badik was the LMT. Even though she held the position for 10 years, she still felt that she was treated as a junior teacher by the School Head. As I interviewed her further, I could see she was frustrated with what she 
perceived as lack of leadership support and unfair leadership practice. She claimed that her heavy workload had added to her lack of ILE implementation. Her entitlement to 12 hours teaching load was not granted and instead she was given 20 hours of teaching. She also argued that junior teachers like her were not evaluated fairly based on performance. Hence, heavy teaching load with responsibility as a LMT had restricted her time to develop her IL knowledge and skills.

Leadership support appeared to be crucial in ILE implementation in this school due to the whole school change requirement. The School Head in Badik seemed to be very open in her leadership style and recognised all the teachers' contributions made in the school equally. She also believed that all teachers contributed to the success of the school to the extent that, according to the LMT, there was no difference in terms of performance evaluation grade between those who performed and non-performed. However, interviews with teachers showed that the School Head's individual perception that all teachers were the same raised dissatisfaction towards this leadership practice and support and thus de-motivated those who did perform their work well. This finding demonstrates that constant and good communication between the school administrator and teachers in order to understand each other is encouraging and is conducive for change, and it acts as an enabler of ILE implementation in the school.

\subsection{Chapter summary}

This chapter has presented the factors affecting ILE implementation in Keris and Badik. Both schools were national schools and the School Head, LMT, Science Teacher, Islamic Religious Studies Teacher and Local Studies Teacher were interviewed.

ILE implementation was considered at the individual and school level. In Keris, the interviewees' responses indicated that they were either at the Early Use Stage or to be implementing ILE in the classroom, except for 
the SAA who did not implement ILE at all. At the school level, although the responses were wide ranging, it seems that the ILE implementation was at the Early Use Stage due to the factors affecting it.

For Badik, most interviewees individually were assessed as being either at the Early Use Stage or implementing ILE, except for the LMT and Ustazah. At the school level, most of them were uncertain about the extent of ILE implementation, with the exception of the School Head who was optimistic with her teachers' effort towards it. Thus, both case study schools were still at the early and "trial" stage of implementing ILE and in the meanwhile were juggling the existing factors that were affecting the school and the in-coming policy change in the primary school curriculum. Interviewees had to deal, adapt and adopt with multiple changes at the same time.

I have divided the factors affecting ILE implementation in Keris and Badik into five factors and sub-factors: (a) Characteristics of ILE; (b) Individual Implementer; (c) Implementing Organisation (School); (d) Ecological Context; and, (e) Implementation Protocols.

Both Keris and Badik shared similar facilitating conditions such as viewing ILE as important to student learning. However, most interviewees claimed they needed IL training. They viewed lack of IL training, teachers' attitudes and dependency on students' performance and syllabus topics as factors that hindered implementing ILE. They also highlighted other hindrances such as heavy workloads, lack of leadership support, students' and teachers' attitudes, limited resources and funding, lack of service and maintenance of equipment, students' attitudes, academic-cumexam orientation, leadership practice, class size, and existing school community's perception, and not having proper ILE Implementation Protocols as guides.

The factors found in both Keris and Badik were further explored in order to discover how these factors were affecting ILE in Malaysian primary 
schools. Both Keris and Badik interviewees mentioned time constraints, emphasis on students' examination, lack of confidence and lack of leadership support as reasons for limited implementation of ILE. They also could not see that the in-house training was adequate to help them implement ILE. Given the lack of leadership support, teachers of both case study schools had kept away from implementing ILE in classrooms.

In the next chapter, the findings from the national-type schools are presented. 


\section{CHAPTER 7 National-type Schools}

\subsection{Introduction}

This chapter reports the case study findings of ILE implementation in national-type schools, that is, Lembing and Kapak. The structure of this chapter is identical to the previous one.

The report of the findings begins with the factors relating to the first research question, and then, factors that relate to the second research question. The chapter concludes with a summary of the factors affecting ILE implementation in each case study.

\subsection{Lembing}

Lembing is the third case study school.

\subsubsection{Stage of ILE implementation}

As with other case studies, the stage of ILE implementation in Lembing was assessed from the individual interviews with the School Head, Science Teacher, Local Studies Teacher, Malay Language Teacher and Library and Media Teacher (LMT).

Both at the school and individual level, Lembing's interviewees provided almost consistent responses when asked about ILE implementation. The responses revealed that ILE was scarcely implemented in the school and some teachers could not accept it with an "open heart" as a teaching and learning strategy in the class. The Malay Language Teacher and LMT thought that ILE was about $20 \%$ to $30 \%$ implemented in the school. The Science Teacher said the implementation was "not much" and it was "less welcome" by the Local Studies Teacher. The School Head did not respond to the question. 


\subsubsection{Factors affecting the ILE implementation}

As with the other case studies, the factors that affected ILE implementation in Lembing are identified in order to understand ILE in this national-type school. Five factors are discussed: (a) Characteristics of ILE; (b) Individual Implementers; (c) Implementing Organisation (School); (d) Ecological Context; and (e) Implementation Protocols.

\subsubsection{Characteristics of ILE}

Findings about the Characteristics of ILE reveal Lembing interviewees' need for IL, the clarity of the IL concept and the complexity of its implementation.

\section{(a) Need for IL}

In the previous chapter, all interviewees of both case studies (Keris and Badik), when asked about ILE, noted that IL was an important skill. They thought the skills were needed for students' knowledge construction and teachers' self-development. The scenario was different in Lembing. Most of Lembing's interviewees did not see the need for ILE implementation in the school, as reported below.

When the School Head was asked what she thought about ILE in the school, she remarked that the school needs to meet the expectation of society on the basis of going 'by our environmental need'. She continued that,

Maybe this one (IL) can be implemented in Western countries but not in Eastern countries because the whole society is very much different between the Eastern and Western societies. So if we leave the students unattended like what the Westerners do, I think we will have a gap there. I think we are trying to follow the Western way but our country is still in an oriental mode. At the moment, if we want to follow what the Western countries said and give more freedom, I don't think our children can grow up in what we expected. (School Head) 
She believed that the Malaysian school children have to be nurtured in a way that was expected by their community because Lembing initially had been established and supported by the local ethnic Chinese community. The aim of this school is to promote and preserve Chinese culture, language and education. Thus, the expectation is that the syllabus should suit the demand of the community the school serves.

Moreover, the culture of Lembing was not conducive to ILE implementation. The Malay Language Teacher commented that the school 'culture' highly upheld the students' discipline so that the learning process could be done smoothly. He observed that the focus on discipline prevented the students from experiencing self-directed learning. As he saw it,

In this school, there is one culture that the students' discipline should be under control. Students of this school are too passive due to the disciplinary approach applied by the school. So normally the teachers do not encourage the students to work on their own. The School Head expects the same too in order to control discipline. In the eye of this school, the student-centred approach can create an uncontrollable situation. (Malay Language Teacher)

The Science Teacher thought the students would enjoy being self-directed and in an active learning environment. As he said, the students 'may like it [ILE]' and it would make it 'easier for them to learn'. But, he himself felt uncomfortable with the idea of implementing ILE because he would be unable to control the students' discipline in the class. Thus, both the Malay Language and Science Teachers maintained their traditional teaching method due to the school climate. ILE was seen as inappropriate for the existing climate.

In addition, when asked about their need for IL training, only two interviewees, the Malay Language and Local Studies Teachers, were interested in participating. Both were junior teachers who had about 7-10 
years of teaching experience. They were still young and very keen to develop themselves.

\section{(b) Clarity}

I had to explain to the interviewees about ILE and how it was related to the student-centred approach because they were unfamiliar with the concept. Lembing's interviewees then commented about ILE from the perspective of reading and language development, the inquiry method, 'generating ideas', group work and locating information. They spoke about the way they dealt with and handled their students in the class. They seemed to be conservative and unwilling to "divert" from the usual teaching.

The School Head, for example, when asked to comment on the studentcentred approach, was keen to explain how the school enforced discipline to ensure students developed their reading skills and habits:

We force the students to read for NILAM program. We can only force students through discipline. Basically they have to master the Language. To me, the key is the Bahasa [language] itself. The one and only way to encourage them to master language is through reading. In order to read, you have to force them. Once they love reading, they can master the language in the future. (School Head)

Further, the School Head added that the students had to be able to pronounce the Chinese passages properly. The challenge for the students was to read books in the 'ancient Chinese Language' which they could hardly understand. When asked what would be the situation after the students had mastered reading, she said they had to continue reading and memorising the proverbs 'until the time when the teacher thought that it was the right time to explain the meaning [proverbs] to the students'. The teaching and learning system in the school seemed to focus on the teacher as the knowledge authority.

The LMT, Local Studies, Science and Malay Language Teachers thought of ILE as a form of group activity in which the students would generate 
and discuss their ideas among themselves and with their teacher. The Science Teacher, when asked about the use of information and other resources, replied that he 'only used resources that were available in the class or in the lab'. The LMT as well responded that the students were allowed to search for information themselves when they were given homework. However, she said that 'during the group discussion [in the class], I did not allow them [the students] to go out from the class' to search for information. Hence, the interviewees seemed to confine their teaching activities to within the classroom walls.

In Lembing, the interviewees' understanding of ILE was still shallow. The teachers knew about the constructivist learning method but they were not practicing it in class. This was clear from my observation of the existing learning system and the teachers' teaching practices.

\section{(c) Complexity}

A few interviewees commented on the complexity of school conditions in relation to ILE implementation.

When discussing staff development and any IL training attended, the Science Teacher gave his opinion about the potential conflicts with the existing goals of the school:

The important thing is not about whether you attended the related training or not. But, it is about the implementation. I feel that the implementation is important. If I attended a related course, I still cannot apply the approach because it will not help to increase the school's performance in the exam. (Science Teacher)

The Science Teacher believed that he would be unable to practice what he might learn in the training courses because of the school's academic goals. He said that his teaching strategies must be in parallel with the target set by the school. Thus, it seemed that, with school's goals in mind, the teachers lacked the courage to be creative in their teaching approach. 
The problem of not being creative in teaching was further complicated by the issue of the teachers' heavy workload. The Malay Language Teacher commented that the teachers' 'outside-of-academic work' reduced the quality of their teaching preparation. He pointed out that

the teachers are so busy to fulfil the needs and want of the MOE, State, District and school itself. All the designated programmes which derive from them have to be done by the teachers in school.... In a certain way, the teachers' additional works have lessened the teachers' focus and interest to prepare for better $T \& L$ resources, and thus, hindered the implementation of studentcentred learning. (Malay Language Teacher)

He also saw the extra work as an obstacle to changing the existing teaching approach to a student-centred one including IL.

Thus, the complexity factors such as the non-transfer of training to the classroom due to school goals, and the teachers' heavy workloads, hindered ILE implementation.

\subsubsection{Individual Implementers}

This second factor addresses the qualification and competency of Lembing's interviewees and thus, leads to understanding their commitment and readiness to implement ILE in the school.

\section{(a) Qualification/ Competency}

Most interviewees, when asked about their staff development and training cycle in the school, responded that their opportunities were limited, but that they had been exposed to IL related courses during pre-service and early in-service training. Then, when asked about their exposure to IL related training recently, only the Local Studies Teacher had had any opportunities. The Local Studies Teacher received recent training about ILE due to the new introduction of primary school policy (KSSR). Among the reasons for the lack of training were: 
It [training opportunity] depends on the school administration. I have been here for years, but never had the chance to attend any courses. (Malay Language Teacher)

Many teachers are in the school and have to queue to attend any course. (LMT)

The interviewees indicated that their lack of exposure to staff development was due to the limited chance to be nominated by the school administrator and due to the large number of teachers waiting for the opportunity to attend related training. The interviewees indirectly made clear that their lack of exposure to staff development was due to the low level of administrative and leadership support.

On the other hand, when asked about their training needs, most interviewees appeared to lack interest with the exception of the Malay Language and Local Studies Teachers (as indicated in section 6.2.1). Responses showed that the Science Teacher and LMT were keener to teach their students in the school rather than attending courses for selfdevelopment.

The lack of IL specific training coupled with no interest in staff development resulted in a lack of IL knowledge and skills among Lembing's interviewees. As revealed by the Science Teacher,

I have never been to the school library to access to any resources.... Normally I provide the students with factual information. I hardly do any group work. (Science Teacher)

He described his non-use of resources in the school library and an unwillingness to engage his students in independent learning by allowing them to the library to search for information. Instead, he 'spoon-fed' his students with the factual information from the textbooks. Thus, he was not implementing ILE in the classroom. 


\section{(b) Commitment}

As with other factors, I have tried to uncover the interviewees' commitment towards ILE implementation. All interviewees in Lembing expressed their preference for using the traditional way of teaching, that is, teacher control or the teacher-centred approach, more than the studentcentred approach.

From the very beginning, we will control them or to force them...to discipline them... (School Head)

The School Head consistently emphasised the need for strengthening the students' disciplinary behaviour and the need to use force in promoting reading habits among the students.

Similarly, the Science Teacher was not open to the students but was concerned about the learning abilities of students when using a nontraditional way of teaching.

The outcome is not good because weak students cannot participate in the related learning activities... It will cause a disciplinary problem for being very noisy. I don't like students to be free on their own. (Science Teacher)

From his response, he equated non-traditional teaching to IL and appeared to be uncomfortable using the student-centred approach, and thus unable to implement ILE in the classroom.

The LMT and Local Studies Teacher, on the other hand, indicated that they used the student-centred approach whenever the syllabus or the students allowed them to do so. However, factors such as time constraints, fear of not completing the syllabus and concerns about the students' discipline, hindered the teachers from using the teaching approach that contributed to implementing ILE. Thus, the teachers felt unable to be creative in their teaching approach due to factors beyond their control. 


\section{(c) Readiness}

Most interviewees, when asked to describe areas most and least competent to implement ILE in their classrooms, expressed concerns about factors such as teachers' working conditions and teachers' perception of students.

When asked further about the teachers' working conditions, the Malay Language Teacher commented on the directive and instruction from the MOE, state, district and school levels. He thought the teachers at school were too busy to fulfil all the activities required by the four levels of education administration. Thus, the teachers had limited time to prepare for quality class instruction including ILE.

The LMT as well, when asked about her job, was unhappy because she had requested several times to step down from her post, but was turned down by the School Head. She said that at one time she felt really burntout. During the interview, she said that in desperation she suggested to the School Head to consider rotating the LMT's job every 5 to 6 years. She claimed that she was not only burdened by her role as a LMT but also with her heavy teaching load. On top of that, she lacked technical support for her role as a LMT and when she tried to obtain student assistance, the students themselves were also tied to their workbooks and homework.

With the heavy workload, the Local Studies Teacher was of the opinion that she had limited time to spend on the syllabus, thus, it was impossible for her to implement ILE. As she said 'the teaching approach slows down the teaching processes'. She thought that if ILE were to be implemented, the Local Studies subject should get an additional time allocation. To the Malay Language Teacher, LMT and Local Studies Teacher time constraints were an obstacle to proper implementation of ILE in the classroom.

The Malay Language Teacher also commented on the conditions required for implementation in which ILE could be readily implemented. Although he admitted that he did not have the time to implement ILE in his class, he 
could see that ILE could be 'successfully implemented on good-toexcellent students' rather than mediocre students. In his eyes, if ILE was implemented in a weaker class, it just wasted time. Thus, he viewed the implementation of ILE to be suitable for implementation only in a certain syllabus and in 'certain classes'. In addition, the Science Teacher and LMT believed that the teachers were not ready to implement ILE because to them the activities would lead the students to become uncontrollable and impolite.

Lembing's interviewees were not ready to implement ILE in the classroom because of their working conditions and the perception they had about the students' ability to accept and cope with the changing role of studentteacher relationship.

\subsubsection{Implementing Organisation (School)}

The organisation's capability influences the quality implementation of a programme. Thus, for the on-going development of ILE, it is crucial to look into the administrative and leadership factors as well as the climate of Lembing in order to understand the need and barriers to its implementation.

\section{(a) Administrative support}

The Science and Local Studies Teachers expressed their concerns about the availability of resources, and the Science Teacher in particular was concerned about the absence of technical support staff to support teaching and learning.

When the Science Teacher was asked about the factors that hindered the implementation of ILE in the lab, he said:

a part of [the factors] ... the students' discipline, let say if I wanted to do a project or an experiment in the lab, I do not have any lab assistant to help me. Therefore, it is not easy for me to let the students to prepare on their own. (Science Teacher) 
The Science Teacher also explained that the reason he did not go to the school library or take his students to the library was because 'information resources in the library are limited'. Hence, to him, these two issues, i.e. no lab assistant and limited library resources prevented him from implementing ILE. The same issue of library resources was posed by the Local Studies Teacher who thought that there were 'no suitable [library] resources' for her subject. This hindered her from using the resources in the library.

On the other hand, when the same question was asked of the School Head, she was convinced that Lembing had adequate funding and resources. She also stressed specifically that the 'fund for the library is more than enough'. She went on to say:

I think, as schools get the funding every year, according to the number of heads in school, so we can get the most for the library. Among all the subjects/sectors, the PSS [school resource centre] got the most. We also get some donation outside also. He is an old boy for this school. He is about 70 years old. He is a librarian in one of the Hong Kong universities. Last year, he paid a visit to the school. He went to see the library. He was really amazed. He donated books from China because the books from China were really cheap. After that he sent me a few pages of book lists and asked me to choose the books. He sent three boxes of library books from Hong Kong to the school. This is what I can get the resources... In fact I do not have any problem with the budget of the school. If I want, I can get anywhere for the funding. I am lucky because I do not have any financial problem in buying books. (School Head)

In terms of the school facilities, she continued saying that "we have a computer lab with internet connection.' She looked very pleased with what the school had.

Hence, funding did not appear to be an issue for Lembing. The issue was the misunderstandings that existed between the School Head and the 
teachers. The School Head thought that the school resources and facilities were 'enough'. But to the Science and Local Studies Teacher, they seemed to be insufficient to support the implementation of ILE in the school.

\section{(b) Leadership and support}

Lembing had a female School Head who led the school for 15 years. In this study, her tenure as a head of school was the longest among all other participating heads. My impression when I first met her was she was confident, friendly and talkative even to a person she had just met like me. But as a leader, I could see that she was strict and determined. Thus, I was eager to find out about the way she led the school, including the decision making process, as explained by her and from the perspective of her staff.

When asked about her support of ILE implementation in the school, the School Head pointed out, "we try to participate in all activities organised by the TAC. The programmes are, from time to time, such as Rakan Pembaca [Peer Readers], NILAM [Reading Competition], and we try to participate in full power...' When asked about the teachers' support for the activities, she recognised the LMT's dedication and hard work:

I have a very good and a very responsible LMT. Once you visit the school resource centre (SRC) then you know what I tell you. Maybe just because of her hard work so the NILAM program can work so smoothly and can be considered quite successful in my school. So you can see my students holding books during the recess time, and even I bring them up for the competition, during the competition session they will read the story books. But I cannot say a very high percentage... I put it this way, more than $50 \%$ of my students really enjoy reading. (School Head)

The School Head also said that she initiated ways of involving the teachers to spark students' interest in reading and motivating the parents to invest their money in the school. She went on and said: 
We also try to promote some good magazines to the students during recess time. The teacher in-charge would set up a stall... and the business is very profitable. They really queue up and buy. Beside that I will do the book exhibition. At least once a year during parents' day... So parents' day is the day where the parents come to school and collect the report card. Normally, in May. Half of the school session will be the normal class day. Starting 11.00 a.m. and above the parents will come, collect the report card and interact with the teachers. I take this opportunity to set up a book exhibition in my hall. So the parents do not have to go to Ipoh [a capital city] to buy books. Normally I will have it once or twice a year. This is the only chance to force the parents to come to school. (School Head)

From the way she administered the school, she seemed to be confident with her leadership practices.

I could also see that she was a dominant character and could make the teachers obey her instructions. This was clear from her statement: 'the teachers know what we want. Actually we have the academic panels. So the academic panels' teachers know and the LMT will call them for meetings and tell them what we are looking for.' It was also evident from a claim by the LMT who said 'I follow whatever are the wishes of School Head'. The Malay Language Teacher as well said that any programme in the school was 'hardly discussed with the teachers'. He indicated that teachers were not consulted about any school activities or programmes planning. Thus the teachers had to execute the school designated programmes without questioning.

Lembing was led by a leader with strong personality who seemed to "know what was best for the school", and this seemed to result in a situation where the teachers had limited voices and resisted change. This kind of school environment was not conducive for the implementation of ILE because the School Head did not think that it was best for the school. 


\section{(c) School climate}

Throughout the individual interview sessions, Lembing's interviewees addressed mostly the need to maintain students' discipline. They thought that when discipline was maintained in the school, the teachers could direct all their energy towards teaching and learning activities and achieve the school's target for students' high achievements in examinations. This was why the School Head, from the very beginning of the interview, kept on reiterating the need for teacher control and teacher authority in the school.

Lembing was also unique in terms of its effort to promote a reading culture within the school community. As mentioned earlier, the School Head was serious about getting the students to read. In the early primary schooling, the students were required to 'memorise and read, read, read and until some time, the teacher [would] go to explanation. The students will memorise without understanding from the beginning of the stage.' The School Head claimed that this learning system was 'what [the] Chinese society wants to do, to train their [the students'] reading and to train their memories'. To the Chinese community, reading is a very important skill.

Another unique feature of Lembing was the heavy use of workbooks in teaching and learning. The Science Teacher said 'to achieve the school's target, I believe that the more students work on their exercise books, the faster the school achieves its target in examination results.' The Local Studies Teacher also shared the same thought. She was used to the idea of 'lots of workbooks' as homework because she was formerly a Lembing student. After completing her teacher's training, she went back to serve her old school. Due to much homework, the LMT said that the students 'had no time to go to the library to search information'. Thus, not only the teachers had limited time to be creative in their teaching and learning, but the students also had restricted time to be creative and enjoy their childhood. 
As a whole, Lembing had a regimented school climate. This is evidenced by the enforcement of discipline to ensure smooth teaching and learning, reading and memorisation exercises as well as heavy reliance on academic workbooks. There appeared to be no opening for ILE to be implemented in such a school climate.

\subsubsection{Ecological Context}

This study identified macro level factors such as those related to the community or society, district and state administrators, and government and other agencies in order to understand the reason for the limited implementation of ILE in the school.

\section{(a) Community/Society}

The School Head, when asked about the parents' involvement in the school, was happy with the involvement of parents in school activities. As she said, 'whatever activities are organised by the school, I will get a good response from the parents'. The parents put their trust in the school to educate their children.

But when asked further about the parents' support after school, the School Head expressed her concern about the parents' parenting skills. She felt that the parents placed their full trust on the school not only to educate their children but also to "babysit" them. This was her comment:

At the rural area, the parents' education level is average. They cannot even assist their children at home. Especially Chinese, they spend the least time with their children. The parents really depend on school. That is why we had a hard time to teach them Malay and English because they really lack of exposure. They only meet Malay and English in the school, half an hour only. That's all. I dare not say $100 \%$ but nearly $80 \%$. Another thing, they have sent their children to tuition, I [the parent] pay the tuition and my [the parent] duty is finished. This is what the rural parents act. From school, pick their children. Then go for lunch, change their dress in 
the car, send to kindergarten, day care, or tuition centre. The mother will go for shopping or facial ... Then 7 o'clock take them back. Then watching TV and bathing time. That's all. (School Head)

The School Head felt that the parents' low education background but high earning power made the school take some of the parents' responsibility in the children's education. For her, at the moment, the school was a handful of academic and other activities. Therefore, she personally believed that the school had a difficult time to focus on change because, as she said,

We should go by our environmental needs. So to me la, if you said give them [the students] more freedom like what the Western [schools] do, I don't think at the moment we can. I don't really agree with that, unless the parents can really care [for] their children. (School Head)

To her, the parents would have to change in order for the school to change and implement IL.

The School Head also spoke about the influence of the society on the parents. She told me about an experience of parents with a special needs child who had to struggle to provide proper education for him:

I have one student Year 4. This year go for home schooling, because the parents are lecturers. The son is facing a physical problem. So he cannot manage to follow the Malaysian education system because we have certain syllabus to cover at certain time and all these ... Just because of the medical health reason, the parents intend to put his son in home schooling. But it is a hard time for the mother also. Just because of the Eastern and Western countries, the mother faced a lot of problem at the beginning stage because she has to guide the son from time to time. But home schooling in Western countries is very common. Let say the parents [Malaysian parents] do home schooling at this moment, they still do their own way [traditional way of teaching and learning], and the children follow the home schooling, what do you 
think? I think the parents should change before they change the children. But how far do our parents change? (School Head)

The School Head thought that in order to use an unconventional learning approach that is common in other cultures such as home schooling, the parents here had to be ready to modify their beliefs and behaviours. It was quite difficult in the beginning because the parents were educated in a conventional manner. Thus, the issue was to what extent the parents were willing to change. Since the parents seemed to live in an environment that was neither supportive nor conducive to the child's need, the School Head believed that the parents would face a hard time accomplishing their mission. She also believed that it is up to parents to prepare themselves for change through reading and gathering information.

The scenario of parents' influence in Lembing was different from the other two case studies. The interviewees at Lembing reported that the parents participated and trusted the school to the extent that they tended to neglect their own role as parents. Unless the parents were willing to change, their over dependency on the school gave the school "extra baggage" to carry. Thus, the school had no way to be creative and innovative and was unable to prepare an environment for ILE due to the parents' background.

\section{(b) District/ State}

When asked about the support from the district and state administrators, the interviewees' comments were very general because they hardly dealt directly with them. Most of the time, the School Head and Senior Administrative Assistant would interact with the district or state administrator. Therefore, in Lembing, the LMT, Local Studies and Malay Language Teachers only commented in terms of staff development and training, and the communication between the school and the higher level administrators.

When asked about ILE support from the district and state level, the LMT who had served Lembing for the past 15 years, responded that she had attended several job related courses especially during her early years as a 
LMT. The courses were organised by the district, state and federal bodies. But none of the courses were specifically about ILE. Further, she commented on the lack of proper guidebooks or manuals specifically for her job. She had not received any throughout her position as LMT. There was one that she showed me, that is, the NILAM (Reading Competition) guidebook, but it was a photocopy, not the original publication. Thus, she had no guidebook to implement ILE in the school.

The Local Studies Teacher said she had attended KSSR (new primary school policy) courses organised by the SED. She was given the chance to attend the courses because she was teaching Year 1 classes, and the policy commenced in early 2011 for Year 1 primary school (see 4.3). During the courses, one of the assignments was to prepare an IL-related activity plan. Her only comment about the training was 'lack of training for classroom implementation'. She actually expected more than a lecture-based course, such as a hands-on session with role playing or mock teaching where she could learn to apply the skills in the class.

In addition, when asked about the factors that hindered ILE implementation, the Malay Language Teacher highlighted the teachers' work burden, and associated the heavy workload with poor communication among the four levels of education administration (the MOE, state, district, and school). He suggested that all levels had to 'sit together' and think through the multiple policies and programmes introduced so that they were 'not redundant', and 'teachers' heavy workload and burn-out' could be reduced. To him, if the teachers were given some space, they would have quality time to prepare for the class. Hence, the district and state administrators had to prioritise any plan and policy and show more empathy with the teachers and students.

On the other hand, the School Head commented that Lembing was given support to improve language learning. For example, Lembing was selected to participate in the English programme by the SED where the school received an English native speaker to assist the teachers in the English 
Language. She was delighted with the selection because she believed that learning English was crucial. As she pointed it out,

for me, Guru Bahasa [Language Teacher] have to force them [students] to master Bahasa [Language] because Bahasa is the kunci [key]. You do not know Bahasa, you know nothing. You can't even access the internet. (School Head)

To her, learning English was a prerequisite for accessing more knowledge and information. Such support by the SED was only given to selected schools based on their merits.

\section{(c) Government and other agencies}

When asked about the role played by the Government and its agencies, again the Malay Language Teacher talked about the multiple plans and policies by the four levels of education administration, and the need to sit together and find solutions to avoid redundancy of activities. To him, this issue, if not taken care of, would jeopardise all the aspirations of the education system.

The Local Studies Teacher's comments were directed towards the improvement of the existing syllabus. She wanted those persons in-charge of curriculum development at the MOE to add more visual information, and publish more Local Studies information resources in the Chinese Language. Thus, this revision was expected to add value to the syllabus and its textbooks as well as to make the syllabus content more accessible to other ethnic groups.

In addition to the role played by the government agencies, the School Head mentioned the support from a corporate body, namely, Malaysian Airline System (MAS). MAS had adopted and supported Lembing, but was not providing direct funding. Instead, MAS conducted the enrichment activities and programmes for the students as well as supplying tools and equipment needed by the school. 
As a whole, again poor communication was the issue for the interviewees when asked about the macro level's support for ILE. At the community level, the parents as members of community put their full trust on the school to the extent that the school was unable to communicate with the parents to convince them about their responsibilities after school hours. At the district, state and government level, each body administered its own agenda and initiatives which were often duplicate and redundant. As a result, the factors at the macro level contributed to the heavy workloads and lack of time for teachers at school becoming factors that hindered ILE implementation. Another concern was the need for syllabus revision, particularly for Local Studies and Malay Language teachers, in order to enhance the readability of its content among Chinese primary school students. The lack of proper information resources was another hindrance factor to ILE. Thus, in this context, poor communication and information resources affected the on-going ILE development in Lembing.

\subsubsection{Implementation Protocols}

When asked about the ILE guidebooks or manuals used to implement ILE, only the LMT and Local Studies Teacher responded that they had not received any.

The Local Studies Teacher said that 'most of the time, teachers have their teaching plan books to plan activities based on the syllabus'. However, she also commented that the activity plan was not written explicitly in the teaching plan book. She added that after attending courses on KSSR, she started to prepare IL specific activities for each syllabus topic. During the course assignments, she was trained to prepare explicit classroom activities.

Both the LMT and Local Studies Teacher claimed that they did not possess any ILE guidebooks, IL lesson plans and other protocols, even though the protocols were made available in the ETD portal. The Local Studies Teacher, despite not having any guides to implement ILE, had the 
opportunity to attend KSSR courses which helped her to plan explicit activities based on student-centred approach.

\subsubsection{How do these factors facilitate or hinder ILE implementation in Lembing?}

In terms of ILE implementation, Lembing could be categorised as a nonimplementer based on the evidence gathered. Interestingly, the social and cultural as well as organisational factors were the dominant factors that hindered the implementation.

In order for change to take place in an individual or organisation, one or more members of the organisation had to be willingly to put the change into effect. For example, in the case of Malaysian ethnic Chinese, they are well-known for their entrepreneurial activity. This implies they are likely to be risk takers in terms of their economic behaviour. However, this behaviour was unlikely to happen in their schooling system. The Malaysian ethnic Chinese were protective of their schools. They had the tendency to maintain their status quo and appeared to be unwilling to change.

When asked about the factors that affected the interviewees of Lembing, the responses were common as in the other two case studies, that is, the lack of IL knowledge and skills, lack of training, lack of availability of information and resources, and students' attitudes. However, all these factors were actually derived from social and cultural factors. This was clear at the organisational (school) level. The School Head, when asked about the possibility of implementing ILE in the school, said she was determined to drive the school in accordance to the needs of society. She felt that the society was not ready to 'follow the Western way' because the society wants their future generation 'to grow up in what we [society] expected.' The School Head believed that any shift in their school pedagogy would be harmful to the durability of Chinese culture and Language. 
Similarly, when asked about the staff development and training opportunities for teachers, the Science Teacher talked about attending training and its potential conflict with the existing structure of the school. Whenever a training course delivered a new approach or syllabus and it was not in line with the aim and philosophy of the existing syllabus, the attendees might not have the chance to apply it in the school. Thus, the teachers were unable to implement the new approach as intended because of this constraint. Thus, at Lembing the school culture was an obstacle to ILE implementation.

As a whole, because of the need to protect and promote the Chinese culture and language through schools, the teachers of Lembing had to maintain their traditional and conventional way of teaching and learning. In addition, Lembing had a powerful leadership figure who was strongly protecting the traditional characteristics of the school. This leadership factor is sufficient to explain the lack of IL training and, thus, the lack of IL knowledge and skills. Certainly any flaws in the school, such as limited suitable information resources as viewed by the Science and Local Studies Teachers, was not acknowledged by the School Head. Thus, the factors that hindered ILE implementation in Lembing were partly because of the aim and philosophy of this ethnic-based school and also because of the directive, authoritarian leadership. The school ecology created an environment in which ILE was unable to thrive.

Secondly, none of the Lembing's interviewees spoke about the in-school training. In-school training could be an important platform for a teacher who attended any course outside the school to share his or her courserelated knowledge and skills with other teachers in the school. However, the sharing of training knowledge was not a practice in Lembing. So, there was no formal opportunity to share knowledge of IL.

The School Head did mention support received from the corporate sector, namely, Malaysia Airline System's adopt a school programme, and from 
SED's English Language programme. These supports were beneficial to students, teachers and school as well. However, as highlighted by the School Head, the support that Lembing received was due to its merits, which implies that the school's academic achievements were approved by the state government and the corporate body.

In short, Lembing's interviewees did not mention in-school training. The training could be almost non-existent because of the absence of opportunities for the teachers to attend courses. The teachers had no way to communicate and share their ideas or knowledge because of the "missing" in-school training.

Third, members of an organisation should have similar needs and wants for change. But in the case of Lembing, the need to protect the Chinese culture and language through schools was so critical that any change of pedagogy or teaching practice was seen as harmful. Thus, the whole school shared a similar understanding of the importance of upholding the aim and philosophy of the school.

As can be seen from their shared views, most interviewees seemed to be unprepared for a new teacher-student role which saw more engagement and involvement in the classroom. They consistently thought that the students had to be well behaved so that they could learn better in the class. The teachers also could not tolerate it if the students were being impolite or noisy in class. The teachers believed that if ILE were to be implemented, their energies would be wasted and they would have less time to teach the students.

Hence, the predominant view of the need for students' discipline among Lembing members was a hindering factor to ILE implementation because it acted as a barrier to modifying the student-teacher role. The teachers maintained their role as "sage on the stage" which led to dependent and passive students. Similarly, the fact Lembing was headed by an 
authoritarian leader created dependent passive followers as well as nondirective teachers. The implementation of ILE in this kind of ecology was hindered by a "mismatch problem" with respect to the teacher-student and leader-follower relationships.

\subsection{Kapak}

The fourth case study school is Kapak.

\subsubsection{Stage of ILE implementation}

At the school level, most interviewees had varied responses when asked about ILE implementation. In our first meeting (which lasted for about 3 hours), the School Head indicated that whatever directives or new policies were introduced by the MOE, the teachers had 'implemented 100\% [them] as required by the government, but the effect was not visible'. Thus, in the case of ILE, she believed that the teachers might have implemented it but she was still unconvinced that ILE could be recognised due to its invisible effect on the students' knowledge construction.

Interestingly, just a week our first meeting, the School Head planned to implement ILE to selected Year 6 students prior to their public examination (UPSR (see section 4.3)). She told me in the second meeting that she and the Year 6 teachers were planning to implement ILE to excellent students of Year 6 by placing them in the school library. The students would be given topics or activities to do, and a teacher would facilitate them in the school library. She said she wanted to see to what extent the students are capable of becoming independent learners'. The implementation was expected to take place after the entire syllabus was completed and thus, the teachers had ample time. This plan was considered a trial because the School Head wanted to see how ILE could help to improve students' preparation and confidence in public examinations. Thus, the school planned to try out ILE but only to selected students and class. 
In terms of ILE implementation, Kapak was at the Early Use Stage of implementation (level 2).

The responses received at the individual level were in line with the school level. The Malay Language Teacher, for example, provided positive indication of the implementation of ILE in the school. She thought that the implementation was 'good'. She said:

All students and teachers are given the chance. All teachers can teach any time. We are provided with time table, schedule to bring students to the computer room, operation room, school resource centre, TV and others. At any time, we can search for resources in the school. So, the school surrounding is good and we have no problem with it [ILE implementation]. We can always improve it from time to time. (Malay Language Teacher)

In fact, the LMT also said that 'many teachers use [the] student-centred approach', which could assist the implementation of ILE. She further elaborated on her efforts as a LMT to ensure ILE was being implemented in the school.

As a Media Teacher, I arrange all the classes once a week for a school library session. The students can apply IL. The teachers teach the students to locate information from books, magazines or encyclopaedia. This is one of the library skills. (LMT)

She thought that her duty as a LMT was to prepare a schedule for a library session for each class, and then the provision of the avenue for the teacher to teach students the skill of locating information was an act of implementing ILE.

The Local Studies Teacher as well implemented ILE in her teaching and learning because she saw the importance of ILE.

When I enter the first class, I will only discuss about the overview of the topic. Just before the first class ends, I will tell the students the topic that I will teach them in the next class and ask them to go back and read and find information regarding with the topic. 
Whenever I enter the class the next morning, it is easier for me.... I will practice that every time I start a new topic...thrice a month. (Local Studies Teacher)

Thus, at the individual level, most interviewees believed that they were working towards ILE implementation. But what motivated them varied depending on factors internal and external to the school.

\subsubsection{Factors affecting the ILE implementation}

I identified five factors that facilitated or hindered implementation of ILE in Kapak.

\subsubsection{Characteristics of IL}

As with other case studies, the examination of the following characteristics of IL itself helps to understand the extent of Kapak's interviewees' needs for, and clarity of, the IL concept and its goals, and the complexity of ILE implementation.

\section{(a) Need for ILE}

All Kapak's interviewees, when asked about ILE, viewed it as an important skill for teachers and students.

The School Head, for example, 'liked the idea...' She felt that ILE gave more freedom for the students to engage and be involved as well as to be in control of their learning activities. As she pointed out,

the students can access information themselves. Teacher is as a facilitator. There is no emotional disturbance. They can learn whenever they want. Their minds develop and learn according to their capabilities. (School Head)

However, she thought that a 'certain group of students can follow this approach [ILE] ... but may take some time [to adapt to it]'. She seemed to have the idea that ILE was only suitable for selected students. 
When further asked about her IL training, the School Head said that she had many opportunities, 'but [was] not interested because had lots of work to do'. She added, 'I attended the courses so that I can guide my teachers'. She claimed that she was not interested in attending courses but she did it in her capacity as school administrator who had to be knowledgeable and guide the teachers to implement the plans and policies introduced.

The Local Studies Teacher saw the need for ILE because she reflected on the students' behaviour towards her teaching approach in the class.

In my first day of teaching, I taught them in a traditional way. The students showed bored faces. They asked me lots of questions and I could not answer them... so the next day, I changed my technique. (Local Studies Teacher)

She had to change her teaching approach because of her students' reaction. She further expressed her preference for ILE because the related approach allowed her to complete her syllabus easily. When asked about IL training, she was eager to attend the course so that she could improve herself. I received the same response from the LMT. She said that 'if I were given the chance to attend a related course, it will be good because I learn about IL more in-depth'. Both the Local Studies Teacher and LMT appeared to be in need of IL training in order to develop their IL knowledge and skills.

The Science Teacher believed the student-centred approach was more effective for level 2 (Year 4, 5, and 6) students than level 1 (Year 1, 2, and 3) students. To her, 'level 1 students still need teacher's input.' She thought that a student-centred approach was suitable for older primary students. Similarly, the same approach seems to be appropriate for implementing ILE with level 2 primary students. When asked about her IL training need, the Science Teacher said that 'the teachers need to be trained on how to integrate the use of ICT in the subject matter'. She perceived IL training as a course related to ICT use. 


\section{(b) Clarity}

Most of Kapak's interviewees, when asked about the understanding of IL, viewed ILE to be about the skills of using and locating information resources from the internet. Other views about ILE were related to the student-centred or constructivist learning activities such as group work or independent learning. The interviewees discussed ILE based on their teaching practices in the class. Their understanding of ILE and its goal appeared to be consistent with the findings of other case studies.

The Local Studies Teacher explained how she implemented ILE in teaching and learning strategy.

In the beginning, I will teach students on how to locate information. Later, the students can search themselves. Many students here are able to search information from the internet.... I will let them present the information that they had accessed from the internet and presented in front of the class.... I will only correct them if there is any [misinformation]. (Local Studies Teacher)

She perceived that teaching the students to locate, use and present the information related to their work was a part of her implementation of ILE. She acted as a 'guide on the side' rather than a "'sage on the stage'. When asked about teaching the students about internet usage and how to evaluate the sources of information, she said that 'the students were taught about the do's and don'ts of websites in their Moral classes'. She did not teach her students how to select information resources because the students learned about the selection process in other classes. When asked further about her awareness of ILE, she answered 'IL means the use of information in the computer'. However, she was not alone in understanding ILE in terms of the use of internet or computer or ICT. The LMT and Malay Language Teacher had similar opinions.

The LMT viewed IL skills as students' abilities to use ICT. As she pointed out,

The students of this school are good at using ICT or internet. It is evidenced in their folio assignments.... They had downloaded 
many resources from the internet. In fact, they already knew how to locate information via websites (LMT)

The Malay Language Teacher as well echoed the ability of 'clever students to do their work independently and locate information... and use computer to prepare for their folio assignments'. In contrast, the weak students were 'locating information via newspapers or magazines'. She thought that the smart students were ICT savvy and the weak ones were manual information searchers.

The Science Teacher described ILE in terms of students' independent learning. She was certain that 'Year 4, 5, and 6 students are able to conduct experiments on their own'. She told me that 'in a year, at least four experiments had to be completed by the students.... The students are arranged in a group [for the experiment activities].... The teachers had to provide complete instructions for the experiments'. She believed in group work where the members of a group were a mix of excellent and weak students. The rationale was 'so that the students could learn with each other'. Thus, she seemed to be open in her approach to the students.

\section{(c) Complexity}

When the complexity factor is highlighted in this study, certain existing conditions are seen as contributors to the existing dilemma. In the case of Kapak, the dilemma of implementing ILE is related to the school ecological factors affecting the maturational level of the school community.

The School Head believed that the school had not fully implemented ILE because the teachers were not used to the student-centred approach. However, she was optimistic that 'it can bring more benefit. Teachers' workload can be reduced. Students can learn independently'. What made her think that ILE was not easily implemented in the school were factors internal and external to the school. She identified the school infrastructure, 
students' high academic performance and parents' background as contributing factors to the complexity of the implementation. The one she highlighted most she phrased in terms of the immaturity of teachers and students with respect to their understanding of student-centred learning:

Actually the concept of student-centred learning introduced by the MOE is good. But our teachers and students are still not matured to accept the concept. If we practice it in a class, there is a tendency for the class to fail in the exam. This is due to the fact that every two months, the students have to sit for standard test. (School Head)

The School Head thought that the teachers and students were not ready for the change, and would become ready only if the school infrastructure was in place and students achieved high academic results due to parental support. In addition, she said that the examinations took place so frequently in the school that there was no way to escape. She seemed to relate the teachers' and students' immaturity in terms of their understanding of student-centred learning with factors such as infrastructure, examination orientation of school and expectation of parents. These diverse sets of factors were the focus of the School Head's concern and became her reasons for setbacks in ILE implementation.

\subsubsection{Individual Implementers}

Consideration of the interviewees' qualifications, competency, commitment and readiness to ILE are further factors that help explain ILE implementation in this national-type school.

(a) Qualification/ Competency

When asked about recent IL training opportunity among Kapak's interviewees, only the School Head and Malay Language Teacher had the opportunity to attend the training. The rest of the interviewees had not attended any IL training. Most of them, however, claimed they attended IL related courses during pre-service and in-service trainings which were 
about three to five years ago. The interviewees' opportunities to attend courses and trainings varied.

In Kapak, the School Head and Malay Language Teacher received the most recent training of ILE due to the introduction of KSSR. The new policy commenced in early 2011 for Year 1 student. Therefore, in the beginning, only Year 1 teachers had the chance to attend related training. Other interviewees have had to wait for their turn to attend similar courses because training opportunities for teachers were based on their teaching option, that is, subject specialisations and levels. Thus, the teachers could not choose to go to any training that they wanted. It was the school administrator or the school management who decided the professional development of staff rather than the teachers identifying their need for and choosing their training.

When asked about her training attendance and experience, the School Head claimed that she was not interested in attending courses because of her heavy workload. As mentioned in section 7.3.2.1(a), she attended the courses in order to be able to guide teachers. She commented:

It was compulsory attending the assigned courses.... So when I was asked to go, I went.... When you were there, you could relax and forget about your work here [at school]. During the training courses, teachers' absorption of the course content was about $20 \%$ to $30 \%$. (School Head)

The School Head felt that attending training courses was not only her responsibility but a "burden" as well because she had to neglect her work at school. She thought that teachers' concentration in the course varied depending on their interest on the topics presented. She also indicated that 'most teachers do not want courses related to teaching and learning' and as a result, most in-school training was not related to teaching and learning, but focused on health and beauty tips, stress management and other "worklife balance" related courses, as requested by the teachers. 


\section{(b) Commitment}

When speaking about their commitment towards ILE, most interviewees had their own reasons for implementing or avoiding ILE in the class.

The Local Studies Teacher said that she did some preparation prior to attending her class, as follows: 'before teaching a topic, I will learn the topic initially, get the information, locate information from the internet or from books.... After doing that, and then only I enter the class.' She said that she needed to be ready in the class to guide the students and used this approach 'three times a month... every time introducing a new topic'. This teacher believed that doing this preparation could help her to guide students better as well build her confidence with the additional knowledge that she gained.

When the LMT and Malay Language Teacher were asked about their commitment, both agreed that ILE was important. But they had not really implemented ILE in their classrooms due to several reasons. The LMT, for example, claimed that she was 'teaching the Year 6 students. So the focus is on the UPSR, preparing the students for exam'. She continued saying that she could not implement ILE in Year 6 classes because 'our main purpose as teachers is to prepare the students for examination.' She made it clear that the goal of teachers' teaching and learning was the students' achievement in the examination. She stressed that time was a factor that hindered the implementation of ILE in her class.

As for the Malay Language Teacher, she preferred a teacher-centred approach due to the 'different level of students' in her class. She needed to use different teaching styles to suit students' different levels of intelligence. She said she was only able to commit herself to a studentcentred approach for $30 \%$ of her teaching time. Despite not implementing a student-centred approach, she believed that the approach was helping to attract the interest of her students. She said that 'I often let my students to stand in front of the class, present their ideas...so that it could reduce their stage fear and encourage [them] to be brave' thus helping to build 
students' self-confidence. Both the LMT and Malay Language Teacher were concerned about the students' academic achievement but appeared to lack the confidence to use a student-centred approach.

Teacher commitment to change such as ILE implementation is very much related to his or her need for ILE, the clarity of the concept as well as practicality in the class. This became clear in the comments received from the Local Studies Teacher which illustrated that the more ILE is implemented in the class, the better the chance for teachers to continue with and get used to it. However, teachers who were only experienced in the traditional way of teaching believed it would enable students to achieve better examination results. Thus, they were reluctant to try out a new approach that they were not confident of. Hence, the teachers' commitment was related to their confidence in implementing ILE themselves.

\section{(c) Readiness}

When asked about readiness to implement ILE in their classrooms, the interviewees' answers varied. Most respondents expressed either their constraints or suggestions for improvement. Among the factors discussed by the interviewees were students' attitudes towards learning, teachers' attitudes and student-teacher relationship.

The Local Studies Teacher, who was positive about ILE in the classroom, thought that students' pre-class preparation to be ready for the new lesson could help the ILE implementation itself. She expected the students to do 'some research' such as 'locating and accessing information' in order to gather prior information about the new subject matter. She also thought that teachers should also do the same preparation before teaching the class. Thus, she believed that students' attitudes towards learning and teachers' preparation prior to coming to the class could either hinder or facilitate implementation. 
The Malay Language Teacher also commented on the teachers' attitude towards work. She had a similar opinion to the Local Studies Teacher, i.e. that teachers had to do 'more preparation' before entering the classrooms. This was to ensure the teachers were ready to implement their teaching plan. Moreover, she also said that 'no one is perfect'. Therefore, she believed that teachers should continue learning and improving themselves. She also highlighted the fact that to be a good teacher, the teachers 'do not have to be afraid to ask questions.' She spoke based on her teaching experience. She had her pre-service training specialising in Tamil Language education and was not trained for teaching the Malay Language subject. But due to lack of Malay language teachers in the school, the School Head requested her to take up the subject. In the first two years of teaching this teacher received many complaints from the students and their parents because of her ineffective teaching approach.

The School Head herself told me that the Malay Language Teacher had improved a lot in terms of her teaching strategies due to her passion and because she was 'not shy to ask and learn from other teachers'. At the time of the study, the School Head had given this teacher a huge responsibility to teach the Malay Language subject for Year 1. The Malay Language teacher herself was willing to be open to peer-to-peer learning and taught herself to be an independent learner.

The Science Teacher said that teachers had to be open with the students in order to encourage them to be independent learners. She believed that students should be given 'opportunities' to 'do what they want... and selfdirect their learning'. However, the LMT saw that the opportunities were limited due to teachers' time constraints. She was actually concerned about the limited time allocation for school library sessions for each class.

\subsubsection{Implementing Organisation (School)}

ILE needs a conducive environment or ecology, that is, appropriate administration of resources and staff, and coordination of activities for its 
on-going development in school. It is crucial to identify the kind of ecology characterised by the administrative and leadership support, the school goals and climate that was in place at Kapak to understand the extent of ILE implementation along with the factors affecting it from the interviewees' perspectives.

(a) Administrative support

Compared to the previous three cases, Kapak's interviewees seemed to be pleased with the school facilities. Their only concerns were about the limited internet access and funding.

The Local Studies Teacher, when asked about the ILE support, replied that 'internet access is limited.' She said that when she was in the classroom, she was unable to access information from the internet. To her, this was a factor that hindered her ILE implementation. When I asked the School Head about the internet access, she also gave a similar answer. She said that the school had limited access to the internet and insufficient computers or laptops for the students' use. She added that the school had to rely on 'individuals and private corporations' to sponsor some of the school facilities because the government funding was not enough to support the school operation.

On the other hand, the Malay Language Teacher thought that 'information resources and reference sources in the school library are adequate...' She believed that students could benefit from the resources in the library through regular visits. She thought that the only part that needed to be improved was 'the facility to locate information in the school'. She suggested that the school library should have an automated catalogue system so that books could be easily accessed.

The Science Teacher as well, when asked about the school facilities, said that 'all resources and equipment for Science subject are complete.' She had all she wanted to teach Science. She believed that the school had adequate school facilities because 'the School Head is often helping the 
teachers' to fulfil their needs and wants. She believed that leadership support had helped the teachers to perform better in teaching and learning.

(b) Leadership and support

As with other case studies, Kapak had a female school head. She had been a school administrator for 21 years. From my observation, she seemed a hard working administrator. She was always at her desk, if she was not teaching in the class. While she was in the office, the teachers, one after another, kept coming into the office to consult her. I also found that she would spare time for her teachers to see her without any appointment. Thus, with such a lively first-hand experience being in a school where the School Head was very approachable to the staff, it was interesting to know from the School Head herself about the way she managed the school, including the decision making process and the teachers' views of her.

In the beginning of the School Head's interview session, I asked about the way she ran the office. I told her that I could see the teachers kept on consulting her about matters relating to the school activities. I wondered, was there any upcoming event that the school was preparing for, but she told me that was a normal phenomenon in this school. She said that the teachers would always want her to be involved or at least be there for them. Hence, her advice was that 'as an administrator, you must read a lot... must know better than your staff.' Reading seemed to be a part of her habit which also helped her to perform her work and deal with her staff members.

The School Head would always want to be updated with any information relating to the school activities, teachers' and students' welfare. She told me that she had organised a 'contact time every two weeks' to motivate teachers and keep abreast with the latest development of teachers and students. The Local Studies, Malay Language and Science Teachers also talked about this same fortnightly meeting. During the 'contact time', she 
told me that the teachers discussed their students' academic performance. If there were any problems with students, they would try to find a solution together. Amazingly, she told me that she knew all the 500 students and their performance in class. I received confirmation of this from the Local Studies Teacher about the ability of the School Head to remember all the students' names.

The School Head also highlighted the issue of funding (see 7.3.2.3(a)). According to the Malay Language Teacher, even though the school received funding from the Government, it was not enough to pay for all the operative needs. She said that the School Head tried to acquire the resources and tools needed for teaching and learning from a variety of different sources.

When asked about the decision making process, the School Head said 'I usually keep one decision to myself, but still open the discussion of the matter to the rest of the teachers during the contact time.... We will accept what the majority agreed upon.' She believed in democratic decision making. Her non-autocratic behaviour was evidenced from statements given by the Malay Language Teacher who said that even when outside of the contact time, 'the teachers can see the School Head any time she or he wanted.' She added that they can voice out their 'views or dissatisfaction at any time of the day. The School Head allows the teachers to do so.' The Malay Language Teacher was very satisfied with the openness of the School Head in managing Kapak.

When asked about teachers' heavy workload, the School Head expressed concern. In Kapak, she said that she 'discouraged' her teachers 'from taking the office work back home. If the work had to be finished soon, we can pool the work and finish it together'. She believed that workload could be reduced through togetherness in all activities.

In relation to staff development and training, the School Head said that she would send her teachers from time to time if necessary to improve their 
knowledge and skills. Her statement was supported by the Malay Language and Science Teachers. The Science Teacher added that the teachers would also have the chance to attend training when a new policy was introduced by the MOE.

Another important aspect of leadership was to have empathy with the staff. The School Head thought that as a leader, 'you have to understand and observe teachers' behaviour...don't be autocratic...don't force them [teachers]... let our staff feel our existence...be flexible.' She also said that she used to 'praise them [teachers]' so that it could boost the morale of the staff. The School Head appeared to treat her staff more as family members than as subordinates. Whenever there were problems at school, she said that she would 'look at the opportunities behind the problems'. She gave an example of a disorganised filing system when she first came to the school. She had to solve the filing issue fast so that she could move on to other jobs. So she began ordering a pile of white files and sought help from the district office to teach her and her administrative staff to develop a proper filing system. When they had the knowledge and skills to do the work, they were able to complete the task within two months.

Consequently, the School Head started to gain respect and cooperation from her staff. Her initial effort had established her reputation. She told me that 'I do not give instruction... but I just request them to follow my order.' She also believed that 'all teachers had the capability to do work and be given responsibility'. Another thing, she said that that she would 'keep the negative ones, and only highlight the positive ones so that we can move forward.' She added, 'school is developed through its leadership and teachers are the backbone of the school'. Kapak had a flexible and open leadership and thus, matched the environmental requirement for ILE implementation.

Having listened to the words of the School Head and her teachers, the School Head had been doing her job well. This was clear from the responses of the Local Studies, Malay Language and Science Teachers. In 
fact, I did not perceive any negative connotations about the School Head from the teachers. Kapak's head engaged all her staff in all activities. She encouraged collaboration and regular meetings with her staff. However, the teachers still depended on the School Head's "agreement" when any activities needed to be conducted.

\section{(c) School goals}

As with other case studies, Kapak's interviewees admitted that the main school goal was to prepare the students to obtain high results in their examinations. Thus, all efforts and activities were channelled to achieving the target.

As a school administrator, the School Head has the ability to move the school in any direction in order to achieve the school goals. Kapak's School Head happened to be flexible in her leadership approach and always open to new ideas. Due to her interest in new ideas such as ILE, she started her move to implement ILE for selected students, namely the Year 6 students who were in the excellent class. ILE was implemented only after the syllabus was completed, and the students were doing revisions for the public examination (UPSR). The School Head appeared to be the key element behind ILE being implemented in this way. Thus, a key facilitating factor for ILE's implementation in Kapak was the readiness of the School Head to implement it.

\section{(d) School climate}

Kapak was an all-girl Tamil missionary school, situated in a suburban area. When asked about the school climate, the interviewees were focused on the teachers' and students' attitudes and behaviours as well as the inschool training.

When asked about the relationship among the teachers, the Science and Malay Language Teachers were of the opinion that there was cooperation and collaboration among them. The Science Teacher, for example, told me that 'there was collaboration among teachers... just like me, any Science terms in English that I did not understand, I would have referred them to 
the English teacher'. She illustrated the way she worked together with other teachers. Both the Science and Malay Language Teachers believed that Kapak's teachers were supportive and cooperative. On the other hand, I also received another side of the story from the School Head herself. She said that 'we do have the opposition group in the school, but we ignore them. At last, they came and supported us when they felt they were being left out.' She said that her strategy was to ensure that the school activities were effective so that their successful operation would attract those who were in opposition to join in and cooperate in upcoming activities.

When asked about the students' behaviour at school, the Science Teacher described the students as obedient and well-mannered. They were also very competitive in the class. In terms of their reading habits, she said that 'the students went to the school library to read story books, but not to search for scientific information or reading Science non-fictions'. She saw the students read more fiction than non-fiction materials.

Kapak had established a robust regime in terms of its communication and knowledge sharing activities between the School Head and the teachers. The school had set 'contact time' fortnightly and in-house training so that the teachers could share and keep abreast of the latest developments, knowledge and skills. This was confirmed by the Malay Language Teacher when she said that 'every time teachers attended courses outside of the school, when they came back, they had to share their knowledge with other teachers'. Thus, Kapak's teachers had good opportunities to get updated information and share knowledge.

\subsubsection{Ecological Context}

(a) Community/ Society

When asked about factors at the macro level (society, community or parents) affecting ILE implementation, the Malay Language and Science Teachers indicated parents as a factor. The Malay Language Teacher, for example, made the following points. 
The Indian society as a whole is now open-minded ... even the parents too. When we called them to discuss about matters pertaining with their children's low achievement, they could accept it [the fact that the children needed help to succeed academically], compared to those days.

The Malay Language Teacher added that

the ethnic Indian community wanted to progress well in all aspects... They [the parents] could accept what the teachers said, and the teachers could accept their opinions. Sometimes the parents contributed their ideas and gave their cooperation [to solve problems at school]. (Malay Language Teacher)

She thought that the Indian parents seemed to be engaged in their children's school activities and often met the teachers to monitor their children's progress.

On the other hand, The Science Teacher, when asked about the parents' involvement at school, thought that the parents wanted their children to be in the highest class and get the most A's in examinations. As she pointed out,

normally the teachers would split the students according to their level of achievement so that the teachers could concentrate on the weaker students.... But the parents insisted the teachers to put their daughter in class A, the first class la... This was for Year 6. We divided them according to their monthly examination results.... The teachers had to explain to the parents why their daughter had to be placed at second or third class. Even the School Head had to explain in order to convince the parents.... The parents were so focussed on A's.... There was parents who were also teachers, just after the trial exams. [They] questioned the teachers at school why their daughter was put in the second class, not in the first class, although they knew that their daughter was not very good in the subject. So they [are] still going for A lah. (Science Teacher) 
From her perspective, the parents yearned for their daughter to excel in the examinations. They could not rationalise their daughter's incapability of achieving that goal.

The Malay Language Teacher saw that the ethnic Indian community was willing to change in order to progress. For the Science Teacher, because of the struggle of the ethnic Indians to change the current condition, some parents pushed their children too hard to achieve academic excellence.

\section{(b) District/ State}

When asked about the support from the district and state administrators, most interviewees were concerned about staff development and training, and the resources needed to implement ILE.

In terms of IL training opportunities, most interviewees thought they were in need of IL training (see section 7.3.2.1(a)) with the exception of the School Head. The Local Studies Teacher, for instance, commented on the courses that she attended. She said that the

course length was only for 2-3 days... courses were held only if there was syllabus revision or upgrading of the syllabus.... Most of the time, training was not in-depth and no application to teaching and learning in the classroom because of the time constraint,... large course attendees...[and] courses held in large halls. (Local Studies Teacher)

She was concerned that the way training was organised was ineffective and superficial.

In addition, the Malay Language Teacher suggested some improvements for future training for teachers. As she said, 'the courses need adequate time length so that the attendees could understand the content of the course.' She commented that the trainees needed 'more hands on sessions' and the organisers need to 'get a more experienced and well prepared trainer.' The School Head expressed similar sentiments, saying 'if 
possible, we want to invite facilitators or experts from outside the school. I think this is more effective [for teacher's IL training]'. She believed that out-of-school course instructors or facilitators would be helpful to enhance teachers' knowledge and skills of IL. The interviewees also highlighted the lack of IL guidebooks in the school, and the fact that they had to rely on the course lecture notes to assist their implementation. This was another obstacle to ILE implementation in Kapak.

The interviewees at Kapak were in need of proper IL training courses (except for the School Head), and IL guidebooks. Based on their experience, the courses organised and conducted by the SETD via TAC were merely a one-shot-lecture mode, short "crash" courses, with large numbers of attendees in a large hall and no training on how to apply the course content in the classroom. Thus, the interviewees saw the need for proper staff development and training and suggested a few ways to improve the existing ones.

\section{(c) Government and other agencies}

When asked about the ILE support from the Government and its agencies, only the School Head and Science Teacher responded. They talked about the resources needed to support the implementation.

The School Head saw that the Government provided computers to the school, and often, the computers placed in a laboratory. But she said that 'at least, the Government should provide 20 laptops to the school so that the laptops could be used in the classroom for the students to access information'. She pointed out the need to have adequate resources and equipment to be used in the classroom so that the students did not have to move from one room to another, and to reduce the time spent on moving. This way would be more convenient for the students and teachers.

When asked about guidebooks from the Government, the Science Teacher told me that the teacher's guidebook had specified teaching plans and 
specifications. Teachers would only have to follow and be creative in their teaching preparation. Thus, each teacher had a complete set of teaching and learning resources from the MOE as a guide to teach a specified subject. It was just a matter of opening, reading and understanding the content, and thus, applying the resources creatively in the classroom. The Science Teacher added that 'it was up to the individual teacher to make use of the resources'. Here again, the teacher's attitudes toward her profession was a factor that hindered or facilitated any change expected in the syllabus, and in this case, ILE implementation.

\subsubsection{Implementation Protocols}

When asked about the ILE guidebooks or manuals used to implement ILE, interviewees responded that they had not received any.

The Local Studies Teacher was the one who changed her teaching approach towards a student-centred one because of the students' feedback. She claimed that her teaching style changed even though she had no guides for ILE or constructive learning or critical thinking in her possession.

On the other hand, the School Head highlighted several factors that hindered ILE implementation such as lack of suitable space in school, limited funds and lack of teaching resources for ILE. She recommended the MOE place a technician in the school to assist ILE implementation.

The LMT commented that she had not attended any specific course for IL. Most courses that she attended as LMT were related to school resource centre (SRC) management and IL. Most courses were conducted by the SETD and the attendees were provided with 'a book related to SRC management'. She added that she was not sure whether the school had any guidebook for IL.

The Language Teacher, however, revealed that she had received 'many manuals' from the District Education Office (DEO), State Education 
Department (SED) and School Head. She even mentioned that one of the manuals was about the student-centred approach.

While most interviewees claimed they did not possess any ILE Implementation Protocols, they expressed different views in terms of their approach towards ILE. The Local Studies Teacher changed her role in teaching and learning which focussed on student-centred approach. The School Head saw a hindrance of ILE implementation from the structural perspective. The LMT seemed unaware of the availability of any IL guidebook or lesson plan in the ETD portal and was not proactive in ILE implementation. Finally, the Language Teacher acknowledged receiving many guides to deliver her syllabus content.

\subsubsection{How do these factors facilitate or hinder ILE implementation in Kapak?}

In Kapak, factors that hindered and facilitated the implementation of ILE were found to be balanced, as viewed by the interviewees. The following describes how these factors affected ILE implementation in Kapak.

First, in terms of ILE implementation, when asked about the factors that affected the interviewees of Kapak, the responses were related to the lack of IL training, lack of availability of information resources and equipment, students' attitudes and behaviour towards learning, as well as leadership support. These factors highlighted the inclinations of Kapak's teachers to either implement or not implement ILE.

In terms of IL training, most interviewees had not had recent IL training except for the School Head and the Malay Language Teacher. The LMT claimed that if she had the opportunity to attend IL training, she might have the knowledge and skills to implement it in the classroom. She added that she was unable to implement ILE because at the time of the study, she was in charge of Year 6 classes and had to prepare the students for the 
public exams. Thus, she was unwilling to implement ILE because she wanted to prepare the students for exams. Since Kapak was the best Tamil school in the district, the teachers had to keep up with the standard set and the expectations of the parents. Therefore, all effort focussed on preparing the students for high performance in exams.

The Local Studies Teacher admitted that the school had limited internet access. She gained confidence to implement ILE because of her students' reactions towards her teaching approach. She modified her teaching approach more towards student centred-learning. Consequently, she began to be open to her students and had more faith in the ability of the students to search for information at home by themselves with the help of their parents. The limited internet access at school was compensated for by letting the students search for the information at home and prepare for the lesson before coming to the class the next day.

Students' attitudes towards learning had been a facilitating factor for ongoing ILE implementation in Kapak. The teachers at this all-girls school perceived the students to be well-mannered and highly competitive, with a love for learning. Most students were from supportive families. Their attitudes in the class were capable of shifting the way teachers taught in the class (for example, the case of Local Studies Teacher). With students' having the right attitude towards learning, teachers were able to implement ILE in the school. Therefore, the teachers' willingness to modify their role in order to match the new approach to learning as expected by the students was an enabler to ILE implementation. In this case, as previously, the student-centred approach was more suitable to ILE than a teacher-centred one.

In terms of the leadership support, the School Head was concerned about implementing ILE in the school because she thought that the outcome was invisible. Due to her lack of confidence in ILE implementation, she demanded a kind of testing tool to assess the students' IL competency. However, despite her uncertainty, she made an effort to try out ILE on 
selected students (see section 6.3.1). Her aim was to see the extent to which ILE could help the students achieve high results in the public examination. Her openness to new ideas was an advantage and her act was driven by her desire to achieve good exam grades for the students.

Hence, the factors in Kapak were different from the other case study schools. When asked about the factors affecting ILE implementation, the Kapak interviewees constantly highlighted positive aspects rather than the negative ones. Though the teachers in Kapak were unwilling to take the risk when dealing with students' achievement in exams, they nonetheless had a positive attitude towards what was needed for the school, and were flexible and open-minded. These qualities helped mitigate the risk aversion in order to make progress towards implementing ILE in the school.

Second, Kapak had regular in-school training. Teachers who attended any courses would share their course-related knowledge and skills with other teachers during the in-school training. In addition, Kapak also had fortnightly staff meetings which were known as 'contact time'. According to the School Head, the staff meetings helped her to keep track of what was happening in the school. Thus, Kapak had two platforms for the teachers - one to get updated information, and the other a place to exchange ideas and concerns.

In-school training was supposed to be a vehicle for sharing job-related knowledge and skills in teaching and learning. However, according to the School Head, Kapak's teachers were uninterested in job-related courses and often the in-school training consisted of courses on non-work related topics such as health and beauty. Because of the ever-changing information and communication technologies, the teachers needed to keep abreast of the latest developments in education and other related fields and thus their lack of participation in IL related course was a hindrance to ILE implementation. In addition, Kapak's in-school training platform could have been used more fully by the teachers to stay up-to-date in education and related fields. Nevertheless, through their ongoing training, the 
teachers could see the willingness of the School Head to invest in their professional development, which boosted their motivation at work and fostered the acceptance of new ideas such as ILE.

In addition, the School Head thought that inviting external instructors or facilitators would help making the delivery of the training courses more effective and thus attract the interest of the teachers to participate in them. Hence, Kapak's School Head seemed to be more proactive in planning for staff development. However, in the case of ILE implementation, the inschool training was still not adequate to support change to happen in the school.

Third, the implementation of ILE is not an individual effort rather it is a shared endeavour. In order to realise a shared endeavour, the school community must have a similar understanding of the need for change. In this case, the needed change was ILE which required a concerted effort to ensure its on-going development.

Kapak was fortunate to have an open and flexible school administrator. The School Head was approachable to the staff and hardworking. Under her leadership, everything went well because of her policy that there was always an opportunity behind a problem. She also believed that all staff members were capable of doing their jobs, if they were given the responsibilities. With her goodwill, she was able to win the hearts of her staff to collaborate and cooperate in all activities.

The School Head's individual perception had turned planning into action and she was able "to walk the talk". In terms of ILE, she was able to get the cooperation from the Year 6 teachers to participate in implementing self-directed learning, a learning environment that matches ILE. I could see that her non-directive type of leadership and regular communication with her staff had created rewarding working experiences, and thus, was conducive for ILE implementation. 


\subsection{Chapter summary}

This chapter has reported the factors facilitating and hindering ILE implementation in Lembing and Kapak. Both case study schools were national-type schools. Each case study school was represented by five interviewees, namely the School Head, Science Teacher, Local Studies Teacher, Malay Language Teacher and Library and Media Teacher (LMT). Lembing's interviewees indicated that ILE was hardly implemented at the individual and school level. Some teachers could not accept the way ILE was supposed to be implemented because a student-centred approach was not commonly practiced in the school. At Kapak, all interviewees seemed optimistic about ILE and indicated that they were working towards implementing ILE in their classrooms. However, what motivated Kapak staff to implement ILE varied. Overall, Kapak's interviewees saw that ILE could help the students to achieve better examination results. Thus, it in terms of ILE implementation, these two case study schools were at different levels of implementation.

Lembing's interviewees were not concerned about ILE implementation, mainly because the teachers were not used to the approach needed to implement ILE and the school had its own way of teaching and learning its ethnic-based curriculum. On the other hand, Kapak's interviewees, though not fully implementing ILE in their classrooms, had a positive attitude towards ILE and were willing to prepare themselves for ILE implementation.

Lembing's interviewees seemed unworried about implementing ILE in the school. In contrast, Kapak's interviewees viewed ILE as important and themselves as being in need of IL training to improve their skills and understanding. Interviewees from both schools did not have proper exposure to IL and thus lacked IL knowledge and skills. When asked about their IL training needs, Kapak interviewees showed more interest in IL training compared to Lembing's. The reasons for Lembing's lack of interest were insufficient training opportunities, familiarity with the 
traditional approach, and the need to control the students' discipline and meet academic targets.

On the other hand, Kapak's interest in IL was motivated by the school leadership. Kapak had a supportive, understanding and flexible leader who was able to engage her staff in all school activities. This kind of leadership is conducive to ILE implementation.

Lembing was more focused on protecting the ethnic Chinese culture and language, and hardly diverted from the traditional way of teaching and learning. In contrast, Kapak was willing to change because of the progressive outlook that the interviewees had in order to improve the condition of the Indian community. Most interviewees revealed that they did not possess any ILE guidebook or other ILE protocols to assist in the implementation.

The factors found in Lembing and Kapak were further explored in order to understand how these factors were affecting ILE in Malaysian primary schools. Both Lembing's and Kapak's interviewees tended to shun implementing ILE. The main factors were time constraints, the exam orientation, a lack of confidence and lack of leadership support. In terms of IL training and in-school training, none of Lembing's interviewees discussed their in-school training which contrasted with those from Kapak. Excessive workbooks and too much emphasis on the traditional approach to learning appeared to be the main factors for limited in-school training in Lembing in contrast to Kapak which had a platform for knowledge sharing and peer-to-peer learning. However, Kapak's teachers, according to the School Head, were only interested in non-job related in-school courses. Thus, as a result of insufficient in-school support, neither case study school was able to develop and enhance ILE implementation.

Lembing had an authoritative leader who was determined to uphold the expectation of the ethnic Chinese community with regard to its future generation. The administration at Lembing appeared to be single-handed. 
At Kapak, the teachers developed a sense of togetherness and shared understanding in all school activities, but they relied solely on the School Head for approval and direction.

In the following chapter, I report the findings of the key informants at district, state, and federal level. 


\section{CHAPTER 8 Key Informants at the District, State and Federal Levels}

\subsection{Introduction}

In this chapter I report the findings from interviews conducted with educational administrators, using a similar structure to the case study chapters. The findings reported here provide insight into the factors affecting ILE implementation from the macro perspective.

The chapter begins with the key informants' perspectives on the stage of ILE implementation in Malaysian schools. Then, the factors relating to the first research question are reported, followed by the factors related to the second research question. The chapter concludes with a summary of the factors affecting ILE implementation at the three levels of education administration.

\subsection{Key informants}

Four key informants were identified in this study, that is, one informant each at the district and state level, and two from the federal level. The key informants selected were the ones who provided the administrative support including staff development and training, allocation of funding and resources, monitoring of the instruction and the teaching and learning process (see section 5.5). Each informant has been given a pseudonym: Melur (district); Buluh (state); Orkid (federal 1); and Mawar (federal 2). The key informants are named after the plant life in Malaysia.

\subsubsection{Stage of ILE implementation}

When asked about the stage of ILE implementation, two interviewees (Melur and Mawar) believed that ILE was 'fully implemented' in schools. Melur said that ILE had been implemented in the schools ever since it was introduced in the curriculum:

We [the teachers] have implemented IL long time ago. Often when we implement IL, but we do not know that it is IL. For example, 
we search information for our research. We search information in the library or in the internet or we read books. Any retrieved information, we use them as our teaching and learning resources. (Melur - District officer)

However, she believed that the teachers did not realise that they applied ILE when they were in the classroom.

Mawar also expressed the same view. She said that IL was blended in the syllabus to the extent that 'teachers do not know that they have integrated the skills in their teaching and learning... because it [IL] is so blended that they cannot see it.' To her, IL was implemented, but the IL activities were 'not classified as IL' because the teachers were unfamiliar with the concept.

On the other hand, Orkid believed that IL was 'less implemented in schools' or in other words, insufficiently implemented for various reasons. At the federal level, she said that most officers and even the top management did not understand the concept of IL. In fact, according to her, the Educational Technology Literacy Management Sector in which both IL and SRC were located as units was struggling to be seen as relevant to the MOE's ICT agenda in the school. She added that since the Sector had not received proper recognition from the management of MOE, the SRC unit was not allowed to conduct its own IL related training for the educational technology officers in all states and was not given funding and resources to perform its role. The Sector had advised its officers at state and district levels to proceed with their plans and programmes on school resource centres and IL. Hence, at the state level, she believed that ILE could be better implemented in schools if the SETD played an effective role in implementing ILE.

Melur, though she believed that the teachers applied IL skills in preparing their teaching and learning activities, said that 'ILE is less happening in the primary schools'. She believed that ILE could be implemented because each school had a LMT to kick start the programme. However, since 
schools had various planned activities and programmes, IL activities happened to be one of many programmes that were not meant to be implemented formally. According to her, ILE was 'just a co-curriculum activity'. That means that although ILE was supposed to be infused in teaching and learning, it was taught outside of the classroom activities.

Melur also believed that the on-going ILE implementation in a school depended on the school leadership support, LMT's and teachers' attitude towards ILE. She recounted a story about how she implemented IL activities in her English class. She used Western songs and lyrics in order to encourage students to be interested in the language. She also brought the students to do activities under a tree within a school compound. In fact, she said, when a school inspectorate came to the school for inspection, she made the students present their assignments in front of the class. She made the students communicate their work independently and in groups before the school inspectorate.

Due to Melur's style of teaching, she was questioned by the School Head. But when the School Head received the written report from the school inspectorate, she was praised because her style of teaching was what was hoped for by the MOE. Thus, leadership support and the teacher's attitude appeared to be crucial factors to ensure on-going ILE implementation in the school.

But towards the end of my interviews with Melur, Orkid and Mawar, I found that they believed that ILE was not fully implemented in schools. To them, the reasons for partial implementation of ILE were because of the lack of IL understanding among school community, lack of leadership support as well as teachers' and LMT's attitude towards ILE. 


\subsubsection{Factors affecting the ILE implementation}

Factors affecting ILE implementation in Malaysian schools, as identified by the key informants are discussed as follows: (a) Characteristics of IL; (b) Individual Implementers; (c) Implementing Organisation (School); (d) Ecological Context; and (e) Implementation Protocols.

\subsubsection{Characteristics of IL}

The first factor, that is, the Characteristics of ILE relates to the key informants' understanding of the need for IL, the clarity of the IL concept, the complexity of its implementation at each education administration level and the individual implementers' perspectives at school level.

(a) Need for IL

When asked about the need for ILE, all the interviewees expressed the importance of IL skills in the education system. Melur described IL as a linking element in the school syllabus. As she pointed out, 'it [IL] is very good because it integrates branches of subjects, for example, physical education could be integrated into science and health subjects.' She believed that the students would be able to relate one subject to another subject and to understand the syllabus holistically, rather than as a compartmentalised type of learning.

Melur stated that since the beginning of 2011, IL has been given emphasis in schools because 'we now have the LMT. LMT's responsibility is to implement IL in his or her classroom'. The LMT had to initiate the implementation so that the other teachers could follow the path set by the LMT. However, she admitted that the lack of IL training courses hindered the effectiveness of ILE implementation. She saw the need 'to increase the frequency of the courses', adding that 'there were no IL courses for the past four years'. Thus, she believed that ILE was important as a linking element in the syllabus, and the school began to focus on IL skills because of the appointment of an LMT. However, she felt the lack of IL training 
among the LMTs was an obstacle to the development of better IL understanding and better ILE implementation in schools.

Orkid, on the other hand, expressed her concern about the MOE's policy to give too much emphasis to ICT. She emphatically said that,

Now the essence of democratisation of education is lost. Those days we had Education TV where everyone can access to the educational TV programmes. But now Education TV is in the form of EduWeb TV. The students need to have the internet access in order to watch the programmes. If they [the students] were not able to access to the internet service, they would not be able to access the information broadcasted in the programmes [EduWeb TV]'. (Orkid)

She believed that the students had to be given various educational technology options practically according to their socio-economic background and living conditions. She saw that currently there was too much focus on the use of the internet, which resulted in limiting access to the education resources.

Another issue that Orkid had mixed feelings about was KSSR, the new policy on primary school curriculum. She said:

All MOE officers were given a briefing about the new policy [KSSR] for Year 1 students in the year 2011. The briefing was about our [Malaysian primary school] curriculum based on the $21^{\text {st }}$ century learning. All the words that they [the top management representatives] used, even the charts and the graphs showed the $21^{\text {st }}$ century learning approach in the syllabus. But the briefing did not mention explicitly about the $21^{\text {st }}$ century learning embedded in the syllabus.... In fact, the assessment is a school-based in order to evaluate the students' performance.... I can see that the IL part is so obvious. (Orkid)

On the one hand, she felt relieved that IL components had been given more emphasis. But on the other hand, she was unhappy because MOE's lack of 
transparency to acknowledge the importance of $21^{\text {st }}$ century learning and IL components in the new policy.

Due to the need for ILE, Orkid said that the Educational Resources Management Sector initiated iQPSS, an online management information system which acted as a tool to monitor the progress of SRCs and their related activities including IL activities in Malaysian schools. According to her, it was first introduced in July 2009. This tool seemed to be an innovative way of using ICT to monitor and support SRC and its activities. Unfortunately, according to Orkid, the tool could not be used as it should due to limited funding to pay for its annual subscription.

Mawar also mentioned another tool known as SPPICTS. This tool was used to monitor the initiatives and implementation of ICT in the schools. According to Mawar, one of the components of the SPPICTS was 'the IL component. The teachers are supposed to fill up the skills that they had... and the data go to the SETD for verification and it comes back to us [the ETD]'. She said that the tool had several online forms that needed to be filled up by the teachers at schools. The forms were then submitted to the officer's in-charge at the SETD, and then the final report went to the ETD. Thus, through the data collected, the ETD was able to keep track of the development of ICT in the schools at any time as needed.

Apparently, according to Melur and Orkid, since early 2011 IL skills have begun to be recognised at all levels of the education administration due to the appointment of an LMT in every school and the introduction of KSSR for Year 1 primary school. For Melur, IL courses need to be given a priority in staff development so that the LMTs and the school community as a whole could have better IL knowledge and skills to implement ILE in their respective schools. Also, at the federal level, according to Orkid and Mawar, the ETD had tools to monitor the development of related SRC and ICT activities including ILE. 


\section{(b) Clarity}

When the key informants were asked about their understanding of IL, three of them did not provide a direct answer to my question. The responses were very much related to their perception of students' and teachers' ability and understanding of IL. Only Melur answered the question directly. She said that 'IL is the way teachers or students obtain information for whatever subjects'. When she provided the answer, she apologised that she could not remember exactly the official definition of IL. From the very beginning of my conversation with her, I perceived that she not only understood IL as an information searching activity, but she also thought about IL as a linking element in the syllabus. She associated IL with teaching the students to use their thinking skills through connecting a topic in a subject to another area of the discipline. She saw IL as encompassing more than obtaining information.

Buluh, when asked about his understanding of IL, commented that to him, the ability 'of the students...to access information manually or even using the ICT or media...is IL'. However, he said that in Malaysia, this was a weakness of the students. He was also referring to IL as an information searching activity.

Orkid commented on the teachers' understanding of IL. She told me that she visited schools in one of the states in Peninsular Malaysia. When she asked the teachers and even the LMTs about IL, they seemed not to have any understanding. The teachers were unfamiliar with the term IL. She said that she had to explain it to them every time she asked them about IL activities in their schools. As she pointed out,

they [the teachers] did not know that KBKK [an acronym for Critical and Creative Thinking Skills], learning skills, higher order thinking skills, and NILAM [reading] programme are under one umbrella...even debate competition, information hunt and other related activities are not considered as IL activities. (Orkid)

To her, the teachers appeared unable to link IL to other learning or school activities. 
I also heard similar comments from Mawar. She viewed the teachers as having inadequate understanding of IL. She said 'the problem with our teachers is that they do not know the [IL] terminology. To them, IL is a subject per se whereby they should be given a subject to teach on IL'. In contrast, she believed that the teachers perceived IL as a distinct subject rather than a set of skills that need to be applied in teaching and learning. She believed that those ETD officers understood IL as skills embedded in the syllabus. As she said,

To us [ETD officers], IL is inter-disciplinary. IL is already inside there [the syllabus]...embedded in whatever they [the teachers] are doing. And they... being a LMT, they are the core people or the role model of using IL in the subject they are teaching.... IL started in Malaysian schools in 2002. The LMTs were provided with guidebooks to implement IL.... In 2006, the LMT was in-charge of the access centre. (Mawar)

Mawar appeared to be a bit defensive during her explanation about the ETD officials' understanding of IL, the role played by the LMTs, and their effort to ensure the implementation of ILE. According to her, when IL was initially introduced to Malaysian schools in 2002 the LMTs were equipped with guidebooks for its implementation. The LMT was not only in-charge of the SRC, but also the access centre equipped with computers, printer, scanner and internet service.

It was clear that the key informants had a good understanding of IL. They were also aware of the lack of IL knowledge and skills among the teachers and students. It was also clear that at federal level, the officers' in-charge initiated and planned the activities for IL to be implemented in schools; however, it seemed too complex to implement ILE in the schools.

\section{(c) Complexity}

Melur and Buluh expressed their concern over the issue of teachers' and LMTs' IL training when discussing staff development and the development of the ETD in relation to ILE implementation. 
Melur said that the TAC had to change its approach in IL training due to changes at the federal level:

Now [in 2011] the Sector of Educational Resources Management has changed its name to the Sector of Educational Technology Literacy Management. With the change of name, we did not use the term IL any more. When the name changed, the scope was also different.... Now we do not teach the teachers on IL and other related activities, but help them to form the IL activities. The teachers themselves have to perform the theory and practical of IL. (Melur)

Melur highlighted the issue of name change at the federal level because the TAC, as a district level administration which dealt directly with the teachers and LMTs, was also the executor of all plans and policies decided at federal level. In a way, the changes affected their training operation and plans. At the moment, their scope was to facilitate the LMTs and the teachers, rather than to educate them about ILE. She seemed uncomfortable with the change of work scope.

Buluh also had the same concern about IL training. He said that the SETD and TAC were only responsible for the training of the LMTs and ICT coordinator (Smart Teacher) in IL and other related activities. The State Education Department (SED) and District Education Office (DEO) were in-charge of IL training for teachers (see Chapter 1 for the functions of SED and DEO). There appeared to be a separation of IL training into two groups of trainees who were trained by two distinct groups of experts: one from educational technology, the other from the pedagogical perspective.

In addition to the issue of IL training as highlighted by Melur and Buluh, Melur told me about a report made by the Inspectorate of Schools (local acronym $J N J K$ ) on the role of the LMT and ICT coordinator at school. According to her, the report in general stated that both 'the LMT and ICT coordinator were not functional in the school'. According to Melur, the 
reason was the Inspectorate could not see the functions of both types of teachers. The Inspectorate recommended the positions be annulled. The Inspectorate of Schools had no confidence that the LMT could function as expected by the MOE. The result of this report could be another indicator that because of the LMT's under-performance ILE was difficult to implement in schools.

To recap, Melur believed that IL staff training was most affected by the policy changing at the federal level. For Buluh, the two different sets of IL training (one for the LMTs and ICT coordinators and another for the teachers) had been a hindrance to ILE implementation because coordination and integration between the agencies involved was absent. Both key informants believed the lack of systematic planning for IL training resulted in the inability of LMTs to implement ILE in schools.

\subsubsection{Individual Implementers}

The key informants were asked to address the issues of LMTs' and teachers' qualification and competency to implement ILE. They were also asked to reflect on the extent of ILE implementation in Malaysian primary schools and their own commitment and readiness in implementing ILE.

\section{(a) Qualification/Competency}

When asked about the LMTs' and teachers' IL development and training, both Melur and Buluh answered that the LMTs and teachers had been exposed to IL. Melur explained her view:

More than $80 \%$ [of the teachers] possess knowledge of IL because schools have their own internal course known as LADAP [inservice training]. IL has been introduced initially to the School Head, followed by the SAAs and LMTs. It is the role of these three important persons in the school to inform the rest of the school community about IL so that all of them [school community] are aware of IL. (Melur) 
She assured me that the information about IL skills was delivered and understood by the majority of school teachers because the LMT was allocated with an amount of time for that purpose. She added that 'the LMT is given 8-12 hours teaching load per week, so the rest of the working hours is supposed to be for implementing ILE'. But she was unsure about the extent of ILE implementation in the classroom.

Buluh was also confident about the capabilities of LMTs implementing ILE based on his experience conducting training for the LMTs. His observation from the courses was that 'I can see the skills they [the LMTs] possess.' When asked further about the reasons for the LMTs' lack of IL skills, he believed that such a situation 'happens to the newly appointed LMTs and those who had not attended the 35 hours required courses'. He added that 'later, they [the untrained LMTs] will be called to attend the related courses organised by the TAC/SETD'. He assured me that all LMTs had equal chances and rights to be trained in their position. He said that this fitted with the requirements for the position, that is, skills and interest in the job.

To him, the only hindrance faced by the LMT was that 'skills acquired through courses attended by the LMTs are not at par with the equipment [educational technology devices such as computer software and hardware] at school'. It seemed to him that there was insufficient application of the LMTs' training to the classroom because of the sub-standard equipment acquired by the school. He believed that the knowledge and skills gained in the courses depended on the availability of equipment in the school.

In contrast to the statement made by Buluh, Orkid, based on her surveillance of schools, said that when she asked the LMT his or her schedule and activities, 'the LMT would talk about books processing and cataloguing, and about NILAM programme and that's it.' She found that the LMT hardly discussed IL activities. The LMT's job scope had got mixed up because, according to her, 'the function of LMT has shifted to 
serve the Smart Sector [focussing on ICT]'. Thus, it appears that the LMT had more job responsibilities than before.

I found that in unpublished research done by the ETD in 2011 for an IL course held in conjunction with the Kuala Lumpur International Book Fair, the respondents of the survey commented on the need to lengthen the course time, and suggested the course coordinator to conduct related courses in the future (Zainudin, 2011). But, I found that none of the respondents highlighted their concerns over the lack of ability to apply IL skills in teaching and learning. It seemed that the IL course coordinator did not receive the real feedback from the course attendees as frequently found in this study.

When asked about other ways to improve the LMT's heavy workload due to the increase in job specifications, Orkid disclosed an initiative made by the Faculty of Information Management, MARA University of Technology (the only tertiary institution in Malaysia providing training in school resource centre management). The initiative was to bring in graduates specialising in school resource centre management as LMTs in every school in Malaysia. However, the former Director-General of the MOE halted the idea because he believed that the MARA graduates' major background 'is not part of a subject in the school syllabuses'. Thus, the graduates were not considered for the post because they had not graduated from the teachers' training institute. According to Orkid, 'this is one of the weaknesses of our [Malaysian] education system'. The MOE's leadership seemed to be unwilling to open to new ideas for improvement.

Mawar, when asked about the teachers' qualifications and competency, commented on teachers' overall attitude towards work. She believed that the teachers did not lack training, but lacked the ability for self-directed learning. As she pointed out,

The problem with our teachers, not only our teachers but everybody, that they do not want to read...do not want to find information on their own... The teachers or LMTs do not know 
how to search information themselves. Whenever we [the Government] provide them with laptops, they use it for Facebook. (Mawar)

Mawar thought the teachers and LMTs were not willing to search for information, even to the extent of obtaining the guidebooks from the ETD portal for teaching and learning use. She looked very frustrated as she continued the conversation, 'it is a matter of searching for one. We [ETD] have uploaded [IL guidebook] in our portal...as well as samples of teaching plans for IL.' Unfortunately, her statement about teachers' attitude was justified. None of the case study schools' participants showed me any IL guidebooks or teaching plans which integrated ILE in the syllabus. In fact, none of them told me about the existence of the ETD's educational resources portal ${ }^{4}$. With the development of this portal, the claims made by the teachers and LMTs that they had not received any IL guidebook may have been unfounded. However, the teachers and LMTs might not have been informed about the ETD's educational resources portal.

Moreover, Mawar was also concerned about 'teachers and LMTs relying on face-to-face training courses so that they could be told what to do'. The teachers and LMTs seem to be waiting for instruction and lacked the ability for independent learning. Thus, she added that the ETD had to create some kind of rewards or to organise competitions and prize-giving ceremonies in order to inculcate independent learning among the teachers. The ETD had to assign activities that could "force" the teachers to be independent and self-directed learners.

According to the key informants, the Malaysian school communities were exposed to IL knowledge and skills. In fact, the LMTs were given less teaching load and more time to implement ILE. Buluh was convinced that

${ }^{4}$ http://bibliografi.MOE.edu.my/sumberpendidikan/index.php/literasi-teknologipendidikan.html 
the LMTs possessed the necessary skills for implementing ILE. However, Orkid admitted that the LMT was more concerned about processing books in the library rather than implementing ILE. Mawar believed that the LMTs and teachers were deficient in ILE implementation because of their dependent, passive attitude and lack of reading habit.

\section{(b) Commitment}

In terms of commitment, it is also interesting to know from the key informants what they had done and those factors which hindered and facilitated ILE implementation at school level.

When asked about the IL exposure among the teachers as reported earlier in this section, Melur explained the commitment and effort made by the TAC and SETD. She said:

The School Heads, SAAs and LMTs were given briefings and courses on IL since the early year of 2000, and again IL were stressed on in 2007 and 2008. These three persons from each school [who attended the IL briefings and courses] had to make the whole school to understand about IL. (Melur)

Thus, the Malaysian school communities had been introduced to IL as early as the year 2000. The concept of IL had existed in Malaysian schools" "diaries" for more than 10 years now.

However, Melur and Orkid agreed that the hindering factor in ILE implementation related to individuals. Melur said that the LMT was supposed 'to create a space for learning and sharing of IL knowledge and skills with the rest of the teachers in the school'. It is the responsibility of the LMT to kick-start and come up with activities that would enhance ILE implementation. Commenting on the role of the LMT, Orkid explained the attitude of many LMTs towards work.

The LMTs worked hard, but they did not know how to work smart. They wanted to do everything by themselves and did not want to use ICT to assist their work. They spent most of their time processing the [library] books. (Orkid) 
To her, the LMTs had to learn to work efficiently and effectively so that they could use their working hours optimally and spend more time implementing ILE.

\section{(c) Readiness}

When were asked about the readiness of Malaysian teachers implementing ILE in their classrooms, Melur and Buluh were again very concerned about the limited time that the teachers had.

When asked about teachers' time management, Melur answered that the individual teacher's time was spent more on 'completing the school syllabuses' than other activities. The teachers had their deadlines to meet and academic targets to achieve. She said the teachers had to do extra work as well because most assigned and planned academic and extra-curricular activities needed to be recorded. These activities of recording and reporting took a lot of teachers' time out of other activities including those relating to the implementation of ILE. Buluh believed that 'the lack of time was a problem before the LMT received an official appointment from the MOE. Now, they [the LMTs] were given lesser teaching workload'. The LMTs had been given more time to prepare and ready for ILE as they qualified for minimal teaching hours (i.e. 6-8 hours per week).

\subsubsection{Implementing Organisation (School)}

For the on-going development of ILE, key informants were asked for their views on the administrative and leadership support from them or at school.

\section{(a) Administrative support}

When asked about the administrative support to ILE, Buluh and Orkid responded by citing the official appointment of a LMT by the MOE in most Malaysian schools. According to Buluh, each school has a LMT 
except for the Low Enrolment Schools (locally known as Sekolah Kurang Murid - SKM) which are often situated in remote areas. Buluh said the School Head was the one who nominated the LMT for the school, and submitted the candidate's name to the SED via SETD. Then, the LMT was expected to receive an official appointment letter endorsed by the SED. The LMT's appointment was one of the MOE's efforts. This was expanded on in a MOE circular:

To develop and strengthen the education system, the Ministry of Education constantly provides proper emphasis on the implementation of various activities which relate to Smart Schools and School Resource Centre' (trans. MOE, 2005, par.2).

In reality, Buluh revealed that 'normally, the new LMT who was nominated by the School Head proceeded with his or her job responsibilities, even though without the official letter of appointment'. Without the official appointment letter, the LMT was ineligible for the new job specification such as 6-8 hours teaching load per week and others. Thus, the LMT who was without an official appointment might have a normal teaching load in addition to her responsibility as a LMT. Orkid revealed that there was an increasing turn-over of LMTs in schools because of the heavy workload and no official appointment.

\section{(b) Leadership and support}

The key informants were asked to comment on the school leadership support for ILE. Three informants, Melur, Buluh and Orkid, strongly believed that the school performance (academic and non-academic activities) depended on the administrator (School Head). As pointed out by Melur, ILE could be implemented in the school, 'if the school administrator was concerned about ILE'. To her, the school leadership not only was responsible for providing the support but also for understanding the need for implementing ILE in the school. 
As discussed above, the LMTs' turnover was frequent due to the heavy workload and no official appointment from the SED. According to Buluh, it was the School Head's responsibility to nominate and submit the name of the new LMT candidate to the SED whenever the existing LMT resigned or retired or transferred to another school, and, failing to do so resulted in no official appointment for the LMT. Without the official appointment, the LMT was not qualified for the new job description such as 6-8 hours teaching load per week. However, Buluh seemed to be satisfied with the School Heads' support for ILE. He indicated that the School Heads had given 'full support [in all activities organised by the SETD], except at SKM [Low Enrolment Schools]. All minutes recommended by the SETD are all complied.' It appears that the School Heads participated in all SETD's activities.

Another reason, according to Orkid, was that 'the School Head cannot see the relevance of LMT to support teaching and learning in school'. She pointed out her concern that 'the School Heads have been exposed to SRC and IL for quite some time, but somehow or somewhere they [the School Heads' understanding of SRC and IL] are lost.' She seemed to be unhappy with the School Heads' limited commitment towards SRC and IL. She further highlighted the 'School Heads' mentality' towards the LMT position. She said that the Heads thought that 'the appointment of LMT must be a new teacher because the seniors do not want to do the job because they considered [LMT] as a tedious job.' This reflected the school community's perception of the LMT's role.

Another view according to Melur, was that "every time the TAC officers came to school, the school administrator will direct us to the SRC to meet the LMT ... We [TAC officers] hope we would be given the chance to help teachers directly in their teaching and learning.' The TAC officers had no chance to communicate with the teachers in school, therefore, the chances to advise and guide the teachers in implementing ILE in the classroom were almost non-existent. She suggested that there is a need 'to involve all levels, starting from the MOE... There is a need to organise IL 
courses at least twice a year to re-familiarise the IL implementers with IL knowledge and skills'. She saw the need for regular IL training among the school communities.

In short, the School Heads appeared to have had a long exposure to IL. However, as pointed out by Orkid, the knowledge of IL had disappeared from their minds. Consequently, the School Heads saw IL as irrelevant to teaching and learning. Hence, Melur suggested regular training to familiarise the school community with IL skills.

\section{(c) School goals}

When asked about the school goals, Melur and Orkid highlighted the issue of exam orientation and the tendency to focus on cognitive activities.

According to Melur, 'due to our exam oriented system, students were used to spoon-feeding and drilling practice' and the students tended to become dependent and passive. She said:

The School Head, instead of organising IL activities or programme at school, he or she would direct the students to revise their lessons in the classroom for examination rather than visiting the school library or watching documentaries at the audio-visual room. (Melur)

Melur claimed that the focus was on getting many A's for examinable academic subjects. Other non-exam academic subject such as Physical Education and Local Studies were often neglected. In addition, assignments (locally known as folios) and coursework were not a part of public examinations, but the evaluation was kept for school purposes. Results of folio and coursework were not used to evaluate the school performance. Only the students' performance in public examination was the school's academic yardstick.

\section{(d) School climate}

When asked about the preparation of Malaysian schools for implementing ILE, the key informants thought that the schools gave too much emphasis 
to academic subjects, namely Bahasa Malaysia, English, Mathematics and Science.

As Orkid pointed out, schools are overly focussed on the cognitive activities rather than the meta-cognitive activities. As a result, 'there was often a segregation between academic and SRC [programmes]'. When the school's focus was academic in nature, all the teachers were directed toward the same purpose. Orkid saw that this situation led to a situation whereby 'the LMT did not have the authority over the academic panels'. As a result, the LMT had to organise activities that were related to what was needed by the academic panels and had minimal chance to organise his or her own planned activities such as ILE. To Orkid, this situation became worse when 'the LMT was not knowledgeable; no one wants to listen to her'. Thus, one of the reasons for the lack of collaboration between the LMT and the academic panels was because of the LMT's lack of IL knowledge and skills. Orkid added that the teachers 'always wanted to be guided and to be told what to do'. Thus, the LMT should have enough IL knowledge and skills to be able to "gain the respect of the teachers" and to guide and "tell them what to do" with ILE.

However, Buluh believed that the School Head heeded to the requirements of the MOE to produce well-rounded students and prepare them for the $21^{\text {st }}$ century skills. The schools did participate in all activities organised at district, state and federal levels; for example, one of the established IL related activities was NILAM (Reading competition). For Buluh, 'school has to move the students [to meet the selection criteria to enter the competition]... and has to organise both teachers and students related activities' in order to participate in the event. Thus, the issues of "eventcreating" and "prize-winning" events had to be agenda items at all education administration levels in order to move the schools away from being too academic oriented. 


\subsubsection{Ecological Context}

The key informants were also asked about the factors affecting ILE implementation at the macro level such as community or society, district and state administrators as well as government and other agencies in order to understand why ILE was not implemented or only partially implemented in the schools.

\section{(a) Community/ Society}

When asked to describe the Malaysian society's culture, beliefs and practices and how they affect the implementation of ILE in the schools, the key informants' responses were varied.

Melur stated that Malaysian society was exposed to various information channels since the availability of the internet in the country. To her, 'the society explores and uses internet service to search information' and there is no doubt that the society was exposed to a variety of kinds of information whether fictitious or factual in nature.

Another perspective about Malaysian society came from Orkid. She adamantly claimed that

Our society ignores the function of library...because we are so academic oriented. Our system of education allows the students to achieve 9As [in the public examinations] without having to go to the library.... Everything is spoon-fed [to the students]. (Orkid)

Orkid was concerned about the position of the library. She said that everywhere people were referring to the internet as if we could get all the information from the internet. To her, the function of the library as a knowledge repository was neglected, although lots of tax payers' money went to developing and acquiring library resources. She hoped that library and information professionals could 'change the people's perception of libraries referring only to books'. Orkid's point was that the accessibility of the internet and the public's pre-conceptions affected the perception of the importance of the role of libraries in society. Thus, it is the role of the 
LMT to enable effective and safe use of information resources including the internet. This role is linked to IL.

Orkid also highlighted the tendency of Malaysian society to be ceremonial and extravagant especially when new plans and policies were introduced to the people. As she pointed out, 'it is our culture which has the tendency to make announcement to a new effort, then organises a ceremony, and the end [closing of the ceremony]'. She believed that the plans or policies introduced ceremoniously were not executed as intended due to the lack of a follow-up or monitoring system. She added, whenever a project failed, the implementer was likely 'to give excuses' as a self-defence strategy. Often another party like the Government had to rescue and take over the "non-performing" projects. Unfortunately, this kind of attitude appears to be deeply ingrained in the society.

Another issue that Orkid was concerned about was the management practices. She believed that

there is a mentality [among the managerial level staff] that...no one wants to work hard, except if the person had any vested interest. The management prefers lazy staff who [would only] work, if they were given instruction.... Our people like to be told what to do. On the other hand, if the staff had come up with new ideas, it was considered as weird. (Orkid)

This was what Orkid felt and experienced working in Malaysian offices. This behaviour predominates and, the plans and policies that were supposed to be properly executed faced a stumbling block. The outcomes of the plans and policies could not be achieved as hoped. This was also another factor to be considered in terms of limited ILE implementation in the schools.

The key informants agreed that Malaysian society was exposed to more sources of information now due to the accessibility of the internet. The society has begun to be more receptive to new ideas and change. The ideas received have led to changes in society through the introduction of plans 
and policies by government agencies. However, Orkid believed that the new programmes such as ILE were grandiosely introduced to the society, but in many cases were left unfinished or poorly executed, and as a result, society was left with unachieved intended outcomes.

\section{(b) District/ State}

The key informants at the district and state levels were asked to comment on their involvement and support to schools in implementing ILE. The information provided was related to their dealings and communication with schools as well as their constraints in performing their tasks.

At the district level, when asked about the TAC's role in ILE implementation, Melur indicated that the TAC had organised several IL courses and IL related courses as well as meetings or gatherings for the LMTs and ICT teachers. However, she admitted that the SETD and TAC had not conducted any IL courses since 3-4 years ago. That means the case study schools' LMTs had not received any recent IL training.

In terms of the monitoring system of ILE implementation in the schools, Melur said 'we [TAC] can go and monitor schools, but we cannot do anything if the schools did not implement ILE. We can only prepare a report and submit the report to the MOE [via SETD]'. To her, the TAC had no authority to take action and to ensure that the schools were implementing ILE. TAC could only communicate the status of implementation to the MOE through a written report.

When asked about the communication between schools and TAC, Melur said the frequency of the communication depended on the schools. She admitted that in terms of ILE implementation, the schools seldom asked for any advice or support from the TAC. Moreover, when asked about the TAC's inter-organisation communication with the state and federal, she said 'there is no communication between the TAC and the MOE because the TAC only reports to the SETD'. The communication system within the education administrations seemed very hierarchical and bureaucratic in 
nature, because any message intended to be delivered to the top management had to pass through several stages before it could be resolved.

At the state level, Buluh, when asked about the SETD's support of ILE, indicated that the SETD officers and facilitators had 'verbally reminded' the LMTs about their roles and responsibilities during the courses organised by them. He also indicated that the School Heads were appointed as members of the management committee at each TAC which they belonged to. As he pointed out,

During the management committee's meeting, the school heads were given all the information and instructions related to the IL and its related activities. This was to ensure that they delivered the messages to the school community and implement the [ILE] policy. (Buluh)

Buluh described the commitment of the SETD to ensure that the MOE's aspiration reached the school community through one of the initiatives, that is, by setting up the management committee among the school heads in the TAC. He pointed out that the management committee members often met to keep informed of any IL related activities. Thus, the members had no excuses for not knowing about ILE. Buluh was confident that the SETD had done its level best and as he put it 'our efforts are continuous.' To him, the SETD had always been supportive in ILE implementation.

However, Buluh admitted that the SETD did face some obstacles in making sure that ILE could be implemented as intended. He highlighted three constraints. The first was the transactions of the SETD with the schools. He said that it was a practice that the SETD did not deal directly with the schools. All the time, it was the TAC's officers who acted and represented the SETD in most school events. The SETD officers would only be on the ground occasionally when the events needed more manpower. He was quite frank about the SETD's role. As he said 'our role is to delegate the training programmes to the TAC. The TAC trains the LMTs in the schools.' He added that the SETD had to delegate some of its responsibilities due to its lack of capacity. 
I also asked about the IL training for the teachers. Buluh admitted that this was another constraint due to the SETD's lack of capacity in terms of manpower and funding to train IL to all the teachers in the state. There was also a ruling from the District Education Office (DEO) that staff training was not allowed during school hours because the training could disturb the teaching and learning as well as sport activities in the schools. Also in most cases, the SED and DEO were in-charge of training the teachers.

The third constraint was the lack of capacity to monitor activities that took place on the sites such as at the time when the school suppliers delivered the equipment to schools. The technical personnel from the State or District offices were unable to be at school on most occasions. As a result, Buluh said:

The supplies to schools were sub-standard.... If ever the SETD had the capacity [more manpower] to monitor the activities [in relation to the supply of equipment], the supplies could be checked on the time of the arrival [at school].... If the equipment [computer hardware and software] in schools achieve the needed standard and specification, the schools could reduce the problem of application. (Buluh)

To him, the teachers at school could apply the skills that they received from training to the classroom if the equipment in the school was of the same standard as what they used during the training. However, in reality, the transfer from training to the classroom was not possible unless the situation could be improved.

In short, Melur and Buluh highlighted certain issues regarding staff development and training, and the level of communication in education administration. As was pointed out, IL training was last held four years ago. Thus, the LMTs had no recent knowledge of IL. Furthermore, if there were any issues with regard to ILE implementation, the TAC had no authority to make changes or solve the problems. The most that TAC could do was to gather, to record and to report in written form and inform 
the higher level authorities such as the SETD and the ETD about the matter. According to Buluh, the SETD was unable to play its role well due to lack of direct transactions with the schools, lack of manpower and funding to train all teachers at schools, and lack of capacity to monitor all supplies activities at schools.

\section{(c) Government and other agencies}

When asked about the role played by the Government and its agencies in supporting ILE implementation, Orkid and Mawar gave their points of view based on their positions as federal officers in one of the divisions of MOE.

Orkid, although she had been a federal officer for five years, was vocal about the existing situation in the MOE. She began by describing the MOE's decision to focus on ICT.

The 2008 [MOE] meeting had made a decision that ETD focussed more on the ICT, ICT maintenance and others.... SRC and related activities [including IL] were placed under the administration of the Textbook Division [locally known as BBT]. SRC was not considered as educational technology.... The sad thing was that the Director [of the ETD] of the day did not defend the status of SRC in the meeting.... Just after the meeting, the Director was transferred to BBT, and then the ETD received a new directorship. (Orkid)

Orkid said she accepted the decision of the MOE's emphasis on the ICT because the project had involved a huge amount of funding. The MOE had to stand up to justify the project in-progress. However, Orkid could not understand why the SRC was not considered as one of the educational technology resources in that particular MOE's meeting, although the SRC had been with the ETD since its establishment. From Orkid's perspective, the SRC and its related activities were not relevant to the MOE's ICT agenda. As she explained, 
The new director instructed the SRC unit to close [the operation at ETD] because the Unit was going to move to the BBT. At the same time, the BBT could not accept the Unit. The Director of BBT said that if the BBT was to accept the Unit into the division, the whole network of the Unit such as the SETDs and TACs should be given to the BBT. (Orkid)

Orkid seemed very sad that the SRC unit was being split between the two divisions in the MOE. The status of the SRC unit was uncertain which led to many other challenges. She continued:

For two years now, the Unit has been neglected.... The whole unit has been downsized, the facilities are denied, the officers are not allowed to conduct courses or talks, and the staff members are shifted to other units or departments... Our instructions to the SETDs and TACs were to continue their efforts on SRC [activities] because at the ETD level, we could not do anything.... The name of the sector [under which the SRC unit is located] changed to Educational Technology Literacy Management Sector and was instructed to perform a new function.... The Smart Sector leads the ETD efforts. All trainings are conducted by the Smart Sector in order to optimise the performance of teaching and learning [in ICT] in schools. The Educational Technology Literacy Management Sector was not allowed to train the LMTs nor attended any related courses. (Orkid)

Orkid highlighted the conditions of the SRC unit which had been denied the administrative and leadership support from the top management of the ETD. According to Orkid, the Unit was unable to function as it was supposed to such as appointing LMTs in schools and other monitoring activities. She said that 'due to all the challenges, as an alternative, educational resources portal has been set up as a mean to deliver the related knowledge and information to the staff members on the ground.' She was delighted that even though she and her staff members were not 
allowed to conduct training and meet the staff members at the state level, the Unit was still able to deliver and educate the staff via using the portal.

Orkid believed that with the development taking place in the MOE, leadership contributed to "the success or failure of certain projects.... It was really an important factor.' She further stated that being in a powerful position, a leader could single-handedly change the direction of an organisation. Hence, she believed that the conditions in the ETD could be changed, if the Director 'knew and understood how to translate a policy into an action.' To Orkid, many directors of the MOE did not know how to implement the MOE's vision and mission. This was another factor that led to the constant change of instructions and directions in plans and policies at all education administration levels. Orkid said that the reason could be that the directors did not have adequate knowledge to perform their designated tasks.

Another reason was the frequent job rotation at the MOE. This meant that the staff members of MOE lacked sufficient experience to be well-versed in their job. Orkid pointed out that there were many unproductive practices among the top management such as 'the research done by the ETD staff members are not used' to improve the situation and 'those less knowledgeable officers are always given the opportunities and trusted to carry out the MOE's efforts, even though the output [of the efforts] is not desirable.' Thus, leadership played a part as a success factor in the MOE's plans and policies. In the situation described by Orkid, a leader had to be able to make full use of the resources available and place the right person in the right position so that the intended programmes could be implemented as hoped.

Orkid commented that most MOE staff members 'did not know about the concept of IL and its philosophy'. Thus, she felt the need for the SRC unit in particular and the Sector as a whole to educate the MOE staff members about IL. However, she admitted that less attention was given to IL because of the recent development in the MOE. She said that, 
At this level, all our energy have been used up, first, on how to improve the situation of SRC unit, to equip the LMTs with proper knowledge, and to ensure the proper management of SRC in terms of its Dewey classification system, acquisition of books, and planning ahead the activities. Second is to move on with the NILAM programme. Third is [to handle] the attitude of staff at the ETD.... The IL wing is not strong and cannot support the SRC wing. Our hands are full and are not able to help them [IL wing]. (Orkid)

Thus, her reasons for the lack of ILE implementation at school level seemed to be administrative factors that hindered the federal level in supporting on-going ILE implementation.

In addition, Orkid suggested some improvements to the current situation in terms of leadership and perception. She indicated the urgency to communicate and educate the key individual: 'if I were given the chance to talk to number one figure in the Ministry, I will explain the concept of IL to him.' She seemed to be determined to convince the Director-General of the MOE about IL so that ILE implementation could receive better support. She also suggested reducing the job rotation exercise in the MOE to maintain experienced staff in all sectors of MOE.

Orkid also believed that another factor that could facilitate a school to implement ILE was the leadership of SETD. The leadership of SETD should have good knowledge and understanding of IL so that the schools under its supervision could implement ILE as hoped. At the same time, Orkid believed that the ETD as one of the divisions in the MOE should try to educate other divisions to understand IL. This effort could create a mutual understanding of IL and thus change the perception of the other divisions of the MOE towards the ETD. Most of the time, the divisions and even the sectors within a division were working in silos. They were unaware of each other's contributions. In addition, Orkid believed that 'the other divisions of MOE do not look up to the ETD' to the extent that the ETD was known as an Unimportant Division. According to Orkid, the 
other divisions did not acknowledge that the efforts made by the ETD were influential and comparable to their endeavours because of the lack of understanding of the important work of others and the need to jointly uphold the development of the nation's education system.

Mawar, when asked about the ETD's role to support ILE implementation, was not ready to discuss the internal affairs of the division although she had been with the ETD for more than 10 years. She tended to blame the teachers at schools rather than the internal problems at the MOE. The only thing that she commented on was about the different interpretation of ILE implementation between the two divisions of MOE, that is, the Curriculum Development Centre (CDC) and the ETD.

Mawar said, 'the CDC thinks that IL should not be taught because it is embedded in the curriculum. But the ETD believes that IL should be taught to the students.' She thought that this discrepancy was only a matter of different opinions and should not be a problem to its implementation at schools. However, she believed that more efforts should be given to ensure ILE could be implemented in schools. Her suggestions were 'to educate the lecturers in IPGM [Malaysian Institute of Teacher Education], the lecturers in universities, especially in the Faculty of Education whereby the components of IL should be addressed in the students' lesson plan.' Thus, to her, each department and division of MOE was playing a part to ensure the on-going development of ILE.

To summarise, both Orkid and Mawar believed that much effort and energy should be applied to ensure the implementation of ILE at schools. They highlighted the obstacles and came up with the suggestions such as educating the lower and upper ranks of MOE about ILE as well as other departments and divisions, changing perceptions of the ETD and thus gain a better chance and support for ILE implementation. With better understanding of IL, it was hoped that all divisions of MOE could work as a team and create conditions conducive for ILE implementation. 


\subsubsection{Implementation Protocols}

When asked about the ILE guidebooks or manuals used to implement ILE, interestingly I received two sets of responses, the first from Melur (district) and Buluh (state), and the second from Orkid and Mawar (federal).

Melur and Buluh indicated that they did not possess any guidebook on ILE. As Melur said, 'we [TAC] only have scope and explanation on IL ... but no detailed syllabus'. Similarly, Buluh also expressed that 'there is no formal guidebook. Most are in the form of course notes and activities done in the courses'. Thus, the absence of ILE Implementation Protocols such as IL guidebooks, IL lesson plans and other protocols occurred at the district and state level of education administration as well as at the case study schools.

On the other hand, Orkid and Mawar claimed that they had delivered all the ILE Implementation Protocols to the Malaysian schools (national and national-type schools). As Orkid stated, "we [the ETD] did supply [IL guidebooks and other protocols] to schools... and at present, we have uploaded [the protocols] in the educational resources portal'. Mawar further added that 'actually we [the ETD] already gave them the [IL] booklet to the LMTs to assist them managing the school resource centre. It depends on them [the LMTs] whether to use or not to use the booklet'.

When asked about the unavailability of IL guidebooks, IL lesson plans and other protocols to assist ILE implementation in schools, Orkid thought that the guidebooks must have been misplaced in the LMT's office or were sitting idly in the School Head's office.

While Melur and Buluh responded that they had no proper ILE Implementation Protocols in their possession, Orkid and Mawar were convinced that the ETD had supplied the protocols to all schools in 
Malaysia. The ETD had even made the protocols available and accessible online. To Orkid, the unavailability of the protocols was due to mismanagement of the protocols in schools. Thus, again the lack of communication appears to have led to a failure to keep teachers and MOE officials informed of ILE protocols.

\subsubsection{How do these factors facilitate or hinder ILE implementation in Malaysian primary schools?}

As reported by the key informants, factors that hindered ILE implementation appeared to be greater than those that facilitated implementation. The following is the explanation of how these factors identified by the key informants affected ILE implementation in schools.

First, when asked about the teachers' IL knowledge and skills, Melur and Buluh, the key informants at the district and state levels, were optimistic that the majority of the teachers were exposed to IL. According to Melur, IL was first introduced to the School Heads, SAAs and LMTs with the intention that three important persons in schools delivered the relevant knowledge and skills to the school community as a whole. Buluh also believed that from his observations during the training courses, the LMTs possessed the skills needed to implement ILE.

However, Orkid was not convinced about the LMTs' IL knowledge and skills. From her perspective, most LMTs had been busy managing the SRCs rather than implementing ILE, and, due to the MOE's emphasis on ICT, the LMTs' job had moved to ICT based activities. Orkid sensed the inability of LMTs to perform the job well because of insufficient IL training. She revealed an alternative to overcome this problem by recommending the recruitment of LMTs from the graduates who majored in school resource centre management, but unfortunately they were without a teacher's training qualification. Thus, the idea was rejected by the top management of the MOE and the situation could not be changed. Even though the teachers at school were exposed to IL, they were unable 
to implement ILE in the classroom. Even the LMTs were unable to do so. This was a major dilemma in the schools.

According to Mawar, the teachers did not lack training, but reluctance to study. She thought that in addition to attending the training courses the teachers should do more reading on ILE to increase their understanding of IL. She also commented on the attitude of the teachers who were very dependent on higher authorities such as the school head, the district, state or federal officers, to tell them what to do. These teachers were also passive. This was evident from my interviews with all the participants at schools. When asked about the availability of guidebooks related to IL or constructivist learning or any other guidebooks, only the LMT of Lembing provided me with a guidebook on the NILAM programme. The rest of the participants had given various reasons for not having IL guidebooks. None of them identified the educational resources portal set up by the ETD. To Mawar, the teachers did not want to read and search for information themselves.

According to the key stakeholders, the teachers were not motivated to perform any responsibilities beyond what was strictly essential. According to Melur, the main factors were the teachers' need to finish the syllabus, prepare for the examinations, and be involved in extra-curricular activities, all of which led to time-constraints that hindered ILE implementation. They also led to the teachers' inability to be creative and critical in their jobs and even to undertake self-development. As a result, the teachers tended to remain complacent rather than risking being unable to meet the targets set by the school. Thus, the teachers did not want to implement ILE t solely because of their personal attitude problems as Mawar saw it, but also because of the factors that were beyond their control.

Second, the key informants did not comment much on in-school support. Only Melur talked about the responsibility of the School Heads, SAAs and LMTs to share the IL knowledge and skills with the teachers in in-school training sessions. These three important roles in the schools were expected 
to communicate the skills and knowledge so that ILE could be implemented. However, from Melur's experience with the schools, the schools seldom asked for advice or support for ILE implementation from the TAC's or SETD's officers. The schools hardly communicated to SETD how much they have implemented ILE except when an activity such as NILAM was organised and the schools were obliged to participate and report progress.

At the federal level, Orkid and Mawar explained the initiatives at the ETD to monitor the development and progress of SRC and ICT using tools such as iQPSS and SPPICTS. They pointed out, however, that the initiatives were not documenting what was happening in the schools, but were just "fill-out the forms" exercises by the teachers and LMTs. The exercises were done as rituals rather than as useful experiences for the teachers. The "fill-out the forms" exercises failed to highlight any limitations or problems in the implementation of the initiatives.

Thus, in the case of ILE implementation, the three educational administrations' support for the school was not enough to ensure on-going ILE implementation.

Third, there was evidence of a lack of understanding of ILE as demonstrated in the story recounted by Melur. She mentioned how she had applied ILE in her English classes and how in the beginning, the School Head reacted negatively because Melur was not teaching the students as commonly practiced. In her situation, Melur had to fight her way to implement ILE in her classes, and it took strong will power and creativity to implement ILE at the individual level.

At the federal level, Orkid put forward the issue of over emphasis on ICT. Most of the top MOE management thought that teachers and students could find all necessary information and knowledge by using ICTs and they could not see the relevance of IL in the classroom. Orkid believed that the misconception of IL was due to the lack of IL understanding among 
the top management themselves. Because of this misunderstanding, the Sector of Educational Resources Management had a difficult time in convincing others about the importance of their roles and responsibilities.

Thus, in terms of ILE implementation in Malaysian schools, there was still a lack of IL understanding among all levels of education administration and lack of application after the training among the LMTs and teachers. The only hope for the on-going implementation of ILE at the moment was the new primary school policy (KSSR) and the individual teacher's or LMT's creativity and proactive effort to implement it in the schools.

Fourth, there was no serious effort to implement ILE in Malaysian schools. This was clear from the lack of IL understanding among all levels of education administration and the lack of implementation at the school level. According to Melur and Mawar, IL was 'embedded' and 'blended' in the curriculum to the extent that the teachers did not know they were implementing it in the classroom. Mawar also commented on how the two divisions, CDC and ETD, perceived ILE implementation. The CDC saw ILE as already integrated in the syllabus. On the other hand, the ETD thought that ILE should be taught to the students. These two perspectives are evidence that there was no clear guideline on how to implement and even measure ILE implementation in the classroom.

From the evidence provided by the key informants, ILE implementation in Malaysian schools did not have an integrated plan to bring all levels of education administration together and to show their full commitment to the common goal. Thus, because of the lack of integrated planning, it was impossible to have a proper and continuous monitoring process as well as the support needed for the on-going development of ILE. 


\subsection{Chapter Summary}

Three of the interviewees, Melur, Orkid and Mawar, indicated that the level of implementation of ILE in schools was very low. According to them, among the factors affecting ILE implementation in school were the lack of IL understanding among the school community, lack of leadership support and the attitude of teachers and LMTs towards ILE.

These interviewees thought that staff training should be prioritised. They commented the attitude of the LMTs and teachers who were dependent, passive and had poor reading habits that led to insufficient ILE implementation and insufficient school administrative and leadership support for ILE implementation, particularly on the issue of LMT appointments.

The key informants said that the leaders tended to be ceremonial in launching new programmes, but rarely finished the effort as intended. This was the case with ILE. Factors such as the lack of communication between the education administration levels and the lack of capacity in terms of manpower and funding to proceed with the staff training and monitoring processes at schools hindered ILE implementation. The consequence of the lack of communication was that the federal officials did not realise that the district and state officials did not possess any ILE Implementation Protocols, except in the form of IL course notes.

All interviewees believed that the teachers and LMTs at schools were exposed to IL. However, they believed that the teachers were unable to implement ILE successfully in their classes because the limited time available was used to finish the syllabus, to prepare for exams and to participate in students' extra-curricular activities. Consequently, even though the teachers and LMTs possessed IL knowledge and skills, they were unable to implement ILE because of the limited time to accomplish their work. 
Online tools such as iQPSS and SPPICTS were among the initiatives by the MOE to support and monitor the progress of Smart Schools and SRC including ILE. However, these efforts and the support were not enough to ensure ILE was implemented in the schools. The Malaysian schools still needed the support from outside their schools and even outside the MOE to push forward and make the difference to the implementation.

The interviewees also believed that the insufficient leadership support was due to the absence of IL understanding among the top education administrators. Leaders at all levels of education administration overemphasised the role of ICT, and thus neglected the role of ILE to enhance the use of ICT in education.

Finally, most interviewees indicated that the efforts and initiatives at all education administration levels tended to be piecemeal rather than reflecting overall planning. For example, IL training for teachers and for the LMTs was done by two different state departments resulting in a lack of coordination and collaboration between the two education departments to jointly train those groups of teachers.

In the following chapter, I present the analysis and interpretation of the findings of the four case study schools and the key informants at district, state, and federal level. The aim is to make sense and to present the deeper meaning of the reported findings of ILE implementation in Malaysian schools by comparing them with those of other studies. 


\section{CHAPTER 9 Information Literacy Education in Malaysia: Synthesis and Interpretation of the Findings}

\subsection{Introduction}

In this chapter, I synthesise and interpret the findings related to the four case study schools and the key informants at the district, state and federal levels of education administration. The purpose of this chapter is to provide the interpretive insight of the findings in previous chapters so that a holistic understanding of the factors affecting ILE implementation can be achieved.

This chapter is organised into the following sections:

- A comparison of the perspectives of key informants from the federal, state and district levels with the perspectives of participants from the case study schools in order to identify gaps between the two groups.

- A discussion of other contextual factors found in the data in order to understand the hidden factors related to these groups.

- A re-examination of the preliminary model and summary of the interpretation.

The discussion revolves around the similarities and differences among the case study schools and key informants, and takes into consideration the literature on ILE, the Western philosophy of education particularly on constructivism, the national education system of Malaysia, and social and cultural influences on learning, thinking and management. A synthesis of ILE and the Malaysia Education System (MES) is provided. The chapter concludes with the re-examination of factors in my preliminary model of ILE implementation from the third chapter. 


\subsection{Comparison of the perspectives of federal, state and district key}

informants with the perspectives of the case study schools' participants

In this section, I discuss the similarities and differences of perspectives between the key informants from the federal, state and district levels (hereafter, simply referred to as "key informants") and the perspectives of participants from the case study schools (hereafter referred to as "participants") about the implementation of ILE. The aim is to identify the gaps in thinking and practice between these diverse groups, and thus, to further understand the factors affecting ILE implementation in schools. I begin with the voices of the key informants and compare their views with findings drawn from the perspectives of participants from the case studies. The topics of discussion are the development of ILE as well as the organisational, individual, social and cultural factors that affected ILE implementation in the case study schools. The following table summarises the key points which are then discussed in the following sub-sections: 
Key Informants' Perspectives (District, State and Federal levels)

Development of ILE

\section{Appointment of LMTs}

The appointment of full-time LMTs
Organisational factors is intended to strengthen and further develop the education system with the implementation of various activities and programmes related to the Smart Schools and School Resource Centres. Individuals selected as LMTs are qualified teachers and are supposed to be trained at least for 14 weeks of school resource centre management.

\section{Introduction of KSSR}

With the introduction of KSSR (a new policy for primary schools), elements such as inquiry-based, problem-based and project-based learning are recommended classroom practices.

\section{Limited awareness and leadership} of ILE

The lack of official appointment resulted in the LMTs' heavy workload.

\section{ILE unfamiliarity}

The MOE top management had limited understanding of IL and placed too much emphasis on ICT over ILE. The MOE top management rarely used staff research to make informed decisions.

\section{Lack of on-going action and} research

The federal key informants confirmed that they have the ILE Implementation Protocols and had distributed them to all schools.
Participants' Perspectives (Keris, Badik, Lembing and Kapak)

\section{Three LMTs have been} officially appointed and undergone the required training.
Two Year One teachers were trained using the inquiry, problem-based and projectbased learning in the classrooms.
Individual

factors

\section{IL knowledge and skills}

$80 \%$ of teachers possessed IL knowledge and a state key informant believed that all LMTs had the required knowledge and skills. But the key informants confirmed that
The case study schools did not have any ILE Implementation Protocols.

The majority of the teachers and LMTs did not have adequate IL training. 


\begin{tabular}{|c|c|c|}
\hline & $\begin{array}{l}\text { there had been long delays for IL } \\
\text { training (about } 3 \text { years). }\end{array}$ & \\
\hline & $\begin{array}{l}\text { Lack of transferability of IL } \\
\text { training to classroom } \\
\text { The LMTs and teachers were not } \\
\text { familiar with the term information } \\
\text { literacy. }\end{array}$ & $\begin{array}{l}\text { The LMTs and teachers did } \\
\text { not know how to integrate ILE } \\
\text { into the class syllabus. }\end{array}$ \\
\hline & $\begin{array}{l}\text { LMT's and teachers' attitudes } \\
\text { towards work } \\
\text { Teachers had poor reading habits } \\
\text { and relied only on reading materials } \\
\text { provided by the MOE. }\end{array}$ & $\begin{array}{l}\text { The case study schools } \\
\text { blamed shortage of time as an } \\
\text { obstacle to ILE } \\
\text { implementation. }\end{array}$ \\
\hline $\begin{array}{l}\text { Social and } \\
\text { cultural } \\
\text { factors }\end{array}$ & $\begin{array}{l}\text { Lack of openness to new ideas } \\
\text { The top management in MOE did } \\
\text { not heed staff member's ideas or } \\
\text { research findings. }\end{array}$ & $\begin{array}{l}\text { The case study schools } \\
\text { claimed that the over } \\
\text { burdening and work stress of } \\
\text { teachers were not given } \\
\text { attention. }\end{array}$ \\
\hline & $\begin{array}{l}\text { Weak governance and monitoring } \\
\text { system } \\
\text { The lack of follow-up and the } \\
\text { insufficient monitoring system could } \\
\text { be related to the constant job rotation } \\
\text { in most departments and divisions at } \\
\text { the MOE. }\end{array}$ & $\begin{array}{l}\text { Teachers and LMTs were not } \\
\text { properly guided and trained to } \\
\text { implement ILE in the } \\
\text { classrooms. }\end{array}$ \\
\hline & $\begin{array}{l}\text { Lack of two-way interaction } \\
\text { Schools rarely asked for help in } \\
\text { implementing ILE. }\end{array}$ & $\begin{array}{l}\text { The education administrations } \\
\text { did not hear the teachers' } \\
\text { voices. }\end{array}$ \\
\hline
\end{tabular}

Table 9.1. Comparison of the perspectives of key informants and of participants from case study schools

As can be seen in Table 9.1, there are significant discrepancies between the perspectives of the informants and those of the participants.

\subsubsection{The development of ILE}

This section discusses the basis of the discrepancies concerning ILE implementation in schools as indicated by the key informants. Two critical factors were identified: the non-appointment of an LMT to each school, and the invisibility of ILE in KSSR. 


\section{a) The non-appointment of LMTs}

The key informants emphasised that the appointment of LMTs was one of the MOE's initiatives to implement ILE in the schools. The appointment of LMTs was finalised when the MOE issued a professional circular stipulating that each Smart School would be provided with a Smart Teacher Coordinator and a full-time LMT (MOE, 2005). The circular makes it explicit that the appointment of full-time LMTs is intended to strengthen and further develop the education system with the implementation of various activities and programmes related to the Smart Schools and School Resource Centres. Those individuals who are selected as LMTs are qualified teachers and are supposed to be trained at least for 14 weeks of school resource centre management.

However, my data showed that not all LMTs interviewed had an official appointment nor had the required training. One LMT was not formally appointed as a LMT and did not receive on-the-job training. The other three LMTs were formally appointed but were not specifically trained in IL. This outcome relates to the finding of the ETD of the Malaysia Ministry of Education that $70 \%$ of teachers were not trained in IL (ETD, 2006). The factor that generally led to this situation was confirmed by most key informants, namely delays in the appointment of the LMT by the School Head, as well as the lack of IL courses and systematic planning by administrators. Therefore, Melur, for example, felt it essential to organise IL courses at least twice a year in order to refresh the LMTs and the School Heads as well as to create better awareness of the importance of IL.

In addition to the LMT appointment, the ETD (federal level) introduced tools such as iQPSS and iNilam to assist in monitoring SRC and IL activities at schools. Orkid believed that such tools could be used to keep track of SRC and IL activities and to be aware of the on-going development of IL and SRCs in schools. The eventual statistics could provide the supporting data for justification for further improvement or actions. 


\section{b) Invisibility of ILE in KSSR}

Another reason for limited ILE implementation mentioned in the data was the invisibility of ILE in KSSR, the new primary school curriculum (see 5.3.2.2). At the time of this study, all Primary One teachers were sent for KSSR training as the policy was introduced in January 2011. All key informants acknowledged that the elements of IL were included in the new school standard. They believed that the new standard contributes to the development and implementation of ILE because it is less-exam oriented and entails less class hours for Primary One to Three teachers. Thus, it appears that the national education system was evolving with KSSR.

Nevertheless, document analysis showed that the MOE top management has not explicitly acknowledged the concept of IL. Even though the components and elements of ILE were clearly described, neither IL nor ILE are specifically referred to in KSSR. This situation was mentioned by Orkid who was disappointed with the lack of visibility of IL and SRCs in the new standard. She said that the most obvious role was given to Smart Division focussing on ICT in education. These findings concur with Singh et al.'s (2005) study of the development of ILE through school libraries. One of the key results of their study was the lack of visibility of ILE among senior MOE officials due to lack of awareness about the role of school library programmes and IL.

\subsubsection{Organisational factors}

In this section, I reflect on the reality of expectations about ILE implementation across the curriculum. The most common responses from the key informants and the case study schools concerned the limited awareness of and leadership for ILE, and the lack of planning and research to improve its implementation. 
a) Limited awareness and leadership

As indicated in section 2.6.2, the official appointment of LMTs has been one of the factors of the MOE's key initiatives at the federal level to integrate ILE in the curriculum. For example, Keris' LMT had no official appointment since taking over the position three years ago. Consequently, she was unable to attend IL training organised at the SETD or TAC. The data suggested that the school leadership was providing limited motivation or vision for ILE implementation. This appeared to be associated with several factors, not all within the school heads' control.

Similarly, in Badik, the School Head was knowledgeable about IL. However, the LMT did not receive the reduced teaching workload even though this was the official incentive promised for this appointment. The LMT also claimed there was no job rotation. In the LMT's eyes, these two instances seemed to reflect limited awareness by the School Head. The same issue was raised during my interviews with the key informants, Melur (district) and Orkid (federal), who indicated that such problems occurred frequently in schools.

At Lembing, the School Head prioritised reading over ILE. The Kapak's School Head was flexible in her administrative practice and willing to explore a new approach to teaching and learning. However, she expressed concern about the teachers' and students' readiness to accept ILE because to her the outcome of ILE was invisible. She was unconvinced of its effect on the students' learning and exhibited her lack of confidence in implementing ILE in the classroom.

Thus, the School Heads, though aware of ILE and its importance, did not provide strong support for ILE implementation. In contrast, teachers used very structured teaching practices in order to ensure students' high achievement in exams, which in turn could help to accelerate school performance. The School Heads tended to be more administrative than 
instructional $^{5}$ in their leadership style because the evaluation of their performance was based on their school's examination results.

According to Melur, Buluh and Orkid, the LMT's heavy workload caused turn-over to be quite high. Melur thought this situation was due to the lack of collaboration between the LMT and teachers. However, all LMTs in the case study schools confirmed receiving good cooperation from the teachers. Therefore, the reasons for their dissatisfaction were more likely related to their attitudes towards work or the lack of understanding and support from the school administration about ILE.

Most key informants felt the exam-orientation of the school system was a major factor affecting the implementation of ILE. They believed that it forced the School Heads to emphasise activities that help students to perform better in exams rather than the non-exam activities such as ILE.

While most key informants claimed that because of the exam orientation system, schools shied away from ILE implementation. Melur commented that ILE was treated as one of the elements implemented across the curriculum and was considered as an extra-curricular programme (see 8.2.1). IL skills thus appear to be taught only as a complementary effort to enhance the quality of the school curriculum. Thus, these two different views of key informants indicate the need to teach ILE directly instead of indirectly to the students, and to introduce ILE as an independent, academic subject.

b) ILE unfamiliarity

I also found those responsible for the curriculum had not explored nor fully understood the implementation of ILE in the school curriculum. No pilot studies were conducted to find out ways to effectively implement ILE

\footnotetext{
${ }^{5}$ According to TALIS (2009), instructional leadership refers to a style of leadership that is concerned with teaching and learning supervision and support for teachers' professional development.
} 
in the classrooms. The MOE top management appeared to place greater emphasis on ICT compared with ILE in the school curriculum.

My data suggest that the limited understanding of IL among the MOE top management contributed to the lack of a clear approach to ILE in the MOE's plans and policies (see 8.2.2.1(a)). Skills such as critical and creative thinking, ICT, inquiry and reflective learning, which are components of ILE, were clearly embedded in all school subject specifications and syllabi in most of the MOE's strategic plans and blue prints. Neither the MOE's top management nor the School Heads, however, understood what the skills meant, or what kind of changes ILE required for teaching and learning and for the SRC and LMT's role in the school. This view was offered by Orkid. Again the finding concurs with Singh et al.'s (2005) study on the lack of awareness among the officials in the MOE.

I also found the MOE officials tended to prefer the infusion or indirect approach in implementing ILE, and to assume that teachers were able to apply ILE without even noticing ILE was implemented in the classrooms (see 8.2.1). The risk factor in this approach is very high because the teachers may have their own teaching preferences or beliefs with regards to learning, change and collaboration. This is explained by Moore and Trebilock (2003) when they discussed the teaching beliefs of teacherlibrarians which help to determine the effectiveness of school library programmes including IL. I found that many interviewees were used to a traditional, teacher-centred approach. A teacher-centred approach tends to generate passive and dependent learners and is not conducive to ILE implementation (Virkus, et al., 2005).

c) Lack of on-going action plans and research

The ILE implementation appeared to have been hindered by the limited availability of systematic Implementation Protocols at the school level. Further, the district and state key informants admitted they did not have 
proper ILE Implementation Protocols. This finding concurs with Tan and Singh's (2008) finding that LMTs did not teach IL due to limited curriculum resources and framework. The likely consequence is that ILE was not being systematically implemented as intended.

This appeared to be associated with a communication and dissemination problem between government departments and schools. The federal key informants showed me their ILE Implementation Protocols which were distributed to all schools in Malaysia. These Protocols included the SRC and IL guidebook for LMTs, IL lesson plans for primary schools, IL modules and IL syllabus and description. Unfortunately, none of the case study schools had any of these protocols.

The final issue relates to a failure to be informed by previous research. Several studies have reported on the efforts of instructional and administrative leaders to improve the on-going implementation of ILE in schools. Unfortunately, these studies were either kept neatly on the institution's library shelf rather than being used to inform the educators and education practitioners (a similar situation to Hashim's (2004) findings) or the practitioners were informed about the results but took them for granted. Orkid suggested that the MOE's top management did not use the staff research findings as a framework or guide to make decisions and solve problems. Eisner (1984) also noted that in the light of educational research, "those who are best informed about educational research seldom use it to make decisions or to shape institutional policy." (p. 448).

\subsubsection{Individual factors}

The data were also analysed to compare the views of the key informants regarding the individual factors that affected the implementation of ILE in schools with the views of participants at case study schools. The key factors identified in the data are as follows. 
a) IL knowledge and skills

It is clear that the inconsistent and unsystematic IL training resulted in an incomplete understanding of IL among the teachers and LMTs. A key informant from the district level commented that most teachers possess IL knowledge which implies that in some way they had been exposed to the concept of IL in education. On the other hand, my data from the case study schools suggest the majority of the teachers and LMTs did not have proper IL training (see 6.2.2.2(a) and 7.2.2.2(a)). These interviewees displayed a lack of IL understanding and repeatedly referred to IL as the use of computers or IT in the classroom, which concurs with the finding of Tan and Singh (2008). Nevertheless, all key informants admitted the long delay of IL training activities affected the teachers' and LMTs' IL understanding and thus affected the on-going implementation of ILE in schools.

LMTs in this study appeared to place greater emphasis on practical library management activities rather than on IL learning and teaching. Melur and Orkid commented on the LMTs' over-emphasis on book processing at the expense of activities related to promoting IL to teachers and students (see 8.2.2.2(a)). Congruent to this comment, in Kapak, one of the case study schools, the LMT did not know the MOE expected her to educate the teachers as well as the students. She reported that she did not know how to impart the IL knowledge and skills to the teachers nor did she have sufficient time to do so because of the need to finish the syllabus and to prepare the students for exams. The lack of opportunity or encouragement to participate in IL activities or courses by the teachers provides an additional explanation of their apparently limited familiarity with IL skills.

b) Lack of transferability of IL training to the classroom

Despite the efforts of the MOE to officially appoint LMTs in schools and to introduce KSSR to enhance the quality of education, the training courses for teachers and LMTs appeared to maintain an academic, subject- 
oriented focus in their teaching practice rather than to integrate elements such as IL with their teaching subjects in the classroom. This led to a situation where the teachers and LMTs found it hard to transfer the new theoretical knowledge into practice in the classroom. This problem was mentioned frequently by Badik's and Lembing's interviewees when the issue of professional development was highlighted. Merchant and Hepworth (2002) similarly discovered that teachers found that the IL skills they learned were not necessarily easily transferable to students. In Merchant and Hepworth's study, however, the teachers were information literate whereas in my study the interviewed teachers did not have sufficient training to develop a full understanding of IL.

The limited impact of the teachers' training may be associated with the teachers being unfamiliar with IL due to its invisibility in the MOE's key official documents. Again this finding concurs with Singh et al.'s (2005) findings of the invisibility of IL in Southeast Asian government documents.

c) LMTs' and teachers' attitudes towards work

A federal key informant commented that teachers in general were not in the habit of reading. She mentioned that even if the teachers were not attending any IL training, they should do some reading on IL and try to apply what they read. She further added that the teachers tended to be very dependent on documents such as textbooks and workbooks supplied by the MOE to teach in the classrooms. To her, the teachers were not creative in their teaching and learning.

The data suggest that teachers' limited professional reading contributed to them being unfamiliar with the implementation of ILE in classrooms, and thus, hampered their ability to impart the relevant knowledge and skills to students. Mokhtar and Majid (2005) found teachers in Singapore hardly read or used the school libraries because of limited resources and services. Those teachers who were infrequent users of the school libraries did not 
find the need to use school library resources for teaching and learning. Thus, to alleviate the problem, the Mokhtar and Majid recommended an IL training programme in teachers' pre-service and in-service training to help teachers to integrate IL into their teaching.

In addition, the data from the case study schools suggests the teachers' limited time and heavy workloads (school activities and out-of-school activities done during school hours) constrained them in preparing teaching activities to enhance students' learning outcomes. This situation reduced the teachers' and LMTs' opportunities to carry out the teaching of IL in their schools.

\subsubsection{Social and cultural factors}

In this last section, the presence of social and cultural factors that influence the on-going development and implementation of ILE are considered. In the discussion of these factors the views of the key informants are compared with the views of the case study school participants with the emphasis on the school's macro environment, that is, factors that are external to the school ecology.

The data from the key informants suggest the Malaysian society was exposed to a variety of information channels (see to 8.2.2.4(a)). This was due to the efforts of the Government to promote ICT which has resulted in the spread of more satellite, cable TV and better internet connection (see National IT Council Malaysia, 2012). This kind of exposure seems to have had an impact on the ways in which Malaysians attempt to accept and receive new ideas from others.

Despite the constant exposure to the latest technology and modern developments, traditional values and practices among Malaysians particularly in terms of behaviour and thinking are still evident and are transmitted from one generation to another (Khoo, 2011; Abdullah \& Pedersen, 2003). Therefore, these traditional beliefs and practices are 
manifested in all spheres of life, and pose challenges to many new changes and developments. These values and practices are deep-seated in the education administration of the country (see 8.2.2.4(a)).

Culture and values that challenge ILE implementation are discussed in turn below.

a) Lack of openness to new ideas

Based on data provided by key informants, the MOE appears to have a somewhat conservative stance with regard to educational governance. For example, Orkid commented that whenever a staff member expressed an opinion in meetings, his or her opinion did not always receive attention. She added that senior management did not appear to use staff research to support decision making or solve problems. This finding aligns with Shaw's observation (1999, cited in Walker \& Hallinger, 2007) that Asian cultures tend to give greater power to the superiors in decision making, and the subordinates are obliged to follow without questioning.

Orkid also suggested that it was the Sector of Educational Technology Literacy Resources Management's staff who seemed to have problems in convincing the top management about the role of the school resource centre and IL particularly in Smart School education (see 8.2.1). According to Orkid, the Sector felt that they were being left out of the ICT agenda of the MOE, although they tried to come up with plans and programmes which were in line with the agenda. She suggested that the Sector was seen to be unimportant to the agenda of the MOE. Consequently, Sector employees like her struggled to improve its image before other divisions in the MOE and tried to make their efforts, in this case, SRC activities and ILE, visible and crucial for the Government's ICT agenda as well as for the introduction of KSSR.

My data suggested that due to the lack of openness to new ideas or suggestions in the MOE, there was still no improvement in terms of reducing the interviewed participants' work burden and stress. There 
seemed no solution to the problem even though the issue has been highlighted frequently in the mass media ${ }^{6}$.

b) Weak governance and monitoring system

All key informants said that ILE was integrated in the school curriculum. Mawar (federal key informant) affirmed that the ETD published and distributed ILE Implementation Protocols to all schools (see 8.2.2.5) to assist LMTs and teachers to implement ILE. However, an evident lack of follow-up and monitoring system impaired most of the efforts and initiatives to ensure ILE implementation. Orkid claimed this situation could be related to the constant job rotation in most departments and divisions at the MOE. Consequently, the officer who was supposed to be in-charge of designated programmes and policies would have to learn and re-learn whenever he or she was transferred to a new portfolio. He or she might not be able to fully develop and enhance the task at hand.

Another factor that contributed to the slow implementation of ILE at schools was the lack of human resources to monitor all the planned activities such as ILE (see 8.2.2.4(b)). However, this seemed to be due to existing staff being under-utilised and being unable to realise their potential as they did not remain in a position long enough. This finding concurs with Moore (1999) on the role of national level or governmental agencies to provide extrinsic motivation towards the emphasis on IL. She found that the crucial part of IL progress was achieved by placing IL in the curriculum and actively monitoring its teaching and application.

\footnotetext{
${ }^{6}$ A Malaysian daily newspaper reported that about $10 \%$ of the 22,000 patients of the University of Malaya Medical Centre's psychiatrist were teachers. http://www.kosmo.com.my/kosmo/content.asp?y=2009\&dt=0322\&pub=Kosmo\&sec=Renca na Utama\&pg=ru 02.htm. Another news coverage on teachers' workload reported the Government's initiative to form a special committee to address the problems. http://www.utusan.com.my/utusan/info.asp?y=2010\&dt=0401\&pub=Utusan Malaysia\&sec= Muka Hadapan\&pg=mh 04.htm
} 


\section{c) Lack of two-way interaction}

The next factor that was a concern of case study schools and key informants was communication. There was a lack of two-way communication between schools and the three levels of education administration. This was in accord with the finding by Shaw (1999, cited in Walker \& Hallinger, 2007) about an apparent assumption in East Asian societies that only the superiors know best. According to a key informant at the district level, the schools in general rarely sought advice or help for ILE from the district office. On the other hand, a Malay language teacher from Lembing claimed that when teachers asked for assistance, their voices were not heard by the education administrators. These differences might be explained by, as mentioned in 8.2.2.4 (b), the desire of people to maintain harmonious relationships with each other. It is very difficult for Malaysian rank-and-file staff to be assertive when confronting those of higher authority. This cultural characteristic has been defined as "power distance" by Hofstede (2001). Hofstede found that Malaysia was a high power distance country. When faced with confusion and difficulties in doing or implementing any programmes, the teachers or School Head in my study refrained from seeking advice or clarification. This could be one of the reasons for the limited communication between these four levels.

The study's participants indicated that many education-related programmes including ILE were loosely coordinated and poorly monitored, and in conjunction with this, the implementers' awareness of IL at the grass-roots level appeared superficial. This seemed to be related to the finding that information about ILE was delivered to the School Heads, deputy heads and LMTs through just a one-off in-service course or merely through the preparation of an annual event such as NILAM or a reading competition. The situation became worse because there was no systematic follow-up by the education administrators on the implementation of ILE. Thus, the conditions highlighted seemed to hinder the application of ILE's content and delivery at case study schools. 


\subsection{Other contextual factors}

Contextual factors such as the education system itself, and the economic, political and cultural influences, are also important to acknowledge.

\subsubsection{The connections between ILE and the Malaysian education system (MES): Content and Pedagogy}

In this section, the similarities and differences of ILE and MES are discussed, particularly in terms of content and pedagogy (summarised in Table 9.2 below). Both ILE and MES aim to promote the acquisition and application of knowledge and skills to solve problems and to make decisions involving individuals, communities and their surroundings.

ILE

Philosophy
Aims
Contents and
Pedagogy

Pedagogy

Democratic and pragmatic
Information literate
individuals - able to solve
problems - development of
self-directed independent
learners who are prepared
for lifelong learning based
on a democratic learning
environment
Student-centred approach,
constructivist learning,
critical thinking, creative
thinking

Malaysian Education System

Contemporary and integrated ${ }^{7}$ but based on faith, value-based

Holistic development of individuals based on faith - development of active, participative learners who are capable of solving problems and making decisions

Mastery learning, learn how to learn skills, constructivist learning, multiple intelligences, future studies

Table 9.2. General Similarities and Differences between ILE and MES.

\footnotetext{
${ }^{7}$ A. Rahman and Ahmad ([2000], p.89)state that the integrated approach blends the elements of knowledge, skills and values in the curriculum planning in order to allow the integrated development of the intellectual, spiritual, emotional and physical aspects of the individual'.
} 
Table 9.2 allows for a comparison of MES (pre-and-post Independence experience) (refer to 5.3) and ILE (see 2.3). Based on the literature and documentary evidence, I summarise the discussion as follows.

Discussions of the concept of IL by Dorner and Gorman (2006, p.284) in the social and cultural context show that the aim of IL is to enable individuals to be aware of and understand the creation and use of information, to critique and integrate relevant and appropriate information to improve their individual daily activities, to solve problems and make decisions through the use of information resources, thus becoming participative citizens as well as life-long learners. This vision of IL is highlighted in the statements of the second edition of the Australian and New Zealand IL framework which states that information literacy enables people to 'individually and collectively search for and use information for decision making and problem solving in order to address personal, professional and societal issues' (Bundy, 2004, p.11).

The American Library Association (ALA) (2006) also highlights IL as "the basis of sound democracy". Democratic education, according to Miller (2007), occurs when students share power and responsibility in schools with the administrators and teachers. Thus students are not 'bound by limitations, expectations or rules', enabling them to experience meaningful participation in society. Teachers' guidance acts as an aid to freedom, not as a restriction to students.

Constructivism is a student-centred learning and the preferred approach for implementing ILE (Loertscher \& Woolls, 1997; Virkus, 2003; Virkus et al, 2005, Limberg, Sundin, \& Talja, 2012). ILE, as envisaged by Bundy (2004) and the ALA (2006), is intended to be implemented in formal education including primary and secondary schools by fostering inquiry and critical thinking skills. Its aim is to produce autonomous, independent and self-directed learners, that is, individuals who can make informed decisions in the workplace and in their personal lives. This intention suggests a constructivist approach to IL learning and teaching, which 
enables students to construct knowledge by integrating existing knowledge with new knowledge (Dorner \& Gorman, 2006) and the learning environment, is democratic (Gray, 1997).

Similarly, MES involves a comprehensive and holistic national education policy and curriculum directed towards the acquisition and application of specific knowledge and skills based on the national philosophy of education (see 5.3 for a general view of the syllabus). According to Hashim (2004), it requires teachers to use multiple teaching approaches including the constructivist approach that is conducive to ILE. The contents of the curriculum are expected to enable the students to acquire and apply knowledge and skills to solve problems and to make decisions with religion at the core. That means for practicing Malay Muslim students, problem solving skills are based on the knowledge acquired from the environment (such as school) and the verses from the Qur'an and the statements from the Prophet Muhammad (also known as Hadith) ${ }^{8}$. Similarly, the Chinese and Indian students use knowledge acquired from the environment and from their religious beliefs to guide them in decision making.

In IL pedagogy, as discussed in 2.3.4, the constructivist approach is promoted by many information professionals (see Loertscher \& Woolls, 1997; Virkus, 2003; Virkus et al, 2005, Limberg, Sundin, \& Talja, 2012). Similarly, in the new MES curriculum, the preferred method of teaching and learning is a child-centred approach based on the students' multiple intelligences as well as active participation of learners (Azizah, 1987, cited in Lee, 1999, p.90). The aims of Integrated Curriculum for Primary School (ICPS) are then retained in the current education reform policies, i.e., Primary School Standard Curriculum (KSSR) (MOE, 2010). The current policy focuses on student-centeredness and active learning, and the teachers are trained to deliver in accordance with these approaches. However, as discovered in my research, the effective implementation of

\footnotetext{
${ }^{8}$ Hadith refers to the "tradition of the Prophet Muhammad consisting of narrative relating to his deeds, sayings" (Hashim, 2004, p. 242)
} 
the new policy is taking some time to be operationalised and thus, break free from the past heritage which emphasised traditional teaching and learning.

In short, both ILE and MES aim to produce individuals who are capable of solving problems and making decisions. Both methods of teaching are supposed to be learner-centred and involve active learner participation. However, this comparative analysis shows that the two are fundamentally and philosophically at odds because of different approaches to learning, i.e., ILE approaches learning democratically, not bound by any limitation, while MES approaches learning holistically, bound by religious values. This could be one explanation for the complexity of implementing ILE in Malaysian schools.

\subsubsection{School types and medium of instruction}

All schools in Malaysia share a common curriculum and assessment method (see 5.3.2). The different types of schools in Malaysia reflect different types of instruction based on the major ethnic groups. Each school type has its own approach to preserve its ethnic group's culture and values through education.

For example, I found that Lembing was largely unconcerned with ILE because the learning approach did not align with the Chinese learning strategies such as memorisation and recitation of ancient texts. Teaching and learning were aimed at maintaining the Chinese culture and linguistic heritage (see 7.2.2.1). The School Head said that the school emphasises the reading skills and reading habits of the students and teachers, who were highly dependent on books. The students were trained to be well-behaved in the classroom so that teaching and learning could run smoothly. According to the School Head, the most preferred approach was teachercentred because they could control the students' learning. 
In Keris, the majority of students and teachers were Malay Muslims. Thus, the education approach was aligned with the national education philosophy to produce holistic and balanced students. Shuriye (2005) contends that Islam encourages its followers to reflect and become critical thinkers. Thus, if Muslims are serious about transforming their education outlook, the instilling of values such as critical thinking, broad-mindedness, confidence and religiosity in education needs to be in place. However, my analysis clearly shows that the Islamic religious studies teachers were still trained in the traditional way. They were lacking in the knowledge and skills to employ and implement ILE into Islamic studies.

In the Tamil school of Kapak, the data suggest that their education approach was a progressive one. The teachers were open to change, but still doubted their ability to implement ILE.

So, the factors affecting ILE implementation in the different types of schools seemed to be related to the education approach to preserve ethnic cultural values, and the school heads' and teachers' confidence to implement ILE in teaching and learning. The different types of case study schools had more similarities in factors affecting ILE implementation than differences.

\subsubsection{Cultural aspect of Malaysian schooling}

This section discusses the cultural perspectives that influence how Malaysian teachers teach and how Malaysian students learn.

- Classroom expectations

Through my analysis of the data I identified two perceptions in the schools which hinder ILE implementation, exemplified by "a quiet class is a learning class" (Keris Science Teacher), and the "student-centred approach leads to uncontrollable situations" (Lembing Science Teacher). Most science teachers in this study indicated that the science curriculum was 
expected to generate more active learning such as posing questions, making observations and conducting experiments inside and outside science (mostly in small group work) as well as to foster the use of other sources of information in order to discover new understandings. My analysis of the present Malaysian school curriculum specifications and syllabus showed that the teachers are expected to involve various classroom activities in their teaching. Thus, as discussed in the following paragraphs, both perceptions appear to derive from the social and cultural context in which the teaching and learning was taking place.

The first observation, "a quiet class is a learning class", illustrates the teachers' beliefs about the appropriate school climate. One of the reasons for this view could be due to the large classes mentioned by interviewees, that is, about 40-50 students per class. The interviewees highlighted the difficulties to control large classes and the need to ensure students' proper behaviour in the classroom in order to achieve smooth teaching and learning. This finding was not surprising given that, according to an OECD report (2009), compared to 23 other countries, a higher percentage of teachers in Malaysia viewed the classroom disciplinary climate negatively and believed that lesson time was lost due to troublesome student behaviour.

Another reason is the nature of a collectivist society such as Malaysia in dealing with people. Most Asian cultures believe in maintaining harmony and trying to avoid any conflict that could cause disharmony (Abdullah \& Pedersen, 2003; Nisbett, 2003). Abdullah and Pedersen (2003) described how most Asian children experience this value at home and are expected to continue this value at school. That is why they rarely disobey their parents and as students, they do not argue with their teachers.

- Teaching and learning approaches: Role of teachers and students in seeking knowledge 
In today's fast paced world, most Malaysians, no matter which ethnic groups they belong to, see education as an important path to adult life success, wealth and happiness (Abdullah, 2010). Despite the changes and challenges globally, the relationship orientations and role of teachers and students are still maintained. My analysis shows that most teachers, especially the more experienced ones, tend to treat their students more like their children rather than as friends. In addition, the younger teachers tend to be quite open with the students, and students are more comfortable posing questions to the junior teachers.

Many research projects on Asian students have also highlighted teachers' parental roles as moral leaders who must set good examples to students (e.g., Cortazzi \& Jinn, 1996) as well their roles as authority figures in knowledge transmission (see Biggs, 1996; Pratt et al., 1999). Dorner and Gorman (2011) also found the same cultural element in Laos where teachers believed that they had to be a good model for students. My findings support the perception that in Asian societies, teachers are expected to become knowledge transmitters, guardians and good role models to the students.

Most of the teachers interviewed thought only excellent students should be exposed to the student-centred approach and to self-directed learning. They felt the bright students should be able to "pick up" higher levels of learning processes and skills better than the poorer, weaker students. The latter could only be approached with more input from the teachers, obviously employing a method involving passive knowledge transmission. This finding concurs with Snow and Lohman's (1984) research on aptitude-treatment interactions which suggested that weak students gain more from structured, teacher-centred learning, while bright students may profit more from less structured, but more complex learning. This could be the teachers' common perception of their students' ability to construct knowledge. 
Another view is that teachers' behaviour towards students could promote ILE implementation. According to Hashim and Hussein (2003), being open-minded, asking several questions to clarify and extend the students' responses, providing time for students to think and answer the query, and using precise spoken language encourages the students to develop critical thinking and inquiry learning. In this study, I found that the languages and science teachers were more open to students and engaged them more in small group work, whole class discussions as well as in the use of information resources and equipment. This is probably because of the nature of the subjects and the personal qualities of the teachers.

In summary, why some schools did not implement ILE more quickly and why others abandoned the process altogether was the result of a complex set of factors. In other words, it was not simply a lack of information facilities and resources at school that impeded the teachers' preparations to implement ILE, or School Heads not providing guidance and support, or teachers being unable to handle the heavy workload and work pressure or not being sufficiently motivated or self-directed. ILE implementation was not just affected by only one or two of these factors. Some or all of these factors impinged, to a lesser or greater extent, on the lives of all the educators. Despite these challenges, some teachers managed to partially implement ILE in their classrooms, whereas others did not.

\subsection{Revisiting factors in the preliminary model of ILE implementation}

It is useful to revisit the factors affecting ILE implementation in the preliminary model in section 3.5 with a view to revising the model. The factors identified in the preliminary model are discussed in the light of the analysis of the research findings.

The first factor underlying the study was the Characteristics of ILE. The need for clarity of the ILE concept and its application are important vis a vis the complexity of the implementation of ILE in schools. ILE 
implementation necessitates the Individual Implementers and learners to alter their behaviour in order to apply new skills and use new materials and equipment, changing from traditional learning to a constructivist approach and creating a democratic learning environment. This factor seems to hold true according to the findings of case study schools and key informants documented in Chapters 6 through 8. The interviewees from four case study schools were clear that ILE was important to them and the students, but they did not have a deep understanding of the concept of ILE and were unable to carry out ILE in their teaching and learning activities.

The second factor identified in the preliminary model was the Individual Implementers. Teachers and LMTs should have the qualifications, competency and other attributes to ensure ILE is implemented in their schools. Chen (2005), in his Program Theory, described implementers as those persons who are responsible to carry out a programme as intended such as ILE. To him, it is very important to know the implementers' qualification, competencies and commitment to ensure effective delivery. In Malaysian schools, the teachers and LMTs are trained and qualified educators who have received a diploma or a bachelor degree in education and other related training during the pre- or in-service period (see 1.4).

This factor is evident in the findings of Chapters 6 and 7 . These interviewees did not receive systematic and structured IL training during pre-service and in-service phases, and thus, were unfamiliar with the concept, but attempted to use IL skills in the classroom. Even those who received one or two training sessions were still unable to demonstrate IL skills in their teaching and learning due to their lack of confidence and motivation to do so. The teachers and LMTs tended to pinpoint factors other than themselves that hindered them from implementing ILE. The other factors are discussed in the following sections.

The third factor was the Implementing Organisation, which is each school. A school is headed by a principal. As a school administrator, he or she has to manage the administrative and educational aspects with the assistance of 
teachers and support staff. In terms of decision making, he or she is the one responsible. Thus, in the case of ILE implementation, the support of the principal or School Head is very crucial to ensure ILE development. This factor appears to be consistent with the case study findings. Judging from the views of the interviewees of the case study schools, lack of support from the school administrator impeded the implementation of ILE. In most cases, the teachers and LMTs did not receive the direction and guidance needed from the School Head. This result is corollary to Ngan's (2011) finding. When principals do not provide adequate and well-planned resources, ILE implementation is hindered.

The fourth factor in the preliminary model was external to the school environment, that is, the Ecological Context. The Ecological Context includes the community or society surrounding the schools, the education administrations at district, state and federal levels as well as other government agencies. This factor, which had a strong influence on the receptiveness and readiness of schools to implement ILE, was beyond the control of the Individual Implementers at the school level. The majority of the interviewees in the case study schools cited their heavy workload and limited time in the classroom as major obstacles standing in their way to implement ILE. The teachers' and LMTs' heavy workloads were due to school activities and programmes designated by the state or federal level and the need to handle large class sizes. A few interviewees at case study schools said that the teachers' burn-out issue had been communicated to the top management but there were no changes taking place. In other words, the voices of the staff on the ground were not being heard.

The fifth and final factor in the preliminary model was the Implementation Protocols. The data showed that the teachers and LMTs did not treat ILE as one of the teaching strategies, nor did they have a proper lesson plan, nor did they display positive attitude towards ILE. Rather, they tended to treat ILE as an extra-curricular activity. Throughout the interview sessions, the ILE Implementation Protocols received minimal comments because most of the interviewees did not possess any Implementation Protocols nor 
did they have any idea about their existence. ILE was being implemented in Malaysian primary schools in the absence of clear Implementation Protocols. In this situation, it was difficult for the teachers and LMTs to move ahead and introduce ILE in the classrooms. This factor, then, was one of the key hindrances to the implementation of ILE in Malaysian primary schools.

The sixth factor is the Social and Cultural Factors. These factors are implicit factors found in this study, and are further discussed in 10.3.

\subsection{Chapter Conclusion}

The discussion in this chapter has demonstrated the complexity of the process due to the interrelated nature of the impacts of the various factors that influenced the implementation of ILE in the case study schools. The discussion also disclosed diverse reasons that Individual Implementers felt unprepared to implement ILE in their classrooms. It also offered the explanation as to what factors influenced the school micro and macro environments as well as why things happened the way they did, such as being due to the social and cultural factors.

The first section provided a comparative analysis of the perspectives of the key informants with those of the participants from the case study schools. This comparison identified the differences and similarities between these two groups of interviewees in terms of the concept of ILE, and the organisational, individual, social and cultural factors.

Firstly, in line with the development of ILE, the MOE was serious about placing two important positions, that is, a Smart Teacher Coordinator and an LMT in most schools. The MOE has introduced a new policy for primary schools (KSSR) in order to enhance the quality of education. The support seems to be aimed at encouraging the development of ILE. However, the appointment of teachers as the Smart Teacher Coordinator 
and the LMT was not given proper attention as was evident from the fact that none of the LMTs in the case study schools had the opportunity to attend any IL training. The main reason for this situation was, as noted by a federal key informant, the top management had a limited understanding of ILE and IL in the curriculum, and tended to favour ICT in education over ILE. This is also another explanation as to why IL courses and training for LMTs and teachers were not properly and systematically organised.

Secondly, at the level of organisation, the LMTs of the case study schools felt that they had not received the support needed which then led to heavy workloads and work stress. The key informants believed that the exam oriented system forced the School Head to give more attention to the academic achievement determining the school ranking rather than paying attention to students' knowledge construction. It was argued that ILE was invisible in the curriculum because of the limited exposure to and understanding of the term IL or ILE. This was due to the way it was expected to be implemented, that is, through infusion or indirect strategy in teaching and learning. In this study, I found that teachers preferred a teacher-centred approach which then affected the implementation of ILE. I also found that the senior MOE management's problematic decisions were due to the lack of proper planning, and the limited use of evidence-based research to support decision making also contributed to the ineffectiveness of many education policies such as ILE.

Thirdly, at the individual level, both case study schools and key informants confirmed that there was limited exposure to the theoretical and practical components of ILE. This factor was an important issue in the partial implementation of ILE taken in conjunction with the teachers' poor reading habits, limited time and heavy workloads.

Finally, there are the social and cultural factors that affected the implementation of ILE. The lack of openness to new ideas can be at least partially attributed to the lack of trust between the superior and 
subordinates in problem solving matters. The superior (such as MOE) was supposed to have a close monitoring system and proper governance in this kind of working environment. However, another problem in the ILE implementation was the weak governance and monitoring system. Thus, ILE implementation situations worsened when problems emerged at the school or district level. The solution took time and could not be achieved due to too much reliance on the need for top management to meet and reach consensus about appropriate actions to take. Another key reason was the lack of manpower. At the federal level, job rotation was a problem. There was no job continuity in the ETD, and thus, it was difficult for the staff members involved to provide their proper commitment and dedication to the assigned job. Hence, the development and implementation of ILE at the school level was given inadequate governance and monitoring, and the importance of ILE to the school curriculum was unnoticed. This unfamiliarity of ILE led to insufficient funding for any systematic and structured ILE activities and programmes.

The powerful influence of top management among the schools created a working environment that did not encourage two-way communication. This situation meant not only that the plans and policies were top-down initiatives, but also that the feedback or reaction to any plans had to come from the top. This practice encouraged ordinary staff only to perform tasks or work that they were specifically asked or instructed to do. Thus, staff involvement in any plan or programme was very mechanical and unthinking.

Other contextual factors provide an explanation for hidden factors that affect ILE implementation in Malaysian primary schools. Three aspects were dominant: (a) the connections between ILE and Malaysian education system in terms of the content and pedagogy; (b) school types and medium of instruction; and (c) cultural aspect of Malaysian schooling. These are summed up as follows. 
The connection between ILE and MES was discussed in terms of the content and pedagogy. While both ILE and MES aim to produce individuals who are capable of solving problems and making decisions, they have different approaches to learning. Next, I discussed the school types and medium of instruction. All Malaysian schools share a common curriculum and assessment method. They also share similarities in factors affecting ILE implementation, even though they are of different school types which maintain their ethnic identities. Finally, in a society which values relationships over task execution, the teachers were very much dependent on the School Head. In order for ILE to be able to be implemented in schools, the School Head has to be the main driving force to ensure the teachers practice IL themselves and teach the students to be information literate. These factors provide important explanations for the partial implementation of ILE in Malaysian schools.

The findings of this study suggest that in Malaysia ILE implementers at the school level do not have access to systematic ILE training. The culture and values of their working environment, such as trust, job continuity, staff involvement and leadership for quality and continuous improvement at the district, state and federal levels, are still not in place and the school environment is not conducive to ILE development. 


\section{CHAPTER 10 Conclusions}

\subsection{Introduction}

In this chapter, I present the conclusions drawn from the findings related to the ILE implementation in the four case study schools and the perspectives of key informants at the three levels of education administration. The conclusions from this study focus on four main aspects of the ILE implementation process: (a) the stages of ILE implementation; (b) the individual factors; (c) the organisational factors; and (d) the social and cultural factors. Implications for theory, policy and practice are discussed, and recommendations for further research as well as limitations are identified.

\subsection{Major findings and conclusions}

In this section, the conclusions are presented as responses to the two research questions:

- What are the factors affecting the implementation of ILE in Malaysian primary schools?

- How do these factors facilitate or hinder ILE implementation in Malaysian primary schools?

The factors affecting ILE implementation are identified and examined in relation to the stages of implementation to determine what and how the factors hindered or facilitated the implementation process.

The stage of ILE implementation of each of the case study schools was identified in sections 6.2.1, 6.3.1, 7.2.1, and 7.3.1. The extent of ILE implementation in the case study schools was considered to be at the early use stage of implementation because the teachers and LMTs were still orienting themselves to ILE. 
On the other hand, I found that the school interviewees considered ILE to be important to their students and teachers. This is illustrated in the preliminary model of ILE implementation for this research, that is, the Characteristics of ILE. The teachers and LMTs expressed their feeling of need for ILE based on the knowledge that they had about ILE; however, the teachers felt comfortable using the traditional, teacher-centred approach in their classes and they only used the student-centred approach and active learning when time permitted and when they considered the syllabus topics to be suitable. Thus, even though ILE was viewed as important, the use of the teacher-centred approach contributed to ILE implementation being only at the early use stage of implementation in the schools.

\subsubsection{What are the factors affecting the implementation of ILE in Malaysian primary schools?}

The case study schools' and key informants' interviewees were asked about the factors that hindered and facilitated their ILE implementation. From their views, I was able to identify individual, organisational, social and cultural factors that affected ILE implementation. These factors are described in sections 6.2.2, 6.3.2, 7.2.2, 7.3.2 and 8.2.2. They are summarised in Appendix 11 and explained below:

(a) Individual factors

The first major finding is that because of limited IL exposure and training, the teachers had little knowledge and understanding of the skills associated with IL and thus felt inadequate to implement ILE in the classrooms. This is illustrated by one of the factors at the second part of the preliminary model, that is, the Individual Implementers.

The finding is consistent with the literature (Tan, Gorman \& Singh, 2012; Tan \& Singh, 2008; ETD, 2006). For example, Tan, Gorman \& Singh (2012) found that Malaysian teachers feel inadequate to teach ILE and that they are in need of IL training. Due to the teachers' primary 
responsibilities for academic and extra-curricular activities in schools and only serving as library and media teachers as a secondary role, they have no time and commitment to undertake IL training.

In sum, factors such as limited IL training, facilities and resources, time pressures and heavy workloads have prevented the teachers from being fully prepared to change their teaching practices to focus on active, inquiry-based and problem-based learning in the classrooms. The frequent use of memorisation and rote learning in the classroom practices in the case study schools discouraged the development of IL competencies for deep learning and knowledge construction.

(b) Organisational factors

The second major finding is divided into two aspects of school leadership: (i) administrative; and, (ii) instructional. The case study schools' interviewees pointed to the lack of equipment and facilities including poor service and maintenance of equipment due to insufficient funding, large class sizes (administrative aspect), as well as limited training opportunities which led to the low number of in-school, knowledge sharing sessions among the teachers (instructional aspect) being an obstacle to ILE implementation. The interaction between the administrative and instructional aspects of leadership is scarcely found in the literature (only in OECD, 2009) and was not shown in the preliminary model of ILE implementation.

My data showed that the School Heads are the driving force in the initiation and implementation of pedagogical practices in the schools (see 6.2.2.3, 6.3.2.3, 7.2.2.3, 7.3.2.3 and 8.2.2.3 (b)). They have to be reminded regularly about ILE and requirements to shape their teachers to become creative and innovative, open-minded and independent learners. This factor is more significant in the context of Malaysian society which values respect for the elderly and those in authority, and requires politeness among Malaysian workers (Abdullah \& Pedersen, 2003). Thus, school 
heads' and principals' consistent and systematic support is required to produce the attitudes and behaviours of teachers that are aligned with ILE.

The third major finding comes from the key informants who were the officials at the district, state and federal levels of education administration. They believed that the MOE had laid the foundation by initiating important developments related to ILE implementation, such as appointing specific staff to be in-charge of managing the school resource centre and teaching ILE in schools, and transforming the primary school curriculum based on $21^{\text {st }}$ century learning needs (see 8.2.2.1(a)). However, the key informants affirmed that there had been long delays in the delivery of IL courses and training for the educators throughout Malaysia. The issue of staff recruitment, staff development activities and new curriculum policy are illustrated in the preliminary model (see Figure 3.7, section 3.5) as an Ecological Context that affects the implementation of ILE.

In this study, the roles of district, state and federal education officials (specifically, the Educational Technology Division (ETD) of the MOE) were the focus of attention because IL training and courses were prepared by the ETD personnel. The issues here are that despite the fact that the foundations for the development of ILE were laid by the MOE, the training and education of IL for teachers and LMTs were not seriously planned and were not systematically performed in order to ensure changes of behaviours and pedagogy to assist ILE implementation.

The fourth major finding is that there was a lack of essential components for the implementation of ILE, such as the content, the structure, and the needed time allocation. This finding was drawn from the views of the participants in the case study schools and the key informants at district and state levels. For example, there were no proper Implementation Protocols which were very much needed by the implementers at the school level and by the officers at the ETD, State Education Technology Division (SETD) and Teachers' Activity Centre (TAC) for monitoring and supervising the 
ILE implementation in schools (see 6.2.2.5, 6.3.2.5, 7.2.2.5, 7.3.2.5 and 8.2.2.5).

The Implementation Protocols as a factor are illustrated in the preliminary model (Figure 3.7) because of their importance as guiding tools for the implementers and for enhancing the quality of programme implementation (Chen, 2004). However, the interviews revealed that the Implementation Protocols were absent from the case study schools, and I only found the protocols in the ETD.

(c) Social and cultural factors

The fifth major finding is a fresh perspective on analysing ILE in the context of democratic and holistic education. The issue is about the differences in terms of principles between ILE and the Malaysian education system (MES). At first glance, it seems that ILE and MES are incompatible (see 9.3.1). This factor was not considered in the preliminary model. Since religion is at the core of Malaysian education philosophy, the doctrine and values are meant to be embedded in the students' holistic knowledge construction, whereas ILE originates from the theories of modern western education and practices democratic learning.

Although the comparative analysis of ILE and MES may appear to be superficial, closer scrutiny of this finding makes it possible to infer that the underpinnings of both educational approaches are concerned with the cognitive, affective and spiritual aspects, that is, the holistic and integrated development of human minds. ILE is the practical side (or pedagogy) to achieve the aim of the education philosophy. This means that the implementation of ILE does not conflict with the philosophy of the education system (in which values are embedded) because the skills acquired through ILE are beneficial to students by helping them to reduce doubt and confusion in their minds. For example, Muslims are enjoined to 
eat halal $^{9}$ food. The foods that are allowed to be eaten are very clearly identified in Islam. With IL skills, the students are able to do their own research, critically evaluate the information gathered, wisely make decisions and solve their problems particularly if they encountered doubt in, for instance, food preparation. The goal here is not to reduce the importance of religious beliefs, but to enable good and informed decision making. Thus, ILE appears to be an important method of instruction or pedagogy in ensuring the curriculum content is delivered and used effectively. The only hindrance in MES principally is the long history of "traditional and bookish methods" that influence teachers to be teachercentred in the classroom and students to be passive receivers of knowledge (Hashim, 2004, p.144). IL skills can never develop in this kind of environment.

The sixth major finding is the elements of relationship and hierarchy which are rooted in Malaysian education administration and schooling. Most case study schools' interviewees preferred the teacher-centred approach which maintains the traditional teacher-student relationship and hierarchical order. In the case study schools, a similar situation was found in the relationship between school head (superior) and teachers (subordinates). During the interviews in these schools, I found that those who were in subordinate roles (teachers to school heads, and students to teachers) had unconsciously developed dependent and passive attitudes. This social norm has been highlighted in the literature of business and management (Abdullah \& Pedersen, 2003; Hofstede, 2001) and has begun to receive significant attention in education and IL literature (Abdullah, 2010; Walker \& Hallinger, 2007; Dorner \& Gorman, 2006). By identifying the combination of individual, organisational, social and cultural factors that affected ILE implementation in the case study schools, I have developed the answer to the second research question.

\footnotetext{
${ }^{9}$ Halal food means foods that are prepared using good and clean ingredients and must not mix with alcohol, pork and meats of cattle ( not slaughtered according to Islamic rules)
} 


\subsubsection{How do these factors facilitate or hinder ILE implementation in Malaysian primary schools?}

Viewing the main factors (findings) from the following four perspectives helps to demonstrate how the factors identified in the previous section have affected ILE implementation in Malaysian primary schools. These perspectives are discussed in the relevant chapters in sections 6.2.3, 6.3.3, 7.2.3, 7.3.3 and 8.2.3. They can be briefly summarised as:

a) Attitude to risk: Risk taking versus risk aversion

b) Organisational network: Out-of-school support versus in-school support

c) Collective orientation: Shared understanding versus individual perception

d) Leadership: Integrated planning versus fragmented effort

The first perspective relates to the interviewees' attitudes to risk. At the individual level, the interviewees tended to skew towards risk avoiders or non-risk takers due to factors such as limited IL training, time constraints, poor resources and facilities, and lack of leadership support. Teachers tended to be risk averse because they felt that they needed to concentrate on finishing the syllabus and preparing students for examination rather than on implementing ILE. Some teachers added that they tended to use a teacher-centred approach compared to a student-centred one due to such circumstances. That would mean the teaching and learning are characterised by an emphasis on memorisation, spoon-feeding and a passive knowledge transfer approach. The tendency to risk aversion as a result of these factors acts as a hindrance to ILE implementation.

The attitude to risk in the school was further influenced by factors such as the lack of relevant information resources and school facilities as well as limited funding. In this study, there was limited opportunity for the teachers to change and to be innovative given these factors at their schools. Thus, when these issues stand in the way of teachers changing how they do things, ILE is implemented in the classrooms at a much slower pace. 
The second perspective relates to the organisational network. The data showed that the in-school support, also known as in-house training in the Malaysian school context, is supposed to be a facilitating factor for teachers and LMTs to implement ILE. This support is meant to be a platform for them to share knowledge and skills and to keep abreast of the latest developments, and it to instil reading habits among the teachers and LMTs. However, the data also demonstrated that this form of support was inadequate particularly in schools which had no IL experts. To overcome this problem, out-of-school support is needed to enhance ILE implementation. The support could come from local and/or international IL professionals and experts as well as from the experiences of other schools in implementing ILE. Regular out-of-school training could encourage changes to happen, enrich teachers' learning experiences and ensure ILE implementation. Hence, a poor organisational network resulting from inadequate in-school and out-of-school support can be a major hindrance to effective ILE implementation.

The third perspective is collective orientation, which concerns the need for teachers to continuously interact and support each other particularly during in-school and out-of-school ILE training. Ideally, through regular interaction, the teachers are able to develop the sense of shared understanding which is crucial to build cooperation or "collegiality" (Fullan, 2001) and togetherness in implementing ILE. The data showed that teachers had no problem cooperating and collaborating with each other in some school activities. However, this did not appear to occur with ILE. The data highlighted that ILE implementation was hindered when the school head and teachers were not sharing a similar vision and mission regarding ILE. Thus, a regular, two-way communication between school head and teachers could assist in building a collective vision and mission as well as gradually reducing individual perceptions in schools that might devalue ILE implementation. 
The fourth perspective is related to the form of planning, namely, integrated or fragmented planning as a condition for a successful ILE implementation by the policy makers. At the education administration levels, there were multiple education and curriculum plans and policies executed in a piecemeal fashion. The data showed that at the time of the study, only the ETD was in charge of ILE implementation and seemed to be working in a silo. The piecemeal policies and silo mentality led to a partial or short-lived implementation or execution of plans or policies. Since ILE teaches more than skills, it is likely to be most effective when integrated into the classroom activities and visible in the MOE's official documentation.

In relation to IL planning, according to Farmer (1992), one of the basic reasons why IL programs do not work is because of the failure of the teaching staff and librarians to see the IL program and its courses as a part of an entire curriculum and a part of the learning plan. Fullan (2001) adds that the government and other agencies play a role in fostering change in schools and to do so, they must "push accountability, provide incentives and foster capacity building" (p.220). He argues particularly for the aspect of professional development of teachers, stating that it should be about achieving deep and lasting changes to the culture of the profession. In the context of ILE, this mean the entire system has to create a dynamic environment for it to develop in schools. However, Fullan does not address the importance of the social and cultural aspects of leadership roles that influence the change process in schools which this study has identified. In Malaysia, leadership plays a paramount role in the on-going development of ILE in schools.

Here, I can conclude that all these perspectives are worthy of attention and are therefore discussed in relation to the second research question, that is, the extent to which the main factors in the findings affected the implementation of ILE in schools. First, the environment that fosters a pattern of risk aversion can be considered as a key factor that might inhibit the teachers and LMTs in schools in their implementation of ILE. With a 
broad range of concerns among them about time constraints, heavy workloads, limited resources and facilities as well as lack of leadership support, it is easy and less risky for them to shy away from implementing ILE in the classroom.

Second, in-school training should exist hand-in-hand with out-of-school training so that teachers can enhance their competencies and can learn (through the failures and successes of ILE implementation) from other organisations. Third, with focussed, on-going support (inside and outside of schools), the teachers and LMTs are more likely to develop a shared perception and understanding of ILE, and thus, motivate all staff in the school to support each other and implement ILE. Lastly, leadership, and particularly the MOE, has an important role to design the implementation of ILE explicitly rather than treat it as a supplementary feature within the curriculum. This study shows that the implementation of ILE needs integrated planning and involvement of all divisions and departments of MOE. Thus, in the context of the Malaysian society, which values relationships and hierarchy, working together is a norm and clarity of direction is essential in order to successfully implement pedagogy as ILE.

\subsection{Implications for Theory}

By focusing on a problem involving the implementation of ILE in schools, my study is relevant not only to the parent disciplines of library and information science but also to the philosophical and social aspects of education. It does this in several ways. First, my study introduces a new perspective in understanding ILE and the MES through the analysis of their respective origins and philosophies. The comparative analysis sheds some light on the fundamental issues in understanding their approaches to learning. While ILE originated from the theories of modern western education which focuses on a democratic approach to learning, MES has attempted to integrate democratic, pragmatist education with religious values in the school curriculum through a holistic approach. Although superficially both education approaches are disconnected, ILE as 
pedagogy is important to achieve the MES philosophy, that is, a constructivist approach that supports holistic learning.

Second, this study also offers another perspective of ILE implementation from the social and cultural context. Operating in a multiracial society, MES tries to accommodate the educational needs as well as the social practices of the three major ethnic groups, namely, the Malay, Chinese and Indian populations. In terms of educational needs, all schools use a common syllabus, but in accordance with their mother tongues. Each school has its own goals to achieve, for example, to protect the cultural heritage and language of the particular ethnic group. In terms of social practices, Malaysian society places greater importance on relationships with others rather than on task completion, and on hierarchy (rank and status) over equal opportunities (Abdullah, 2010). In order to implement ILE successfully, the social and cultural context has to be taken into consideration (Dorner and Gorman, 2006). Thus, my study highlights the need for the effective understanding of the different cultural configurations of Malaysian schools in order to help reconstruct the Individual Implementers' expectations, as well as the administration and leaderships' expectations, on teaching and learning.

Third, my study also provides new insights which are represented by the model in Figure 10.1. The factors and sub-factors in this model are useful elements to plan teaching and learning activities as well as to support a successful ILE implementation model for schools. Below is a table that compares the factors in the preliminary model with the factors (and subfactors) found in the data. When the factors in the data were renamed, this is noted in the table. 


\begin{tabular}{|c|c|}
\hline Factors in preliminary model & Factors found in the data \\
\hline \multicolumn{2}{|c|}{ Characteristics of ILE } \\
\hline $\begin{array}{ll}\text { - } & \text { Need } \\
\text { - } & \text { Clarity } \\
\text { - } & \text { Complexity }\end{array}$ & $\begin{array}{l}\text { - Yes } \\
\text { - Yes } \\
\text { - Yes }\end{array}$ \\
\hline \multicolumn{2}{|c|}{ Individual Implementers } \\
\hline $\begin{array}{ll}\text { - } & \text { Qualifications } \\
\text { - } & \text { Competency } \\
\text { - } & \text { Readiness }\end{array}$ & $\begin{array}{ll}\text { - } & \text { Yes. Renamed as } \\
& \text { Qualifications/Competency } \\
\text { - Yes } \\
\text { - Yes }\end{array}$ \\
\hline \multicolumn{2}{|c|}{ Implementing Organisation (School) } \\
\hline $\begin{array}{l}\text { - } \quad \text { Administrative support } \\
\text { - } \quad \text { Leadership and support } \\
\text { - School goals } \\
\text { - School climate }\end{array}$ & $\begin{array}{l}\text { - Yes } \\
\text { - Yes. Data found on the issue } \\
\text { of instructional school } \\
\text { leadership } \\
\text { - Yes } \\
\text { - Yes }\end{array}$ \\
\hline \multicolumn{2}{|c|}{ Ecological Context } \\
\hline $\begin{array}{ll}- & \text { Macro level context } \\
\text { - } & \text { District level } \\
\text { - } & \text { Government and other } \\
& \text { agencies } \\
\end{array}$ & $\begin{array}{ll}\text { - } & \text { Yes. Renamed as } \\
& \text { Community/Society } \\
\text { - } & \text { Yes. Renamed as } \\
& \text { District/State } \\
\text { - } & \text { Yes } \\
\end{array}$ \\
\hline \multicolumn{2}{|c|}{ Implementation Protocols } \\
\hline \multirow[t]{3}{*}{$\begin{array}{l}\text { - } \quad \text { Programme model } \\
\text { - } \text { Quality of delivery } \\
\text { - } \\
\text { - } \text { Pre-planning } \\
\text { - } \quad \text { Technich of materials support model } \\
\text { - } \text { Quality of technical support }\end{array}$} & $\begin{array}{l}\text { Not present in case study } \\
\text { schools. } \\
\text { Present in the ETD of the } \\
\text { MOE (federal level) as } \\
\text { documentary evidence such } \\
\text { as: IL lesson plans, IL } \\
\text { syllabus and specifications, } \\
\text { Teaching and Learning } \\
\text { Module using School } \\
\text { Resource Centre and IL. }\end{array}$ \\
\hline & Social and Cultural Factors \\
\hline & $\begin{array}{ll}\text { - } & \text { Education philosophy } \\
\text { - } & \text { Political process: Hierarchical } \\
& \text { structure and relationships } \\
\text { - } & \text { Cultural and ethnic protection }\end{array}$ \\
\hline
\end{tabular}

Table 10.1. Comparison of factors identified in the preliminary model and this study

In Table 10.1, the suggested main factors in the preliminary model, namely, the Characteristics of ILE, Individual Implementers, Implementing Organisation (School), Ecological Context and 
Implementation Protocols, all remain valid. Though the Implementation Protocols were absent in the case study schools, they were present in the ETD and thus remain as a factor for inclusion in the modified model. An important finding in my study was that the absence of Implementation Protocols was one of the main obstacles to the implementation of ILE.

One main factor found in the data has been added to the preliminary model, namely, Social and Cultural Factors. Most of the sub-factors in the preliminary model were found to be relevant and remain for inclusion in the modified model. A few are renamed (such as Qualifications/Competency, Community/Society and District/State) so that they reflect the meanings provided by the interviewees. Three sub-factors are added to the suggested one, that is, education philosophy, political process, and cultural and ethnic protection (sub-factors for the Social and Cultural factor.

As shown in Table 10.1, the preliminary model of ILE implementation (Figure 3.7) needed to be modified. The main factor and sub-factors found in the data have provided a deeper understanding of the factors affecting the implementation of ILE in the context of Malaysian primary schools.

Several aspects of the factors found in the study need clarification. The sub-factors under the newly added Social and Cultural Factors may seem to be already covered in other factors; for example, cultural and ethnic protection may be viewed as a school goal; however, "school goals" is a sub-factor under Implementing Organisation. And, education philosophy, that is, the holistic approach to education, can be perceived as a part of government policy thus being part of "government and other agencies" in the Ecological Context. However, based on my findings, I considered Ecological Context and sub-factors such as school goals to be explicit factors. I define explicit factors are those that are derived from explicit knowledge, that is, knowledge "that can be expressed in words or numbers and shared in the form of data, scientific formulae, specifications, manuals and the like" (Nonaka \& Konno, 1998, p. 42). Explicit knowledge is 
transmitted in a formal and systematic way, such as through research reports. The explicit factors in the preliminary model were used to guide the data gathering process of this study.

As I went deeper into the data analysis process, I found the implicit factors, that is, the Social and Cultural Factors and the related sub-factors which were not mentioned explicitly in the preliminary model. The Social and Cultural Factors that I found are more accurately explained as being at an implicit or unconscious level. These factors are the hidden dimensions of local culture based on the collective values and norms. During the data gathering process, I originally was only looking at explicit aspects of the factors in the preliminary model, for example, when examining data related to the Ecological Context I was looking at aspects such as community support, and the strategies and procedures that took place in ILE implementation. However, my analysis of the findings led me to understand there were implicit factors related to the behaviours of Malaysians that are not easily understood by other cultures (see 7.2.2.1, 8.2.1, 8.2.2.4). Thus, the following is the modified model of ILE implementation in Malaysian primary schools (see Figure 10.1) 


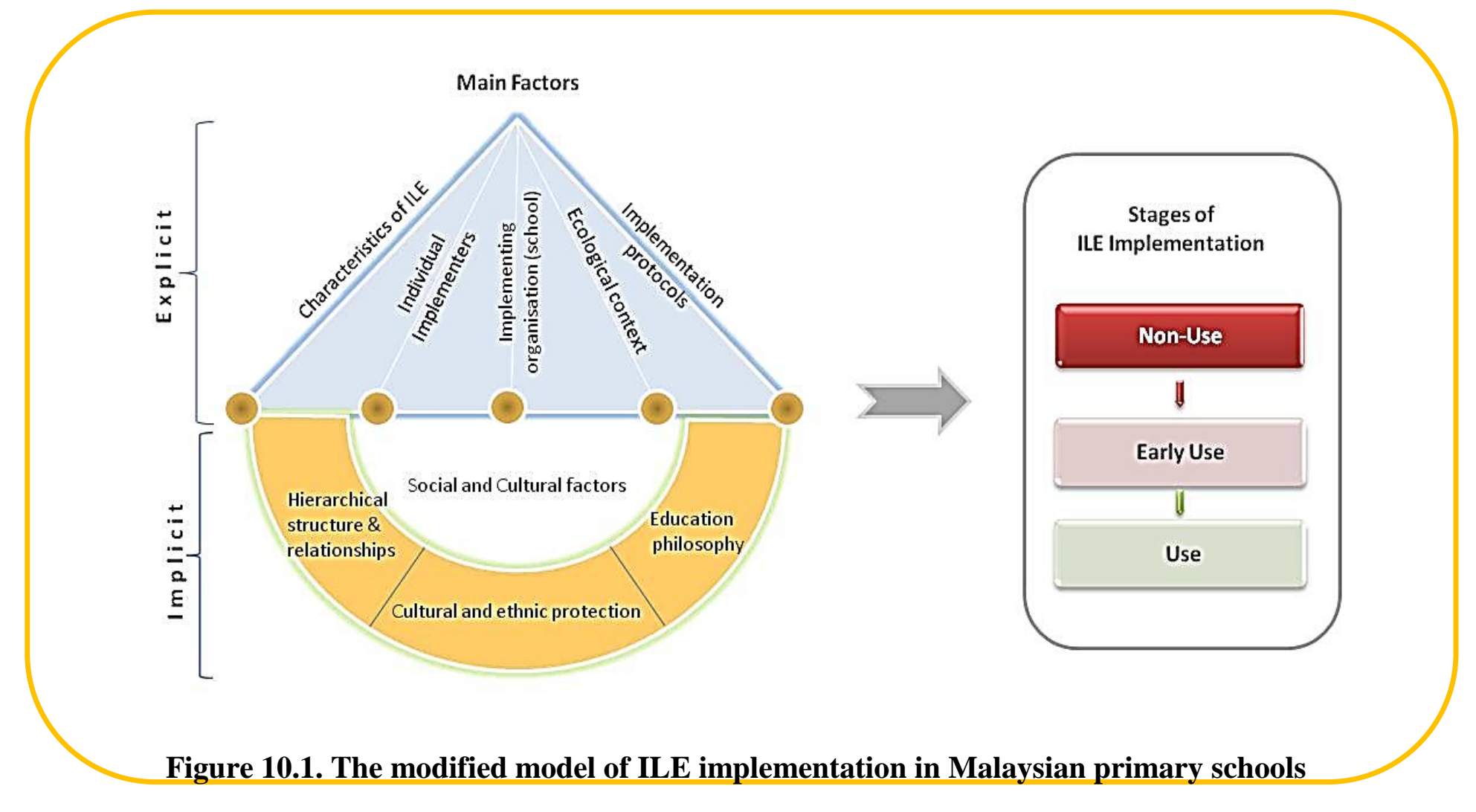


The modified model of ILE implementation illustrates the interaction of various factors in ILE implementation. It has three parts: 1) the main factors (explicit level); 2) the main factors (implicit level); and, 3) the stages of ILE implementation.

The upper level are the explicit factors: (1) Characteristics of ILE; (2) Individual Implementers; (3) Implementing Organisation (School); (4) Ecological Context; and, (5) Implementation Protocols. I found these factors to be critical in ILE implementation. When looking at the on-going development of ILE, however, I found that these factors were affected by the factors in the lower level.

The Social and Cultural Factors, situated in the lower level, have an important place particularly in the movement from Non-use to Early Use, i.e., the beginning of implementation, because of their relationship to the factors in the upper level, especially on the Individual Implementers (teachers and LMTs). For example, in terms of hierarchical structure and relationships, the leaders (the government and the school administrators) are expected by the subordinates to be "parental figures" taking care of the needs of the subordinates and being knowledgeable. Hofstede (2001) describes this situation as a signifier of power distance. The leaders must offer facilities so that individual teachers will have time and real possibilities for getting acquainted with and becoming experts on ILE, and have proper Implementation Protocols (such as an IL guidebook, and technical support) at their disposal. The results from my analysis suggest that government and administrators should take a stronger leadership role in ILE because teachers and LMTs expect and respond to direction from superiors. As for the cultural and ethnic preservation, for example in the case of Lembing, the school uses the same curriculum and focus on exam results as national schools. But the teaching strategies follow the "ancient Chinese" system. This is not mentioned explicitly anywhere in the 
curriculum, but the data came from the School Head. These implicit factors are inherent in the cultural, social and professional environment.

There is a need, especially in the early use, i.e., beginning phase, for clear and recommended ILE teaching materials. The teaching materials should suit the two types of primary schools, namely, national schools and national-type schools, in order to adapt to different ethnic and linguistic needs.

The third part is the indication of the stages of ILE implementation. The stages of ILE implementation are: (1) Non- Use; (2) Early Use; and, (3) Use. In section 10.2, I briefly described the extent of ILE implementation in the case study schools, that is, partial implementation. The participants (teachers and LMTs) of the case study schools were still at the Early Use stage of ILE implementation because they were not actively playing their roles as Individual Implementers.

The interaction of factors in the modified model is not linear. In Figure 10.1 the left hand part is the main factors (implicit and explicit) which interact and influence each other. The right hand part is the stages of ILE implementation. The relationship between the left and right hand parts is represented by an arrow which suggests a linear, unidirectional relationship. For example, the relationship between the Characteristics of ILE and the Individual Implementers could be that the participants in the case study schools and the key informants have a clear understanding of the goals and content of ILE (which would facilitate ILE implementation) or it could be the opposite (which would hinder ILE implementation). Although this example illustrates only one of the possible relationships between the main factors, it illustrates how these relationships impact on the stage of implementation, and therefore how they relate (through the arrow) to the Stages of ILE Implementation.

As mentioned by Fullan (2001) in his Change Theory in education, the clarity of the goals and content of an innovation influence its 
implementation (see 3.4). In my study, I found the lack of IL training and the absence of any ILE Implementation Protocols to be related to the clarity factor. Chen (2005), in his Program Theory, proposed the use of implementation protocols that clarify the nature, content and procedures of a programme (see 3.3). Fullan emphasised that these factors are enabling if they are interacting and supportive of each other. In my study I found that the implementation of ILE in the schools was affected by the teachers' knowledge of the subject matter which in turn was related to the availability of training courses and implementation protocols. Support from the three levels of education administrations and the school administrators was also of great influence. Thus, a dynamic environment in which the variables or factors are developing and interacting over time will help ILE as pedagogy in teaching and learning begin to flourish.

According to Hall \& Hord's (2006) Concerns Theory, change is a process and there will be no change in outcomes until new practices are implemented (see 3.2). This point of view suggests that in order for ILE to be implemented in classes, teachers and LMTs are the most important players. I found, however, that the decision of how ILE is implemented was left to the school heads. Hall and Hord note that the principals, school board and administrators have lesser influence in the implementation process. In the case of ILE implementation, continuous support from principals and education administrators is essential to ensure a long term successful implementation.

It is worthwhile to remark that in my study ILE was rarely considered to be a method of instruction or pedagogy; rather it was thought to be similar to an extracurricular activity or an add on, to which the school should just pay minimal attention. To change this perception, the MOE in particular has to provide strong leadership to design an ILE implementation plan that is explicit and that accommodates the educational needs of Malaysia's three major ethnic groups. 


\subsection{Implications for Policy and Practice}

The findings, analysis and conclusions of this study have implications for teacher education, the school system, and the MOE.

\section{Implications for Teacher Educators}

The study provided evidence that the study schools' participants supported the idea of ILE, however they had an inadequate level of understanding about IL knowledge and skills due to limited opportunities for relevant professional learning. This has significance for teacher educators because there is a need for foundational IL learning and practice during pre-service education courses, as well as continuing professional development through in-service courses.

Very few participants in this study attended IL training courses. As a consequence, many of them felt inadequate to implement ILE in the classrooms. This situation could be improved if teachers and LMTs receive focussed, on-going and systematic IL training from IL experts. Teacher preparation programmes should include an IL course to equip the teachers with the necessary understanding of concepts and to teach them the skills required to apply IL in the classrooms according to the students' needs.

This study also revealed that some junior teachers and LMTs had some knowledge of IL, but they lacked confidence to implement ILE in the classrooms. A systematic exposure to IL skills in teachers' colleges would help to increase the confidence of new teachers and LMTs. Thus, it is very important for all teachers colleges and faculties of education which offer courses on IL to review and re-examine their curricula to see whether student teachers are taught adequately about the theory of IL (knowledge), and the methodologies and strategies of IL (skills). To ensure that student teachers and LMTs can develop their own information literacy over time, every required course should include the components of IL. In addition, 
their IL skills should be assessed in the practical teaching of their subject specialisations.

Since IL is expected to be directly taught in the curriculum, the in-service course should be conducted by IL experts as if it was a required school subject. This should help to introduce the knowledge of IL and practical side of IL into teaching and learning. These courses should adopt a constructivist approach, since according to Savasci and Berlin (2012), the in-service courses of constructivism (which is the preferred teaching method of ILE) should provide opportunities for teachers to learn and experience constructivist components as well as to discuss, evaluate and participate in peer classroom observations. For effectiveness, the learners should watch model IL expert teachers implementing ILE in the classrooms via live or audio visual recording.

Finally, for the enhancement of ILE implementation in schools, teachers and LMTs should not only be given time to schedule ILE in their syllabus and to attend IL training courses to improve their knowledge and skills, they also should be given time to familiarise themselves with the theoretical and practical sides of ILE in teaching and learning. This is consistent with a suggestion made by Williams and Wavell (2006) that teachers need time to understand basic information of ILE before they will buy into any IL training offered to them. Because of their misconception that implementing ILE would lead to a longer time to complete the syllabus, the teachers have to be given time to come to grips with the idea of ILE. It is hoped that opportunities to watch model teachers as they are teaching IL will help teachers to adopt and implement ILE in their own teaching and learning.

\section{Implications for the School System}

This study has drawn out some concerns of teachers, LMTs and school heads with regards to the school syllabus, IL materials and school leadership support. The following recommendations are made here to alleviate these concerns. 
First, this study showed that the teaching of IL skills was dependant on syllabus topics and students' performance levels (such as, only to good and excellent students) because of the time constraints on teachers and the density of the curriculum. Therefore, the school syllabus should be adapted to allow more time for ILE to be implemented in all subjects and to all students. To develop IL skills students need to understand information and how it works, which will require a lot of enquiry and discussions in order to know the forms of information, to determine the information needed for the specific context, to locate it, to critically evaluate it and to use it effectively and ethically (see Dorner \& Gorman, 2006; Badke, 2010). This would require more time for teachers to prepare to help students to search for the right information or reading materials.

Second, there is an evident need for extensive ILE materials to support implementation because teachers and LMTs had no IL teaching resources. I recommend that they take the initiative to gather the theoretical knowledge of ILE through readings and that they exercise knowledge sharing with colleagues and information professionals.

It can be concluded that the LMTs and teachers quickly have to make changes to their attitudes and beliefs so that they are appropriate to the way students' learn. The teachers and LMTs should break away from the traditional perception that students believe their teachers have the answer to every question. The teachers and LMTs have to improve themselves and to be more than knowledge transmitters. To support these changes, the IL Implementation Protocols (existing instructional materials) should be improved so that they can assist teachers and LMTs in teaching and learning, and made available and accessible to teachers and students at all times. The protocols should be designed in such a way that teachers and LMTs can also become self-directed independent learners themselves. .

Third, with regard to leadership, the study revealed that the school heads played a dominant role in decision making and prioritised academic 
achievement in subjects tested in the public exams. Consequently, activities including ILE that could help to develop the creative and critical minds of students were neglected. Thus, the school heads should involve the teachers in some of the administrative and instructional aspects of the school such as flexible class scheduling, acquisition of resources to support learning, and staff development. In contrast to the current situation, a more democratic environment would reduce the gap between the superior (school head) and the subordinates (teachers). Thus, a democratic working environment might in turn prompt the teachers to treat their students in the same democratic way which would be conducive to ILE implementation.

Fourth, this study also showed that the lack of information resources and facilities as well as limited opportunities to participate in professional development were obstacles to ILE implementation. This indicates the need for the school heads to re-examine the conditions of the school facilities and equipment as well as the professional development of staff. In this way, the school head can ensure that the school conditions and the teaching staff are prepared to meet ILE goals, create an environment that is conducive to ILE implementation and encourage teachers to be creative, innovative, problem solvers and life-long learners.

\section{Implications for the MOE and the ETD}

This study has revealed some of the problems encountered at the Educational Technology Division (ETD), the Educational Technology Literacy Management Sector of the ETD, State Educational Technology Division (SETD), and Teachers' Activity Centre (TAC). This discussion sets out recommendations to overcome these problems.

First, the study showed that ILE was only partially implemented in schools. This indicates a need for the ETD and its officials at state and district levels to review the development of ILE in schools on an on-going basis to ensure that the teachers and LMTs are prepared to implement ILE fully. In addition, the ETD has a responsibility to ensure that the ILE 
Implementation Protocols are ready to use and each school has a complete set. The primary purpose of having an ILE Implementation Protocol is to provide the Individual Implementers at school level with sound guidance and motivation to go about implementing ILE in the classrooms. Such protocol would need to be readily available and revised from time to time.

Second, this study found two fresh social and cultural perspectives that connect ILE with the Malaysian education system (MES). With a collaborative effort on ILE, the ETD, the Curriculum Development Centre (CDC) and the Teachers Education Division (TED) of the MOE could reorient the education and training system of teachers and LMTs to integrate teaching beliefs and to incorporate the religious values and different ethnic groups' requirements into IL training courses.

Third, the study discovered that the ETD was viewed by some participants as an unimportant division in the MOE because other divisions had limited knowledge and understanding of the ETD's roles and functions in the KSSR policy. Thus, it might be beneficial for the ETD to develop more collaborative relationships with the CDC and the TED. This could ensure that the development and transformation of the school curriculum, the teachers' and LMTs' pre-service and in-service courses and training all take into consideration the concept and use of ILE.

Fourth, the MOE, particularly the ETD's top management, might consider revisiting their ILE assessment tools, rewards and recognition system for the ETD staff members at the district and state levels. The attention of the top management and the decision and policy makers could expedite the enhancements of the system and create further incentives for the advancement of ILE.

Finally, the study uncovered large class sizes as an obstacle to ILE implementation. Thus, at the MOE level, the leadership and decision makers should think of a way to reduce the teacher-student ratio in classrooms, particularly in schools in highly populated town areas. 


\subsection{Recommendations for Future Research}

Based on the findings of this research, I recommend further research to be conducted in order to get a better picture and a comprehensive understanding of ILE implementation in primary schools. In light of this, I propose these future studies should be considered:

(a) A survey of a large sample of ILE Implementers at school level and at education administration levels. This quantitative study would be to determine whether similar results to the current study would be generated from a large study, and thus mitigate the limitations of the current study.

(b) Further research using the same approach of the current study but more in-depth and specifically focused on subject specialisations such as science, mathematics, linguistic or religious studies in relation to ILE implementation. I also propose research to specifically assess the factors affecting ILE at the senior management level of all divisions of the MOE to understand their perspectives on ILE.

(c) An investigation of the impact of risk aversion on the factors affecting the implementation of ILE in schools or even in other workplaces. This study would also help to explain risk aversion as an important determinant in decision making in ILE implementation.

\subsection{Limitations}

I have identified two important limitations of my study. Firstly, the key informants did not include all departments and divisions in the MOE, though in the Malaysian educational process all these departments and divisions have their roles and responsibilities in the planning, implementation and evaluation of the curriculum. It would have been interesting to include their views and experiences about ILE and the factors that influence them in the implementation of ILE. 
Secondly, the research sites of my case study schools were within one district area in a state of Malaysia, even though there were other similar sites in other states of Malaysia. By focussing on one research site involving a small number of research participants, it will inevitably introduce bias in the data gathered for analysis. My interpretations of the findings are specific to the views and experiences of the cases and informants that were being studied producing in-depth understandings, but only indicative findings. 


\subsection{REFERENCES}

A. Rahman, Z., \& Ahmad, M. (2000). Malaysia. Curriculum planning, development and reform. Retrieved October 17, 2013 from http://www.ibe.unesco.org/curriculum/Asia\%20Networkpdf/ndrepm y.pdf

Abdul Kader, B. K. (2008). Malaysia's experience in training teachers to use ICT. Retrieved October 7, 2009 from http://www.unescobkk.org/fileadmin/user_upload/ict/ebooks/Teacher_Education_Case_Studies/Malaysia_s_Experience_in _Training_Teachers_to_Use_ICT.pdf

Abdullah, A., \& Pedersen, P. (2003). Understanding multicultural Malaysia: delights, puzzles \& irritations. Petaling Jaya, Malaysia: Pearson/Prentice Hall.

Abu Seman, N., \& Mohd Saad, M.S. (2005).IL initiatives, developments and future directions in primary, secondary and higher education in Malaysia. Paper presented at the Information Skills for Learning: Part II: “Empowering 8” International Workshop, Patiala, 3-7 October 2005.

Ahmad, R.H. (1998). Educational development and reformation in Malaysia. Past, present and future. Journal of Educational Administration 36(5), 462-475.

Alias, N.A., \& Zainuddin, A.M. (2005). Innovation for better teaching and learning: Adopting the learning management system. Malaysian Online Journal of Instructional Technology 2 (2), 27-40.

Alkin, M.C., \& Chritie, C.A. (2004).An evaluation theory tree. In M.C. Alkin (ed.), Evaluation roots: Tracing theorists' views and influences (pp.12-66). Thousand Oaks, Calif.: Sage.

Alshammari, B. S. (2000). The developmental stages of concern of teachers toward the implementation of the information technology curriculum in Kuwait. Unpublished doctoral dissertation, University of North Texas, US. 
American Library Association (ALA). Presidential Committee on IL. (1989). Final Report. Chicago: American Library Association. Viewed 12 November 2014 at: http://www.ala.org/acrl/publications/whitepapers/presidential American Library Association (ALA). (2006, July 25). Introduction to information literacy. Retrieved October 3, 2013 from http://www.ala.org/acrl/issues/infolit/overview/intro

Andersen, J. (2006). The public sphere and discursive activities: IL as socio-political skills. Journal of Documentation 62(2), 213-228.

Anderson, S.E. (1997). Understanding teacher change: Revisiting the concerns-based adoption model. Curriculum Inquiry, 27 (3), 331367.

Andretta, S. (2005).IL: A Practitioner's Guide. Oxford: Chandos.

Asian Development Bank (ADB). (2010). Malaysia: Factsheet. Retrieved April 14, 2010 from http://www.adb.org/Documents/Fact_sheets/MAL.pdf

Askar, P., \& Usluel, Y. (2001). Concerns of administrators and teachers in the diffusion of it in schools: A case study from Turkey. Paper presented at the Society for Information Technology and Teacher Education International Conference.

Badke, W. (2011). Why information literacy is invisible. Communications in Information Literacy, 4(2), 129-141.

Balakrishnan, V. (2009).Teaching moral education in secondary schools using real-life dilemmas. Unpublished doctoral dissertation, Victoria University, Wellington, New Zealand.

Bapoo Hashim, N.R. (2009). Sekolah cluster lonjak institusi pendidikan (Cluster school accelerate the education institutions). Majalah Pendidik (Educators Digest), 18-21.

Batson, T., \& Bass, R. (1996). Primacy of process: Teaching and learning in the computer age. Change 28 (2), 42-47.

Beauchat, K., Blamey, K., \& Walpole, S. (2009). Building preschool children's language and literacy one storybook at a time. The Reading Teacher, 63, 26-39. 
Behrens, S.J. (1994). A conceptual analysis and historical overview of IL. College and Research Libraries 55(4), 309-322.

Bereiter, C., \& Scardamalia, M. (1987). An attainable version of high literacy: Approaches to teaching higher-order skills in reading and writing. Curriculum Inquiry 17 (1), 9-30.

Biggs, J. (1996). Enhancing teaching through constructive alignment. Higher education, 32(3), 347-364.

Biggs, J. B. (1987). Study Process Questionnaire Manual. Student Approaches to Learning and Studying. Hawthorn: Australian Council for Educational Research Ltd.

Bitan-Friedlander, N., Dreyfus, A., \&Milgram, Z. (2004). Types of 'teachers in training': The reactions of primary school science teachers when confronted with the task of implementing an innovation. Teaching and Teacher Education, 20, 607-619.

Bloom, B.S. (1968).Learning for mastery. Education Comment, 1(2).Retrieved July 19, 2010 from http://www.eric.ed.gov/ERICWebPortal/contentdelivery/servlet/ERI CServlet?accno=ED053419

Boon, S., Johnston, B., \& Webber, S. (2007). A phenomenographic study of English faculty's conceptions of Information Literacy. Journal of Documentation, 63(2), 204-228.

Breivik, P.S. (1998).Student learning in the information age. Phoenix, Arizona: Oryx.

Brown, G. K. (2007). Making ethnic citizens: The politics and practice of education in Malaysia. International Journal of Educational Development, 27(3), 318-330.

Bruce, C.S. (1994). Information Literacy blueprint. Queensland, Australia: Division of Information Services, Griffith University.

Bruce, C.S. (1997). Seven faces of Information Literacy. Adelaide, Australia: Auslib Press.

Bruce, C.S. (1999). Workplace experiences of Information Literacy. International Journal of Information Management 19, 33-47. 
Bruce, C.S. (2000). Information Literacy research: Dimensions of the emerging collective consciousness. Australian Academic and Research Libraries 31 (2), 91-109.

Bruce, C.S. (2002). Information Literacy as a catalyst for educational change: a background paper. White Paper prepared for UNESCO, the US National Commission on Libraries and Information Science, and the National Forum on IL, for use at the IL Meeting of Experts, Prague, and The Czech Republic. Retrieved August 10, 2009 from http://www.nclis.gov/libinter/infolitconf\&meet/papers/bruce_fullpap er.pdf

Bruce, C.S., \& Candy, P.C., eds. (2000). Information Literacy around the World: Advances in Programs and Research. WaggaWagga, NSW: Charles Sturt University.

Bryman, A. (2008). Social research methods ( $3^{\text {rd }}$ ed.). Oxford: Oxford UP. Bundy, A. (2004). One essential direction: Information Literacy, information technology fluency. Journal of eLiteracy 1, 7-22.

Bundy, Alan, ed. Australian and New Zealand Information Literacy Framework: Principles, Standards and Practice. 2nd ed. Adelaide: Australian and New Zealand Institute for Information Literacy, 2004. Retrieved April 20, 2010 from http://www.literacyhub.org/documents/InfoLiteracyFramework.pdf Byrne, M. (2001).Data analysis strategies for qualitative research. Association of Operating Room Nurses AORN Journal, 74(6), 904905.

Byrne, M. (2001).Interviewing as a data collection method. Association of Operating Room Nurses AORN Journal, 74(2), 233 - 235.

Campbell, R. F., Bridges, E. M., \& Nystrand, R. O. (1977). Introduction to educational administration. ( $5^{\text {th }}$ ed.). Boston: Allyn \& Bacon.

Campbell, S. (2004). Defining Information Literacy in the $21^{\text {st }}$ century. Paper presented at the World Library and Information Congress: $70^{\text {th }}$ IFLA General Conference and Council, August 22-27, Buenos Aires. Retrieved April 2, 2009 from http://www.ifla.org/IV/ifla70/papers/059e-Campbell.pdf 
Cavaye, A.L.M. (1996). Case study research: a multi-faceted research approach for IS. Information Systems Journal 6, 227-242.

Central Intelligence Agency (CIA). (2011). The World Fact book Online. Last updated on March 8, 2011. Retrieved March 16, 2011 from https://www.cia.gov/library/publications/the-worldfactbook/geos/my.html

Central Intelligence Agency (CIA). (2014). The World Fact book Online. Last updated on June 20, 2014. Retrieved September 23, 2014 from https://www.cia.gov/library/publications/the-worldfactbook/geos/my.html

Chalmers, A., \& Slyfield, H. (1993). Contributions to learning: Libraries and New Zealand schools. Wellington: Research Unit, National Library of New Zealand

Chan, F. M. (2002). Developing Information Literacy in Malaysian Smart Schools: resource-based learning as a tool to prepare today's students for tomorrow's society In: Singh, D et al. (Ed.): School Libraries for a Knowledge Society. Proceedings of the 31st Annual Conference of the International Association of School Librarianship, Petaling Jaya, Kuala Lumpur, Malaysia (4-9 August, 2002). Seattle, WA, IASL: 203-215

Chan, S-N. (2003). Making information literacy a compulsory subject for undergraduates: The experience of the University of Malaya. IFLA Journal, 29(4), 328-335.

Chen, H.T. (2004). The roots of theory-driven evaluation: current views and origins. In M.C. Alkin (ed.), Evaluation roots: Tracing theorists' views and influences (pp.132-152). Thousand Oaks, Calif.: Sage.

Chen, H.T. (2005). Practical program evaluation: Assessing and improving planning, implementation, and effectiveness. Thousand Oaks, Calif.: Sage.

Chen, H.T. (2006). A theory-driven evaluation perspective on mixed methods research. Research in the schools, 13 (1), 75-83.

Chen, H.T., Quane, J., Garland, N., \& Mracin, P. (1988).Evaluating an anti-smoking program: Diagnostics of underlying causal mechanism. Evaluation and the Health Professions, 11, 441-464. 
Chowdhury, K.P. (1995). Literacy and primary education. Working Papers No. 14052. Human Resources Development and Operations Policy. Washington D.C.: World Bank.

Church, A.P. (2008). The instructional role of the library media specialist as perceived by elementary school principals. American Library Association.

Clifford, G.J. (1984). Buch und Lesen: Historical perspectives on literacy and schooling. Review of Educational Research 54(4), 472-500.

Cohen, L., Manion, L., \& Morrison, K. (2000).Research methods in education (5th ed.). New York: RoutledgeFalmer.

Conway, P., \& Clark, C. (2003). The journey inward and outward: A reexamination of Fuller's concerns-based model of teacher developments. Teaching and Teacher Education, 19, 465-482.

Cortazzi, M., \& Jin, L. (1996). Cultures of learning: Language classrooms in China. Society and the language classroom, 169, 206.

Creswell, J.W. (2009). Research design: qualitative, quantitative and mixed methods approaches ( ${ }^{\text {rd }}$ ed.). California: Sage.

Darus, S. (2010). The current situation and issues of the teaching of English in Malaysia. Ritsumeikan Studies in Language and Culture, $22(1), 19-28$.

Daud, W. M. N. W. (1989). The concept of knowledge in Islam. Mansell: London and New York.

Denzin, N.K., \& Lincoln, Y.S. (2000).Handbook of qualitative research ( $2^{\text {nd }}$ ed.). Thousand Oaks: SAGE.

Domitrovich, C.E., \& Greenberg, M.T. (2000). The study of implementation: Current findings from effective programs that prevent mental disorders in school-aged children. Journal of Educational and Psychological Consultation 11(2), 193-221.

Dorner, D. G., \& Gorman, G. E. (2011). Contextual factors affecting learning in Laos and the implications for information literacy education. Information Research: An International Electronic Journal, 16(2), n2. Retrieved April 20, 2012 fromhttp://informationr.net/ir/16-2/paper479.html 
Dorner, D., \& Gorman, G.E. (2008).Indigenous knowledge and the role of Information Literacy Education. Paper presented at the World Library and Information Congress: $74^{\text {th }}$ IFLA General Conference and Council, 10-14 August, Quebec, Canada. Retrieved August 14, 2009 from http://archive.ifla.org/IV/ifla74/papers/090-Dorner-en.pdf

Dorner, D.G., \& Gorman, G.E. (2006).Information Literacy Education in Asian developing countries: Cultural factors affecting curriculum development and program delivery. IFLA Journal 32(4), 281-293. Dorrell, L., \& Lawson, L. (1995). What are principals' perceptions of the school library media specialist? NASSP Bulletin, 79(2), 72-80.

Doyle, C.S. (1992) Outcome measures for IL within the national education goals of 1990: final report of the National Forum on IL. Summary of findings. Washington, DC: US Department of Education. (ERIC document no; ED 351033). Retrieved August 27, 2009 from http://eric.ed.gov/ERICDocs/data/ericdocs2/content_storage_01/000 0000b/80/23/4a/12.pdfl

Doyle, C.S. (1994). IL in an information society: a concept for the information age. Syracuse, NY: ERIC (ERIC Document Reproduction No. ED 372763).

Edzan, N.N. (2008). Information Literacy via blended learning. Paper presented at Konvensyen Teknologi Pendidikan ke-19, September 911, Langkawi, Malaysia. (unpublished)

Edzan, N.N., \& Mohd Saad, M. S. (2005). NILA: A National Information Literacy agenda for Malaysia. Malaysian Journal of Library \& Information Science10 (1), 91-103. Eisenberg, M.B., \& Berkowitz, R.E. (1988).Curriculum initiative: An agenda and strategy for library media programs. Norwood, N.J.: Ablex.

Eisenhardt, K. (1989). Building theories from case study research. Academy of Management Review 14 (4), 532-550.

Eisner, E. W. (1984). Can educational research inform educational practice? The Phi Delta Kappa, 65(7), 447-452.

Elkind, D. (1991). Perspectives on early childhood education: Growing with young children toward the $21^{\text {st }}$ century (NEA Early Childhood 
Education Series). Washington, D.C.: National Education Association.

Elkind, D. (1997). Chapter 2: Schooling and family in the postmodern world. In A. Hargreaves (ed.), ASCD Yearbook: Rethinking educational change with heart and mind, (p.27-42), Alexandria, VA: Association for Supervision and Curriculum Development.

Eng, T.O., \& Ruthven, K. (2010). The distinctiveness and effectiveness of science teaching in the Malaysian 'Smart School', Forthcoming in Research in Science and Technological Education 28 (1), 25-41. Retrieved July 19, 2010 from http://www.educ.cam.ac.uk/people/staff/ruthven/Ong\&RuthvenRST Epreprint.pdf

Esposito, N. (2001). From meaning to meaning: The influence of translation techniques on non-English focus group research. Qualitative Health Research 11(4), 568-579.

Farmer, D. W. (1992). Information literacy: Overcoming barriers to implementation. New Directions for Higher Education, 1992(78), 103-112.Farmer, L.S.J., \& Henri, J. (2008).IL assessment in K-12 settings. Landham, Maryland: Scarecrow Press.

Fontaine, R. (2008). Problem solving: an Islamic management approach. Cross Cultural Management: An International Journal, 15(3), 264274.

Foster, P., \& Purves, A. (1996). Literacy and society with particular reference to the non-western world. In R. Bar, M. L. Kamil, P. B. Mosenthal, and P. D. Pearson (eds.), Handbook of Reading Research (Vol.2).Mahwah, NJ: Erlbaum.

Frankel, R.M., \& Devers, K.J. (2000). Qualitative research: A consumer's guide. Education for Health 13 (1), 113-123.

Fullan, M. (1993). Change forces: Probing the depths of educational reform. London: Falmer.

Fullan, M. (1994). Implementation of innovations. In T. Husen T.N. Postlethwaite (eds.), The International Encyclopedia of Education (2nd ed.). Oxford: Pergamon. 
Fullan, M. (2001). Leading in a culture of change. San Francisco: JosseyBass.

Fullan, M. (2001).The new meaning of educational change. New York: Teachers College Press.

Fullan, M., \& Stiegelbauer, S. (1991).The new meaning of educational change. London: Cassell.

Fullan, M., ed. (2005).Fundamental Change. In The international handbook of educational change (Vol.3). Dordrecht: Kluwer.

Gavin, B. (1999). IL curriculum and assessment: Implications for schools from New Zealand. In J. Henri and K. Bonanno (eds.), The information literate school community: Best practices (pp.57-78). WaggaWagga, NSW: Centre for Information Studies.

Gawith, G. (1991). Information skills and school libraries. Reading Forum New Zealand, 2, 11-16.

Geertz, C. (1973). The interpretation of cultures: selected essays. New York: Basic Books.

Giacquinta, J.B. (1973). 6: The process of organizational change in schools. Review of Research in Education 1, 178-208. Goodin, M.E. (1991). The transferability of library research skills for high school to college. School Library Media Quarterly 19(1).33-42.

Goodman, J. (1995). Change without difference: School restructuring in historical perspective. Harvard Educational Review 65(1), 1-29.

Gorman, G.E., \& Clayton, P. (2005).Qualitative research for the information professional: A practical handbook $\left(2^{\text {nd }}\right.$ ed.) London: Facet.

Gottlieb, N.H., Lovata, C.Y., Weinstein, R., Gree, L.W., \& Eriklsen, M.P. (1992).The implementation of a restrictive worksite smoking policy in a large decentralized organization. Health Education Quarterly, 19 (1), 77-100.

Grassian, E.S., \& Kaplowitz, J.R. (2001).Information Literacy Instruction. Theory and Practice. New York: Neal-Schuman.

Gray, A. (1997). Constructivist teaching and learning. SSTA Research Centre Report \#97-07. Retrieved October 3, 2013 from 
http://www.saskschoolboards.ca/old/ResearchAndDevelopment/Res earchReports/Instruction/97-07.htm

Guba, E.G., \& Lincoln, Y.S. (1989).Fourth generation evaluation. Newbury Park: Sage.

Hall, G., \& Hord, S. (2005). Implementing change: Patterns, principles, and potholes. Boston: Allyn and Bacon.

Hall, G.E. (1992). The local educational change process and policy implementation. Journal of Research in Science Teaching, 29 (8), 877-904.

Hall, G.E., \& Hord, S.M. (1987). Change in schools: Facilitating the process. Albany, NY: State University of New York Press.

Hall, G.E., Wallace, R.C., \& Dossette, W.A. (1973).A developmental conceptualisation of the adoption process within educational institutions (Rep. No. 3006). Austin, Texas: The University of Texas at Austin, The Research and Development Centre for Teacher Education. [ERIC Document Reproduction No. ED 095126] Hannafin, M.J., \& Hill, J.R. (2007).Resource-based learning. In M. Spector, M.D. Merrill, J. Van Merrienboer, and M.P. Driscoll (eds.), Handbook of research on educational communications and technology ( $3^{\text {rd }}$ ed., pp.525-536). Mahwah, NJ: Erlbaum.

Hargreaves, A., ed. (1997). Rethinking educational change with heart and mind (ASCD Yearbook). Alexandria, VA: Association for Supervision and Curriculum Development.

Hargreaves, A., et al., ed. (2005).International handbook of educational change. (Vols 1-4). Dordrecht: Kluwer.

Hartzell, G. (2002, November). Why should principals support school libraries? (EDO-IR-2002-06). Retrieved April 26, 2010 fromhttp://fundourfuturewashington.org/resources/ERIC+PrincipalsLibraries.pdf

Hashim, R. (2004). Educational dualism in Malaysia: Implications for theory and practice. Kuala Lumpur: The Other Press.

Hashim, R., \& Hussein, S. (2003). Teaching thinking in Malaysia. Kuala Lumpur: International Islamic University Malaysia. 
Hassan, S. (2008). Integrating ICT in teaching and learning: Country report: Malaysia. Retrieved October 10, 2009 from http://www2.unescobkk.org/elib/publications/ICT_Classroom/Count ry_malaysia.pdf

Haycock, K. (1989). Summary of EL research findings to date: What works, research: The implications for professional practice. Emergency Librarian. ERIC ED327181.

Henri, J. \& Boyd, S. (2002). Teacher librarian influence: Principal and teacher librarian perspectives. School Libraries Worldwide 8(2), 117. Henri, J. (1995). The information literate school community: Exploring a fuzzy concept. Scan, 14 (3), 25-28.

Henri, J., \& Hay, L. (1996).The principal's role in developing and supporting an information literate school community. In Beyond the Horizon: Proceedings of the $14^{\text {th }}$ Biennial Conference of the Australian School Library Association (pp.111-125). West Perth: The Association.

Henri, J., \& Bonanno, K., ed. (1999). Information literate school community: Best practice. WaggaWagga, NSW: Centre for Information Studies, Charles Sturt University.

Henri, J., Hay, L., \& Oberg, D. (2002). An international study on principal influence and information services in schools: Synergy in themes and methods. School Libraries Worldwide, 8(1), 49-70.

Henri, J., Hay, L., \& Oberg, D. (2002). The role of the principal in an information literate school community: Findings from an international research project. Paper presented at the 68th IFLA Council and General Conference, August 18-24, 2002.Retrieved April 28, 2012 from http://archive.ifla.org/IV/ifla68/papers/031097e.pdf

Hepworth, M. (2000).Developing IL programs in Singapore. In C.S. Bruce and P.C. Candy (eds.), IL Around the World: Advances in Programs and Research. WaggaWagga, NSW: Charles Sturt University.

Hofstede, G. (2001). Culture's consequences: Comparing values, behaviours, and organisations across nations ( $\left.2^{\text {nd }} e d.\right)$. Thousand Oaks, Calif.: Sage. 
Horton, F.W. (2006). IL and information management: A $21^{\text {st }}$ century paradigm partnership. International Journal of Information Management (UK) 26(4), 263-267.

Implementer, n. (2010).In Merriam-Webster's online dictionary. Retrieved April 14, 2010 from http://www.merriamwebster.com/dictionary/implementer

Integrate, v. (2010). In Oxford English Dictionary Online. Oxford University Press. Retrieved April 14, 2010 from http://www.oed.com/

International Monetary Fund (IMF). (2005). Malaysia: Statistical Appendix (IMF Country Report No. 05/102). Washington: Author.

Institute of Development Studies (IDS) et al. (2013). Training toolkit: The monitoring and evaluation for information literacy training initiatives in Africa: a journey approach. Brighton: IDS.

Ismail, S. (2002). ICT in the classroom: A Malaysian perspective. Retrieved October 10, 2009 from http://www2.unescobkk.org/elib/publications/ICT_Classroom/Count ry_malaysia.pdf

Ivanitskaya, L., O’Boyle, I., and Casey, A. (2006.) Health information literacy and competencies of information age students: Results from the Interactive Online Research Readiness Self-Assessment (RRSA). Journal of Medical Information Research 8(2). Retrieved November 12,2014 from http://www.ncbi.nlm.nih.gov/pmc/articles/PMC1550696/

Johnston, B. \& Webber S. (2003). IL in Higher Education: a review and case study. Studies in Higher Education 28 (3): 335-352.

Joyce, B., \& Showers, B. (2002).Student achievement through staff development ( $3^{\text {rd }}$ ed.). Alexandria, VA: ASCD.

Jusoh, F. (2002).School libraries in Malaysia. Paper prepared for the 2002 IASL Conference, 4-9 August, Petaling Jaya, Malaysia. Retrieved August 30, 2009 from http://www.iaslonline.org/events/conf/conference2002-fatimah.html

Kaestle, C.F. (1985). Chapter 1: The history of literacy and the history of readers. Review of Educational Research 12, 11-53. 
Kankaanrinta, I. (2003). Finnish kindergarten student teachers' attitudes towards modern information and communication technologies. Retrieved November 1, 2009, from http://www.edu.helsinki.fi/media/mep9/kankaanrinta_mep9.pdf

Karelse, C. (2000). INFOLIT: A South African experience of promoting quality education. In IL Around the World: Advances in Programs and Research, eds. C.S. Bruce and P.C. Candy. WaggaWagga, NSW: Charles Sturt University.

Kinta North District Education Office (EO) Official Portal. (2003). Retrieved January 3, 2011 from http://ppdkinta.edu.my/ Kinta North District Teachers' Activities Centre (TAC). (2010). Kinta North district schools' portal, Perak Darul Ridzuan. Retrieved January 3, 2011 from http://kintautara.net/

Kolencik, P.L. (2001). Principals and teacher-librarians: Building collaborative partnerships in the learning community. Unpublished EdD dissertation, University of Pittsburgh.

Krauss, E.S. (2005). Research paradigms and meaning making: A primer. The Qualitative Report 10(4), 758-770. Retrieved May 31, 2010 from http://www.nova.edu/ssss/QR/QR10-4/krauss.pdf

Kuhlthau, C.C. (1987). Information Skills for an Information Society: A Review of Research. Syracuse, NY: ERIC.

Lance, K. C., Rodney, M. J., \& Russell, B. (2007). How students, teachers and principals benefit from strong school libraries. Retrieved from Association for Indiana Media Educators. Retrieved April 28, 2012 http://www.ilfonline.org/clientuploads/AIME/2007MSArticle.pdf

Lee, E. A., Reed, B., \& Laverty, C. (2012). Preservice Teachers' Knowledge of Information Literacy and Their Perceptions of the School Library Program. Behavioural \& Social Sciences Librarian, 31(1), 3-22.

Lee, M.N.N. (1997). Education and the state: Malaysia after the NEP. Asia Pacific Journal of Education 17 (1), 27-40.

Lee, M.N.N. (1998). Malaysia: Review of educational events in 1997. Asia Pacific Journal of Education 18 (1), 87-93. 
Lee, M.N.N. (1999). Education in Malaysia: Towards Vision 2020. School Effectiveness and School Improvement 10(1), 86-98.

Lennox, M.F., \& Walker, M.L. (1993).IL in the educational process. Educational Forum 57(3), 312-324.

Library and Information Association of New Zealand Aotearoa. (2001). Towards a national information strategy: LIANZA/TRW recommendations for a national information strategy. Wellington: LIANZA. Retrieved July 16, 2009 from http://www.lianza.org.nz/text_files/nis_7nov02.pdf

Limberg, L., Sundin, O., \& Talja, S. (2012). Three theoretical perspectives on information literacy. Human It Open Section, 11, 93-130.

Loertscher, D.V., \& Woolls, B. (1997). The IL Movement of the School Library Media Field: A Preliminary Summary of the Research. Retrieved March 6, 2010 from http://slisweb.sjsu.edu/courses/250.loertscher/modelloer.html

Mahat, A.R. (2005). Education in Malaysia: Unifying or Divisive? In A. R. Baginda and P. Schier (eds.), Education in Malaysia: Unifying or Divisive? (MSRC-KAF Inter-Cultural Discourse Series III).Kuala Lumpur: Malaysian Strategic Research Centre and KonradAdenauer-Foundation.

Malaysia. Ministry of Education. (2005). A Shift "Teacher Coordinator of School Resource Centre to Library and Media Teacher" (Professionals Circular Number 3/2005). Kuala Lumpur: Author. Malaysia. Ministry of Education. Educational Technology Division (ETD).(2006). A country report on IL in Malaysia. (Unpublished). Paper presented at International Workshop on IL, Petaling Jaya, Malaysia.

Malaysia. Ministry of Education. Curriculum Development Centre (CDC). (2001a). Pembelajaran secara konstruktivisme (Learning by means of constructivism). Kuala Lumpur: Author.

Malaysia. Ministry of Education. Curriculum Development Centre (CDC). (2001b). Pembelajaran masteri (Mastery learning). Kuala Lumpur: Author. 
Malaysia. Ministry of Education. Curriculum Development Centre (CDC). (2001c). Belajar cara belajar (Learn how to learn). Kuala Lumpur: Author.

Malaysia. Ministry of Education. Curriculum Development Centre (CDC). (2002). Kemahiran berfikir dalam pengajaran dan pembelajaran (Thinking skills in teaching and learning). Kuala Lumpur: Author. Malaysia. Ministry of Education.(2006). Education Act 1996. Kuala Lumpur: The Commissioner of Law Revision, Malaysia under the authority of the revision of laws Act 1968 in collaboration with Percetakan Nasional Malaysia Berhad. Retrieved April 14, 2010 from http://www.agc.gov.my/Akta/Vol.\%2011/Act\%20550.pdf Malaysia. Ministry of Education. Curriculum Development Centre (CDC) Official Website. (2008). Retrieved August 17, 2010 from http://www.moe.gov.my/bpk

Malaysia. Ministry of Education. Educational Planning and Research Division.(1990). Education in Malaysia, 1989. Kuala Lumpur: Ministry of Education.

Malaysia. Ministry of Education. Educational Planning and Research Division.(2012). Pelan Strategik Interim, 2011-2020 (Interim Strategic Plan, 2011-2020). Kuala Lumpur: Ministry of Education. Malaysia. Ministry of Education. Educational Technology Division (ETD) Official Website. (2011). Retrieved March 2, 2011 from http://www.moe.gov.my/btp/

Malaysia. Ministry of Education. (2014). Maklumat Asas Pendidikan (Basic Education Information). Educational Management Information System Portal. Retrieved May 2, 2014 from http://emisportal.moe.gov.my/emis/emis2/emisportal2/ Malaysia. Ministry of Education. Smart School Project Team. (1997). The Malaysian Smart School. An MSC Flagship Application. A Conceptual Blueprint. Kuala Lumpur: Ministry of Education. Malaysia. Ministry of Education. Teacher Education Division (TED). (2009). Pengoperasian latihan dalam perkhidmatan secara school based (The operation of school- based in-service training). Retrieved December 25, 2010 from http://www.jpnns.gov.my/ 
Malaysia. Multi Media Development Corporation. (2005).The Smart School roadmap 2005-2020 : An educational odyssey. Retrieved June 1, 2007

fromhttp://www.msc.com.my/smartschool/downloads/roadmap.pdf Malaysia. Prime Minister Department. Economic Planning Unit. (2009). The Malaysian Economy in Figures 2009. Updated: 12 July 2010. Retrieved October 20, 2010 from http://www.epu.gov.my/c/document_library/get_file?p_1_id=29580 \&folderId=29570\&name=DLFE-1612.pdf

Malaysia. Selangor State Educational Technology Division (SETD).(2007). Buku panduan pengurusan pusat sumber sekolah untuk guru perpustakaan dan media (Guidebook on school resource centre management for library and media teacher). Shah Alam, Selangor: Author.

Markless, S. \& Streatfield, D. (2007 ). Three decades on information literacy: redefining the parameters. Retrieved April 28, 2012 fromhttp://www.informat.org/pdfs/Streatfield-Markless.pdf

Marland, M. (1987).Libraries, learning, and the whole school. Emergency Librarian, 15(2), 9-14.

Marshall, C., \& Rossman, G.B. (1999).Designing qualitative research ( $3^{\text {rd }}$ ed.). Thousand Oaks, Calif.: Sage.

May, C. (1998). Capital, knowledge and ownership: The 'information society' and intellectual property. Information, Communication \& Society 1(3), 246-269.

McBrien, J.L., \& Brandt, R.S. (1997).From the language of learning: A guide to education terms. Alexandria, VA: Association for Supervision and Curriculum Development.

McCracken, A. (2001). School library media specialists' perceptions of practice and importance of roles described in Information Power. School Library Media Research. Retrieved May 3, 2004, from http://www.ala.org/ala/aasl/aaslpubsandjournals/slmrb/slmrcontents/ volume42001/mccracken.htm

McGregor, J. H. (2002). Flexible scheduling: How does a principal facilitate implementation? School Libraries Worldwide, 8(1), 71-84. 
Mckay, S.L. (2006). Researching second language classrooms.

New Jersey: Lawrence Erlbaum.

McKinzie, LA. (1997). Transformation learning theory and the adult learner: The development of IL skills in response to the informational context. Unpublished doctoral dissertation, Texas Technology University, Texas, US.

McLaughlin, M.W. (1987). Learning from experience: Lessons from policy implementation. Educational Evaluation and Policy Analysis, 9(2), 171-178.

McLuhan, M. (1962).The Gutenberg Galaxy. Toronto: University of Toronto Press.

Merchant, L., \& Hepworth, M. (2002). IL of teachers and pupils in secondary schools. Journal of Librarianship and Information Science, 34 (2), 81-89.

Miles, M., \& Hubermann, A.M. (1994).Qualitative Data Analysis: An Expanded Sourcebook. ( $2^{\text {nd }}$ ed.). Thousand Oaks, CA: Sage.

Miller, R. (2007). What is democratic education? Retrieved October 17, 2013 from http://www.pathsoflearning.net/articles_What_Is_Democratic_Educa tion.pdf

Ministry of Education Malaysia. Malaysia Education Blueprint 2013-2025. A preliminary Report. 2012. Accessed 30 Sept 2012. http://www.cpps.org.my/upload/105554958-Malaysia-EducationBlueprint-2013-2025-Preliminary-Report-Executive-Summary.pdf.

Ministry of Education Malaysia. Primary School Standard Curriculum: World of Science and Technology Year 1. Kuala Lumpur: Curriculum Development Division;2011.

Mohamad, M. (1991). Malaysia: The Way Forward. Working paper presented at the Inaugural Meeting of the Malaysian Business Council. Kuala Lumpur: Centre for Economic Research \& Services, Malaysian Business Council.

Mohamad, M. (2002).Speech.31 ${ }^{\text {st }}$ IASL Conference, 4-9 August, Petaling Jaya, Malaysia. 
Mokhtar, I.A., \& Majeed, S. (2005). Use of school libraries by teachers in Singapore schools. Library Review, 54 (2), 108-118.

Mokhtar, I.A., Foo, S., \& Majid, S. (2007). Bridging between Information Literacy and information technology in Singapore schools: an exploratory study. Information Communication Technology NRT, 1(4). Retrieved October 11, 2009 from http://pkp.sfu.ca/ojs/demo/present/index.php/jce/article/view/179/68 Moore, P. (1999). Information literate school communities: Beyond teacher librarians. In J. Henri and K. Bonanno (eds.), The information literate school community: Best practices (pp.99-120). WaggaWagga, NSW: Centre for Information Studies.

Moore, P. (2000). Primary school children's interaction with library media. Teacher Librarian, 27(3), 7-11.

Moore, P. (2002). Information Literacy. What's it all about? Wellington: New Zealand Council for Educational Research.

Muir, A., \& Oppenheim, C. (2001).Report on developments world-wide on national information policy. Prepared for Resource and the Library Association by Adrienne Muir and Charles Oppenheim with the assistance of Naomi Hammond and Jane Platts, Department of Information Science, Loughborough University, London: Library Association. Retrieved February 10, 2009 from http://www.lahq.org.uk/directory/prof_issues/nip/

Nagata, J. A. (1974). Adat in the city: Some perceptions and practices among urban Malays. Bijdragen tot de Taal-, Land-en Volkenkunde, 130(1), 91-109.

Nakamura, Y. (2000). Teachers' perceptions of school libraries: Comparisons from Tokyo and Honolulu. School Libraries Worldwide, 6(1), 66-87.

National IT Council Malaysia (Official portal). (2012). Multimedia Super Corridor (MSC) Malaysia. Retrieved September 4, 2013 from http://nitc.mosti.gov.my/nitc_beta/index.php/key-ictinitiatives/multimedia-super-corridor-msc-malaysia

New Oxford Dictionary of English on CD-ROM (NODE). (2001). Oxford: Oxford University Press. 
Newmann, F.M., \& Wehlage, G.G. (1995).Successful School

Restructuring: A Report to the Public and Educators by the Centre and Organization and Restructuring of Schools. Madison, WI:

Centre on Organization and Restructuring of Schools.

Ngan, Elisabeth Mei-Xing. (2011). Unlocking the Potential of School

Libraries: What Actions are New Zealand Primary School Principals

Taking to Integrate the School Library in Information Literacy

Initiatives? Final Report. Master of Information System, Victoria

University of Wellington, NZ. Retrieved April 28, 2012 from

http://researcharchive.vuw.ac.nz/bitstream/handle/10063/1969/thesis .pdf? sequence $=2$

Nisbett, R. E. (2003). The geography of thought: Why we think the way we do. New York: Free Press.

Nonaka, I., \& Konno, N. (1997). The concept of "Ba": Building a foundation for knowledge creation. California Management Review, 40(3), 40-54.

Oberg, D. (2006). Developing the respect and support of school administrators. Retrieved April 28, 2012 http://www.redorbit.com/news/education/397062/developing the re spect_and_support_of_school_administrators/

OECD (2009). Overview of country results in TALIS: Malaysia.

Organization for Economic Co-operation and Development (OECD). Retrieved on 01 February 2011 from http://www.oecd.org/

Oka, T., \& Shaw, I. (2003).Qualitative research in social work. Retrieved January 25, 2011 from http://pweb.sophia.ac.jp/oka/papers/2000/qrsw/qrsw.html

Orlikowski, W.J. \& Baroudi, J.J. (1991).Studying information technology in organizations: Research approaches and assumptions. Information Systems Research, 2(1), 1-28.

Overbaugh, R., \& Lu, R. (2008). The impact of a federally funded grant on a professional development program: Teachers stages of concern toward technology integration. Journal of Computing in Teacher Education, 25 (2), 45-55. 
Owusu-Ansah, E.K. (2003). IL and the academic library: A critical look at a concept and the controversies surrounding it. The Journal of Academic Librarianship, 29(4), 219-230.

Owusu-Ansah, E.K. (2005). Debating definitions of IL: enough is enough! Library Review, 54(6), 366-374.

Parush, I., \& Brener, A. (1995). The politics of literacy: Women and foreign languages in Jewish society of $19^{\text {th }}$ century Eastern Europe. Modern Judaism, 15(2), 183-204.

Perak Tamil schools website. (2009). Last updated: 16/09/2009. Retrieved October 20, 2010 from http://pelajaranperak.gov.my/kt/index.htm

Perak. State Educational Technology Division (SETD) Official Portal. (2009). Retrieved October 20, 2010 from http://btpnperak.MOE.edu.my/portal/

Perak. State Department of Education (DOE) Official Portal. (2009a). Retrieved October 20, 2010 from http://pelajaranperak.gov.my/v2/

Perak. State Department of Education (DOE) Official Portal. (2009b). Frequently Asked Question (FAQ): ICT. Retrieved October 20, 2010 from http://pelajaranperak.gov.my/v2/

Perkins, D.N. (1995). Smart schools: Better thinking and learning for every child. New York: The Free Press.

Peters, M., \& Lankshear, C. (1996).Critical literacy and digital texts. Educational Theory, 46 (1), 51-70.

Pinsonneault, A. \& Kraemer, K.L. (1993). Survey research methodology in management information systems: An assessment. Journal of Management Information Systems, 10(2), 75-106.

Plomp, T., \& Carleer, G. (1986). Factors affecting the introduction and computer literacy (ICL) courses. Paper presented at the Annual Convention of the American Educational Research Association, 1620 April, San Francisco. Retrieved April 14, 2010 from http://eric.ed.gov/

Pratt, D.D., Kelly, M., Wong, W.S.S. (1999). Chinese conceptions of effective teaching in Hong Kong: Towards culturally sensitive evaluation of teaching. International Journal of Lifelong Education $18,241-258$. 
Probert, E. (2009). IL skills: Teacher understandings and practice. Computers \& Education, 53, 24-33.

Proctor, R. W. (2005). Methodology is more than research design and technology. Behaviour Research Methods, 37(2), 197 - 201.

Punch, K. (2005). Introduction to Social Research. $2^{\text {nd }}$ ed. London: Sage.

Rader, H. (1991). Bibliographic instruction or IL. College and Research Libraries News, 51(1), 18-20.

Raman, K.S., \& Yap, C.S. (1996). From a resource rich country to an information rich country: An evaluation of information technology policies in Malaysia. Information Technology for Development, 7(3), 109-131.

Ratnavadivel, N. (2007). The Social Origins of the Educational System in Peninsular Malaysia. Tanjung Malim, Malaysia: Penerbit Universiti Pendidikan Sultan Idris.

Reigeluth, C.M., \&Garfinkle, R.J. (1994). Systemic change in education. Englewood Cliffs, NJ.: Educational Technology Publications.

Rivera, F.D. (2003). Chapter 32: In Southeast Asia: Philippines, Malaysia, and Thailand: Conjunctions and collisions in the global cultural economy. In W.F. Pinar (9 ed.), International handbook of curriculum research (p.553-574). Mahwah, NJ: L. Erlbaum.

Rout, G.K., Priyadarshani, N., Hussin, Z., Pritinanda, A., Wan Mamat, W.H., \&Goh, L.Z. (2010). Implementation of new sixth form geography curriculum: Concerns and levels of use of teachers in Malaysia. International Journal of Educational Administration, 2 (1), 63-72.

Savasci, F., \& Berlin, D. F. (2012). Science teacher beliefs and classroom practice related to constructivism in different school settings. Journal of Science Teacher Education, 23(1), 65-86.

SCONUL (Standing Conference of National and University Libraries).(1999). SCONUL Briefing Paper. Information Skills in Higher Education. SCONUL.

Seidman, I. (1988) Interviewing as qualitative research: A guide for researchers in education and the social sciences. New York: Teachers College, Columbia University. 
Serotkin, P.B. (2006). Understanding the paradigm shift: A descriptive case study of the impact of changes in IL instruction methods on librarians, faculty, and students at a private, comprehensive institution. Unpublished doctoral dissertation, Indiana University of Pennsylvania, US.

Shapiro, J.J., \& Hughes, S.K. (1996).IL as a liberal art. Educom Review[Online] 3(2). Retrieved August 12, 2009 from http://www.educom.edu/web/pubs/review/reviewArticles/31231.htm 1

Sheikh Kadir, S.A. (2003). Experience and Efforts in Literacy Programmes: Brief Country Report. Kuala Lumpur : Perpustakaan Negara Malaysia.

Shenton, A.K. (2004). Research into young people's information seeking: perspectives and methods. Aslib Proceedings 56(4), 243-254.

Shim, S. H. (2008). A philosophical investigation of the role of teachers: A synthesis of Plato, Confucius, Buber, and Freire. Teaching and Teacher Education, 24(3), 515-535.

Shuriye, A.O. (2005). Islamic Education: Issues in History and approach. In A.R.A. Baginda and P. Schier (eds). Education in Multicultural Societies: Perspectives on Education in Malaysia, London: Asean Academic Press Limited.

Silverman, D. (2005). Doing qualitative research: a practical handbook. London: Sage.

Singh, D., David, L., Cheunwattana, A., Guaysuwan, P., \& Choovong, L. (2005).Development of IL through school libraries in Southeast Asian countries. Bangkok: United Nations Educational, Scientific, and Cultural Organization. Retrieved March 28, 2010 from http://www2.unescobkk.org/elib/publications/06INF/information.pdf

Skov, A., \& Skaerbak, H. (2003).Fighting an uphill battle: Teaching IL in Danish institutions of higher education. Library Review, 52(7), 326332.

Small, G. (1993).Integrating information skills into the mainstream curriculum. The evolution of a model. School Librarian, 41 (4), 142144. 
Snavely, L., \& Cooper, N. (1997).The information debate. Journal of Academic Librarianship 23(1), 9-20.

Snow, R. E ., Lohman, D. F. (1984). Toward a theory of cognitive aptitude for learning from instruction. Journal of Educational Psychology 76, 347-76

Society, n. (2009).In Oxford English Dictionary Online. Oxford University Press. Retrieved April 14, 2010 from http://www.oed.com/

Southeast Asian Ministers of Education Organization. Regional Center for Educational Innovation and Technology (SEAMEO-Innotech). (c2003). Profile of SEAMEO countries: Malaysia. Retrieved May 1, 2010 from http://www.seameoinnotech.org/resources/seameo_country/seameo country.asp

Spitzer, K.L., Eisenberg, M.B., \& Lowe, C.A. (1998).IL: Essential skills for the information age. Syracuse, NY: Syracuse University.

Stake, E.R. (1995).The art of case study research. London: Sage.

Steinwachs, K. (1999). Information and culture - the impact of national culture on information processes. Journal of Information Science, 25(3), 193-204.

Straub, E.T. (2009). Understanding technology adoption: Theory and future directions for informal learning. Review of Educational Research, 79 (2), 625-649.

Sundin, D., \& Fahy, K. (2008). Critical, post-structural, interpretive interactionism: an update on Denzin's methodology. Nurse Researcher, 16(1), 7 - 23.

SWIM. (2003). Homepage: Streaming Web-based Information Modules. Denmark: Aalborg University Library. Retrieved May 1, 2010 from http://www.swiminfo.dk/english.html

Tan, S. M., Gorman, G., \& Singh, D. (2012). Information Literacy Competencies among School Librarians in Malaysia. Libri, 62(1), 98-107.

Tan, S.M., \& Singh, D. (2008).An Assessment of the IL Levels of Library and Media Teachers in the Hulu Langat District, Malaysia. Paper 
presented at ICOLIS 2008, Kuala Lumpur, organized by LISU, FCSIT, University of Malaya.

Tremblay, MA. (1957). The key informant technique: A non-ethnographic application. American Anthropologist, New Series 59 (4), 688-700.

UNESCO IBE (2006). World Data on Education. In 6th (Ed.), Principles and general objectives of education. Retrieved April 28, 2012 http://www.ibe.unesco.org/fileadmin/user_upload/archive/Countries/ WDE/2006/ASIA and the PACIFIC/Malaysia/Malaysia.pdf

UNESCO IBE (2010). World Data on Education. In 7th (Ed.), Principles and general objectives of education. Retrieved April 28, 2012 http://www.ibe.unesco.org/fileadmin/user_upload/Publications/WDE /2010/pdf-versions/Malaysia.pdf

United Nations Educational, Scientific and Cultural Organization (UNESCO). (2006). Using ICT to develop literacy. Bangkok: UNESCO.

United Nations Educational, Scientific and Cultural Organization (UNESCO). (2004).The plurality of literacy and its implications for policies and programmes. Paris: UNESCO. Retrieved August 15, 2009, from http://unesdoc.unesco.org/images/0013/001362/136246e.pdf

United Nations Educational, Scientific and Cultural Organization (UNESCO). (2003). The Prague Declaration: “Towards an information literate society". UNESCO, National Commission on Libraries and Information Science (NCLIS), \& National Forum on IL (NFIL). Retrieved August 24, 2009 from http://www.nclis.gov/libinter/infolitconf\&meet.html

University of Leeds. (2002). The big blue. Final Report. Leeds: University of Leeds. Retrieved March 13, 2009 from http://www.leeds.ac.uk/bigblue/finalreportful.htm

Venezky, R.L. (1996). The development of literacy in the industrialized nations of the West. In R. Barr, M.L. Kamil, and P.B. Mosenthal (eds.), Handbook of reading research (Vol.2, pp.46-67). Mahwah, NJ: Erlbaum 
Virkus, S. (2003). IL in Europe: a literature review. Information Research, 8(4). Retrieved August 18, 20009, from http://informationr.net/ir/84/paper159.html

Virkus, S. (2008). Overview of the current IL world. Paper presented at UNESCO “Training the Trainers in IL Workshop", Tallinn University, Estonia, 21.08.2008. Retrieved August 24, 2009, from http://www.slideshare.net/NielsD/overview-of-the-current-il-worldpresentation

Virkus, S., Boekhorst, A.K., Gomez-Hernandez, J.A., Skov, A., \&Webber, S. (2005) "Information literacy and learning", European Curriculum Reflections on Library and Information Science Education, 64-83. Retrieved April 28, 2012 http://www.um.es/gtiweb/jgomez/publicaciones/alfinliscurriculumgr upo3.pdf

Walker, A., \& Hallinger, P. (2007). Navigating culture and context: the principalship in east and southeast Asia. In R. Maclean (ed.), Learning and teaching for the twenty-first century: Festschrift for Professor Phillip Hughes (pp.255-273). Netherlands: UNESCOUNEVOC and Springer.

Wan Ali, W.Z., Mohd Nor, H., Hamzah, A., \& Alwi, H. (2009). The conditions and level of ICT integration in Malaysia smart schools. International Journal of Education and Development using ICT 5 (2). Watkins, D., \& Ismail, M. (1994). Is the Asian learner a rote learner? A Malaysian perspective. Contemporary Educational Psychology, 19(4), 483-488.

Webb, J., \& Powis, C. (2004).Teaching information skills: Theory and practice. London: Facet.

Whitaker, P. (1993). Managing change in schools. Buckingham: Open University Press.

Williams, D., \& Wavell, C. (2006). Information literacy in the classroom: secondary school teachers' conceptions. Retrieved April 28, 2012 https://openair.rgu.ac.uk/bitstream/10059/42/1/SESfinalreportPDF17 _07_06.pdf 
Wilson, P., \& Blake, M. (1993).A study and a plan for partnership. Emergency Librarian, 21(1), 19-24.

Wilson, S. (2001). What is an indigenous research methodology? Canadian Journal of Native Education 25 (2), 175-179.

Yin, R.K. (2009). Case study research design and methods. ( $4^{\text {th }}$ ed.). Los Angeles: SAGE.

Zaltman, G., Florio, D.H., \& Sikorski, L.A. (1977).Dynamic educational change: Models, strategies, tactics, and management. New York: Free Press.

Zaman, H. B. (1998.Glimpses into research on literacy in Malaysia. Reading Online. Retrieved April 14, 2010 from http://www.readingonline.org/international/malaysia/article.html

Zurkowski, P. G. (1974). The information service environment: Relationships and Priorities. National Commission on Libraries and Information Science. 
Appendix 1 - Letter of Approval from the Human Ethics Committee, School of Information Management

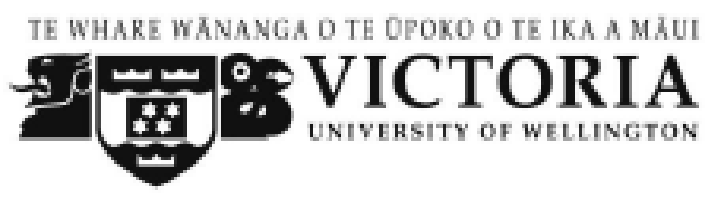

\section{SIM HUMAN ETHICS COMMITTEE \\ Comments on Application for Human Ethics Approval}

Date: 15 April 2011

Principal Researcher: Saidatul Akmar Ismail

Research Project: Factors Affecting the Implementation of Information Literacy

Education in Malaysian Primary Schools

Supervisor: Dr Daniel Dorner, Dr Gillian Oliver

Reference No: \#18462

Your HEC application has been reviewed and the Committee's decision is the following

Approval Given after Amendments made - Application accepted.

Human Ethics Approval valid until: (Date: as in application or no more than 3 years)

Thank you for the amendments you have made to your HEC appication. These meet the committee's required changes. On behalf of the HEC Chair I am authorised to inform you that you may now proceed with your research. You may begin your data collection immediately but please note that a hard copy of your application signed by both you and your supervisor (or other researchers involved for staff applications) is required within one month to ensure that we have a complete record of the approval of your application. This should be submitted to me at

Wendy Chen

School of Infomation Management

Victoria University of Wellington

Room 518, Rutherford House

23 Lambton Quay

Wellington

Wendy Chen

HEC Administrator

SIM Human Ethics Committee 


\section{Appendix 2 - Information sheet for school}

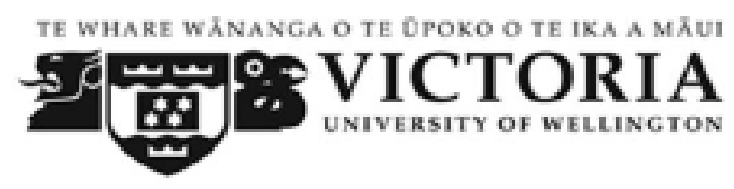

INFORMATION SHEET: School

Project Title: Factors Affecting the Inplementation of Information Literacy Education (II.E) in Malaysian Primary Schools

Researcher: Saidatul Alkmar Ismail

I am a PhD student in the School of Information Management at Victoria University of Wellington. I am undertaking my $\mathrm{PhD}$ studies with funding from a scholarship from the Ministry of Higher Bducation and with the support of ny enployer MARA University of Technology. As part of my degree I am undertaking a research project which will lead to the prochuction of a thesis. This research is aimed to identify and understand the factors affecting the inmlementation of ILE in Malaysian primary schools.

\section{Research Goals}

The goals of this study are: (1) to identify the factors affecting II.E implementation in Malaysian primary schools; (ii) to determine how these factors affect the implementation of IIE in Malaysian primary schools; and (iii) to develop a model to explain what is facilitating and hindering IIE implementation in the Malaysian echucation system. By achieving these research goals, it should be possible to plan a better progranme for ILE that will belp the implementers to progress in incorporating $\Pi \mathrm{E}$ into their teaching practices. As part of carrying out this research, ethical approval has been obtained from the University.

\section{Individual Interviews}

My research consists of face-to-face interviews and documentary analysis. I am now conchucting indivichual interviews.

I am currently seeking participants for individual interviews who are involved directly or indirectly in II.E inplementation at school level. The participants will inchude: (1) school head, (2) teacher from the following subject areas: science, social science and language, and (3) library and media teacher (LMT).

If you choose to participate in this research, you will have the opportumity to discuss your views on IIE with me. It is expected that the interview will last for approximately 1 bour. Each interview will be recorded on a digital audio recorder and transcribed by me

\section{Confidentiality}

All responses will be confidential and will only be reported in an ageregated way or in a way where individuals and their associated groups will not be able to be identified.

All electronic data will be kept in a password protected file. Any written material collected will be kept in a locked cabinet. All materials will be kept confidential, and will only be seen by me, and my 
supervisors, Dr Dan Dorner and Dr Gillian Oliver. The thesis will be submitted for marking to the School of Information Management and deposited in the University Library and the university's digital repository. It is also intended that one or more articles using the data will be submitted for publication in scholarly journals or conference papers. All raw data from the interviews, including ancio tapes or files, will be destroyed two years after the end of the project.

\section{Withdrawal from Study}

Withdrawal from the study will be permitted until $1^{\text {t }}$ Angust 2011. If you wish to withdraw, please notify me in writing by emailing me at saidatulismailavuw.ac.nz indicating that you no longer wish to participate in the study. At that point, any information you have provided will be destroyed and will not be used in the research

\section{Contact}

A summary of the results will be available after the data from all of this phase of the research has been completed. If you wish to receive this summary, please indicate so on the consent form and provide as email address where it can be sent.

If you have any questions or would like furtber information about the project, please contact me or one of my supervisors:

Saidatul Akmar Ismail

$$
\text { saidatul ismaila }
$$

+64 4463-5504 (New Zealand)

05 546-8806 (Malaysia)

Dr Dan Dorner

dan dorner âuw.ac.nz

$+644463-5781$

Dr Gillian Oliver

gillian oliver:avuw.ac.nz

$+644463-7437$

Attached, you will find a consent form, a request for contact details, and an overview of the main topics we will discuss during the interview. I will be in touch again to arrange a suitable time for the interview.

Thank you,

Saidatul Akmar Ismail 


\section{Appendix 3 - Consent Form}

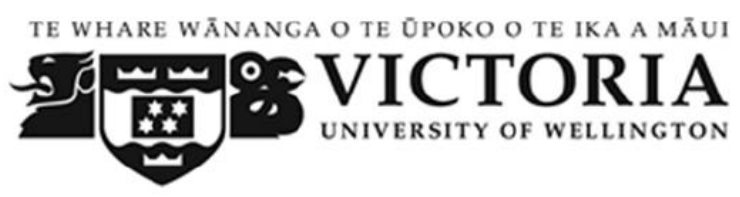

School Head's Consent to Participate in Research

Project Title: Factors Affecting the Implementation of Information Literacy Education (ILE) in Malaysian Primary Schools

Please tick $(\sqrt{ })$ each box

I give consent for Saidatul Akmar Ismail, $\mathrm{PhD}$ student at Victoria University of Wellington, to orally inform the classroom teachers and library and media teacher of the research purpose and to invite them to participate in her research.

I agree to participate in this research under the conditions set out in the information sheet.

I have been given the information about this project and I understand the explanation of this research project.

I have had the opportunity to ask questions and have them answered to my satisfaction.

I understand that I may withdraw myself from this project before data analysis starts on the $1^{\text {st }}$ of August 2011, without having to give reasons. In such a case, the data that I provide will be excluded from the study and deleted.

I understand that any information provided will be confidential. No information will identify the school and the participants in particular.

I understand that all information will be used only for this research, publications and presentations arising from this research project.

I understand that all transcriptions of interviews and document evidence will be destroyed after the research is completed.

Signature

Name

Date

I would like to receive a summary of the research: YES / NO

Please send the summary to the following email address (please write email address below). 


\section{Appendix 4 - Interview Protocol}

\section{Interview Protocol}

Participant Code

Date:

Time In:

Location:

Time Ort:

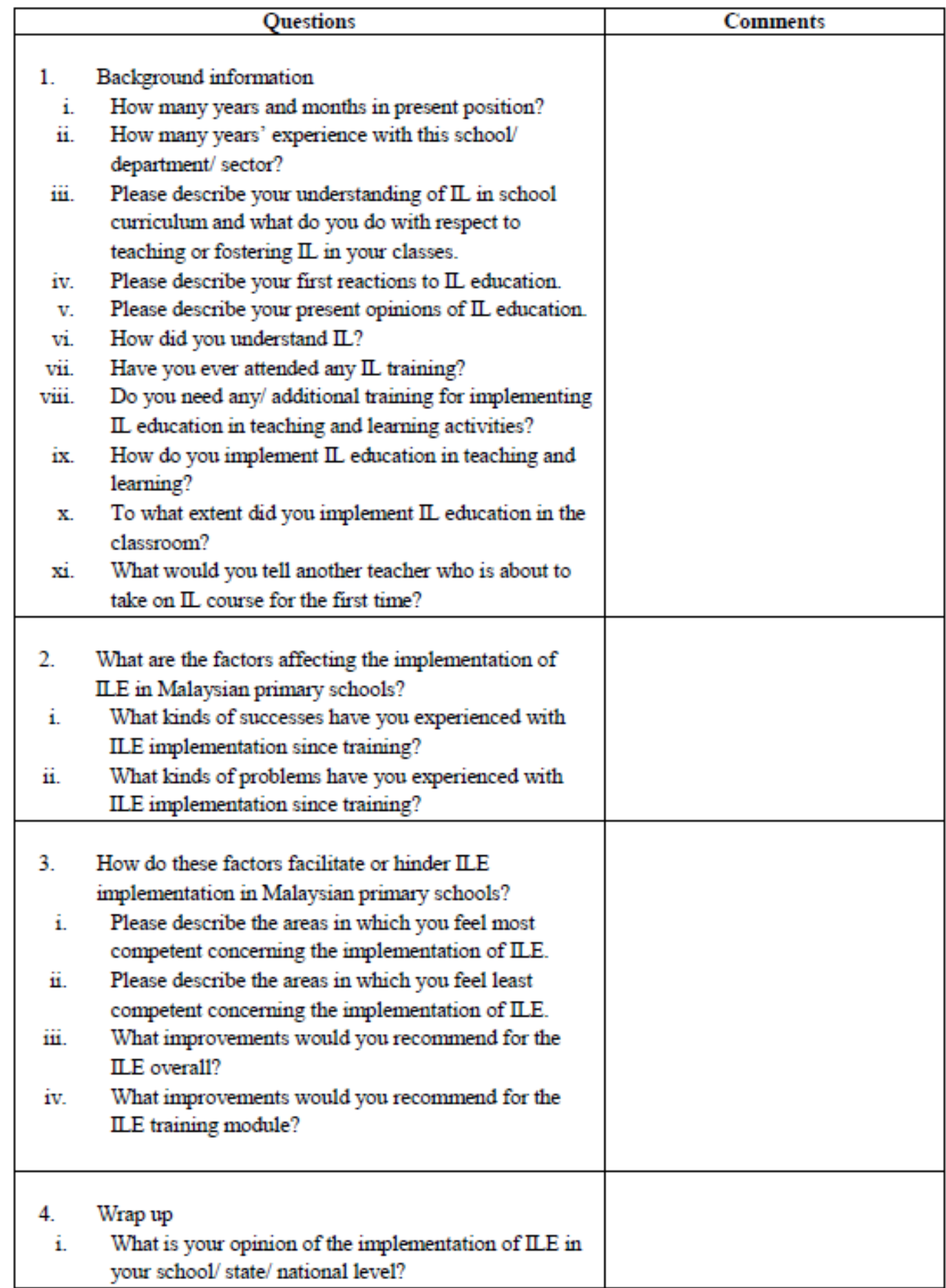


Appendix 5 - Government channels negotiated for accessing participants and key informants

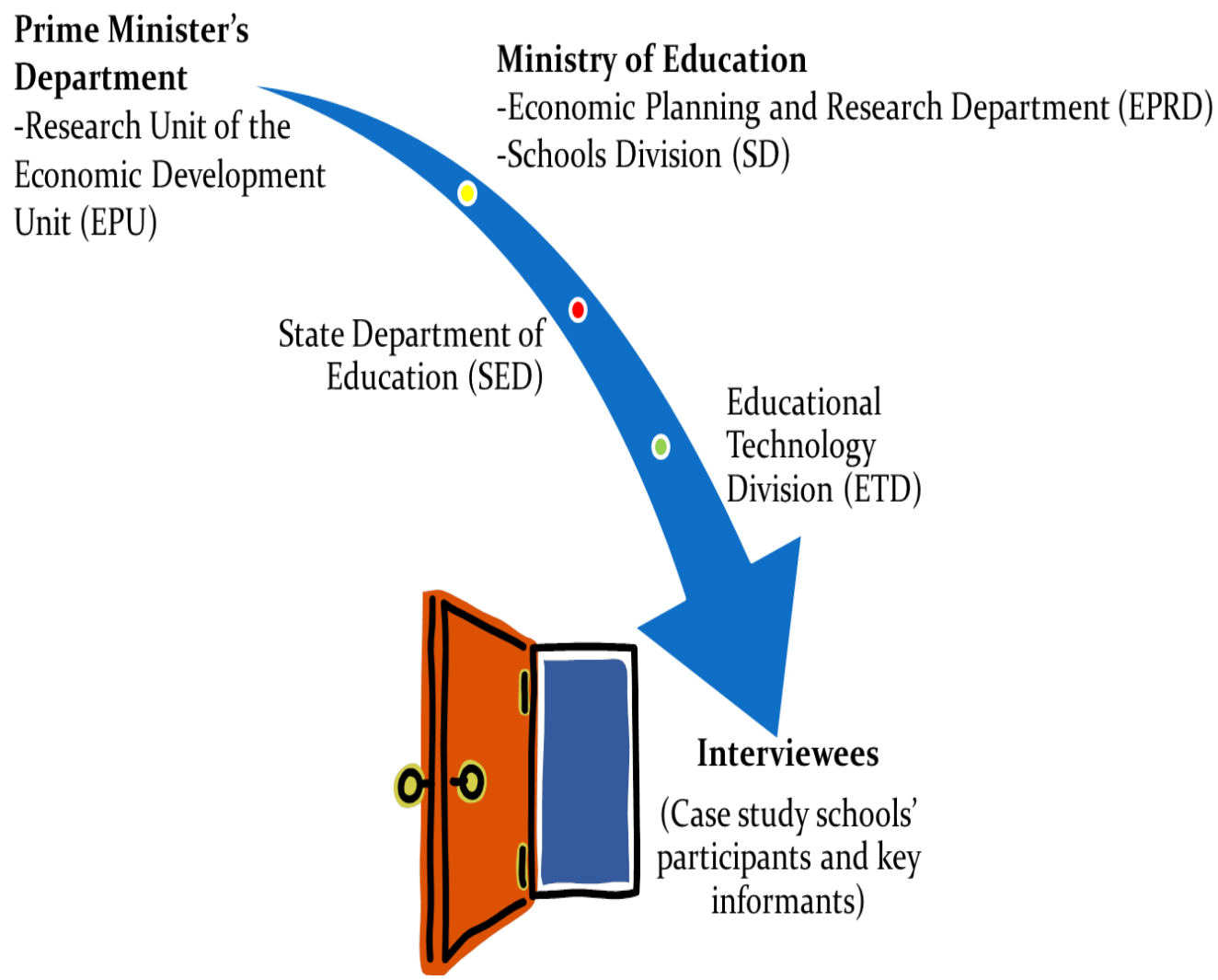




\section{Appendix 6 - Interview transcript and highlighted important terms}

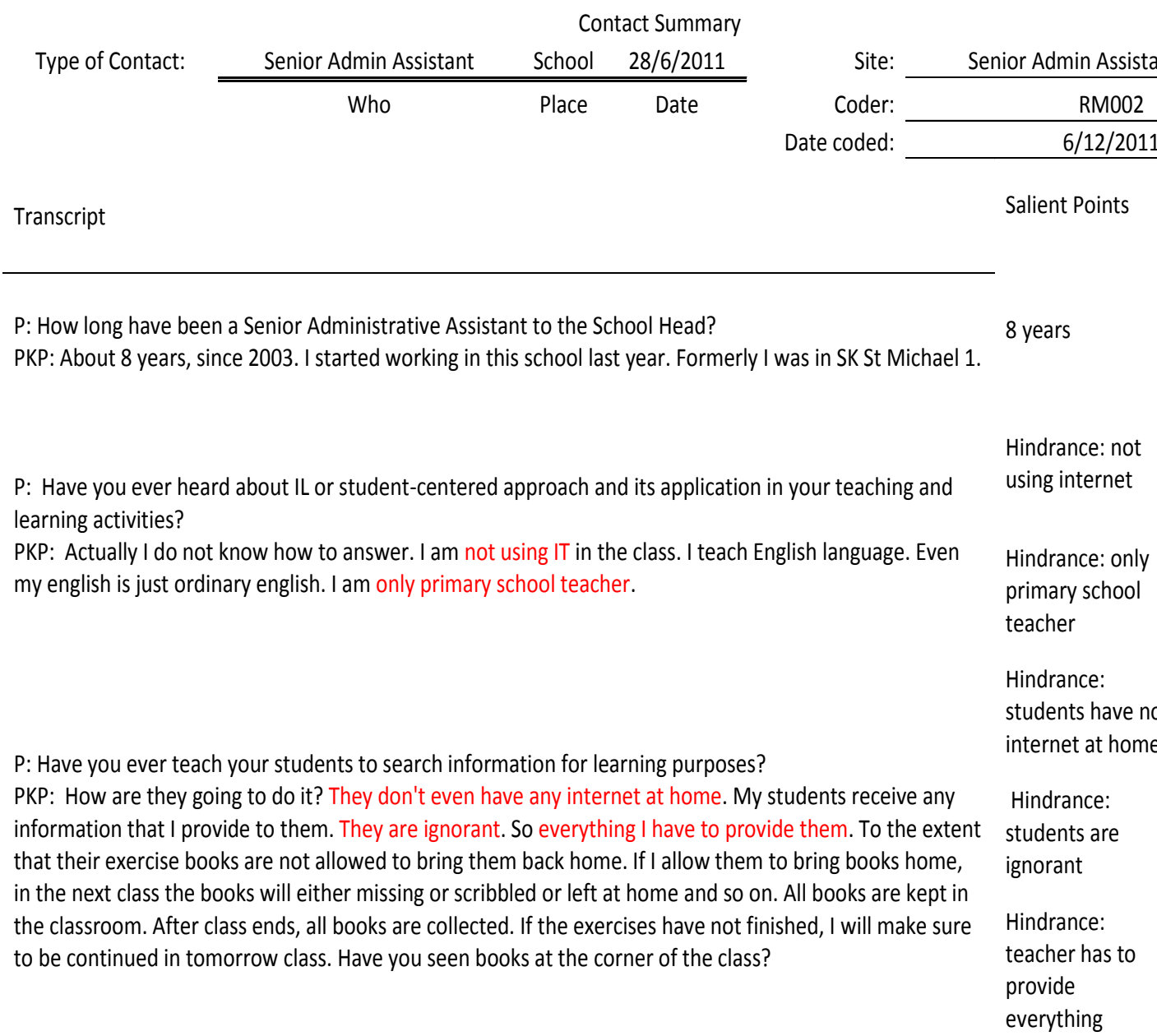




\section{Appendix 7 - Initial coding of case study schools}

\begin{tabular}{|c|c|c|c|c|c|}
\hline \multirow{2}{*}{ Factors / Level } & \multicolumn{5}{|c|}{ School } \\
\hline & School Head & LMT & Science Teacher & Social Science Teacher & Humanities Teacher \\
\hline \multicolumn{6}{|l|}{ Characteristics of Change } \\
\hline \multirow[t]{4}{*}{ Need } & Hindrance: not interested & Feel very important & $\begin{array}{l}\text { need training to enhance } \\
\text { skills }\end{array}$ & $\begin{array}{c}\text { If I am in my } 40 \text { s and still } \\
\text { agressive, I never avoid } \\
\text { attending any courses. But } \\
\text { now, I am doing things } \\
\text { based on my level best }\end{array}$ & $\begin{array}{l}\text { In need of training for } \\
\text { constructivist approach }\end{array}$ \\
\hline & $\begin{array}{l}\text { Hindrance: feels very } \\
\text { disturbing }\end{array}$ & $\begin{array}{l}\text { Really in dire need of } \\
\text { training }\end{array}$ & $\begin{array}{c}\text { In my opinion, if the } \\
\text { teacher let the students } \\
\text { search informantion on } \\
\text { their own, they may like it } \\
\text { and easier for them to learn }\end{array}$ & $\begin{array}{c}\text { Attended courses on ICT } \\
\text { and SRC related, to gain } \\
\text { experience }\end{array}$ & $\begin{array}{l}\text { Searching information is a } \\
\text { co-curiculum activity. }\end{array}$ \\
\hline & $\begin{array}{l}\text { Hindrance: do not want to } \\
\text { attend any training }\end{array}$ & $\begin{array}{c}\text { I did student centred } \\
\text { activity because I want } \\
\text { my students to come up } \\
\text { with their ideas in order } \\
\text { to answer the exam } \\
\text { questions. }\end{array}$ & $\begin{array}{c}\text { Implementation of student } \\
\text { centred approach - Level 2 } \\
\text { (year } 4,5,6) \text { students is } \\
\text { more effective. For Level } 1 \\
\text { students, they still need } \\
\text { teachers input. }\end{array}$ & $\begin{array}{c}\text { The student centred } \\
\text { approach is good. The } \\
\text { students can search } \\
\text { information themselves and } \\
\text { more fun. }\end{array}$ & \\
\hline & Effective T\&L & $\begin{array}{l}\text { The method is fun for } \\
\text { students and makes the } \\
\text { students braver and the } \\
\text { teachers can also gain } \\
\text { new knowledge. }\end{array}$ & $\begin{array}{c}\text { Training need - the teachers } \\
\text { need to be trained on how } \\
\text { to integrate the use of ICT } \\
\text { in the subject matter. }\end{array}$ & $\begin{array}{c}\text { Teacher's reaction - I } \\
\text { believe student centred } \\
\text { approach is better. Students } \\
\text { are able to learn in more } \\
\text { detail, more indepth, and } \\
\text { not being spoon feed. }\end{array}$ & \\
\hline
\end{tabular}




\section{Appendix 8 - Data display}

\begin{tabular}{|c|c|c|c|c|c|c|}
\hline Category & Subcategory & $\begin{array}{l}\text { Related terms/phrases in the } \\
\text { transcripts }\end{array}$ & Identified factors & $\begin{array}{l}\text { Factors from the } \\
\text { prelim model }\end{array}$ & \begin{tabular}{|c|} 
Stages of IL \\
implementation
\end{tabular} & Participant \\
\hline \multirow[t]{2}{*}{$\begin{array}{l}\text { School head's } \\
\text { belief }\end{array}$} & $\begin{array}{l}\text { Unworried about } \\
\text { IL }\end{array}$ & Hindrance: not interested & Hindrance & Change - need & Not use & $\begin{array}{l}\text { Senior Admin } \\
\text { Assistant }\end{array}$ \\
\hline & Self-concern & Hindrance: feels very disturbing & Hindrance & Change - need & Not use & $\begin{array}{l}\text { Senior Admin } \\
\text { Assistant }\end{array}$ \\
\hline \multirow[t]{2}{*}{ Training needs } & Self-concern & $\begin{array}{l}\text { Hindrance: do not want to attend } \\
\text { any training }\end{array}$ & Hindrance & Change - need & Not use & $\begin{array}{l}\text { Senior Admin } \\
\text { Assistant } \\
\end{array}$ \\
\hline & \begin{tabular}{|l|} 
School head's \\
understanding of \\
IL
\end{tabular} & It is from the internet & & Change - clarity & Not use & $\begin{array}{l}\text { Senior Admin } \\
\text { Assistant }\end{array}$ \\
\hline $\begin{array}{l}\text { School head's } \\
\text { belief }\end{array}$ & \begin{tabular}{|l|}
$\begin{array}{l}\text { Teachers' } \\
\text { characteristics }\end{array}$ \\
\end{tabular} & Hindrance - teachers' attitudes & Hindrance & Change - complexity & Not use & $\begin{array}{l}\text { Senior Admin } \\
\text { Assistant } \\
\end{array}$ \\
\hline $\begin{array}{l}\text { Teachers' } \\
\text { abilities }\end{array}$ & $\begin{array}{l}\text { No ICT } \\
\text { competency } \\
\end{array}$ & $\begin{array}{l}\text { Hindrance: not competent using the } \\
\text { computer }\end{array}$ & Hindrance & $\begin{array}{l}\text { Implementers - } \\
\text { competency }\end{array}$ & Not use & $\begin{array}{l}\text { Senior Admin } \\
\text { Assistant } \\
\end{array}$ \\
\hline $\begin{array}{l}\text { Teachers' } \\
\text { abilities }\end{array}$ & $\begin{array}{l}\text { No ICT } \\
\text { competency } \\
\end{array}$ & Hindrance - handling of resources & Hindrance & $\begin{array}{l}\text { Implementers - } \\
\text { competency }\end{array}$ & Not use & $\begin{array}{l}\text { Senior Admin } \\
\text { Assistant }\end{array}$ \\
\hline \multirow[t]{4}{*}{$\begin{array}{l}\text { Roles and } \\
\text { responsibilities }\end{array}$} & Self-concern & $\begin{array}{l}\text { Hindrance: only primary school } \\
\text { teacher }\end{array}$ & Hindrance & $\begin{array}{l}\text { Implementers - } \\
\text { commitment }\end{array}$ & Not use & $\begin{array}{l}\text { Senior Admin } \\
\text { Assistant }\end{array}$ \\
\hline & T\&L strategy & teacher centered & & $\begin{array}{l}\text { Implementers - } \\
\text { commitment }\end{array}$ & Not use & $\begin{array}{l}\text { Senior Admin } \\
\text { Assistant }\end{array}$ \\
\hline & $\begin{array}{l}\text { Unworried about } \\
\text { IL }\end{array}$ & Hindrance: do not implement IL & Hindrance & $\begin{array}{l}\text { Implementers - } \\
\text { commitment }\end{array}$ & Not use & $\begin{array}{l}\text { Senior Admin } \\
\text { Assistant }\end{array}$ \\
\hline & Not using ICT & Hindrance: not using internet & Hindrance & $\begin{array}{l}\text { Implementers - } \\
\text { readiness }\end{array}$ & Not use & $\begin{array}{l}\text { Senior Admin } \\
\text { Assistant }\end{array}$ \\
\hline
\end{tabular}


Appendix 9 - Mind mapping: Factors affecting ILE implementation from participants at case study schools

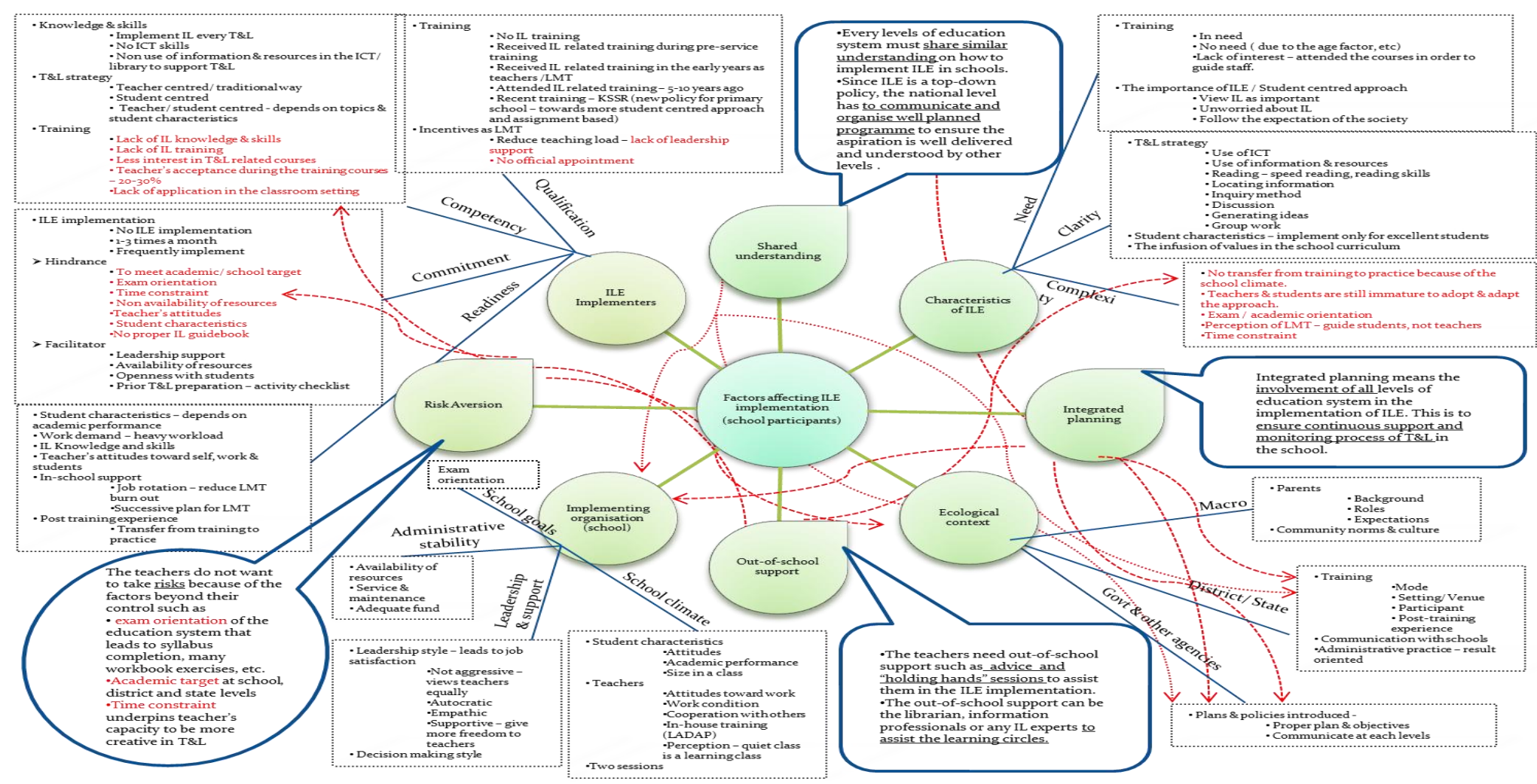


Appendix 10 - Logical flow of the thesis

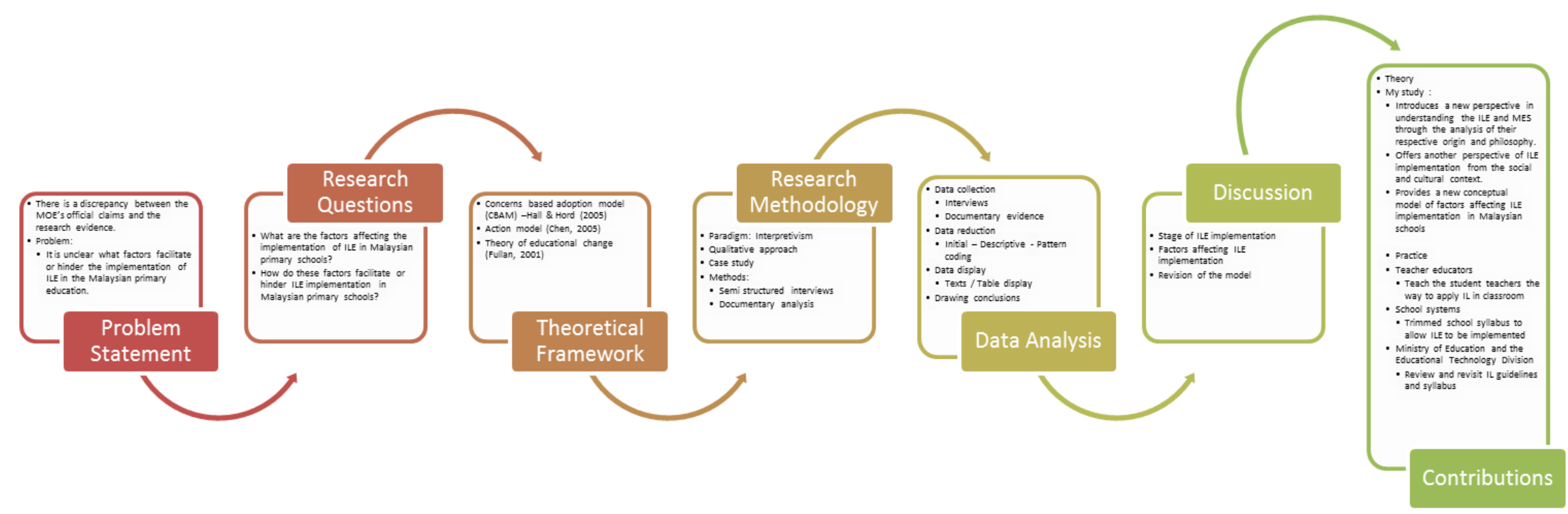


Appendix 11 - A summary of factors that facilitated and hindered ILE implementation in Malaysian primary schools

\begin{tabular}{|c|c|c|c|c|}
\hline & \multirow{2}{*}{\multicolumn{2}{|c|}{ Participants of case study schools }} & \multirow{2}{*}{\multicolumn{2}{|c|}{ Key informants }} \\
\hline Factors & & & & \\
\hline Characteristics of ILE & $\begin{array}{l}\text { View IL as important } \\
\text { Understood IL as student centered } \\
\text { learning }\end{array}$ & $\begin{array}{l}\text { Misconception and ILE as an } \\
\text { independent subject } \\
\text { Different oriventations to ILE } \\
\text { baseed on teachers' subject } \\
\text { specialization }\end{array}$ & $\begin{array}{l}\text { Appointment of LMT } \\
\text { Introduction of KSSR } \\
\text { Development of tools (iQPSS } \\
\text { \& SPPCTS) to monitor IL } \\
\text { activities }\end{array}$ & $\begin{array}{l}\text { Lack of IL courses and systematic } \\
\text { plan } \\
\text { Lack of multiplicity of education } \\
\text { resources } \\
\text { Lack of recognition at the MOE's } \\
\text { management } \\
\text { Teachers' not familiar with IL term } \\
\text { Changes at ETD led to changes of } \\
\text { work scope } \\
\text { LMT's underperform } \\
\text { Two training camps }\end{array}$ \\
\hline Individual implementer & $\begin{array}{l}\text { Peer learning } \\
\text { Teacher's initiatives } \\
\text { Regular monitor } \\
\text { Openness with the students } \\
\text { LMT receives reduce teaching load } \\
\text { In need of training } \\
\text { Sense of accountability } \\
\text { Teacher's preparation } \\
\text { Sacrifice one's time } \\
\text { Teacher's initiative } \\
\text { LMT successive plan } \\
\text { Leadership support } \\
\text { Positive outcome from initial } \\
\text { implementation of ILE }\end{array}$ & $\begin{array}{l}\text { Lack of proper IL training } \\
\text { Time constraints and heavy } \\
\text { workload }\end{array}$ & $\begin{array}{l}\text { 80\% teachers possess IL } \\
\text { knowledge } \\
\text { LMT's } 8-12 \text { hours teaching } \\
\text { load } \\
\text { LMTs possess IL skills }\end{array}$ & $\begin{array}{l}\text { Lack of transfer from training to } \\
\text { classroom because of substandard } \\
\text { school equipment } \\
\text { LMT overemphasis on book } \\
\text { processing than ILE } \\
\text { Teachers' lack of reading habit } \\
\text { Teachers' dependent, passive } \\
\text { attitudes } \\
\text { LMT's attitude towards work, time } \\
\text { management } \\
\text { Teachers' time constraints }\end{array}$ \\
\hline
\end{tabular}

Continue on the next page 


\begin{tabular}{|c|c|c|c|c|}
\hline $\begin{array}{l}\text { Implementing } \\
\text { organisation (school) }\end{array}$ & $\begin{array}{l}\text { Adequate information and resources } \\
\text { Supportive leadership } \\
\text { Immobile teacher } \\
\text { Made ILE compulsory } \\
\text { Continuous monitor and inspection } \\
\text { In-school training } \\
\text { Instructional leadership } \\
\text { Leadership support } \\
\text { Empower the academic panels to } \\
\text { monitor teaching and learning } \\
\text { Holistic nature of curriculum } \\
\text { Continuous improvement of } \\
\text { curriculum } \\
\text { Teamwork among teachers } \\
\text { Increase teacher population } \\
\text { Students" high interest in learning }\end{array}$ & $\begin{array}{l}\text { Receptiveness of the } \\
\text { students } \\
\text { Lack of physical facilities } \\
\text { Lack of leadership support } \\
\text { Teachers' perception on } \\
\text { students learning behaviour }\end{array}$ & $\begin{array}{l}\text { Official appointment of LMT } \\
\text { Regular IL training to familiar } \\
\text { and refresh the school } \\
\text { community with the concept } \\
\text { Competition and prize-giving } \\
\text { ceremonies }\end{array}$ & $\begin{array}{l}\text { No official appointment led to no } \\
\text { incentive as a LMT - heavy workload } \\
\text { LMT turn over } \\
\text { Lack of leadership support } \\
\text { Performance in public exams as a } \\
\text { yardstick for school performance } \\
\text { ILE not an academic subject } \\
\text { Too much emphasis on academic } \\
\text { activities } \\
\text { Lack of collaboration between LMT } \\
\text { and teachers } \\
\text { LMT's lack of IL knowledge and skills }\end{array}$ \\
\hline Ecological context & $\begin{array}{l}\text { Administrative support } \\
\text { Communication with schools } \\
\text { Parents" background }\end{array}$ & $\begin{array}{l}\text { Parents' background } \\
\text { Community norms and } \\
\text { culture } \\
\text { Parents' expectations }\end{array}$ & $\begin{array}{l}\text { Malaysian society exposed to } \\
\text { variety of information channel } \\
\text { Receptive to new ideas and } \\
\text { concepts }\end{array}$ & $\begin{array}{l}\text { MoE's leadership not open to new } \\
\text { ideas from staff } \\
\text { Function of library neglected } \\
\text { Ceremonial and extravagance } \\
\text { lifestyle }\end{array}$ \\
\hline
\end{tabular}

Continue on the next page 


\begin{tabular}{|c|c|c|c|c|}
\hline & $\begin{array}{l}\text { Parents' involvement } \\
\text { Follow-up courses } \\
\text { Regular LMT gatherings } \\
\text { Training course syllabus revision }\end{array}$ & $\begin{array}{l}\text { Societal expectations } \\
\text { Lack of technical support } \\
\text { Lecture based training mode } \\
\text { Lack of training in classroom } \\
\text { application } \\
\text { Lack of communication } \\
\text { No after training support } \\
\text { service } \\
\text { Result orientation }\end{array}$ & & $\begin{array}{l}\text { Plans and policies lack of follow-ups } \\
\text { and monitoring system } \\
\text { Dependent on the Government } \\
\text { Dependent, passive management } \\
\text { practices } \\
\text { No recent IL courses ( } 4-5 \text { years) } \\
\text { No action taken for not implementing } \\
\text { ILE } \\
\text { Schools seldom seek advice } \\
\text { regarding ILE from the TAC/SETD } \\
\text { Hierarchical and bureaucratic system } \\
\text { of education administration } \\
\text { SETD lack of manpower and funding } \\
\text { to monitor IL activities } \\
\text { Lack of communication with schools } \\
\text { The struggle of the Sector of } \\
\text { Educational Technologv Literacy } \\
\text { Resources Management to be seen } \\
\text { relevant in the ETD and MOE as a } \\
\text { whole } \\
\text { Lack of leadership support } \\
\text { Lack of IL understanding at the MOE }\end{array}$ \\
\hline $\begin{array}{l}\text { Implementation } \\
\text { protocol }\end{array}$ & Training courses notes & $\begin{array}{l}\text { Lack of IL guidelines and } \\
\text { modules }\end{array}$ & $\begin{array}{l}\text { Development of educational } \\
\text { resources portal }\end{array}$ & $\begin{array}{l}\text { Schools did not seek advice from the } \\
\text { MOE regarding ILE implementation }\end{array}$ \\
\hline
\end{tabular}

